\title{
The use of pulsed radiofrequency in the treatment of chronic pain
}

Citation for published version (APA):

Van Zundert, J. H. M. (2005). The use of pulsed radiofrequency in the treatment of chronic pain. [Doctoral Thesis, Maastricht University]. Maastricht University Press. https://doi.org/10.26481/dis.20051124jz

Document status and date:

Published: 01/01/2005

DOI:

10.26481/dis.20051124jz

Document Version:

Publisher's PDF, also known as Version of record

\section{Please check the document version of this publication:}

- A submitted manuscript is the version of the article upon submission and before peer-review. There can be important differences between the submitted version and the official published version of record.

People interested in the research are advised to contact the author for the final version of the publication, or visit the DOI to the publisher's website.

- The final author version and the galley proof are versions of the publication after peer review.

- The final published version features the final layout of the paper including the volume, issue and page numbers.

Link to publication

\footnotetext{
General rights rights.

- You may freely distribute the URL identifying the publication in the public portal. please follow below link for the End User Agreement:

www.umlib.nl/taverne-license

Take down policy

If you believe that this document breaches copyright please contact us at:

repository@maastrichtuniversity.nl

providing details and we will investigate your claim.
}

Copyright and moral rights for the publications made accessible in the public portal are retained by the authors and/or other copyright owners and it is a condition of accessing publications that users recognise and abide by the legal requirements associated with these

- Users may download and print one copy of any publication from the public portal for the purpose of private study or research.

- You may not further distribute the material or use it for any profit-making activity or commercial gain

If the publication is distributed under the terms of Article $25 \mathrm{fa}$ of the Dutch Copyright Act, indicated by the "Taverne" license above, 
The use of pulsed radiofrequency in the treatment of chronic pain 



\section{The use of pulsed radiofrequency in the treatment of chronic pain}

Proefschrift

ter verkrijging van de graad van doctor aan de Universiteit Maastricht, op gezag van de Rector Magnificus,

Prof. mr. G.P.M.F. Mols

volgens het besluit van het College van Decanen

in het openbaar te verdedigen op

donderdag 24 november 2005 om 16.00 uur.

door

Jan H.M. Van Zundert

geboren te Antwerpen op 12 augustus 1965 


\section{Promotor:}

Prof. dr. M. van Kleef

\section{Co-promotoren:}

Dr. E.A.J. Joosten

Dr. J.Patijn

\section{Beoordelingscommissie:}

Prof. dr. J.S.H. Vles (voorzitter)

Prof. dr. J.E. Devulder (Universiteit Gent, België)

Prof. dr. R.G.T. Geesink

Prof. dr. M.H. Prins

Prof. dr. W.W.A. Zuurmond (Vrije Universiteit Amsterdam) 
There are three factors in the practice of medicine:

the disease, the patient, and the physician.

The physician is the servant of science,

and the patient must do what he can to fight the disease

with the assistance of the physician.

Hippocrates, The Epidemics, Book I 
Het onderzoek werd uitgevoerd en gefinancierd door de afdeling Anesthesie/ Pijnbehandeling en het Pijnkenniscentrum van het Universitair Medisch Centrum Maastricht, Maastricht, Nederland, in samenwerking met de afdeling Kritische Diensten van het Ziekenhuis Oost-Limburg, Genk, België.

Jan Van Zundert

ISBN-10: 9090199845

ISBN-13: 9789090199849

Copyright@: No part of this publication may be reproduced without the prior written permission of the author.

Opmaak: Nicole Van den Hecke

Druk: Datawyse/ Universitaire Pers Maastricht

Cover: Detail barenzaal (electriciteits - schakelcentrale), mijngebouw Winterslag, Genk, België 


\section{Table of content}

Chapter I: Introduction: Historical overview of radiofrequency techniques in the management of chronic pain

References.

Chapter II: Clinical application of radiofrequency techniques in pain management 19

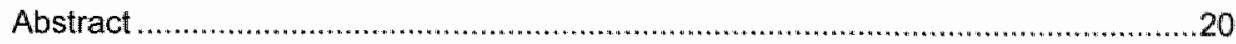

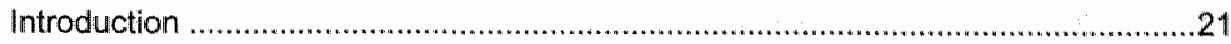

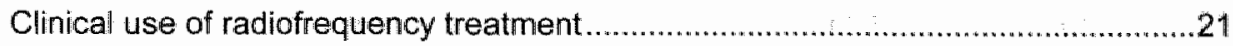

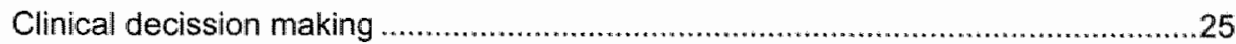

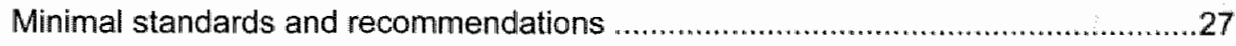

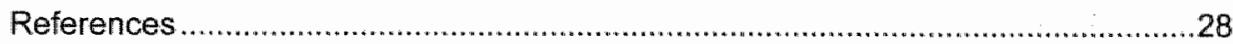

Chapter III: The role of the dorsal root ganglion in cervical radicular pain: diagnosis, pathophysiology and rationale for treatment

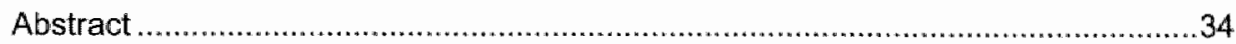

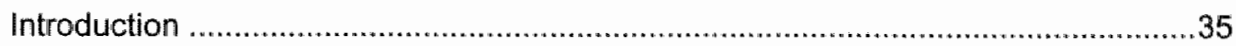

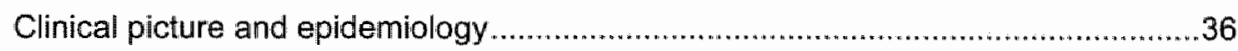

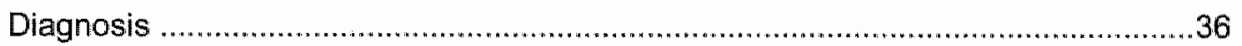

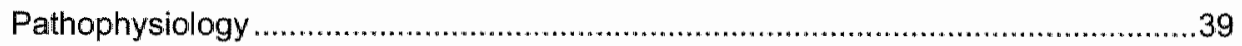

Rationale and level of evidence for treatment modalities targeting the cervical

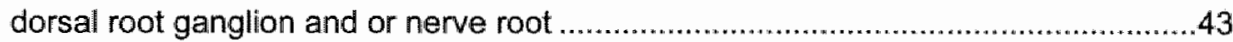

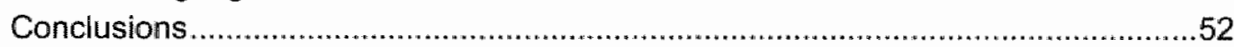

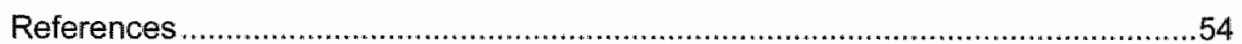

Chapter IV: Electrophysical principles of pulsed radiofrequency current: Theoretical considerations 61

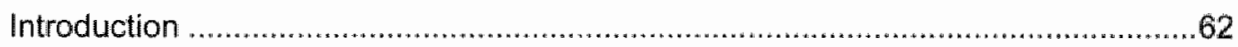

Electrophysical mechanisms induced by radiofrequency current ..........................62

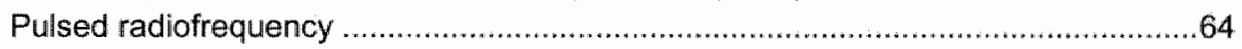

Generator settings in clinical use of pulsed radiofrequency ....................................71

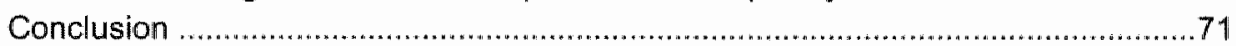

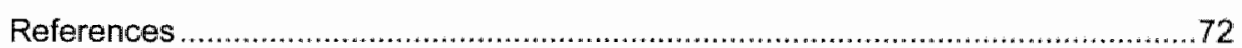

Chapter V: Pulsed and continuous radiofrequency current adjacent to the cervical dorsal root ganglion of the rat induces late cellular activity in the dorsal horn $\quad 73$

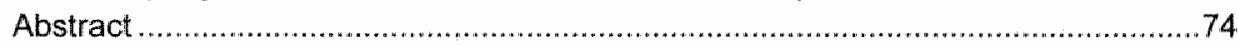

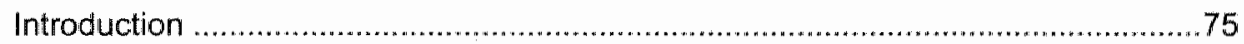

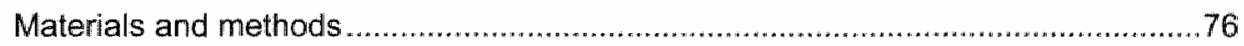

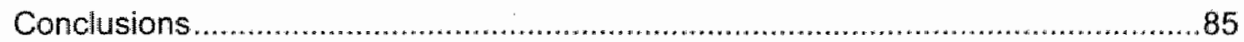

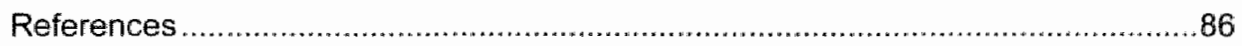


Chapter V: Pulsed radiofrequency treatment of the Gasserian ganglion in patients with idiopathic trigeminal neuraigia

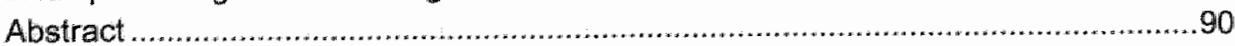

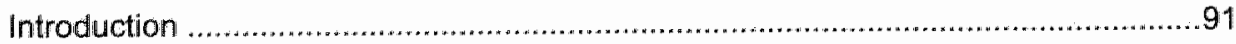

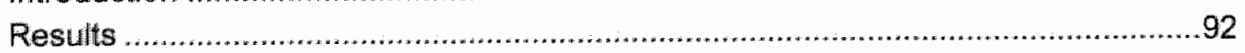

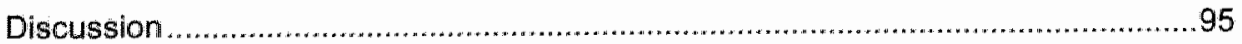

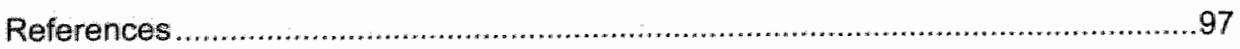

Chapter VIl: Percutaneous pulsed radiofrequency treatment of the cervical dorsal root ganglion in the treatment of chronic cervical pain syndromes: A clinical audit 99

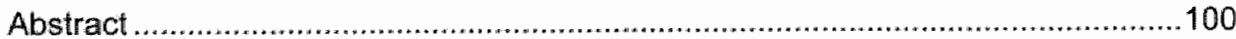

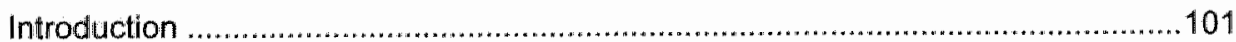

Materials and methods ............................................................................. 102

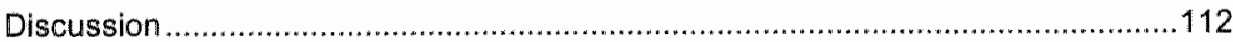

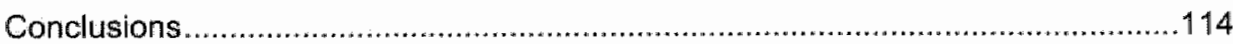

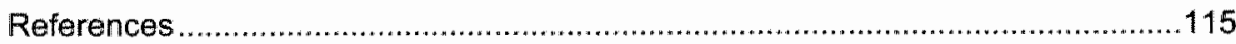

Chapter VIII: Pulsed radiofrequency adjacent to the cervical dorsal root ganglion in chronic cervical radicular pain: a double blind sham controlled randomized clinical trial.

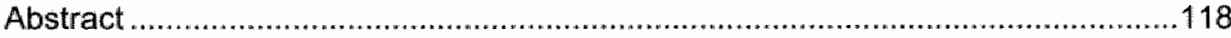

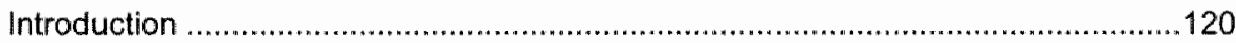

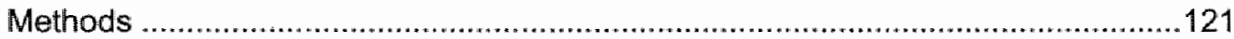

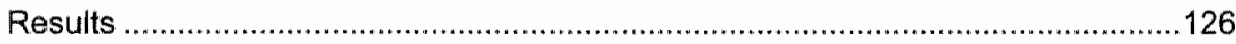

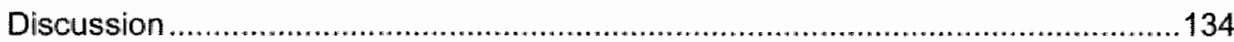

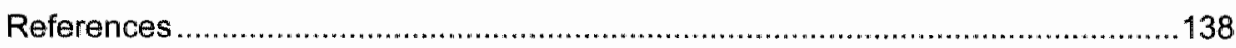

Chapter IX: Pulsed radiofrequency: Current clinical and biological literature available

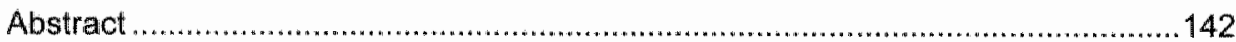

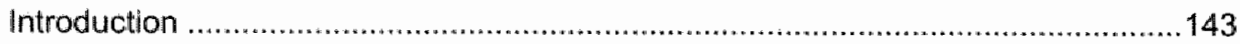

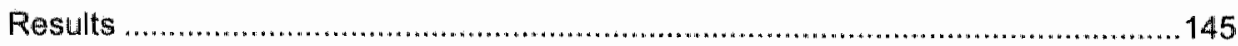

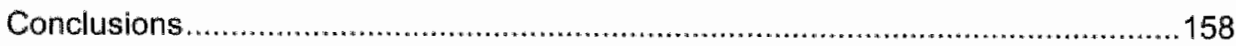

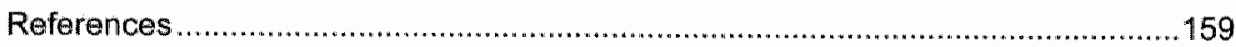

Chapter X: General discussion $\quad 165$

1 Basic research into the mode of action of pulsed radiofrequency ......................166

2 Clinical research on the use of pulsed radiofrequency in chronic pain

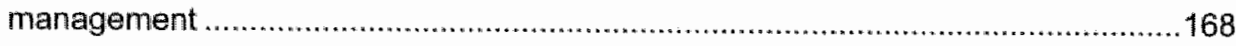

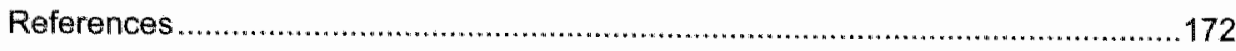


Chapter XI: Summary 175

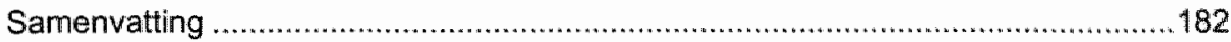

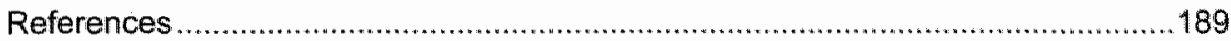

Chapter XII: CV and publications $\quad 193$

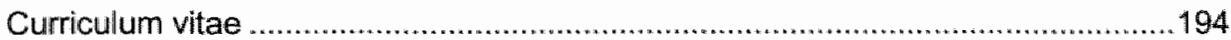

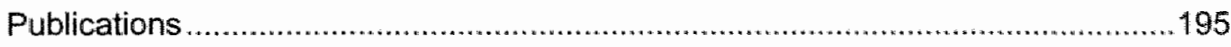

Chapter XIII: Dankwoord 199

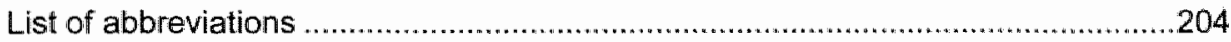


CHAPTER I

Introduction: Historical overview of radiofrequency techniques in the management of chronic pain 
The use of electric current for pain management has a long history but its popularity has waxed and waned over time, because of concerns about safety and technical improvements. Already in the second half of the 19th century brain lesions in animals were made with direct current application and empirical rules for quantifying lesion size based on current and time were developed ${ }^{1,2}$. The first use in humans dates back from 1931, when direct current of 350 mAmp was delivered through a needle with $10 \mathrm{~mm}$ uninsulated tip placed in the Gasserian ganglion under fluoroscopic control for the management of trigeminal neuralgia ${ }^{3}$. This technique produced lesions with unpredictable size, with consequent induced complications ${ }^{4}$. Therefore, the use of high frequency electric current was advocated to be more appropriate in obtaining lesions of predictable size $\mathrm{e}^{4-6}$. Since high frequencies of $300-$ $500 \mathrm{KHz}$ were also used in radiotransmitters, the current was called radiofrequency (RF) current. Later on temperature monitoring was suggested to be the most important parameter in obtaining a standardized lesion size, when performing stereotactic brain surgery with a RF current ${ }^{7}$. The use of RF in pain management dates from 1965 for percutaneous lateral cordotomy for unilateral pain in cancer patients ${ }^{6}$ and $a$ few years later it was also used for the treatment of trigeminal neuralgia ${ }^{8}$.

The first use of RF current for spinal pain was reported by Shealy ${ }^{9}$ who performed RF lesioning of the medial branch for lumbar zygapophyseal joint pain, using a 14 Gauge (G) thermistor electrode introduced through a $12 \mathrm{G}$ guide needle, which is a fairly large needle diameter that may produce mechanical lesions besides the desired thermolesions ${ }^{10}$. Another application in spinal pain was introduced by Uematsu $^{11}$ who described the RF lesion of the dorsal root ganglion (DRG), using the same electrode as used by Shealy for medial branch block. The recommended tip temperature was $75^{\circ} \mathrm{C}$. Combined with the large electrode diameter this produced sizeable lesions, and consequently this technique was soon abandoned ${ }^{10}$.

A turning point came in 1980 when small-diameter electrodes, known as Sluijter Mehta Kit (SMK)-systems, for the treatment of spinal pain were introduced ${ }^{12}$. The system consists of a $22 \mathrm{G}$ disposable cannula with a fine thermocouple probe inside, allowing more precise temperature measurement at the needle tip. The smaller electrode size resulted in a diminished discomfort during the procedure. It was demonstrated that if an electrode is actually resting on the nerve, a minimum stimulation level of 0.25 volts $(V)$ is required to produce a discharge for a tissue impedance of $500 \mathrm{Ohm}(\Omega)$. Moving the needle away from the nerve increases the required threshold for discharge ${ }^{13}$.

The small size electrode and the precision of the needle placement presently allows performing transforaminal lesions adjacent to the DRG with less risk for mechanical injury to major nerve trunks ${ }^{1,10}$. The DRG is an important site in the pathophysiology of pain because all nerves conducting nociceptive information to the spinal cord 
have their cell bodies in the dorsal ganglion, making it a possible target for therapeutic interventions ${ }^{14}$.

The value of RF lesioning adjacent to the DRG in the management of chronic radicular pain was evaluated in three randomized controlled trials (RCT's) ${ }^{15-17}$. One RCT evaluating the efficacy of RF treatment of the lumbar DRG for lumbosacral radicular pain syndrome, found no difference in outcome between RF treatment and sham intervention ${ }^{17}$. Two RCT's on RF treatment adjacent to the cervical DRG ${ }^{15,16}$ resulted in limited evidence for the treatment of cervical radicular pain according to two systematic reviews ${ }^{18,19}$. The reported side effects and complications were mostly minor and transient. However, RCT's are not designed to evaluate the safety' because they are underpowered for detecting rare complications. Nevertheless, RF lesioning of the DRG remains a controversial issue due to the potential risk of deafferentation syndromes ${ }^{20}$. Consequently the majority of the RF procedures used in chronic pain in clinical practice, focused on lumbar and cervical facet pathology ${ }^{21}$.

The rationale for the use of RF techniques in the management of different chronic pain syndromes is based on the assumption that thermocoagulation of the nerve fibers will interfere with the conduction of nociceptive stimuli ${ }^{22}$. It has been hypothesized that the mode of action of RF treatment is due to the heating effect caused by the current, but this has not been elucidated yet. There are contradictory research findings on the selectivity of RF lesions ${ }^{11,22,23}$. In an in vitro model of the cat saphenous nerve, a fiber selective effect is suggested, since differential elevation of the amplitude of the action potential by radiofrequency current and heat on small $\mathrm{A}$ $\delta$ and $C$ fibers was found, followed by a delayed effect on fibers in the A- $\alpha$ and $B$ group ${ }^{23}$. However, other authors have described an "indiscriminate" effect on all types of peripheral nerve fibers in an in vivo madel using the sciatic nerve of the cat $^{11}$. Those findings were later confirmed in another in vivo model of beagle dogs, performing lumbar transforaminal lesions between $45^{\circ} \mathrm{C}$ and $85^{\circ} \mathrm{C}^{22}$. At different time intervals, up to 6 weeks, all types and sizes of fibers were destroyed. The authors explained the discrepancy in findings on selectivity by the difference in the model used, in vivo versus in vitro. In the in vitro model the changes in action potential were monitored over 30 minutes $^{23}$. But this could not be confirmed in the in vivo model longer after the intervention ${ }^{22}$. Later RF lesions at $67^{\circ} \mathrm{C}$ in the DRG were compared to lesions outside the DRG (adjacent to) in the goat. Two weeks after the procedure the lesions were studied for size as well as for effects on proliferation of satellite cells and regeneration of damaged nerve fibers using Ki-67 (MIB-1). An RF lesion inside the DRG destroys myelinated fibers. A lesion adjacent to the DRG only increases MIB-1 activity, indicating proliferation and regeneration ${ }^{24}$. Considering the contradictory findings regarding the selectivity in nerve fiber destruction, it is assumed that different mechanisms other than thermocoagulation are involved. Furthermore, in clinical practice it is observed that, RF lesioning adjacent to the DRG 
induces sensory loss in the relevant dermatome, which can be considered as heat related. This sensory loss is only transient, while the pain relief may be of much longer duration ${ }^{25}$. The role of heat was also questioned by the publication that no differences in outcome were noted when two different tip temperatures $\left(40^{\circ} \mathrm{C}\right.$ and $67^{\circ} \mathrm{C}$ ) were applied to the cervical DRG in chronic cervical radicular pain ${ }^{15}$.

A modification of the RF technique, resulting in less neurodestruction, would be more attractive for certain indications in chronic pain management. In 1998 Sluijter, Cosman, Rittman, and van Kleef introduced the use of a modified RF application, known as pulsed radiofrequency (PRF) ${ }^{20}$. It is a different use of electrical current, though the target nerve structures are approached with a similar electrode as used in continuous RF. In this modified technique, in $1 \mathrm{~s}$ two bursts of $20 \mathrm{~ms}$ each of a RF current are delivered. During one cycle the "active" phase of $20 \mathrm{~ms}$ is followed by a silent period of $480 \mathrm{~ms}$ to allow for washout of the generated heat. The output is usually set at $45 \mathrm{~V}$, which is much higher than the output used in continuous RF that is approximately $20 \mathrm{~V}$, depending on the vascularity of the tissue. If the electrode tip temperature exceeds $42^{\circ} \mathrm{C}$, it is decreased to prevent cell damage. This temperature is selected based on the findings that necrosis in various soft tissue cell lines could only be induced by heating to temperatures greater than $43^{\circ} \mathrm{C}^{26,27}$.

Because of the potentially better risk/benefit ratio, PRF treatment may have a complementary role with other interventional techniques as part of a multidisciplinary approach for the management of chronic pain patients. After the first publication in 1998 , there is an increasing number of data on the use of PRF in the management of chronic pain syndromes without reported neurological complications ${ }^{28}$. The published clinical data consist however mainly of case reports, case series, retrospective analyses and only few prospective trials. Therefore more research on the mode of action, efficacy and safety of PRF is justified.

We focused our research project on the use of PRF in cervical radicular pain, because this is a well-circumscribed pain syndrome in which experience in clinical research was obtained in the past in our center ${ }^{16.25}$. This syndrome affects approximately 1 on 1,000 adults per year ${ }^{29}$, with high impact on the patient's quality of life $\mathrm{f}^{30}$. It can be defined as pain originating from the cervical spine, radiating from the neck passing the posterior side of the shoulder, into the upper limb with referral to a particular segmental distribution ${ }^{34}$. Although many treatment madalities are described in the literature, the available evidence for efficacy does not allow formulating definitive conclusions on the optimal therapy ${ }^{32,33}$.

The aim of this thesis was to evaluate the role of PRF treatment in chronic pain management, with special attention for PRF application adjacent to the cervical DRG in chronic cervical radicular pain. 


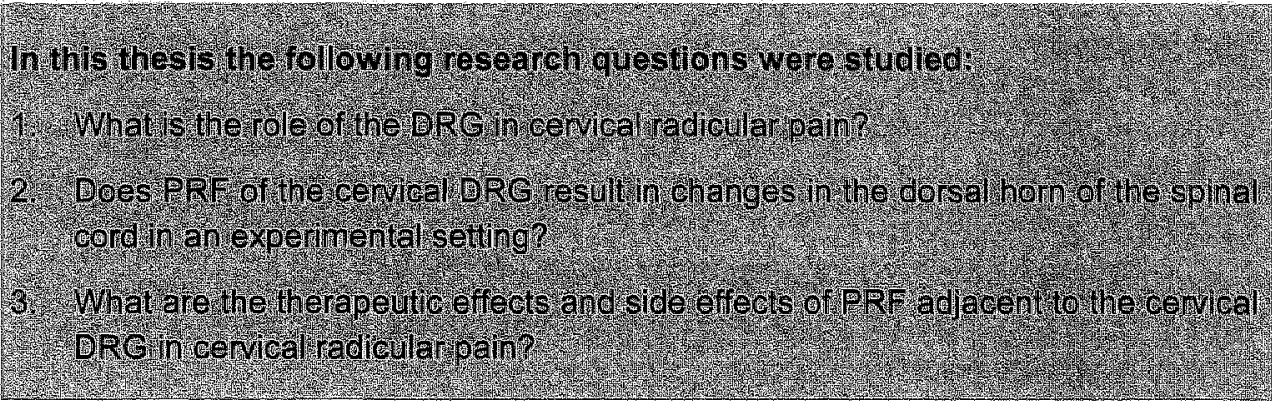

In the present thesis, on overview on the use of RF techniques in chronic pain management prior to the start of our research on PRF is given in chapter II. The first research question is addressed in chapter 111 , reporting a literature review on the role of the DRG in cervical radicular pain with special attention for diagnosis, pathophysiological mechanisms and the potential link to treatment modalities. In chapter IV the electrophysical principles underlying PRF are outlined. The second research question is addressed in chapter $\mathrm{V}$, reporting findings of a study in an animal model on the histopathological changes in the rat dorsal horn 7 days after RF; PRF or sham intervention. In chapter $\mathrm{V}$, the first results of PRF treatment of the Gasserian ganglion of patients suffering idiopathic trigeminal neuralgia are reported. The third research question is addressed in chapters VII and VIII reporting the clinical audit and the outcome of a sham controlled randomized trial on PRF treatment adjacent to the cervical DRG for the management of chronic cervical radicullar pain. In chapter $I X$, a review on the currently available clinical and biological literature on PRF is presented. In the discussion, chapter $X$, directions and ideas for future research are proposed. Finally, in chapter XI, the previous chapters are summarized. 


\section{References}

1. Ahadian FM. Pulsed radiofrequency neurotomy: advances in pain medicine. Curr Pain Headache Rep 2004; 8. 34-40

2. Tepperman J. Horsley and Clarke: a biographical medallion. Perspect Biol Med 1970; 13: 295308

3. Kirschner M. Zur Electrochirugle: Arch Klin Chir 1931; 161:761-768

4. Sweet WH Mark VH. Unipolar anodal electrolyte lesions in the brain of man and rat: report of five human cases with electrically produced bulbar or mesercephalic tractotomies. AMA Arch Neurol Psychiatry $1953 ; 70: 224-234$

5. Hunsperger RW, Wyss OAM. Quantititive Ausschaltung van Nervengewebe durch Hochfrequenzkoagulation. Helv Physiol Acta $1953 ; 11: 283-304$

6. Rosomoff HL, Brown Cil, Sheptak P. Percutaneous radiofrequency cervical cordotomy: technique. J Neurosurg 1965; $23: 639-644$

7. Mundinger $F$, Riechert T, Gabriel E. [Studies on the physical and technical bases of highfrequency coagulation with controlled dosage in stereotactic brain surgery.]. Zentralbl Chir 1960; 85: 1051-1063

8. Sweet WH, Wepsic JG. Controlled thermocoagulation of trigeminal ganglion and root for differential destruction of pain fibers. Part I: Trigeminal neuralgia. J Neurosurg 1974; 39: 143-156

9. Shealy CN. Percutaneous radiofrequency denervation of spinal facets. J Neurosurg $1975 ; 43$ 448-451

10. Sluijter ME. Radiofrequency part I Filvopress, Meggen, Switzerland, 2001

11. Uematsu S. Percutaneous electrothermocoagulation of spinal nerve trunk, ganglion and rootlets, New York, Grune and Stratton, 1977.

12. Slujiter $M$, Mehta $M$. Treatment of chronic back and neck pain by percutaneous thermal lesions. Persistent pain, modern methods of treatment, Edited by Lipton S. London, Academic Press, 1981, pp 141-179

13. Ford DJ, Pither $C$, Raj PP. Comparison of insulated and uninsulated needles for locating peripheral nerves with a peripheral nerve stimulator. Anesth Analig 1984; 63: 925-928

14. Van Zundert $J_{*}$ Harney $\mathbb{D}_{\text {, Joosten }} E A$, et al. The role of the dorsal root ganglion in cervical radicular pain: diagnosis, pathophysiology and rationale for treatment. Submitted

15. Slappendel $R$, Crul B.J, Braak G.J, Geurts JW, Booij LH, Voerman VF, de Boo T. The efficacy of radliofrequency lesioning of the cervical spinal dorsal root ganglion in a double blinded randomized study: no difference between 40 degrees $C$ and 67 degrees $C$ treatments. Pain 1997; 73 : $159-163$

16. van Kleef $M$, Liem $L$, Lousberg $R$, Barendse $G$, Kessels $F$, Sluijter $M$. Radiofrequency lesion adjacent to the dorsall root ganglion for cervicobrachial pain: a prospective double blind randomized study. Neurosurgery 1996; 38: 1127.1131; discussion 1131-1122

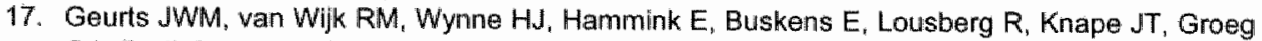
GJ. Radiofrequency lesioning of dorsal root ganglia for chronic lumbosacral radicular pain. A randomised, double blind, controlled trial. Lancet 2003; 361:21-26

18. Geurts J, van Wijk RM, Stolker R, Groen GJ. Efficacy of radiofrequency procedures for the treatment of spinal pain. a systematic review of randomized clinical trials. Reg Anesth Pain Med 2001; 26: 394-400

19. Niemisto $L$, Kalso $E$, Malmivaara A, Seitsalio $S$, Hurri $H$. Radiofrequency denervation for neck and back pain. A systematic review of randomized controlled trials. Cochrane Database Syst Rov 2003: CD004058

20. Sluifter ME, Cosman ER, Rittman IWB, van Kleef $M$. The effects of pulsed radiafrequency field applied to the dorsal root ganglion - a preliminary report. The Pain Clinic 1998; 11: 109-117

21. Raj PP, Erdine S. The Current Status of the Practice of Radiofrequency in the World. Pain Practice 2002; 2: 176-17922.

22. Simith HP, McWhorter JM, Challa VR. Radiofrequency neurolysis in a clinical model. Neuropathological correlation. J Neurosurg 1981; 55: 246-253 
23. Letcher $\mathrm{FS}_{\mathrm{r}}$ Goldring $\mathrm{S}$. The effect of radiofrequency current and heat on peripheral nerve action potential in the cat. J Neurosurg 1968; 29:42-47

24. de Louw AJA, Vles HSH, Freling G, Herpers M.JHM, Arends $\mathbf{M W}$, van Kleef M. The morphological effects of radiofrequency lesion adjacent to the dorsal root ganglion (RF-DRG) - An EXperimental study in the goat. Eur. J. of Pain 2001; 5: 169-174

25. van Kleef M, Spaans $F$, Dingemans $W$, Biarendse GAM, Floor $E_{n}$ Sluijter ME: Effects and side effects of a percutaneous thermal lesion of the dorsal root ganglion in patients with cervical pain syndrome. Pain 1993; 52: 49-53

26. Yonezawa $M_{1}$ Otsuka $T$, Matsui $N_{\text {, Matsui }} N_{n}$ Tsjuji $H$, Kato $\mathrm{KH}_{\text {, Moriyama }} \mathrm{A}_{\text {, Kato }} \mathrm{T}$. Hyperthermia induces apoptosis in malignant fibrous histiocytoma cells in vitro. Int $\mathrm{J}$ Cancer 1996; 66: $347-351$

27. Hildebrandt $B$, Wust $P$, Ahlers $O$, et al. The cellular and molecular basis of hyperthermia. Crit Rev Oncol Hematol 2002; 43: 33-56

28. Cahana $A$, Van Zundert J, Macrea L, van Kleef M, Sluijter M. Pulsed radiofrequency: Current clinical and biological literature available. Submitted

29. Radhakrishnan $K_{n}$ Litchy WJ, O'Fallon WM, Kurland LT. Epidemiology of cervical radiculopathy. A population-based study from Rochester, Minnesota, 1976 through 1990. Brain 1994: 117 (Pt) 2): $325-335$

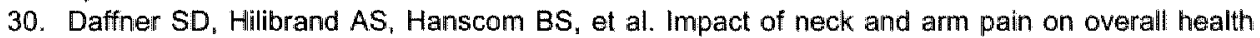
status. Spine 2003; 28: 2030-2035

31. Merskey $\mathrm{H}$, Bogduk N. Classification of Chronic Pain: Descriptions of Chronic Pain Syndromes and Definitions of Pain Terms. 2 Seattle, Wash: IASP Press, 1994,

32. Rathmell JP, Aprill C, Bogduk N. Cervical transforaminal injection of steroids. Anesthesiology 2004; 100: 1595-1600

33. Bogduk N. Medical Management of acute cervical radicular pain: and evidence-based approach, 1st. Newcastle, Australia, The Newcastle Bone and Joint Institute, 1999. 


\section{CHAPTER II}

\section{Clinical application of radiofrequency techniques in pain management}

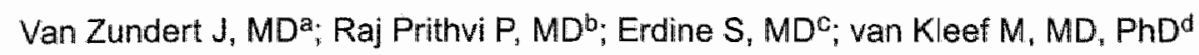

a. Department of Anesthesiology, Critical Care and Multidisciplinary Pain Center, Ziekenhuis Oost-Limburg. Genk, Belgium b. Department of Anesthesiology, Texas Tech University Health Services Center, Lubbiock, Texas, USA c. Department of Algology, Istanbui Medical Feculty, Istanbul, Turkey d. Department of Anes thesiology and Pain Management, Uniwersity Hospital Maastricht, Maastricht, The Nethertands 


\section{Abstract}

Many therapeutic interventions for chronic pain are available, and decisions about optimal management are not easy to make. Radiofrequency treatment is classified as a percutaneous minimal invasive procedure for patients who do not respond to appropriate medical and rehabilitation therapy. Although RF treatment is widely used, differences in current practice exist due to ongoing controversies. This review is based on the point of view of different experts in their specific area.

- Cranio facial pain

- Chronic cervical pain

- Pain originating from the thoracic spine

- Low back pain

- Discogenic pain

- Pain in the sacral and pelvic area

- Complex Regional pain syndrome

- Viseral pain

- Peripheral neuralgia

- Intractable cancer pain

The available information on RF treatment indicates that it may be a useful tool, but the evidence varies from one indication to another. The technique has a low invasive character, a target selective approach and can be performed as outpatient treatment. Following conditions should be fulfilled: patients are carefully selected with attention to both somatic and psychosocial factors; the technique is performed by an experienced clinician in the optimal environment. 


\section{Introduction}

The management of patients suffering chronic pain, intractable to pharmacotherapy has proven to be a complex process. The multifactorial aspect of chronic pain has even led to redefining acute versus chronic pain whereby the chronicity is not only a factor of duration of pain but also of persistence beyond expected recovery times, or the inability of the body to restore its physiological functions to normal homeostatic levels ${ }^{1}$. Recognition of the multifactorial aspect of pain highlights the need for a multidisciplinary approach. This approach has allowed the establishment of multidisciplinary pain centers (MPC) which are considered to be 3rd line referral centers where health care professionals with multiple specialties work together for establishing a diagnosis and consensus based treatment scheme ${ }^{2,3}$.

Radiofrequency (RF) treatment is classified as a minimal invasive procedure that can be considered for some patients. Radiofrequency treatment is currently used in most countries of the world, though not to the same extent ${ }^{4}$. Differences can mainly be attributed to a lack of accepted guidelines, accurate training programs and reimbursement policy. Eligibility criteria for RF treatment will depend on the pain location and identified triggers. Psychological factors should also be considered for eligibility or exclusion. A psychosocial evaluation is recommended in candidates for RF therapy prior to treatment and has the objective to determine the presence of psychological and social characteristics and stressors ${ }^{5}$. At present, however, there are no known psychological factors that by themselves can be predictive of successful outcomes.

\section{Clinical use of radiofrequency treatment}

The most frequently described indication for RF treatment is trigeminal neuralgia, an indication for which there is extensive experience ${ }^{6}$. A review of 25-years experience with 1,600 patients receiving percutaneous RF trigeminal rhizotomy for idiopathic neuralgia indicates acute pain relief in $97.6 \%$ of the patients and continued complete pain relief at 5 years follow-up in $57.7 \%$. Complications in this series were: diminished corneal reflex, masseter weakness and paralysis, dysesthesia, anesthesia dolorosa, keratitis and transient paralysis of cranial nerves II and VI. Comparisons with other techniques are mainly based on retrospective evaluations ${ }^{8-16}$. Limited experience with PRF treatment of idiopathic neuralgia has been reported ${ }^{17019}$. Cluster headache as a syndrome is well described. Reports of open trials using RF treatment of the sphenopalatine ganglion indicate promising results ${ }^{20}$.

Chronic cervical pain can arise from several structures in the cervical region including zygapophyseal joints, discs, nerve roots, ligaments and myofascial struc- 
tures ${ }^{21}$. The prevalence of cervical pain is judged to be as frequent as low back pain. The cervical pain syndromes which are accessible for invasive RF treatment are: cervical pain, cervicobrachialgia and cervicogenic headache ${ }^{22}$. Each pain syndrome may have more than one nociceptive source. As a consequence more than one RF treatment modality may be needed in relieving patient's pain. Chronic cervical spinal pain can be defined as mechanical neck pain originating from the facet joints or from the intervertebral disc ${ }^{21}$. Cervicobrachialgia is described as pain originating from the cervical spine radiating from the neck beyond the gleno-humeral joint into the upper limb with referral to a particular spinal segment ${ }^{23}$. Cervicogenic headache could originate from structures in the neck. The cardinal feature delineating cervicogenic headache from the other headache syndromes is the concept that the pain originates from a structural abnormality in the cervical spine ${ }^{24}$. Various structures in the cervical spine, such as the facet joints, segmental nerves, intervertebral discs, muscles and ligaments are capable of causing neck pain and headache.

The value of RF neurotomy of the medial branch for chronic cervical zygapophyseal joint pain has been demonstrated in one randomized controlled trial (RCT) with excellent results for RF compared to sham ${ }^{25}$. The management of cervicobrachialgia with $\mathrm{RF}$ treatment was described in one open and two randomized controlled studies $^{26-26}$. One of the RCT's compared RF treatment at $67^{\circ} \mathrm{C}$ with RF treatment at $40{ }^{\circ} \mathrm{C}^{26}$. The clinical efficacy varies from one trial to another and in a recent review Geurts et al. ${ }^{29}$ concluded that there is limited evidence for RF facet denervation in chronic cervical pain after whiplash and there is only limited evidence that RF dorsal root ganglion (DRG) is more effective than placebo in chronic cervicobrachialgia ${ }^{29}$.

The first publications on the use of RF treatment for neck pain and headache suggested some chance of benefit ${ }^{30,34}$. But due to the absence of a consensus about the diagnostic classification of cervicogenic headache and the uncontrolled study set-up, those results are not compelling. A recent open prospective study showed a significant improvement in patients selected based on the diagnostic criteria described by Sjaastad et al. ${ }^{24,32}$. Postoperative burning pain is mentioned by $10-20 \%$ of the patients, but this disappears spontaneously after some weeks.

Pain syndromes originating from the thoracic spine occur in 5-7\% of the patients seen in a pain clinic. In this type of patients diagnostic evaluations should exclude underlying pathology such as herniations, aneurysms, tumors, old fractures or infections. One should distinguish thoracic pain, which can be described as pain originating from the zygapophyseal joints and/or thoracic disc and thoracic segmental pain with referral into one or more particular spinal segments due to involvement of the segmental nerve in the pain syndrome, related to vertebral collapse, $12^{\text {th }}$ rib syndrome and segmental peripheral neuralgia ${ }^{33,34}$. 
Documentation on the use of RF treatment in the thoracic region is relatively scarce and restricted to open studies ${ }^{35}$. After thoracic facet denervation $>80 \%$ of the patients experienced good pain reduction for at least 2 months ${ }^{34,36}$. RF treatment adjacent to the thoracic DRG is a difficult technique due to the need of drilling through bone $^{37}$. Potential complications are segmental nerve injury, spinal cord injury, pneumothorax, and thoracic neuritis. Two open studies using RF DRG at thoracic level report good short- and long-term results ${ }^{38,39}$.

Radiofrequency treatment of low back pain is most frequently used and most often described ${ }^{40}$. This phenomenon is partly due to the fact that incapacitating chronic low back pain develops in more than $14 \%$ of the patients. The vast majority of those patients suffer non-specific low back pain that may be of discogenic origin , from the facet (or zygapophyseal) joints or from the sacroiliac joint. Low back pain is frequently divided into two components: neurogenic radicular pain and mechanical low back pain ${ }^{41}$. Radiofrequency lesioning of the DRG is developed as an alternative to the surgical rhizotomy; use is based on the principle that nociceptive input at the level of the primary sensory neuron might be reduced by coagulation of a small part of the DRG without causing sensory deficit ${ }^{42}$. One prospective and six retrospective studies have reported beneficial effects of lumbosacral RF DRG ${ }^{23,42-47}$. One randomized controlled study failed to show advantage over sham treatment with local anesthetic ${ }^{48}$.

Lumbar percutaneous facet denervation (PFD) by means of RF treatment is based on the premise that neurolysing the medial branches of the distal portions of the spinal posterior rami nerves that supply painful lumbar facet joints, will result in alleviation of back pain and a return of function. Technically there are two prerequisites for success of RF PFD; the identification of the painful joint using diagnostic blocks and the precise localization of the nerve supply to the targeted joints ${ }^{40}$. The clinical outcome of this technique has been described in 18 retrospective, 7 prospective studies and 4 randomized clinical trials ${ }^{29,40}$. The results of the RCT's are somewhat contradictory though comparing them is not possible because of differences in patient selection criteria, use of diagnostic blocks and efficacy parameters followed by each study $\mathrm{y}^{30,43,49,50}$. The negative outcome from the study of Leclaire et al. partly can be attributed to the patient selection, relying on the results of diagnostic injection done by the referring physician, which may result in greater heterogeneity of the study sample than in earlier studies, with inclusion of some patients whose pain was not truly of facet origin ${ }^{49.51}$.

Radiofrequency treatment of discogenic pain is a novel application relying on indirect heating of the annulus of the intervertebral disc ${ }^{52}$. The initial positive findings of a retrospective study could not be substantiated in an $\mathrm{RCT}^{53-55}$. Subsequently alter- 
native methods of producing thermal lesion in the lumbar intervertebral disc have been introduced using flexible catheters allowing heating of the nuclear/annular interface. The efficacy was later reported in one $\mathrm{RCT}^{56}$.

Radiofrequency has been used for interruption of the sympathetic chain to treat intractable pain in the sacral-pelvic region ${ }^{57}$ or for the management of visceral pain $^{59}$ and/or CRPS (Complex Reflex Pain Syndrome) ${ }^{59}$. The application of RF current in this indication differs from its use for other targets such as sensory nerve tissue because no sensory threshold can be achieved in the sympathetic nerves. The use of RF treatment has the advantage over surgical resection, phenol or alcohol neurolysis that it is more selective and may cause fewer complications ${ }^{60,61}$. Radiofrequency treatment of CRPS was compared with phenol neurolysis. The efficacy of RF treatment seems to be comparable to phenol neurolysis but the incidence of complications was lower ${ }^{59}$. One should be aware of the potential injury of the genitofemoral nerve, especially if multiple RF lesions are performed, but no controlled trials are available. Visceral pain due to chronic pancreatitis, pancreatic cancer, liver cancer or post-abdominal surgery pain that is not or no longer responding to pharmacological treatment can be managed by RF lesioning of the splanchnic nerves. From the available experience, retrospectively analyzed we can deduct that this technique is more selective and causes fewer complications ${ }^{58}$.

The management of peripheral neuralgia could only be developed when the pulsed radiofrequency (PRF) technique became available ${ }^{62}$. There are currently several case reports on the PRF treatment of peripheral nerves. In a small series of patients suffering chronic shoulder pain a good pain relief was noted ${ }^{63}$.

Neuroablative procedures have been used frequently in the past for the management of intractable cancer pain. At present the percutaneous cervical cordotomy represents the most important neurablative technique in cancer pain treatment ${ }^{64-69}$. Success rates have been reported to be high (54/62 patients) ${ }^{70}$. Considering the potential for major permanent complications: urinary retention hemiparesis and mirror image pain, percutaneous cordotomy should only be used for unilateral pain ${ }^{70}$. Recent pharmacological developments in sustained release of opioids have resulted in increasing degree of pain relief thus restricting the number of patients for an intervention.

Evolution to pulsed radiofrequency: Radiofrequency treatment may be a valuable treatment option for patients suffering refractory pain resistant to conventional treatment. Its use is still somewhat restricted due to the remaining controversies in accurate patient selection; the available level of evidence and the risk for neurological complications due to heat induced nerve damage. The current evolution of RF from the initial neuro destructive thermocoagulation towards PRF may perhaps 
enlarge its therapeutic value in the management of chronic pain. However no confroled studies comparing conventional continuous RF at $67^{\circ} \mathrm{C}$ with PRF are currently available. In 1998 Shujter et al. compared the effects of continuous RF current at $42^{\circ} \mathrm{C}$ with PRF with a maximum of $42^{\circ} \mathrm{C}$ and found better results in the PRF group $^{7 /}$. It is a minimally or non-destructive alternative to the RF thermocoagulation, whereby the tip temperature of the electrode does not exceed $42{ }^{\circ} \mathrm{C}$. This is achieved by exposing the nerve to a high-frequency electric field of $45 \mathrm{~V}$ during only $20 \mathrm{~ms}$ per $500 \mathrm{~ms}$, allowing the $480 \mathrm{~ms}$ pause to eliminate the heat generated during the active cycle. During application of RF current the generation of heat is not the only event that occurs; the tissue is also exposed to an electric field. Such electric fields are known to have a biological effect, which may contribute in the mode of action of RF although the mechanism is still ill understood ${ }^{72}$.

\section{Clinical decision making}

The avallable documentation on the RF treatment in different pain syndromes indicates that this option will only be considered when conservative causative and symptomatic treatment has been used to its full extent and fails to provide satisfactory pain relief. For the well-documented indications, authors mention patient selection criteria, consisting of clinical signs, medical imaging, and identification of the causative nerve structure - if possible by means of diagnostic blocks - and psychological assessment. The optimal environment for applying RF treatment is a multidisciplinary setting facilitating diagnosis, treatment and guidance in terms of expectations and coping with the rest pain.

The application of RF in the management of chronic pain may be a useful tool because of its low invasive character, the target selective approach, the possibility of outpatient treatment and its safety if done by a well-trained pain physician in the right setting. In line with the WHO treatment ladder for the management of chronic cancer pain, we propose an integrated treatment algorithm, including pharmacological, interventional and multidisciplinary management as illustrated in figure 1. 


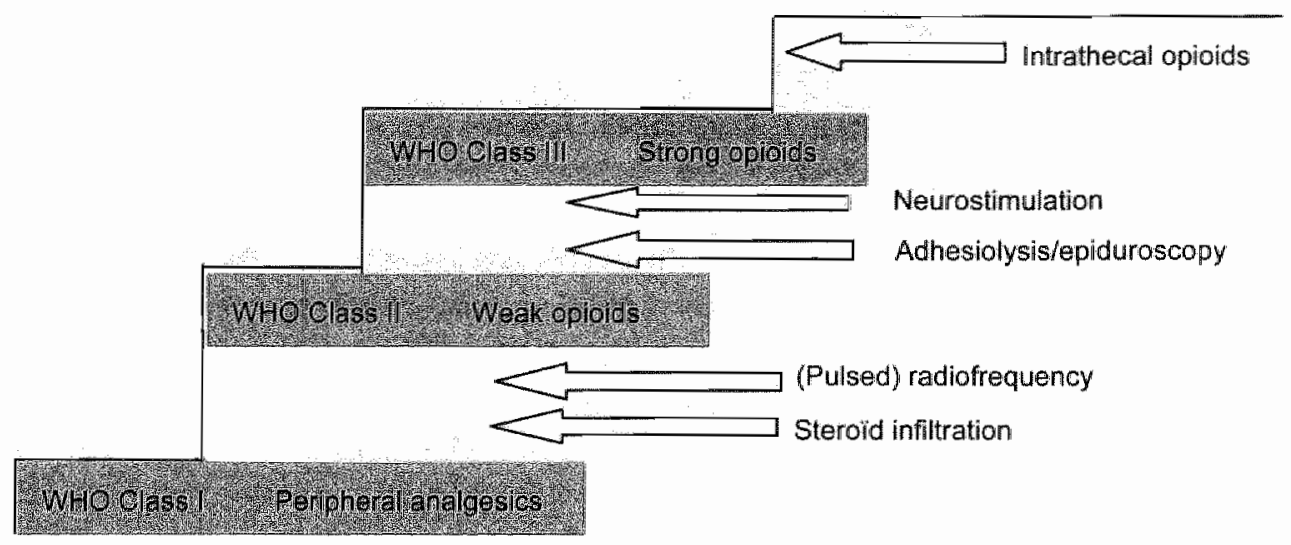

Ongoing Multi-Disciplinary approach:

- Adjuvant analgesics

- Psychologic counseling

- Physical therapy

- Evaluation of causal diagnosis/treatment

Figure 1: Schematic representation of the step-wise approach of chronic pain. 


\section{Minimal standards and recommendations}

Among the invasive pain management options, RF treatment is probably the most described. RF treatment as part of a multimodal and multidisciplinary approach, may avoid the use of more invasive and often more expensive treatment options ${ }^{73}$. We recommend the use of RF techniques under following conditions:

- Multidisciplinary patient selection, using validated selection criteria

- An informed consent is recommended

- Where indicated, use of diagnostic blocks

- Use of fluoroscopy

- Standardized report on the intervention including: impedance, volt, temperature, time and radiographic photos

- Standardized patient follow-up with validated outcome evaluation tools

- Physicians should receive an accurate training including the anatomy, technical aspects, practical treatment and radiation protection. 


\section{References}

1. Loeser JD, Melzack R. Pain: an overview. The Lancet 1999; 353: 1607-1609

2. Vanderschueren S. Kosten en Baten van Multidisciplinaire Pijncentra, Acta Hospitalia 1998; 3 $46-54$

3. Flor $\mathrm{H}_{3}$ Fydrich $\mathrm{T}$, Turk DC. Efficacy of multidisciplinary pain treatment centers: a meta-analytic review. Pain 1992; 49: 221-230

4. Prithvi Raj P. Erdine S. The Current Status of the Practice of Radiofrequency in the World. Pain Practice 2002; $2: 176-179$

5. Beltrutti $D$, Lamberto A. Psychological Assessment of Candidates for Radiofrequency Treatment. Pain Practice 2002; 2: 201-205

6. Rulz-Lopez R. Erdine S. Treatment of Cranio-Facial Pain with Radiofrequency Procedures. Pain Practice 2002; 2: 206-213

7. Kanpolat $Y$, Savas $A$, Bekar A, Berk C. Percutaneous Controlled Radiofrequency Trigeminal Rhizotomy for the Treatment of Idiopathic Trigeminal Neuralgia: 25- years Experience with 1600 Patients. Neurosurgery $2001 ; 48: 524-534$

8. Taha $\mathrm{JM}, T e w . \mathrm{IM}, \mathrm{J}$. Comparison of surgical treatments for trigeminal neuralgia: reevaluation of radiofrequency thizotomy. Neurosurgery 1996; 38: 865-871

9. Broggi G, Franzini A Lasio G, Giorgi C, Sverello D. Long term results of percutaneous retrogasserian thermorhizotomy for "essential" trigeminal neuralgia. Neurosurgery 1990; 26: 783787

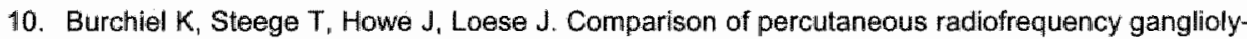
sis and microvascular decompression for the surgical management of tic douloureux. Neurosurgery 1981:9: 111-119

11. Fraioli $B$, Esposito $V$, Guidetti $B$, Crucci $C$, Mangredi $M$. Treatment of trigeminal neuralgia by thermocoagulation, glycerolization and percutaneous compression of gasserian ganglion and or retrogasserial rootlets: Long term results and therapeutic protocol. Neurosurgery $1989 ; 24$ : $239-245$

12. Burchiel $K$. Percutaneous retrogasserian gllycerol thizolysis in the management of trigeminal neuralgia. J Neurosurg 1988; 69: 361-366

13. Wilkinson $H$. Trigeminal nerve peripheral branch phenoliglycerol injections for tic douloureux. $J$ Neurosurg 1999; 90: 828-832

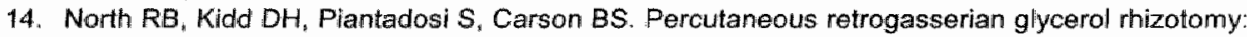
predictors of success and failure in treatment of trigeminal meuraigia. J Neurosurg 1990; 72 : 851.856

15. Sweet WH, Poletti $C E$, Macon JB. Treatment of trigeminal neuralgia and other facial pains by retrogasserian injection of glycerol. Neurosurgery 1981; 9: 647-654

16. Lobato RD, Rivas JJ, Rosario $S$, Lamas $E$. Percutaneous microcompression of the gasserian ganglion for trigeminal neuralgia. J Neurosurg 1990; 72: 546-553

17. Brabant S, Van Zundert J, Van Buyten JP, Vueghs P, Smet I, Van Duffel L: Pulsed Radiofrequency (RF) treatment of the Gasserlan Ganglion in patients with essential trigeminus neuralgia: a retrospective study. In: 9th World Congress. (Clinic TP, Ed), San Francisco - USA. (2000).

18. Erdine S: Pulsed RF does not relleve trigeminal neuralgia. In: 2nd World Congress of WIP. (Raj PP. Ed). Blackwell Science, Istanbul. (2001). 384

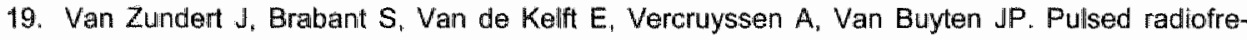
quency treatment of the Gasserian ganglion in patients with idiopathic trigeminal neuralgia. Pain 2003; $104: 449-452$

20. Sanders $M$, Zuurmond WW. Efficacy of sphenopalatime ganglion blockade in 66 patients suffering from cluster headache: a 12* to 70-month follow-up evaluation. J Neurosurg 1997; 87 : 876880

21. Bogduk $N$, Aprill $C$. On the nature of neck pain, discography and cervical zygapophysial joint blocks. Pain 1993; 54: 213-217 
22. van Kleef $M$, wan Sujlekom JA. Treatment of Chronic Cervical Pain, Brachialgia, and Cervicogenic Headache by Means of Radiofrequency Procedures. Pain Practice 2002; 2: 214-223

23. Sluijiter $M$, Mehta $M$. Treatment of chronic back and neck pain by percutaneous thermal sions, Persistent pain, modern methods of treatment, Edited by Lipton S. London, Academic Press, 1981 , pp 1.41-179,

24. Sjaastad $O$, Fredriksen $T, V$. Cervicogenic headache: diagnostic criteria. Headache 1990; 30: $725-726$

25. Lord SM, Barnsley L, B.J.Wallis. Percutaneous radiofrequency neurotiomy in the treatment of cervical zygapophyseal joint pain. N Engl J Med 1996; 335: 1721-1726

26. Slappendel R, Crul BJ, Braak GJ, Geurts JW, Booij LH, Voerman VF, de Boo $T$. The efficacy of radiofirequency lesioning of the cervical spinal dorsal root ganglion in a double blinded randomized study: no difference between 40 degrees $C$ and 67 degrees $C$ treatments. Pain 1997; 73: $159-163$

27. van Kleef $M$, Spaans $F$, Dingemans $W$, Barendse GAM, Floor $E$, Sluijter ME. Effects and side effects of a percutaneous thermal lesion of the dorsal root ganglion in patients with cervical pain syndrome. Pain 1993; $52: 49-53$

28. van Kleef $M$, Liem $L$, Lousberg $R$, Barendse $G$, Kessels $F$, Slujiter $M$. Radiofrequency lesion adjacent to the dorsal root ganglion for cervicobrachial pain: a prospective double blind randomized study. Neurosurgery 1996; 38: 1127-1131; discussion 1131-1122

29. Geurts Jovan Wijk RM, Stolker R. Groen GJ. Efficacy of radiofirequency procedures for the treatment of spinal pain; a systematic review of randomized clinical trials. Reg Anesth Pain Med 2001; 26: 394-400

30. Hildebrandt $J$. Percutaneous nerve block of the cervical facets - a relatively new method in the treatment of chronic headache and neck pain. Manual Medicine 1986; 2: 48-52

31. van Kleef $M$, Sluijter $M E$. Radiofrequency lesions in the treatment of pain of spinal origin. In Textbook of stereotactic and functional neurosurgery. Eds. Gildenberg PL, Tasker RR, Franklin PO. New York, The Mc Graw-Hill Companies, 1998, pp 1585-1599

32. van Suijlekom JA, van Kleef $M$, Barendse $G$, Sluijter ME, Sjaastad $O$, Weber WEJ. Radiofrequency cervical zygapophyeal joint neurotomy for cervicogenic headache. A prospective study in 15 patients. Functional neurology 1998; 13:297-303

33. Merksey $H$, Bogduk N. Classification of chronic pain, International Association of the study of Pain, 1994,

34. Stolker RJ, Vervest ACM, Groen GJ. Percutaneous facet denervation in chronic thoracic spinal pain. Acta Neurosurg 1993; 122: 82-90

35. Lou L, Gauci CA. Radiofrequency treatment in thoracic pain. Pain Practice 2002: $2: 224-225$

36. Tzaan WC. Tasker RR. Percutaneous Radlofrequency Facet Rhizotomy - Experience with 148 Procedures and Reappraisal of its Value. Can J. Neurol Sci 2000; 27: 125-130

37. Sluijter ME, Dingemans W, Barendse G. Comment on: "Ischemic spinal cord lesions following percutaneous radiofrequency spinal rhizotomy". Pain 1991; 47: 241

38. Stolker RJ, Vervest $A C M$, Groen $G$ J. The treatment of chronic thoracic segmental pain by radiofrequency percutaneous partial rhizotomy. J Neurosurg 1994: 80:

39. van Kleef $M$. Spaans $F$. The effects of producing a radiofrequency lesion adjacent to the dorsal root ganglion in patients with tharacic segmental pain by radiofrequency percutaneous partial rhizotomy. Clin J Pain 1995: 11: 325-332

40. Geurts JW, Lou L, Gauci CA, Newman P, van Wijk RM. Radiofrequency treatments in low back pain. Pain Practice 2002; 2: 226-234

41. Waddell G. Low back pain: a twentieth century health care enigma. Spine 1996; 21:2820-2825

42. Pagura JR. Percutaneous radiofrequency spinal rhizotomy. App. Neurophysiol 1983; 46: 138146

43. Gallagher $J$, Vadi PLP, Wesley JR. Radiofrequency facet joint denervation in the treatment of low back pain-a prospective controlled double-blind study in assess to efficacy. Pain clinic 1994; 7: 193-198

44. Uematsu $S$, Udvarhelyi $G B$, Benson DW, Siebens AA. Percutaneous radiofrequency rhizotomy. Surg Neuroll 1974; 2: 319-325 
45. J.C.Verdie, Lazorthes $Y$. Thermocoagulation percutanee analgesique des racines rachidiennes. Nour Presse Med 1982; 11: 2131-2134

46. Niv D. M.S.Chayen. Reduction of localized cancer pain by percutaneous dorsal root ganglia lesions. Pain Clinic 1992; 5: 229-234

47. van Wijk RM, Geurts $M W$, Wynne HJ. Long-lasting analgesic effect of radiofrequency treatment of the lumbosacral dorsal root ganglion. J Neurosurg 2001; 94:227-231

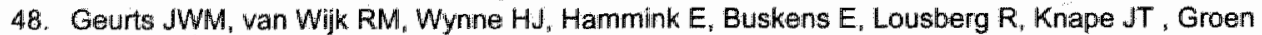
GJ. Radiofrequency lesioning of dorsal root ganglia for chronic lumbosacral radicular pain. a randomised, double blind, controlled trial. Lancet 2003; 361: 21-26

49. Leclaire $R$, Fortin $L$, Lambert $R$, Bergeron $Y M_{1}$ Rossignol $M$. Radiofrequency facet denervation in the treatment of low back pain: a placebo-controlled clinical trilal to assess efficacy. Spine 2001; 26: $1411-1416$.

50. van Kleef M, Barendse GA, Kessels F, H.M.Voets, Weber WE "de Lange S. Randomized trial of radiofrequency lumbar facet denervation for chronic low back pain. Spine 1999; 24: 1937 1942

51. Deyo RA. Point of View. Spine 2001; 26: 1417

52. Finch $P$. The use of radiofrequency heat lesions in the treatment of lumbar discogenic pain. Pain Practice 2002; 2: 235-240

53. van Kleef M, Barendse G, Wilmink JT, Lousberg R, Bulstra SK, Weber WE, Sluijter ME. Percutaneous intradiscal radio-frequency thermocoagulation in chronic non-specific low back pain. The Pain Clinic 1996; 9: 259-268

54. Barendse $G$, van Den Berg SG, Kessels $F$, Weber WE, wan Kleef $M$. Randomized controlled trial of percutaneous intradiscal radiofrequency thermocoagulation for chronic discogenic back pain: lack of effect form a 90 -second $70^{\circ} \mathrm{C}$ lesion. Spine $2001 ; 26: 287-292$

55. Ercelen O. Buluticu $E_{\text {。 }}$ Oktenoglu $T$, Sasani M, Bozkus $H_{3}$ Cetin Saryogiu A, Ozer F. Radiofrequency lesioning using two different time modalities for the treatment of lumbar discogenic pain: a randomized trial. Spine 2003; 28: 1922-1927

56. Pauza $\mathrm{KJ}$, Howell S, Dreyfuss $\mathrm{P}$, Peloza JH, Dawson $\mathrm{K}$, Bogduk N. A randomized, placebocontrolled trial of intradiscal electrothermal therapy for the treatment of discogenic low back pain. Spine J 2004; 4: 27-35

57. Plancarte RS, Mayer-Rivera FJ. Radiofrequency Procedures for Sacral and Pelvic Region Pain. Pain Practice 2002; 2: 248-249

58. Prithvi Raj $P$, Sahinder B, Lowe M. Radiofrequency lesioning of splanchnic nerves. Pain Practice 2002; 2: 241-247

59. Racz GB, Stanton-Hicks M. Lumbar and thoracic Sympathetic radiofrequency lesioning in complex regional pain syndrome. Pain Practice 2002; 2: 251-256

60. Noe CE. Haynesworth R. Lumbar radiofrequency sympatholysis. J Vasc Surg 1993; 17: 801806

61. Noe CE, Haynesworth $R$. Percutaneous lumbar sympathectomy: A comparison of radiofrequency denervation versus phenol neurolysis. Anesthesiology 1991; $74: 459-463$

62. Rohof OJJM. Radiofrequency treatment of Peripheral Nerves. Pain Practice 2002; 2: 257-260

63. Rohof OJJM, wan Dongen VCPC: Pulsed Radiofrequency of the suprascapular nervi in the treatment of chronic intractable shoulder pain. In: 2nd World Congress of Pain "Pain Practice edn. (Raj PP, Ed). Blackwell Science, Istanbul. (2001). 114

64. Tasker R. Neurosurgical and neuroaugmentative intervention, Cancer Pain, Edited by Patt RB. Philadelphia, J.B. Lippencott Company, 1993, pp 471-500,

65. Ischia S, Luzzani A, Ischia A, Pacini L. Role of unilateral percutaneous cervical cordotomy in the treatment of neoplastic vertebral pain. Pain 1984; 19: 123-131

66. Ischia S, Luzzani A, Ischia A, Magon F, Toscano D. Subarachnoid neurolytic block (L5-S1) and unilateral percutaneous cenvical cordotomy in the treatment of pain secondary to pelvic malignant disease. Pain 1984; 20: 139-149

67. Ischia $\mathrm{S}$, Luzzani A, Ischia A, Maffezzoli G. Bilateral percutaneous cervical cordotomy: immediate and long-term results in 36 patients with neoplastic disease. J Neurol Neurosurg Psychiatry $1984 ; 47: 1411-147$ 
68. Ischia $S$, Ischia $A$, Luzzani $A$, Toscano $D$, Steele A. Results up to death in the treatment of persistent cervico-thoracic (Pancoast) and thoracic maignant pain by unilateral percutaneous cervical cordotomy. Pain 1985; 21: 339-355

69. Ischia $S$, Polati $E$, Finca $G$, Goltin $L$. Radiofrequency treatment of cancer pain. Pain Practice $2002 ; 2: 261-264$

70. Sanders $M_{8}$ Zuurmond $W$. Safely of unilateral and bilateral percutaneous cervical cordotomy in 80 terminally ill cancer patients. J Clin Oncol 1995; 13: 1509-1512

71. Sluijter $M E$, Cosman $E R$, Rittman IIWB, van Klleef $M$. The effects of pulsed radiofrequency field applied to the dorsal root ganglion - a preliminary report. The Pain Clinic 1998; 11:109-117

72. Archer S, Li TT, Evans AT, Britland ST, Morgan H. Cell reactions to dielectrophoretic manipulation. Biochem Biophys Res Comm 1999; 257: 687-698

73. Van Zundert J. De behandeling van (chronische) lagerugpijn in een multidisciplinair pijncenIrum: effecten en kosten. Verhandeling "Ziekenhuisbeleid en management" KU Leuven 2001. 


\section{CHAPTER III}

\section{The role of the dorsal root ganglion in cervical radicular pain: diagnosis, pathophysiology and rationale for treatment}

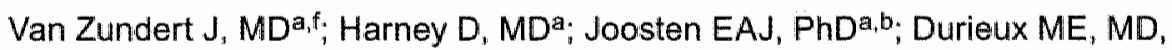
PhDc; Patijn J, MD, PhDa,d; Prins MH, MD, PhD ; Van Kleef M, MD, PhD ${ }^{a}$

a. Department of Anesthesiology and Pain Management, University Hospital Maastricht, Maastricht, The Netherlands b. Department of Neuroscience, University Maastricht, Maastricht, The Netherlandis c. Departments of Anesthesiology and Neurological Surgery, University of Virginia, Charlottesville, Wirginia, USA d. Neurologist, Department of Anesthesiology and Pain Management, University Haspital Maastricht. Maastricht, "The Netherlands e. Department of Epidemiology, Uniwersity Maastricht, Maastricht, The Netherlands f. Department of Anesthesiology and Mutticlisciplinary Pain Center, Ziekenthuis Oost-Llimburg, Genk, Belgium 


\section{Abstract}

Cervical radicular pain affects 83 per 100,000 adults annually. Diagnosis by means of physical examination, imaging and electrophysiological studies, is characterized by high specificity but low sensitivity. In this review, we focus in particular on the role of the dorsal root ganglion and those treatment modalities that aim at pathophysiological mechanisms occurring after nerve injury in the dorsal root ganglion. Cervical nerve injury initiates multiple events that lead to changes in nerve function and result in spontaneous firing at the dorsal root ganglion. Among these, inflammation and changes in ion channel function play a pivotal role. Although many treatment modalities are described in the literature, the available evidence for efficacy does not allow us to formulate definitive conclusions on the optimal therapy. A lack of evidence is reported for cervical spine surgery. Interlaminar epidural steroid administration and radiofrequency techniques adjacent to the cervical dorsal root ganglion have weak recommendations. 


\section{Introduction}

Cervical radicular pain is pain perceived in the upper limb, shooting or electric in quality, caused by irritation and or injury of a cervical spinal nerve ${ }^{1,2}$. This condition was first described in the literature by Parkinson in 1817, as a "rheumatic disease of the deltoid muscle" . Almost one century later, Dejerine (1914) formulated the concept of "cervical radiculitis" the Study of Pain (1994), cervical radicular pain is defined as pain perceived as arising in the upper limb caused by ectopic activation of nociceptive afferent fibers in a spinal nerve or its roots or other neuropathic mechanisms ${ }^{5}$. This is a problematic definition, as the presence of ectopic activation has rarely, if ever, been demonstrated in a clinical setting. Cervical radicular pain should be distinguished from cervical radiculopathy, a condition where an objective loss of sensory and or motor function is present. Radicular pain and radiculopathy are therefore not synonymous, although they are frequently not differentiated in the literature. The former is a symptom caused by ectopic impulse generation. The latter also includes neurological signs. The two conditions may nonetheless coexist and may be caused by the same clinical entities e.g. narrowing of the intervertebral foramen, intervertebral herniated disc and radiculitis due to arthritis, infection or inflammatory exudates ${ }^{5}$. The two syndromes can be part of a continuum, and radiculopathy may follow radicular pain as the underlying disease progresses.

A variety of treatment modalities for cervical radicular pain are described, but the optimal treatment approach remains unclear ${ }^{1}$. In clinical practice treatment is often started conservatively ${ }^{6}$, but an interventional or surgical treatment may be considered as part of a multidisciplinary approach in the management of intractable pain. The appreciation of the potential effect of the different treatment possibilities can only be made based on a good understanding of the underlying pathophysiology.

The aim of this review is to describe the clinical picture and diagnosis of cervical radicular pain. We will focus in particular on the role of the dorsal root ganglion (DRG) and those treatment modalities that aim at the underlying pathophysiological mechanisms occurring after nerve injury in the DRG. Central sensitization and changes in the dorsal horn will not be discussed. 


\section{Clinical picture and epidemiology}

In cervical radicular pain the symptoms and signs are related to dysfunction of cervical spinal nerve roots, and should be perceived along the distribution of the affected nerve $\operatorname{root}^{2,7,8}$. This distribution was verified in clinical experiments, where radicular pain was elicited in the characteristic distributions by mechanical stimulation of cervical spinal nerves with a needle under fluoroscopic control. The distribution of the different patterns of the cervical nerves is documented by Slipman et al. and illustrated in Figure $1^{9}$. Bogduk summarized the distributions as follows: pain from $\mathrm{C} 4$ is restricted to the neck and suprascapular regions. Pain from $\mathrm{C} 5$ extends into the upper arm, while pain from $\mathrm{C} 6$ and $\mathrm{C} 7$ extends from the neck and shoulder into the forearm and hand. In both instances the pain covers the lateral border of the upper limb, but that of $\mathrm{C} 7$ extends more onto the dorsal aspect. Pain from successive spinal nerves overlaps considerably, and no particular region of the upper limb is characteristic of any particular segment ${ }^{2}$. Somatic referred pain from the zygapophyseal joint or from the cervical intervertebral disc can have distributions similar to radicular pain, when the pain is perceived in the proximal upper limb ${ }^{10,11}$. However, when pain is distributed in the forearm and or hand it is far more likely to be radicular in origin. Nevertheless radicular pain should not be restricted to a dermatome, and might be perceived in any of the structures innervated by the affected nerve, because cervical spinal nerves are also distributed to deep structures, such as muscles, joints and ligaments as well as $\mathrm{skin}^{2}$.

\section{Diagnosis}

As with other types of spinal pain, if cervical radicular pain does not resolve spontaneously within 3 months, vertebral column infections and cancer (e.g. pancoast tumor) should be ruled out before further symptomatic treatment is offered. Somatic referred pain and shoulder pathology should also be excluded, because their clinical presentation may be similar to radicular pain ${ }^{2,14}$. Neurological examination of patients with cervical radicular pain includes testing of strength, muscle stretch reflexes and sensibility ${ }^{15}$. Five different clinical tests have been reported as useful for the diagnosis of cervical radicular pain: the neck compression test or Spurling test ${ }^{16}$. shoulder abduction test ${ }^{17}$, Valsava's maneuver ${ }^{18}$, axial manual traction test ${ }^{19}$, and Elvey's upper limb tension test ${ }^{20}$. The validity of three tests: Spurling, axial manual traction and shoulder abduction test, in the diagnosis of root compression in cervical disc disease, was investigated regarding radicular pain, neurological signs and root compression signs in myelography. All tests had a high specificity $(81-100 \%)$ but a low sensitivity $(26-50 \%)$ for the validity parameters ${ }^{19}$. 

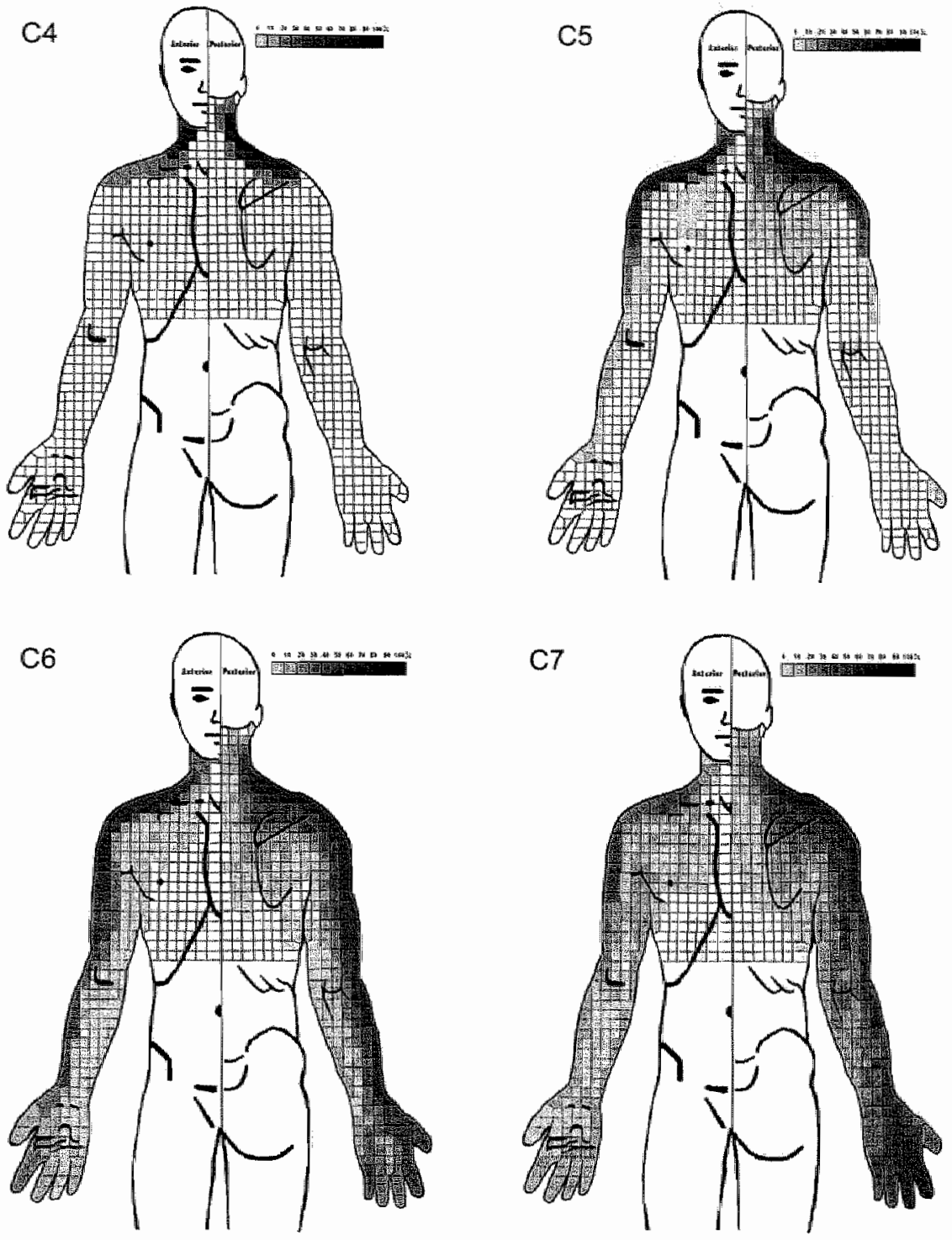

Figure 1: Percent occurrence of symptom provocation per bit for the $\mathrm{C} 4$ to $\mathrm{C} .7$ roots.

Reproduced from: Slipman, CW, Plasteras CT, Palmitier RA. Huston CW, Sterenfeld EB. Symptom provocation of fluoroscopically guided cervical nerve root stimulation. Are dynatomal maps identical to dermatomal maps? Spine, 1998; 23 (20): 2235- 2242 Figure 4. With permission of Lippencatt Williams \& Wilkins 
Spurling's test has also been validated in a controlled trial using electromyography as a reference, with comparable results (sensitivity of $30 \%$; specificity of $93 \%$ ) ${ }^{2}$. Despite low sensitivity the three investigated tests are considered valuable aids in the clinical diagnosis of a patient with neck and arm pain ${ }^{19}$

The most commonly used complementary diagnostic tools to establish the etiology of cervical radicular pain are imaging techniques and electrophysiological studies. Imaging studies provide information relative to anatomic abnormalities while electrophysiological studies allow detection of neurological dysfunction. The primary role of plain radiography is to rule out other disease processes ${ }^{22}$. Computed tomography scanning is particularly useful for cortical bony structures. It is more sensitive to changes in bone than is magnetic resonance imaging (MRI), but has limited ability to detect soft tissue lesions ${ }^{23-25}$. Magnetic resonance imaging is better suited to identify changes of the disc, spinal cord, nerve root, and surrounding soft tissue structures $^{24}$. Some authors state that MRI is the imaging modality of choice in patients with cervical radicular pain, and this appears to be consistent with current practice $^{22,24}$. However, data on specificity and sensitivity of various imaging techniques in this setting are limited, because a diagnostic gold standard for cervical radicular pain does not exist. Moreover, prospective studies showed abnormal MRI scans of the cervical spine in $19 \%$ to $28 \%$ of asymptomatic subjects, depending on the age ${ }^{26,27}$. Therefore interpretation of any imaging finding must be done in the context of a patient's clinical presentation ${ }^{26,28}$.

Electromyography is used to sample motor unit behavior in selected limb muscles as well as the cervical paravertebral muscles in order to detect neurophysiological pathology related to a cervical nerve root or roots. Nerve conduction studies are also performed in conjunction with electromyography in order to rule out other causes of symptoms such as a peripheral nerve involvement ${ }^{29}$. Several other electrophysiological procedures "such as analysis of motor unit action potentials and the evaluation of evoked potential latencies have been suggested to increase the sensitivity ${ }^{30}$, but until now electromyography remains the most sensitive method ${ }^{31,32}$. An initial report on the use of quantitative sensory testing as a selection tool for appropriate treatment for patients suffering lumbar radicullopathy caused by disc herniation indicates potential value, but there are no results on cervical radicular pain available yet ${ }^{33}$. Summarizing, diagnostic procedures such as imaging techniques, electrophysiological testing and quantitative sensory testing provide useful complementary data, but they can not replace the clinical diagnosis ${ }^{29,32}$.

Radiological imaging provides excellent morphological detail of the pathology and its relation to the neuraxis, and so allows exclusion of other processes such as can$\operatorname{cer}^{34}$, infection ${ }^{35}$ and neurovascular pathology ${ }^{36}$. However, in patients with chronic radicular pain it is often not possible to determine with any certainty, which disc and 
or nerve root is symptomatic in the degenerative cervical spine ${ }^{37}$. Prior to deciding on any interventional treatment option, attempts should be made to confirm that the level as determined by clinical examination and ancillary investigations is truly the one which causes the signs and symptoms. Therefore, selective diagnostic nerve root blocks may be recommended. This technique, injecting a small volume $10.5-1$ $\mathrm{ml}$ ) of local anesthetic adjacent to the DRG, controlled by prior injection of non-ionic contrast medium under direct real-time fluoroscopy, has been described by van Kleef et al. ${ }^{38}$. Wolff et al studied the accuracy of selective diagnostic nerve root blacks in the lumbar region, by using standard dermatomal maps. They found that interpretation of an adequately performed segmental nerve block in the presumed dermatome is more reliable when the overlap of neighboring dermatomes is taken into account ${ }^{39}$. In an extensive review on the value of neural blockade for diagnostic and prognostic purposes no data were obtained on cervical spinal nerve blocks ${ }^{40}$. The authors conclude that the confusion and complexity that typifies diagnosis in chronic spinal pain may justify selective use of diagnostic blocks that make anatomic and physiologic sense, even if their validity is incompletely proved ${ }^{40}$.

In conclusion, diagnosis of cervical radicular pain and radiculopathy requires a complete medical history, clinical diagnosis using standardized test methods of physical examination, imaging techniques, electrophysiological investigation and determination of the symptomatic level by means of diagnostic selective nerve root blocks. Nevertheless, the discrepancy found in clinical practice between symptoms and pathology identified with imaging techniques and electrophysiological testing often remains striking. Moreover, recent research on genetically determined differences in sensitivity to pain highlight the problem of inter-individual variability, which is often observed in clinicall practice where pain symptoms and treatment effects vary among patients with similar clinical conditions ${ }^{41,42}$.

\section{Pathophysiology}

Despite the fact that the exact pathophysiological mechanisms underlying radicular pain in humans are not yet fully understood, fundamental research in various animal models has provided important insights. In line with the literature on the pathophysiology of lumbar radicular pain two major mechanisms in the nerve are thought to induce cervical radicular pain: (1) nucleus pulposus material leaking onto the nerve root, and or (2) compression of the nerve root by anatomic abnormalities. Either of these pathogenic mechanisms will induce two processes in the nerve: (1) an inflammatory reaction, and - related to this $-(2)$ changes in ion channel functioning. Eventually, these effects cause a pattern of hyperexcitability and spontaneous ectopic activity in the DRG, which is interpreted as pain. In addition, discharges enter the spinal cord and induce central sensitization at the synapses located in the dorsal 
horn $^{43}$. Howe et al. in a classical paper in 1977 recognized that repetitive spontaneous firing took place following minimal compression of the normal $D R G^{44}$. It was this paper that provided the stimulus for further research into the pathophysiological changes in the DRG as a driving mechanism for pain following an injury to a nerve ${ }^{45,46}$. In this section we will discuss nerve and DRG inflammation and changes in ion channel functioning as possible causes of cervical radicular pain ${ }^{44}$ (Figure 2).

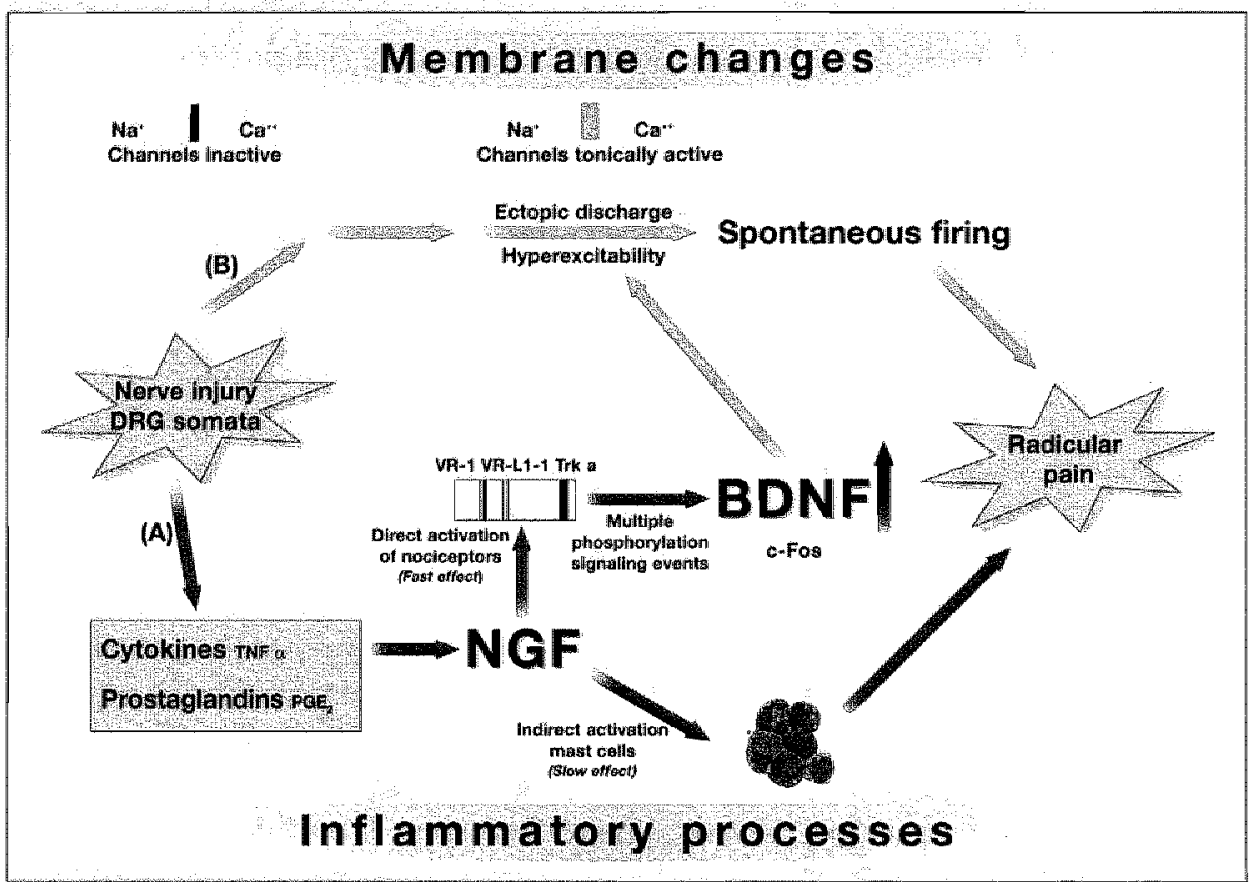

Figure 2: Known changes at the dorsall root ganglion following merve injury at the dorsal root ganglion somata include an inflammatory cascade (A) with release of inflammatory cytokines and pros. tagllandins ultimately leading to the release of nerve growth factor (NGF). NGF has a simultaneous effect via direct activation of nociceptors "fast effect" binding to the mitogen activated protein kinase (MAPK) receptor tyrosine-kinase-A (TrkA) or waniloid receptors (VR1) and heat-sensitive vanilloid like receptors (VR-L.1). These results in multiple signaling events, which then cause massive release of brain derived neurotrophic factor (BDNF) and increased c-Fos expression. In addition NGF initiates an indirect activation "slow effect" via mast cells and degramulation product release, the latter results in a further release of NGF. In parallel there are changes in the ion channels (B) whereby $\mathrm{Na}^{+}$and $\mathrm{Ca}^{2+}$ channels become tonically active. As a result of ian channell modification ectopic discharge, hyperexcitability and spontaneous firing occurs at the $D R G_{n}$ This spontaneous firing together with the increased BDNF expression is the primary mechanism underlying radicular pain. 


\section{Inflammatory process}

Inflammation of a cervical DRG and or nerve root can be caused by injury or exposure to nucleus pulposus material of the cervical disc, leading to the release of many trophic molecules and cytokines that play a role in the development of pain ${ }^{47}$. Amongst these molecules prostaglandins (PGs) and nerve growth factor (NGF) are the most important. Arachidonic acid, the most abundant precursor of PG in mammals, is released from cell membrane phospholipids by the action of phospholipase present in nucleus pulposus material ${ }^{48}$. Prostaglandins are generated from arachidonic acid by the enzyme cyclo-oxygenase (COX) of which there are two isoforms ${ }^{49}$. COX-1 is a constitutive enzyme present in platelets, stomach, intestines and kidneys. In these tissues it performs a "housekeeping" function to synthesize PGs that regulate normal cell activities. COX-2 is the form induced at inflammatory sites in various cell types (i.e. macrophages, synoviocytes, fibroblasts etc.). Although it has been shown that COX-2 is induced in dorsal root neurons following peripheral injury in rats ${ }^{50}$, its role in DRG and/or nerve root injury remains unproven. Several findings, however, suggest that it may play a causative role in the development of radicular pain. COX-2 mediates central PG synthesis, which may be important in the generation of pain ${ }^{51}$. Basal release of PGs occurs in the spinal cord and dorsal root ganglia. Acute and chronic inflammation increases the expression of COX-2 and the release of PGE2 and PGI248. Inflammatory cytokines (e.g. tumor necrosis factor- $\alpha$ $(T N F-\alpha))$ and interleukins are involved in the initiation of intracellular changes through activation of different mitogen activated protein kinase (MAPK) pathways ${ }^{52}$. In a rat model of experimental disc herniation an increased expression of TNF- $\alpha$ in the DRG was described ${ }^{53}$.

Nerve growth factor is released following injury at the DRG somata and acts via both a fast and a slow effect ${ }^{54-56}$. The fast effect of NGF is an activity on nociceptors such as vanilloid receptors and heat-sensitive receptors such as vanilloid-like receptors. Vanilloid receptors are present in tyrosine kinase A-positive $\mathrm{C}$-fibers; no expression is observed in cells with myelinated axons ${ }^{57}$. Slow effects of NGF include the upregulation of various molecules, including $c-F o s$, within the neuron. A- $\beta$ and $A-\delta$ - fibers are involved in the NGF-mediated slow effect but C-fibers are not ${ }^{58}$. Following nerve injury at the DRG only some fibers may be directly damaged, however a degree of modulation takes place in all neurons ${ }^{59}$. Nerve injury exposes noninjured afferents to an inflammatory environment that affects their function and activity. Signals generated during Wallerian degeneration may affect neighboring intact afferents. Nerve growth factor, for example, regulates the expression of neuropeptide genes in adult sensory neurons ${ }^{60}$ "Nerve growth factor expression in the DRG has previously been linked to increased expression of brain-derived neurotrophic factor (BDNF) $)^{61-64}$. Recently Obata et al. described extracellular signal-regulated 
protein kinase signaling in the DRG following injury in the DRG somata as a link between NGF and BDNF expression, and proposed this as a mechanism for radicular pain ${ }^{65}$. There is also evidence that the increase in BDNF, which is constitutively expressed in sensory neurons and transported from DRG to terminals in the spinal $\mathrm{cord}^{3 \mathrm{~B}}$, may be a major inducer of the central mechanisms of inflammatory-induced hyperalgesia ${ }^{67-69}$.

In summary, although few studies have addressed this issue directly, indirect data suggest that inflammation may well be a major mechanism in the pathophysiology of cervical radicular pain, mainly as a result of injury or exposure of nervous tissue to nucleus pulposus material. This induces a cascade of events. Importantly, after nerve injury both injured and non-injured fibers are involved in this inflammatory process, where NGF and BDNF are key players.

\section{Ion channel modulation}

Nerve injury initiates membrane changes whereby the functioning of voltage-gated $\mathrm{Na}, \mathrm{K}$ and $\mathrm{Ca}$ ion channels is modified. Although neurophysiologic doctrine has traditionally referred to "the" voltage-gated $\mathrm{Na}$ channel ( $\mathrm{Nav}$ ), it is now clear that there are at least nine genes that encode molecularly and physiologically distinct $\mathrm{Na}$ channels. Plasticity in $\mathrm{Na}$ channel gene expression is accompanied by electrophysiological changes that prime these cells to fire spontaneously or at inappropriately high frequencies ${ }^{70}$. Many workers have identified increased expression of voltage dependent $\mathrm{Na}$ channels in the DRG following injury ${ }^{71,72}$. Cummins et all. recognized Nav 1.3 channels as responsible for abnormal hyperexcitability of DRG neurons $^{73}$. Furthermore, Nav 1.9 channels and possibly also Nav 1.3 channels are dramatically reduced both in radicular pain and in neuropathic pain ${ }^{74}$. The result is a shift in resting membrane potential, which could relieve resting inactivation. This implies that neurons both injured and non-injured are primed and in a hyperexcitable state and can fire repetitively, leading to cervical radicular pain.

The reduction of $K$ currents in DRG cells has been illustrated after peripheral nerve axotomy ${ }^{75}$. K channels play an important role in the generation of ectopic discharges and the reduction in $\mathrm{K}$ currents after peripheral injury contributes to neuronal excitability $^{76}$. However the exact function of $\mathrm{K}$ currents in ectopic discharge generation mechanisms is not yet clear. In order to further elucidate the role of $\mathrm{Na}, \mathrm{Ca}$ and $\mathrm{K}$ ion channels, Liu et al. ${ }^{77}$ examined the effect of $\mathrm{Na}, \mathrm{Ca}$ and $\mathrm{K}$ ion channel blockers in a model of neuropathic pain (spinal nerve ligation $7-14$ days prior). It was shown that ectopic discharges from DRG were inhibited in the presence of $\mathrm{Na}$ channel blockers, suggesting that $\mathrm{Na}$ channels are critical for the ability of damaged nerves to generate repetitive firing of action potentials. Nonspecific $\mathrm{Ca}$ channel blockers $\left(\mathrm{Cd}^{+}, \mathrm{Co}^{2+}, \mathrm{Ni}^{2+}\right)$ also were effective in reducing the rate of ectopic discharges when 
applied to the $\mathrm{DRG}^{77}$, as were a specific L-type blocker (verapamil) and $\mathrm{N}$-type blocker (omega-conotoxin). Blockade with omega-conotoxin is an irreversible blockade producing long-lasting inhibition of ectopic discharges ${ }^{78,79}$.

In addition to dysregulated channel expression, altered channel trafficking also might play a role in the pathophysiological process after nerve injury. For correct physiological functioning, ion transport proteins must be targeted to the appropriate domains of cell membranes as shown in several fundamental studies ${ }^{80,84}$. In conclusion, after nerve injury, $\mathrm{Na}$ ion channels are primarily involved in hyperexcitability of the neuron fibers whilst $\mathrm{Na}, \mathrm{K}$ and $\mathrm{Ca}$ ion channels are focal points in the generation of ectopic neuronal discharge.

\section{Spontaneously firing $D R G$}

As indicated above, it has been difficult to pinpoint the causative dysfunction in the DRG that is responsible for radicular pain. Part of the reason for this difficulty is that effects at various molecular targets are tightly interlinked. A modulation of the ion channels in the membrane of the DRG neurons has been reported. There is concurrent increased expression of BDNF, which has recently been shown to directly and rapidly gate $\mathrm{Na}$ channels. This BDNF-induced gating of ion channels causes membrane depolarization of neurons and eventually results in the firing of action potentials ${ }^{82,83}$. Finally, both pathways can result in repetitive spontaneous firing following a transient nerve injury. It has been illustrated that many ion channels may be modulated in a nerve injury. The real crux of the pathophysiology is to elucidate which modulated ion channels have functional significance in causing pain ${ }^{46,75,84}$. The application of new techniques such as gene arrays and proteomic technologies may help to speed up the process of identifying a more complete list of proteins that are components in a pathophysiological process of ongoing radicular pain.

\section{Rationale and level of evidence for treatment modalities targeting the cervical dorsal root ganglion and or nerve root}

Chronic cervical radicular pain is a complex syndrome that has a high impact on patients' quality of life ${ }^{85}$. An integrated approach involving psychological counseling, physical therapy, cognitive behavioral treatment and symptomatic management of the pain is recommended $d^{86}$. The multidisciplinary evaluation also aims at providing guidance for the selection of any treatment ${ }^{22.87}$. In the section below, we limit our discussion to treatment modalities, which, at least in theory, have a mode of action that interferes with the pathophysiological mechanisms described above at the level of cervical DRG or nerve root. Literature was identified by a search in electronic databases, including Cochrane Controlled Trials Register (Issue 2, 2005), 
OLDMEDLINE from 1960 to 1966, MEDLINE from 1966 and EMBASE from 1974 to December 2004. We conducted literature searches specifically for the treatment of cervical radicular pain, using for MEDLINE the exploded Mesh headings "radiculopathy" combined with the key word "cervical" and another combining the Mesh headings "Pain", "Neck" and "Radiculopathy or "Spinal Nerve Roots" additionally a search using the abstract words "radicular", "pain" and "cervical" was conducted. For EMBASE we used the following EMTREES: "Radicular Pain", "Neck", "Chronic pain", "Cervical neuralgia" and "Therapy" and limited the search to "human". Combining the results of those searches with "drug" and/or "pharmacological therapy" yielded no references. The publications were screened based on the abstract. The reference lists from identified articles and relevant textbooks were manually searched for additional papers. Pharmaceutical companies were contacted in order to obtain unpublished information or data presented at congresses or in nonindexed journals.

Application of the level of evidence and the grade of recommendation was done by an experienced epidemiologist (MP: methodological quality of the evidence) and two clinicians (MVK and JVZ: clarity of the risk/benefit balance), according to the authorative and recently published "Evidence-Based Guidelines" by G. Guyatt for the American College of Chest Physicians ${ }^{88}$. This proposed grading provides information on the clarity of the risk/benefit balance, and about the methodological quality of the evidence resulting in strength of recommendation from strong to very weak as illustrated in table 1. We looked for the publications with the highest level of evidence for the different treatment modalities of cervical radicular pain targeting the cervical DRG and or nerve root; the summary is listed in table 2. 
Table 1: Grade of recommendations according to The American College of Chest Physicians:

\begin{tabular}{|c|c|c|c|}
\hline $\begin{array}{l}\text { Grade of Recom- } \\
\text { mendation }\end{array}$ & $\begin{array}{l}\text { Clarity of } \\
\text { Risk/Benefit }\end{array}$ & $\begin{array}{l}\text { Methodological Strength of } \\
\text { Supporting Evidence. }\end{array}$ & Implications \\
\hline $1 \mathrm{~A}$ & Clear & $\begin{array}{l}\text { RCT's without important limita- } \\
\text { tions }\end{array}$ & $\begin{array}{l}\text { Strong recommendation cain } \\
\text { apply to most patients in } \\
\text { most circumstances without } \\
\text { reservation }\end{array}$ \\
\hline $16+$ & Clear & $\begin{array}{l}\text { No RCT's but strong RCT } \\
\text { results can be unequivocally } \\
\text { extrapolated or owerwhelming } \\
\text { evidence from observational } \\
\text { studies }\end{array}$ & $\begin{array}{l}\text { Strong recommendation; can } \\
\text { apply to most patients in } \\
\text { most circumistances }\end{array}$ \\
\hline 18 & Clear & $\begin{array}{l}\text { RCT's with important limita- } \\
\text { tions (inconsistent results, } \\
\text { methodological flaws) }\end{array}$ & $\begin{array}{l}\text { Strong recommendations; } \\
\text { likely to apply to most pa- } \\
\text { tients }\end{array}$ \\
\hline 10 & Clear & Observational studies & $\begin{array}{l}\text { Intermediate-strength rec- } \\
\text { ommendation; may change } \\
\text { when stronger evidence is } \\
\text { available }\end{array}$ \\
\hline $2 A$ & Unclear & $\begin{array}{l}\text { RCT's without important limi- } \\
\text { tations }\end{array}$ & $\begin{array}{l}\text { Intermediate-strength rec- } \\
\text { ommendation; best action } \\
\text { may differ depending on } \\
\text { circumstances or patients' or } \\
\text { societal values }\end{array}$ \\
\hline $2 \mathrm{C}+$ & Unclear & $\begin{array}{l}\text { No RCT's but strong RCT } \\
\text { results can be unequivocally } \\
\text { extrapolated } \text { "or overwhelming } \\
\text { evidence from observational } \\
\text { studies }\end{array}$ & $\begin{array}{l}\text { Weak recommendlation; best } \\
\text { action may differ depending } \\
\text { an circumstances or pa- } \\
\text { tients' or societal values }\end{array}$ \\
\hline $2 \mathrm{~B}$ & Unclear & $\begin{array}{l}\text { RCT's with important limita- } \\
\text { tions (inconsistent results, } \\
\text { methodological flaws) }\end{array}$ & $\begin{array}{l}\text { Weak recommendation; } \\
\text { alternative approaches likely } \\
\text { to be better for some pa- } \\
\text { tients under some circum- } \\
\text { stances }\end{array}$ \\
\hline $2 \mathrm{C}$ & Unclear & Observational studies & $\begin{array}{l}\text { Very weak recommenda- } \\
\text { tions; other alternatives may } \\
\text { be equally reasonable }\end{array}$ \\
\hline
\end{tabular}

Method used for evaluating the methological strength of the available evidence and the cllarity of the risk/benefit balance, reprinted with permission of the American College of Chest Physicians ${ }^{2 \theta}$

RCT: randomized clinical trial 
Table 2: Evidence for treatment of cervical radicular pain

\begin{tabular}{|c|c|c|c|c|c|}
\hline Treatment & Publication & Type & $\begin{array}{l}\text { Clarity of } \\
\text { risk/benefit } \\
\text { ballance }\end{array}$ & $\begin{array}{l}\text { Level of } \\
\text { evidence }\end{array}$ & Results \\
\hline $\begin{array}{l}\text { Interlaminar } \\
\text { steroid }\end{array}$ & $\begin{array}{l}\text { (Stav A. et all. } \\
1993)^{\text {gig }}\end{array}$ & $\begin{array}{l}\text { Prospective, } \\
\text { randomized, } \\
\text { epidural vs. } \\
\text { intramuscular }\end{array}$ & unclear : 2 & $B$ & $\begin{array}{l}\text { Good pain } \\
\text { relief in } 68 \% \\
\text { of epidural } \\
\text { group vs. } 12 \\
\% \text { in intra- } \\
\text { muscular } \\
\text { group }\end{array}$ \\
\hline $\begin{array}{l}\text { Transforaminal } \\
\text { steroid (fluoros- } \\
\text { copy guided) }\end{array}$ & $\begin{array}{l}\text { (Vallee JN et } \\
\mathrm{al}, 2001)^{105}\end{array}$ & $\begin{array}{l}\text { Non- } \\
\text { comparative } \\
\text { prospective }\end{array}$ & unclear : 2 & C & $\begin{array}{l}53 \% \text { succesis } \\
\text { rate at } 6 \\
\text { months }\end{array}$ \\
\hline $\begin{array}{l}\text { Transforaminal } \\
\text { steroid (CT } \\
\text { guided) }\end{array}$ & $\begin{array}{l}\text { (Cyteval C et } \\
\left.\mathrm{al}^{2}, 2004\right)^{100}\end{array}$ & $\begin{array}{l}\text { Non- } \\
\text { comparative } \\
\text { prospective }\end{array}$ & unclear : 2 & C & $\begin{array}{l}60 \% \text { success } \\
\text { rate at } 6 \\
\text { months }\end{array}$ \\
\hline $\begin{array}{l}\text { RF cervical } \\
\text { DRG }\end{array}$ & $\begin{array}{l}\text { (van Kleef M et } \\
\text { al, 1996) }\end{array}$ & $\begin{array}{l}\text { Prospective, } \\
\text { randomized, } \\
\text { double blind RF } \\
\text { vs. sham }\end{array}$ & unclear : 2 & $B$ & $\begin{array}{l}\text { Significant } \\
\text { more pain } \\
\text { reduction in } \\
\text { RF group vs. } \\
\text { sham at } 8 \\
\text { weeks }\end{array}$ \\
\hline $\begin{array}{l}\text { RF cervical } \\
\text { DRG }\end{array}$ & $\begin{array}{l}\text { (Slappendel R } \\
\text { et al, 1997) }\end{array}$ & $\begin{array}{l}\text { Prospective } \\
\text { randomized } \\
\text { double blind RF } \\
40^{\circ} \mathrm{C} \text { vs. RF } \\
67^{\circ} \mathrm{C}\end{array}$ & unclear: 2 & $\mathrm{~B}$ & $\begin{array}{l}\text { Significant } \\
\text { pain reduc- } \\
\text { tion equal in } \\
\text { both groups } \\
\text { at } 3 \text { months }\end{array}$ \\
\hline $\begin{array}{l}\text { Pulsed RF cer- } \\
\text { vical DRG }\end{array}$ & $\begin{array}{l}\text { (Van Zundert J } \\
\text { et al, 2003) }\end{array}$ & $\begin{array}{l}\text { Non- } \\
\text { comparative } \\
\text { prospective }\end{array}$ & unclear: 2 & C & $\begin{array}{l}72 \% \text { success } \\
\text { rate at } 8 \\
\text { weeks, and } \\
33 \% \text { at } 1 \\
\text { year }\end{array}$ \\
\hline Neck surgery & $\begin{array}{l}\text { (Persson L et } \\
\text { al, 1997) }\end{array}$ & $\begin{array}{l}\text { Prospective } \\
\text { randomized, } \\
\text { surgery vs. } \\
\text { physiotherapy } \\
\text { or cervical collar }\end{array}$ & unclear: 2 & $\mathrm{~B}$ & $\begin{array}{l}\text { Surgery not } \\
\text { more effec- } \\
\text { tive than } \\
\text { cervical collar } \\
\text { or physio- } \\
\text { therapy after } \\
3 \text { and } 12 \\
\text { months }\end{array}$ \\
\hline
\end{tabular}

Publications with the highest level of evidence for the specific management of cervical radicular pain.

$\mathrm{CT}=$ Computed tomography; $\mathrm{RF}$ = radiofrequency; $\mathrm{DRG}=$ dorsal root gangliom. 


\section{Therapies targeting the inflammatory changes (NGF and BDNF modulation)}

Pharmacological anti-inflammatory treatment relies mainly on the use of nonsteroidal anti-inflammatory drugs, corticosteroids and perhaps in the future TNF-a inhibitors.

\section{Non-steroidal anti-inflammatory drugs}

Non-steroidal anti-inflammatory drugs (NSAIDs), the most commonly used analgesics, are potent agents for the treatment of inflammatory pain. Their analgesic action (inhibiting $P G$ synthesis) is postulated to be primarily at peripheral sites of inflammation $^{89}$, but evidence is accumulating that PGs are also produced in the DRG and the spinal cord ${ }^{48,90}$. NSAIDs inhibit $P G$ synthesis through inhibition of COX enzymes, which is responsible for both therapeutic and unwanted effects. Unfortunately, serious cardiovascular adverse events have been described recently after long-term use of selective $\mathrm{COX}-2$ inhibitors ${ }^{91-93}$. Non-steroidal anti-inflammatory drugs are efficacious in a variety of pain syndromes ${ }^{94,95}$ but none of the different NSAIDs have been investigated in the management of cervical radicular pain. Hence, no evidence is available to support or refute efficacy in this setting.

\section{Corticosteroids}

The anti-inflammatory effect of corticosteroids is achieved by the inhibition of the phospholipase A2- initiated arachidionic acid cascade ${ }^{96}$. Also, a local anestheticslike effect is postulated ${ }^{97}$. The epidural administration of corticosteroids, either by the interlaminar or transforaminal route, aims at delivering the medication in the surroundings of the inflamed nerve root. We did not find published studies comparing intrallaminar versus transforaminal approaches. A clinical trial comparing intramuscular steroid with cervical epidural steroid administration indicates a good pain relief in $68 \%$ of the patients one year after the last injection (level $2 \mathrm{~B}$ recommendation) The Cochrane review indicates limited evidence of effectiveness of interlaminar epidural injection of steroids for cervical radicular pain ${ }^{9 *}$. In a retrospective cohort stuidy on the complications of fluoroscopic guided interlaminar cervical epidural injections only minor complications were mentioned (in $17 \%$ of the patients). These complications resolved without morbidity ${ }^{100}$. However, case reports mention nerve injury or spinal cord damage after cervical epidural steroid injections ${ }^{101,102}$. Intrinsic spinal cord damage was reported in two patients receiving intravenous sedation, which is now generally considered as contraindicated ${ }^{10 \%}$.

The transforaminal route has gained in popularity over the last decade because it is supposed to deliver the drug as close as possible to the inflamed nerve root, 103, 104 . 
Vallee et $a^{105}$ performed a prospective non-comparative cohort study using fluoroscopy as control for the needle placement. After 6 months $53 \%$ of the patients experienced excellent or good pain relief (level $\mathrm{C}$ evidence). Also, a good pain relief was reported in $60 \%$ of the patients after $\mathrm{CT}$ guided cervical periradicular foraminal steroid infiltrations in an open prospective study with 6 months follow-up (level $C$ evidence) ${ }^{106}$. Recently several case reports indicate the possibility of serious adverse events such as spinal cord injury after cervical transforaminal injections, which are hypothesized to be related to intra-arterial injection of particulate steroid occluding critical vessels that supply the spinal cord ${ }^{107-110}$. Hence, some colleagues doubt the suitability of this approach ${ }^{111}$, and even suggest temporarily abandoning the technique above the $\mathrm{L} 3$ level until more scientific data are available ${ }^{112}$.

At this moment the debate regarding efficacy and safety of cervical transforaminal versus interlaminar injection of corticosteroids is ongoing. Therefore both techniques should be handled with caution and only after the patient has been fully informed of the risks. Based on the unclear risk/benefit balance the use of transforaminal epidural steroids yields a very weak $(2 \mathrm{C})$ recommendation.

\section{TNF- $\alpha$ inhibitors}

Basic research demonstrates that TNF- $\alpha$ is involved in the development of nucleus pulposus-induced nerve injuries ${ }^{113}$ "and TNF- $\alpha$ inhibitors can provide pain relief. This is in accordance with recent findings indicating that TNF- $\alpha$ inhibitors attenuate the elevated BDNF levels induced by nucleus pulposus application to the nerve root $^{113}$. Open label trials using systemically injected TNF- $\alpha$ inhibitors in the management of lumbar radicular pain indicate a potential benefit of this treatment option ${ }^{114-117}$. There are however no data on the treatment of cervical radicular pain. 


\section{Therapies targeting ion channel modulation}

\section{Sodium channel blockers}

Sodium channel blockers such as the anticonvulsant drugs carbamazepine and oxcarbazepine have been widely used for the treatment of central and peripheral neurogenic pain ${ }^{118}$. Valproic acid is used also for the treatment of neuropathic pain, although a randomized clinical trial indicated that valproic acid is not superior to placebo for the management of polyneuropathy ${ }^{199}$. Mexiletine has been reported to be effective in a variety of neuropathic pain syndromes. More recent reports, however, question the efficacy of oral mexiletine in neuropathic pain, making it difficult to draw definitive conclusions ${ }^{120-122}$.

\section{Calcium channel antagonists}

Modulation of calcium channels may have an additional role to play in the management of cervical radicular pain. Gabapentin is known to bind to the $\alpha 2 \delta$ unit of voltage-gated dependent calcium channels ${ }^{123}$. Several randomized, large-scale studies are now available ${ }^{124}$. The efficacy of gabapentin was demonstrated in patients with post herpetic neuralgia and painful diabetic neuropathy in two placebo-controlled trials ${ }^{125,126}$. A report of 10 cancer patients with neuropathic pain in head or neck shows pain relief with gabapentin ${ }^{127}$. Recently Sabatowski et al. have shown that pregabalin, another drug modulating the calcium channels, is also effective in treating neuropathic pain ${ }^{128}$. In conclusion, ion channel antagonists are commonly used as co-analgesics for the treatment of neuropathic pain ${ }^{129}$, but their value has never been investigated in the management of cervical radicular pain. It should be stressed that for most of the pharmacological agents a more complex mode of action is described, working via several ion channels. 


\section{Other treatments targeting the cervical dorsal root ganglion and or nerve root}

\section{Radiofrequency/ Pulsed radiofrequency}

Radiofrequency (RF) treatment has been used in a variety of pain syndromes because of its ability to interrupt the pain conducting pathways ${ }^{86,130: 131}$. However, the mode of action is not yet clear. The efficacy of RF treatment adjacent to the cervical DRG has been illustrated in two randomized clinical trialls ${ }^{38,132}$. Van Kleef et al demonstrated a significant reduction in pain 8 weeks after RF at $67^{\circ} \mathrm{C}$ compared to sham (level B evidence) ${ }^{38}$. Additionally, Slappendel et al. found that treatment with RF at $40^{\circ} \mathrm{C}$ was equally effective as treatment at $67^{\circ} \mathrm{C}$ (level $\mathrm{B}$ evidence) ${ }^{132}$. ACcording to two systematic reviews, there is currently limited evidence that RF treatment of the DRG is more effective than placebo in chronic cervical radicular pain $^{131,133}$. Recently pulsed radiofrequency (PRF) was introduced in clinical practice as a non-or minimally neurodestructive modification of conventional RF heat lesions $^{134}$. A potential mechanism of action of RF/PRF treatment may be via an NGFinitiated intracellular pathway with downstream modification of intracellular signaling. Higuchi et al. demonstrated that PRF treatment adjacent to the DRG induced c-Fos expression (as an indicator of neuronal activation) in the dorsal horn 3 hours after the intervention ${ }^{135}$. Furthermore, 7 days after RF and PRF treatment adjacent to the rat cervical DRG, c-Fos is expressed in pain modulating zones of the dorsal horn ${ }^{136}$. A first clinical audit ${ }^{137}$ on the use of PRF treatment adjacent to the cervical DRG of patients suffering chronic pain in the cervical region radiating into the arm or the head, showed a positive outcome in $72 \%$ of the patients after 8 weeks and in $33 \%$ after one year (level $\mathrm{C}$ evidence). No side effects or neurological complications were reported. The available literature for RF and PRF adjacent to the cervical DRG yields a weak (2B) recommendation for $R F$ and a very weak $(2 \mathrm{C})$ recommendation for PRF. Considering the potential better risk/benefit balance of PRF further research is justified.

\section{Neck surgery}

Cervical spondylosis and or disc herniation can cause cervical radicular pain by compressing the roots or the spinal cord. Surgical techniques for decompression with or without anterior interbody fusion are often performed to reduce the pain and disability, but are associated with a small but definite risk ${ }^{138}$. A randomized clinical trial, from Person et al. in patients with long lasting cervical radicular pain, indicate that three different treatment modalities, (cervical collar, physiotherapy, or surgery) appear to be equally effective in the long-term, and a multidisciplinary rehabilitation with cognitive behavioral therapy is recommended, indicating a level B evidence that surgery is not more effective than conservative therapy in the long-term ${ }^{139}$. These 
data are summarized in a systematic review of Cochrane group from Fouyas who concluded that it is not clear whether the short-term risks of surgery are offset by any long-term benefits ${ }^{139}$. In 2004 another systematic review by Jacobs ${ }^{140}$ appeared in the Cochrane database, aiming at evaluating different anterior interbody fusion techniques for cervical degenerative disc disease. Although this review was not specific for cervical radicular pain or radiculopathy, some of the referred studies were dealing with it. This review could not formulate definitive conclusions regarding the different cervical anterior body fusion techniques because of the low quality of the trials.

Based on the available evidence of efficacy and the risk/benefit ratio there is weak (2B) recommendation against the use of neck surgery for cervical radicular pain. Furthermore, after an additional analysis of the patients form Person's randomized clinical trial on pain, coping, emotional state, and physical function, a multidisciplinary treatment with cognitive behavioral therapy and psychological interventions was recommended ${ }^{144}$.

\section{Potential future treatment modalities}

\section{MAPK pathways}

Future therapies in the management of cervical radicular pain originating at the DRG may include drugs such as mast cell stabilizers, which could potentially abate some of the effects of NGF. As the p38 MAPK pathway is involved in multiple normal physiological processes, inhibiting the pathway as anti-inflammatory therapy might not be best achieved by inhibiting p38 MAPK itself, but rather by targeting upstream or downstream signal transduction ${ }^{142}$. Specific downstream targets of $p 38$ MAPK could include tyrosine kinase inhibitors such as an inhibitor of extra signalregulated protein kinase signaling protein.

\section{Vanilloid receptors}

Other emergent therapies include vanilloid receptor blockers - a trial of resinferatoxin (an ultra potent capsaicin analogue) has been used in the management of patients with hypersensitive disorders of the lower urinary tract $^{143}$.

\section{Long acting local anesthetics}

Local anesthetics act through inhibition of the $\mathrm{Na}$ channels and play a major role in the identification of the causative nerve structure. The duration of action is however relatively short, which makes these drugs not suited for the management of chronic pain syndromes. Recent reports of experiments with long acting local anesthetics 
such as butamben ${ }^{144}$ and tonicaine ${ }^{145}$ indicate that this type of molecules may be an alternative treatment option. This must be confirmed in human subjects.

\section{Tricyclic antidepressants}

The mode of action of these compounds is classically attributed to serotonin and norepinephrine reuptake blockade ${ }^{146,147}$. It was suggested that amitryptiline may also be a potent blocker of neuronal sodium channels ${ }^{148}$, and recent literature demonstrate the possible role of tricyclic antidepressants as long-acting local anesthetics $^{149-151}$. Preliminary studies of amitryptiline showed no better nerve blockade properties than current locall anesthetics and risks for neurotoxicity have to be considered $^{152}$.

\section{Gene therapy}

Gene therapy has made advances where a number of specific disease entities are now been treated including severe combined immunodeficiency in children. Vectors constructed from recombinant herpes simplex virus have special utility for gene transfer to the nervous system. Subcutaneous inoculation of the herpes simplex virus vectors can be used to transduce neurons of the DRG to provide a therapeutic effect in models of polyneuropathy and chronic regionall pain. In human trials, direct injection of repllication-competent herpes simplex virus into brain tumors has proven safe and herpes simplex virus gene transfer by subcutaneous inoculation for the treatment of chronic intractable pain is the next trial due to commence ${ }^{153}$.

\section{Conclusions}

Chronic cervical radicular pain and radiculopathy affects approximately 1 on 1,000 adults, with a high impact on the patient's quality of life. These patients require a multidisciplinary approach and are therefore frequently referred to pain centers. The most frequently recognized etiology is root injury by disc herniation and stenosis of the intervertebral foramen. Pathophysiological changes in the DRG after nerve injury are hypothesized to play an important role in cervical radicular pain. We focus in this review in particular on currently available and emerging treatment modalities that aim at pathophysiological changes occurring after nerve injury at the cervical DRG. This nerve injury induces inflammatory processes and membrane changes leading to spontaneously firing DRG. The inflammatory process that is initiated by the release of many trophic mollecules and cytokines results in the release of NGF, which acts via a "fast effect" and a "slow effect". The fast effect is obtained via direct activation of nociceptors leading to the expression of BDNF by multiple phosphorylation signaling events. The slow effect or indirect activation occurs via mast cells 
and degranulation product release. Nerve injury aiso initiates membrane changes whereby sodium and calcium channels become overly active. As a result of ion channel modification there is ectopic discharge, hyperexcitability and spontaneous firing DRG, which may cause radicular pain.

The available pharmacological therapies interfering with the above-described pathophysiological mechanisms such as NSAIDs, TNF- $\alpha$ inhibitors and the different ion channel antagonists have documented efficacy for the management of a variety of pain syndromes, though controlled trials evaluating their efficacy for the treatment of cervicall radicular pain are largely lacking. Interventional treatments targeting the cervical DRG and or nerve root have been studied in more detail. Although spine surgery for relieving cervical radicular pain is often performed, there is lack of evidence to support it. For this reason less invasive percutaneous interventional pain management techniques have gained in interest during the last decade, resulting in a higher level of evidence.

\section{Acknowledgements:}

The authors thank Professor Marshall Devor Professor and Chairman, Dept. Cell \& Animal Biology and Centre for Research on Pain, Institute of Life Sciences, Hebrew University of Jerusalem, Jerusalem, Israel for his constructive remarks on the manuscript, Nicole Van den Hecke, administrative research coordinator, Multidisciplinary Pain Centre, Ziekenhuis Oost-Limburg, Genk, Belgilum for literature search and administrative coordination and Resy Van den Broeck, administrative research coordinator, Department of Anesthesiology and Pain Management, University Hospitall Maastricht, Maastricht, The Netherlands for the valuable help in collecting the articles. 


\section{References}

1. Rathmell JP, Aprill C, Bogduk N. Cervical transforaminal injection of steroids. Anesthesiology 2004: 100: 1595-1600

2. Bogduk N. Medical Management of acute cervical radicular pain: and evidence-based approach. 1st. Newcastle, Australia, The Newcastie Bone and Joint Institute, 1999;

3. Parkinson J. An essay on the shaking palsy, London, 1817 ,

4. Dejerine J. Sémiologie des affections du système nerveux, Paris, 1914 ,

5. Merskey $\mathrm{H}_{1}$ Bogduk $\mathrm{N}$. Classification of Chronic Pain: Descriptions of Chronic Pain Syndromes and Definitions of Pain Terms, 2 Seattle, Wash: IASP Press, 1994,

6. Saal JS, Saal JA, Yurth EF. Nonoperative management of herniated cervical intervertebral disc with radiculopathy. Spine 1996; 21: 1877-1883

7. Devereaux MW. Neck and low back pain. Med Clin North Am 2003; 87: 643-662

8. Bland J. Cervical spine syndromes. J Muscoloskel Med 1986; 3: 23-41

9. Slipman CW, Plastaras CT, Palmitier RA, Huston CW, Sterenfeld EB. Symptom provocation of fluoroscopically guided cervical nerve root stimulation. Are dynatomal maps identical to dermatomal maps? Spine $1998 ; 23: 2235-2242$

10. Dwyer A, C A, Bogduk N. Cervical zyglapophyseal joint pain patterns. I/ A study in normal volunteers. Spine 1990; 15: 453-457

11. Schellhas KP, Smith M, Grundy C, Pollei S. Cervical Discogenic Pain. Prospective Correlation of Magnetic Resonance Imaging and Discography in Asymptomatic Subjects and Pain Sufferers. Spine 1996; $21: 300-311$

12. Radhakrishnan K, Litchy WJ, O'Fallon WM, Kurland LT. Epidemiology of cervical radiculopathy. A population-based study from Rochester, Minnesota, 1976 through 1990. Brain 1994; 117 (Pt 2): $325-335$

13. Sluijter ME. Cervicobrachialgia, Radiofrequency Part 2, Edited by Sluijter ME. Meggen (LU), Switzerland, Flivopress, SA, 2003, pp 9-22,

14. Date $E, G r a y L$. Electrodiagnostic evidence for cervical radiculopathy and suprascapular neuropathy in shoulder pain. Electromyogr Clin Meurophysiol 1996; 36: 333-339

15. Fager CA. Identification and management of radiculopathy. Neurosurg Clin N Am 1993; 4:1-12

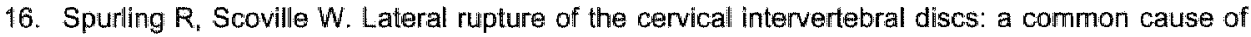
shoulder and arm pain. Surg Gynecol Obstet 1944; 78: 350-358

17. Davidson RI. Dunn EJ, Metzmaker JN. The shoulder abduction test in the diagnosis of radicular pain in cervical extradural compressive monoradiculopathies. Spine 1981; 6: 441-446

18. Rothstein J, Roy S, Wolf S. The Rehabilitation Specialist"s Handbook, Philadelphia, $\mathrm{Pa}, F A$ Davis, 1991.

19. Viikari-Juntura $E_{\text {, Porras }} M$, Laasonen EM. Validity of clinical tests in the diagnosis of root compression in cervical disc disease. Spine 1989; 14: 253-257

20. Elvey $R$. The investigation of arm pain: signs and adverse responses to the physical examination of the brachial plexus and related tissues.. Grieve's Modern Manual Therapy, Edited by Boyling J \& Pallastanga, N. New York, NY, Churchill Livingstone, 1994, pp 557-585,

21. Tong $\mathrm{HC}_{\text {" }}$ Haig $\mathrm{AJ}$, Yamakawa $\mathrm{K}$. The Spurling test and cervical radiculopathy. Spine 2002; 27 : $156-159$

22. Wainner RS, Gill H. Diagnosis and monoperative management of cervical radiculopathy. J Orthop Sports Phys Ther 2000; 30: 728-744

23. Brown BM, Schwartz RH, Frank E, Blank. NK. Preoperative evaluation of cervical radiculopathy and myelopathy by surface-coil MR imaging. AJR Am J Roentgenol 1988; 151 : 1205-1212

24. Jalnnke RW, Hart BL. Cervical stenosis, spondylosis, and hemiated disc disease. Radiol Clin North Am 1991; $29: 777-791$

25. Madic MT, Masaryk TJ, Mulopulos GP, Bundschuh $C$, Han JS, Bohiman H. Cervical radiculopathy: prospective evaluation with surface coil MR imaging, CT with metrizamide, and metrizamide myelography. Radiology 1986; 161: 753-759 


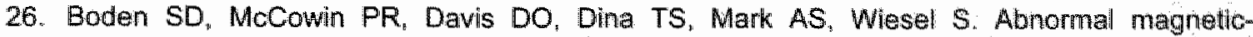
resonance scans of the cervical spine in asymptomatic subjects. A prospective investigation. J Bone Joint Surg Am 1990; $72: 1178-1184$

27. Teresi LM, Lufkin RB, Reicher MA, Motfit BJ, Vinuela FV, Wilson GM, Bentson JR, Hanafee WN. Asymptomatic degenerative disk disease and spondylosis of the cervical spine: MR imaging. Radiology $1987 ; 164: 83-88$

28. Healy JF, Healy $B B$, Wong $W H$, Olson EM. Cervical and lumbar MRI in asymptomatic older male lifelong athletes: frequency of degenerative findings. J Comput Assist Tomogr 1996; 20: $107-112$

29. Dimitru D. Electrodiagnostic Medicine, Philadelphia, Pa, Hanley \& Belfus, Inc, 1995 ,

30. Haldeman $S$. The electradiagnostic evaluation of nerve root function. Spine 1984; $9: 4248$

31. Eisen $A$. The utility of proximal nerve conduction in radiculopathies: the cons. Electroencephalogr Clin Neurophysiol 1991; 78: 171-172; discussion 167

32. Partanen J, Partanen $K$, Oikarinen $H$, Niemitukia $L$, Hernesniemi J. Preoperative electroneuromyography and myelography in cervical root compression. Electromyogr Clin Neurophysiol 1991: $31: 21-26$

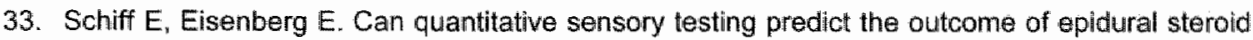
injections in sciatica? A preliminary study. Anesth Analg 2003; 97:828-832

34. Clar SA, Cianca JC. Intracranial tumor imasquerading as cervical radiculopathy: a case study. Arch Phys Med Rehabil 1998; 79: 1301-1302

35. Friedmand DP, Hills JR. Cervical epidural spinal infection: MR imaging characteristics. A.JR Am I Roentgenol 1994; 163: 699-704

36. Hetzel $A$, Berger $W$, Schumacher $M_{n}$ Lucking $C H$. Dissection of the vertebral artery with cervical nerve root lesions. J Neurol 1996; 243: 121-125

37. Anderberg $L$, Annertz $M$, Brandt $L$, Saveland $H$. Selective diagnostic cervical nerve root block-correlation with clinical symptoms and MRI-pathology. Acta Neurochir (Wien) 2004; 146: 559565; discussion 565

38. van Kleef $M$, Liem $L$, Lousberg $R$, Barendise $G$, Kessels $F$, Sluijter M. Radiofrequency lesion adjacent to the dorsal root ganglion for cervicobrachial pain: a prospective double blind randomized study. Neurosurgery 1996; 38: 1127-1131; discussion 1131-1122

39. Wolff AP, Groen G.J, Crul BJ. Diagnostic lumbosacral segmental nerve blocks with local anesthetics: a prospective double-blind study on the variability and interpretation of segmental effects. Reg Anesth Pain Med 2001; 26: 147-155

40. Hogan $Q H$, Abram SE. Neural blockade for diagnosis and prognosis. A review. Anesthesiology $1997 ; 86: 216-241$

41. Mogil JS. The genetic mediation of individual differences in sensitivity to pain and its inhibition. Proc Natl Acad Sci U SA 1999; 96: 7744-7751

42. Mogil JS, Wilson SG, Bon $K_{\text {" Lee }}$ SE, Chung K, Raber P, Pieper JO, Hain HS, Belknap JK, Hubert L, Elmer Gl, Chung JMI, Devor M. Heritability of nociception II. 'Types" of nociception revealed by genetic correlation analysis. Pain $1999 ; 80: 83-93$

43. Guo $W$, Zou $S$, Guan $Y$, Ikeda $T$, Tal M, Dubner R, Ren $K$. Tyrosine phosphorylation of the NRR2B subunit of the NMDA receptor in the spinal cord during the development and maintenance of inflammatory hyperalgesia. J Neurosci 2002" 22: 6208-6217

44. Howe JF, Loeser JD, Calvin WH. Mechanosensitivity of dorsal root ganglia and chronically injured axons: a physiological basis for the radicular pain of nerve rool compression. Pain 1977: $3: 25-41$

45. Wall PD, Devor M. Sensory afferent impulses originate from dorsal root ganglia as well as from the periphery in normal and nerve injured rats. Pain 1983; 17:321-339

46. Devor $M$. Saltzer $Z$. Pathophysiology of damaged nerves in relation to chronic pain, Textbook of Pain, Edited by Wall PD MR. London, Churchill Liwingstone, 1999, pp 129-164

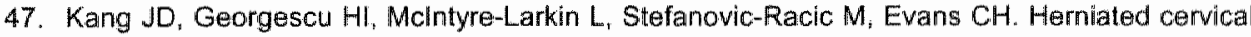
intervertebral discs spontaneously produce matrix metalloproteinases, mitric oxide, interleukin6. and prostaglandin E2. Spine 1995; 20: 2373-2378

48. Vanegas $H$, Schaible HG. Prostaglandins and cyclooxygenases [correction of cycloxygenases] in the spinal cord. Prog Neurobiol 2001; 64: 327-363 
49. Herschman HR. Prostaglandin synthase 2. Biochim Biophys Acta 1996; 1299: 125-140

50. Ebersberger $A$, Grubb $B D$, Willingale $H L$, Gardiner NJ, Nebe $\mathbb{A}$, Schaible $H G$. The intraspinal release of prostaglandin E2 in a model of acute arthritis is accompanied by an up-regulation of cyclo-oxygenase-2 in the spinal cord. Neurosicience 1999; $93: 775-781$

51. McCrory $C_{*}$ Fitzgerald D. Spinal prostaglandin formation and pain perception following thoracotomy: a rolle for cyclooxygenase-2. Chest 2004: 125: 1321-1327

52. Woolf $\mathrm{CJ}$, Allchorne $\mathrm{A}$, Safieh-Garabedian $\mathrm{B}$, Poolie $\mathrm{S}$. Cytokines, nerve growth factor and inflammatory hyperalgesia: the contribution of tumour necrosis factor alpha. $\mathrm{Br} J$ Pharmacol $1997 ; 121: 417-424$

53. Murata $Y$, Onda A, Rydevik $B$, Takahashi $K$, Olmarker $K$. Distribution and appearance of tumor necrosis factor-alpha in the dorsal root ganglion exposed to experimental disc herniation in rats. Spine $2004,29: 2235-2241$

54. Andreev $N$, Dimitrieva $N$, Koltzenburg $M_{i}$ McMahon SB. Peripheral administration of nerve growth factor in the adult rat produces a thermal hyperalgesia that requires the presence of sympathetic post-ganglionic neurones. Pain 1995; 63: 109-115

55. Bennett $G_{n}$ al-Rashed $S_{n}$ Hoult JR, Brain $S D$. Nerve growth factor induced hyperalgesia in the rat hind paw is dependent on circulating neutrophils. Pain 1998; $77: 315-322$

56. Shu $X$. Mendell $L M$. Nerve growth factor acutely sensitizes the response of adult rat sensory neurons to capsaicin. Neurosci Lett 1999; 274: 159-162

57. Tominaga M, Caterina MJ, Malmberg $A B$, Rosen $T A$, Gilbert $H$, Skinner $K$, Raumann $B E_{i:}$ Basbaum All, Julius $\mathrm{D}$. The cloned capsaicin receptor integrates multiple pain-producing stimuli. Neuron $1998 ; 21: 531-543$

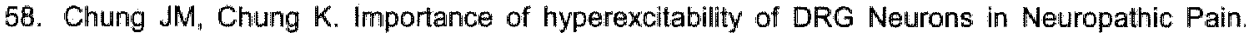
Pain Practice 2002; 2: 87-97

59. Obata $K$, Yamanaka $H_{\text {, Fukuoka }}$, , Yi D, Tokunaga $A$, Hashimoto $N$, Yoshikawa $H$, Noguchi $K$. Contribution of injured and uninjured dorsal root ganglion neurons to pain behavior and the changes in gene expression following chronic constriction injury of the sciatic nerve in rats. Paim 2003; 101:65-77

60. Lindsay $\mathrm{RM}_{1}$ Harmar AJ. Nerve growth factor regulates expression of neuropeptide genes in adult sensory neurons. Nature 1989; $337: 362-364$

61. Apfel SC, Wright DE, Wiideman AM, Dormia C, Snider WD, Kessler JA. Nerve growth factor regulates the expression of brain-derived neurotrophic factor mRNA in the peripheral nervous system. Moll Cell Neurosci 1996; 7: 134-142

62. Michael GJ, Averill S, Nitkunan A, Raltray M, Bennett DL, Yan Q, Priestley JV. Nerve growth factor trealment increases brain-derived neurotrophic factor selectively in TrkA-expressing dorsal root ganglion cells and in their central terminations withir the spinal cord. J Neurosci 1997: 17: $8476-8490$

63. Thompson SW, Bennett DL, Kerr BJ, Bradbury EJ, McMahon SB. Brain-derived neurotrophic factor is an endogenous modulator of nociceptive responses in the spinal cord. Proc Natl Acad Sei, U S A. 1999; 96: 7714-7718

64. Lever I, Cunningham J, Grist J, Yp PK, Malcangio M. Release of BDNF and GABA in the dorsal horn of neuropathic rats. Fur J Neuroscl 2003; 18: 1169-1174

65. Obata K, Yamanaka $H$, Dai $Y$, Mizushima $T$, Fukuoka $T$, Tokunaga $A$, Noguchi K. Activation of extracellular signal-regulatted protein kinase in the dorsal root ganglion following inflammation near the nerve cell body. Neuroscience 2004; 126: 1011-1021

66. Zhou XF, Rush RA. Endogenous brain-derived neurotrophic factor is anterogradely transported in primary sensory neurons. Neuroscience $1996 ; 74: 945-953$

67. Cho $\mathrm{HJ}_{\mathrm{i}} \mathrm{Kim}, \mathrm{JK}$, Zhou XF, Rush RA. Increased brain-derived neurotrophic factor immunoreactivity in rat dorsal root ganglia and spinal cord following peripheral infiammation. Brain Res 1997; $764: 269-272$

68. Groth R, Aanonsen L. Spinal brain-derived netrotrophic factor (BDNF) produces hyperalgesia in normal mice while antisense directed against either BDNF or trkB, prevent inflammationinduced typeraigesia. Pain 2002; 100: 171-181 
69. Kerr BJ, Bradbury EJ, Bennett DL, Trivedi PM, Dassan P, French J, Shelton DB, McMahon SB, Thompson SW. Brain-derived neurotrophic factor modulates nociceptive sensory inputs and NMDA-evoked responses in the rat spinal cord. J Neuroscil 1999; 19: 5138-5148

70. Waxman SG. Acquired channelopathies in nerve injury and MS. Neurology $2001 ; 56: 1621$ 1627

71. Matzner $O_{n}$ Devor $M$. Hyperexcitability at sites of nerve injury depends on voltage-sensitive Nat chamnels. J Neurophysiol 1994; $72: 349-359$

72. Zhang $\mathrm{JM}$, Donnelly $\mathrm{DF}$, Song $\mathrm{XJ}$, Lamotte $\mathrm{RH}$. Axatomy increases the excitability of dorsal root ganglion cells with unmyelinated axons. J Neurophysiol 1997; $78: 2790-2794$

73. Cummins TR, Aglieco F, Renganathan M, Herzog RI, Dib-Hajj SD, Waxman SG. Nav1.3 sodium channels: rapid repriming and slow closed-state inactivation display quantitative differences after expression in a mammalian cell line and in spinal sensory neurons. J Neurosci 2001; 21: 5952-5961

74. Abe $M$, Kurihara $T$. Han $W$, Shinomiya $K$, Tanabe $T$. Changes in expression of voltagedependent ion channel subunits in dorsal root ganglia of rats with radicular injury and pain. Spine 2002; 27: 1517-1524; discussion 1525

75. Everill B, Kocsis JD. Reduction in potassium currents in identified cutaneous afferent dorsal root ganglion neurons after axotomy. J Neurophysiol 1999; $82: 700-708$

76. Devor M. Potassium channels moderate ectopic excitability of nerve-end neuromas in rats. Neuroscil Lett $1983 ; 40: 181-186$

77. Liu $X$, Zhou JL, Chung $K$, Chung JM. Ion channels associated with the ectopic discharges generated after segmental spinal nerve injury in the rat. Brain Res 2001; 900: 119-127

78. Boland LM, Morrill JA, Bean BP. omega-Conotoxin block of $\mathrm{N}$-lype calcium channels in frog and rat sympathetic neurons. J Neurosci 1994; 14: 5011-5027

79. Churchill D, Macvicar BA. Biophysical and pharmacological characterization of voltagedependent $\mathrm{Ca} 2+$ channels in neurons isolated from rat nucleus accumbens. I Neurophysiol 1998; 79:635-647

80. Chou $\mathrm{KC}$. Insights from modeling three-dimensional structures of the human potassium and sodium channels. J Proteome Res 2004; 3: 856-861

81. Muth TR, Caplan MJ. Transport protein trafficking in polarized cells. Annu Rev Cell Dev Biol 2003; 19: 333-366

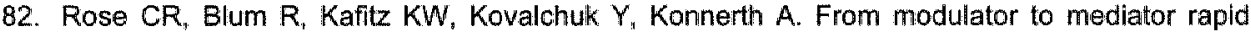
effects of BDNF on ion channels, BioEssays 2004; 26: 1185-1195

83. Kafitz $\mathrm{KW}$, Rose $\mathrm{CR}$, Thoenen $\mathrm{H}$, Konnerth $\mathrm{A}$. Neurotrophin-evoked rapid excitation through TrkB receptors. Nature 1999; 401: 918-921

84. Amir R, Michaelis M, Devor M. Membrane potential oscillations in dorsal root ganglion neurons: role in normal electrogenesis and neuropathic pain. J Neurosci 1999; 19: 8589-8596

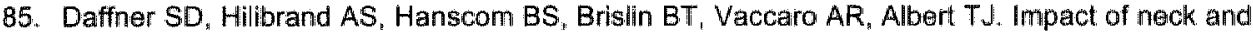
arm pain on overall health status. Spine 2003; 28: 2030-2035

86. Van Zundert J, Raj P, Erdine S, van Kleef M. Application of Radiofrequency Treatment in Practical Pain Management: State of the Art. Pain Practice 2002; 2: 269-278

87. Kerns RD, Habib $S$. A critical review of the pain readiness to change model. J Pain $2004 ; 5$ : 357-367

88. Guyatt G, Schunemann HJ, Cook D, Jaeschke R, Pauker S. Appllying the grades of recommendation for antithrombotic and thrombolytic therapy: the Seventh ACCP Conference on Antithrombotic and Thrombolytic Therapy. Chest 2004; 126: 179S-187S

89. Vinegar $R$. Truax JF, Selph $J L$. Quantitative comparison of the analgesic and anti-inflammatory activities of aspirin, phenacetin and acetaminophen in rodents. Eur J Pharmacol 1976; 37: 2330

90. Baba $\mathrm{H}$, Kohno $T$, Moore KA, Woolf $\mathrm{CJ}$. Direct activation of rat spinal dorsal horn neurons by prostaglandin E2. J Neurosci 2001; 21: 1750-1756

91. Topol $E_{8}$ Falk G. A coxib a day won't keep the doctor away. The Lancet $2004 ; 364: 639-640$

92. Ray WA, Stein $C M$, Daugherty $J R$, Hall $K$, Arbogast $\mathbb{P G}$, Griffin MR. COX-2 selective nonsteroidal anti-inflammatory drugs and risk of serious coronary heart disease. Lancet 2002; 360; $1071-1073$ 


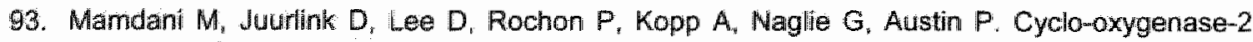
inhibitors versus non-selective non-steroidal anti-inflammatory drugs and congestive heart failure outcomes in elderly patients: a population-based cohort study. The Lancet 2004; 363 : $1751-1756$

94. Hawkey CJ. COX-2 inhibitors. Lancet 1999; 353: 307-314

95. van Tulder MW, Scholten R.J, Koes BW, Deyo RA. Nonsteroidal anti-inflammatory drugs for low back pain: a systematic review within the framework of the Cochrane Collaboration Back Review Group. Spine 2000; 25: 2501-2513

96. Crocker IC, Zhou CY, Bewtra AK, Kreutner W, Towniley RG. Gucocorticosteraids inhibit leukotriene production. Ann Allergy Asthma Immunol 1997; 78: 497-505

97. Johansson A, Hao J, Sjolund B. Local corticosteroid application blocks transmission in normal nociceptive C-fibres. Acta Anaesthesiol Scand 1990; 34: 335-338

98. Stav A, Ovadia L, Stemberg A, Kaadan M, Weksier N. Cervical epidural steroid injection for cervicobrachialgia. Acta Anaesthesiol Scand 1993, 37: 562-566

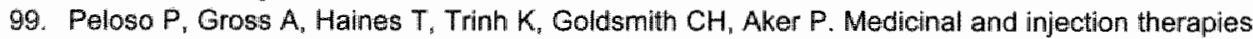
for mechanical neck disarders. Cochrane Database Syst Rev 2005; CD000319

100. Botwin K, Castellanos $R_{4}$ Rao $S$, Hanna A, Torres-Ramos F, Gruber R, Bouchlas C, Fuoco $G$ Complications of fluoroscopically guided interlaminar cervical epidural injections. Arch Phys Med Rehabil 2003; 84: 627 633

101. Hodges $S_{n}$ Castleberg $L_{n}$ Miller $T_{n}$ Ward $R$, Thornburg $C$. Cervical epidural steroid injection with intrinsic spinal cord damage. Spine 1998; 23: 2137-2141

102. Field $\mathrm{J}$, Rathmell $\mathrm{JP}$, Stephenson $\mathrm{JH}$, Katz NP. Neuropathic pain following cervical epidural steroid injection. Anesthesiology 2000; $93: 885-888$

103. Rowlingson JC. Epidural steroids: do they have a place in pain management? Barcelona, $V$. Permanyer Publications, 1996.

104. Hession WG, Stanczak JD, Davis KW, Choi Jل. Epidural steroid injections. Semin Roentgenol 2004; $39: 7-23$

105. Vallee JN, Feydy A, Carlier RY, Mutschler $C_{\text {" }}$ Mompoint $D$, Vallee CA. Chronic cervical radiculopathy: lateral-approach periradicular corticosteroid injection. Radiology 2001; 218: 886-892

106. Cyteval C. Thomas E, Decoux E, Sarrabere MP, Cottin A, Blotman F. Taourel P. Cervical radiculopathy: open study on percutaneous periradicular foraminal steroid infiltration performed under CT control in 30 patients. AJNR Am J Neuroradiol 2004; 25:441-445

107. Baker $R$, Dreyfuss $P$, Mercer $S$, Bogduk N. Cervical transforaminal injection of corticosteroids into a radicular artery: a possible mechanism for spinal cord injury. Pain 2003; 103: 211-215

108. Brouwers PJ, Kottink EJ, Simon MA. Prevo RL. A cervical anterior spinal artery syndrome after diagnostic blockade of the right C6-nerve root. Pain 2001; 91:397-399

109. Rasenkranz M, Grzyska U, Niesen $W$, Fuchs $K$, Schummer $W$, Weiller $C$, Rother J. Anterior spinal artery syndrome following periradicular cervical nerve root therapy. $J$ Neurol $2004 ; 251$ : $229-231$

110. Karasek $M$, Bogduk $N$. Temporary neurologic deficit after cervical transforaminal injection off local anesthetic. Pain Med 2004; 5: 202-205

111. Rathmell JP, Benzon HT. Transforaminal injection of steroids: should we continue? Reg Anesth Pain Med 2004; 29: 397-399

112. Huntoon MA, Martin DP. Reply to drs. Raghavendra and Harney. Reg Anesth Pain Med 2005; 30: $208-209$

113. Onda A, Murata $Y$, Rydevik B, Larsson K, Kikuchi S, Olmarker K. Infliximab attenuates immunoreactivity of brain-derived neurotrophic factor in a rat model of herniated nucleus pulposus. Spine 2004; 29: 1857-1861

114. Korhonen T, Karppinen J, Malmivaara A, Autio R, Niinimaki J, Paimela L, Kyllonen $E$, Lindgren $K A$, Tervonen $O$, Seitsalo $S$, Hurri $H$. Efficacy of infliximab for disc herniation-induced sciatica: one-year follow-up. Spine 2004; 29: 2115-2119

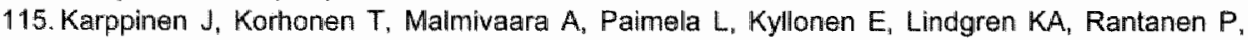
Tervonen O, Niinimaki J, Seitsalo S. Hurri H. Tumor Necrosis. Factor-alpha Monoclonal Antibody, Unfliximab, Used to Manage Severe Sciatica. Spine 2003; 28: 750-753 
116. Shin K: Treatment of neck and back pain originating from herniated nucleus pulposus with fumor necrosis factor alpha inhibitor. In: International Society for the Study of the Lumbar Spine. (Week S, Ed), Porto, Portugal. (2004).

117. Geneveay S: Efficacy of etanercept in the treatment of acute and severe sciatica: A pillot study.). Annals of Rheumatic Diseases. (2004).

118. McQuay $H$. Carroll $D$, Jadad $A R$. Wiffen $P$, Moore A. Anticonvulsant drugs for management of pain: a systematic review. Bmj 1995; 311: 1047-1052

119. Otto $M$, Bach FW, Jensen TS, Sindrup SH. Valproic acid has no effect on pain in polyneuropathy: a randomized, controlled triall. Neurology $2004 ; 62: 285-288$

1:20. Nishiyama K, Sakuta M. Mexiletine for painful alcoholic neuropathy. Intern Med 1995; $34: 577$. 579

121. Wright JM, Oki JC, Graves $L, 3 r d$. Mexiletine in the symptomatic treatment of diabetic periphm. eral neuropathy. Ann Pharmacother 1997; 31: 29-34

122. Wallace MS, Magnuson S, Ridgeway B. Efficacy of oral mexiletine for neuropathic pain with allodynia: a double-blind, placebo-controlled "crossover study. Reg Anesth Pain Med 2000, 25 : $459-467$

123. Gee NS, Brown JP, Dissanayake VU, Offord J, Thurlow $R$, Woodruff $G N$. The novel anticonvulsant drug, gabapentin (Neurontin), binds to the alphazdelta subunit of a calcium channel. $J$ Biol Chem 1996; 271: 5768-5776

124. Hansson PT, Dickenson AH. Pharmacological treatment of peripheral neuropathic pain conditions based on shared commonalities despite multiple etiologies. Pain 2005; 113: 251-254

125. Backonja $M$, Beydoun A, Edwards $K R_{n}$ Schwartz SL, Fonseca V, Hes M, La Moreaux L, Garofalo $E$. Gabapentin for the symptomatic treatment of painful neuropathy in patients with diabetes mellitus: a randomized controlled trial. Jama 1998; 280: 1831-1836

126. Rowbotham M, Harden N, Stacey B, Bernstein P. Magnus-Miller L. Gabapentin for the treatment of postherpetic neuralgia: a randomized controlled trial. Jama 1998; 280: 1837-1842

127. Sist TC, Filadora VA, 2nd, Miner M, Lema M. Experience with gabapentin for neuropathic pain in the head and neck: report of ten cases. Reg Anesth 1997; 22: 473-478

128. Sabatowski R, Galvez R, Cherry DA, Jacquot F, Vincent E, Maisonobe P, Versavel M. Pregabalin reduces pain and improves sleep and mood disturbances in patients with post-herpetic neuralgia: results of a randomised, placebo-controlled clinical trial. Pain 2004; 109: 26-35

129. Sindrup SH, Jensen TS. Efficacy of pharmacological treatments of neuropathic pain: an update and effect related to mechanism of drug action. Pain 1999; $83: 389-400$

130. Kampolat $Y$, Savas A, Bekar $A$, Berk C. Percutaneous Controlled Radiofrequency Trigeminal Rhizotomy for the Treatment of Idiopathic Trigeminal Neuralgia: 25- years Experience with 1600 Patients. Neurosurgery 2001; 48: 524-534

131. Geurts J van Wijk RM, Stolker R, Groen GJ. Efficacy of radiofrequency procedures for the treatment of spinal pain: a systematic review of randomized clinical trials. Reg Anesth Pain Med 2001; 26: 394-400

132. Slappendel R, Crul BJ, Braak GJ, Geurts JW, Booij LH, Voerman VF, de Boo T. The efficacy of radiofrequency lesioning of the cervical spinal dorsal root ganglion in a double blinded randomized study: no difference between 40 degrees $C$ and 67 degrees $C$ treatments. Pain 1997; 73 : $159-163$

133. Niemisto L, Kalso E, Malmivaara A, Seitsalo S, Hurri $H$. Radiofrequency denervation for neck and back pain. A systematic review of randomized controlled trials. Cochrane Database Syst Rev 2003; CD004058

134. Sluijter ME, Cosman ER, Rittman II WB, wan Kleef $M$. The effects of pulsed radiofrequency field applied to the dorsal root ganglion - a preliminary report. The Pain Clinic 1998; 11: 109117

135. Higuchi $Y$, Nashold BS, Sluijter ME, Cosman E, Pearlstein RD. Exposure of the dorsal root ganglion in rats to pulsed radiofrequency currents activates dorsal horn lamina I and II neurons. Neurosurgery 2002; 50: 850-856 
136. Van Zundert J, de Louw AJ, Joosten EA, Kessels AG, Honig W. Dederen $P J$, Veening JG, Vles $J_{S}$, van Kleef $M$. Pulsed and continuous radiofrequency current adjacent to the cervical dorsal root ganglion of the rat induces late cellular activity in the dorsal horn. Anesthesiology 2005; 102: 125 m 131

137. Van Zundert J, Lame IE, de Louw A, Jansen $\mathrm{J}_{1}$ Kessels F. Patijn J "van Kleef M. Percutaneous Pulsed Radiofrequency Treatmient of the Cervical Dorsal Root Ganglion in the Treatment of Chronic Cervical Pain Syndromes: A Clinical Audit. Neuromodulation 2003; 6: 6-14

138. Fouyas IP, Statham PF. Sandercock PA. Cochrane review on the role of surgery in cervical spondylotic rädiculomyelopathy. Spine 2002; 27: 736-747

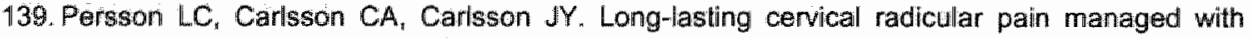
surgery, physiotherapy; or a cervical collar A prospective, randomized study. Spine $1997 ; 22$ : 751.758

140. Jacobs $W$, Anderson P, Limbeek J, Willems P : Paviov P. Single or double-level anterior interbody fusion techniques for cervical degenerative disc disease. Cochrane Database Syst Rev 2004; CD004958

141. Persson LC, Lilja A. Pain, coping, emotional state and physical function in patients with chronic radicullar neck pain. A comparison between patients treated with surgery, physiotherapy or neck collar--a blinded, prospective randomized study. Disabil Rehabill 2001; 23: 325-335

142. Saklatvala $\mathrm{J}$. The p38 MAP kinase pathway as a therapeutic target in inflammatory disease. Curr Opin Pharmacol 2004; 4: 372-377

143. Lazzeri $M$, Spinelli $M$, Bieneforti $P$, Malaguti $S$, Giardiello $G$, Turini $D$. Intravesical infusion of resiniferatoxin by a temporary in situ drug delivery system to treat interstitial cystitis: a pilot study. Eur Urol 2004; 45: 98-102

144. Mitchell VA, White $D \mathrm{AM}$, Cousins MJ. The long-term effect of epidural administration of butamben suspension on nerve injury-induced allodynia in rats. Anesth Analg 1999; 89: 989-994

145. Gerner $P$, Nakamura T, Quan CF, Anthony DC, Wang GK. Spinal tonicaine: potency and differential blockade of sensory and motor functions. Anesthesiology 2000; 92: 1350-1360

146. Carter GT, Sullivan MD. Antidepressants in pain management. Curr Opin Investig Drugs 2002; 3: $454-458$

147. Feighner JP. Mechanism of action of antidepressant medications. J Clin Psychiatry 1999; 60 Suppl 4: 4-11; discussion 12-13

148. Pancrazio JJ, Kamatchi GL, Roscae AK, Lynch $C_{n}$ 3rd. Inhibition of neuronal Na+ channels by antidepressant drugs. J Pharmacol Exp Ther 1998; 284: 208-214

149. Strumper D, Durieux ME. Antidepressants as long-acting local anesthetics. Reg Anesth Pain Med 2004; 29: 277-285

150. Sudoh $Y$, Cahoon EE, Gerner $P$, Wang GK. Tricyclic antidepressants as long-acting local anesthetics. Pain 2003; 103: 49-55

151. Sudoh $Y$, Cahoon EE, De Girolami U, Wang GK. Local anesthetic properties of a novel derivative, N-methyl doxepin, versus doxepin and bupivacaine. Anesth Analg 2004; 98: 672-676, table of contents

152. Fridrich $P$, Eappen $S$, Jaeger W, Schernhammer E, Zizza AM, Wang GK, Gerner P. Phase la and Ib study of amitriptyline for ulnar nerve block in humans: side effects and efficacy. Anesthesiology $2004 ; 100: 1511-1518$

153. Glorioso JC, Fink DJ. Herpes Vector-Mediated Gene Transfer in Treatment of Diseases of the Nervous System. Annu Rev Microbiol 2004; 58: 253-271 


\section{CHAPTER IV}

\section{Electrophysical principles of pulsed radiofrequency current: Theoretical considerations}

Van Zundert J, MD ${ }^{a, e}$; Cosman ER Jr. M, Eng ${ }^{b}$; Joosten, EA, PhDa; van Kleef M, MD, PhD ${ }^{\text {; }}$ Sluijter M, MD, PhDa,c; Cosman ER Sr. PhD

a. Department of Anesthesiology and Pain Management, University Hospilal Maastricht, Mastricht, The Netherlands. b. Department of Electrical Engineering and Computer Science, Massachuseths Institute of Technology, Cambridge, Massachuselts, USA. c. Department of Anesthesiology, Intensive Care and Pain Treatment, The Swiss Paraplegic Center, Notwil, Switzerland. d. Department of Physics, Miassachusetis Insittute of Technology, Cambridge, Massachusetts, USA. e. Department of Anesthesiology and Multidisciplínary Pain Center, Ziekenhuis Oost-Limburg, Genk, Beligium 


\section{Introduction}

The use of electrical current for the management of chronic pain syndromes has a long history. On one hand electrical current has been applied percutaneously close to nerve structures with the objective to generate heat and thus destructing the pathways conducting nociceptive stimuli ${ }^{1}$. On the other hand, electric current is also used in neurostimulation techniques, whereby electrical pulse generators connected to electrodes placed around the nervous tissue are permanently implanted. The continuous application of electrical stimulation to the neural tissue induces changes in the perception of the pain signal. This technique is based on the gate control theory of Wall and Melzack ${ }^{2}$.

Pulsed radiofrequency (PRF) treatment is a different application of electrical current, though the target nerve structures are approached with a similar electrode as used in continuous radiofrequency (RF), the high frequency current is delivered in pulses of $20 \mathrm{~ms}$ with a higher output than in $\mathrm{RF}^{3}$. In this modified technique, in $1 \mathrm{~s}$ two bursts of $20 \mathrm{~ms}$ each of a RF current are delivered. The oscillating frequency of the alternating current is $500 \mathrm{KHz}$. During one cycle the "active" phase of $20 \mathrm{~ms}$ is followed by a silent period of $480 \mathrm{~ms}$ to allow for washout of the generated heat. The output is usually set at $45 \mathrm{~V}$, but if the electrode tip temperature exceeds $42^{\circ} \mathrm{C}$, it is decreased to prevent cell damage. This temperature is selected based on the findings that necrosis in various soft tissue cell lines could only be induced by heating to temperatures greater than $43^{\circ} \mathrm{C}^{4,5}$. The aim of this chapter is to discuss electrophysical principles underlying PRF in general and in particular the role of the electric fields induced by PRF and their possible effects on the neuronal membranes.

\section{Electrophysical mechanisms induced by radiofrequency current}

Application of high frequency current, also called RF current, for the management of chronic pain has been in use for several decades. The earliest RF lesion generators and electrodes were built by B.J. Cosman, S. Aranow, and O.A. Wyss in the 1950's'. Their devices all used continuous wave RF power sources in the 0.1 to 1 $\mathrm{MHz}$ frequency range, and the commercial RF generators of today use that same frequency range.

Heat is formed since RF current is flowing through tissue. The tissue acts as a resistor and current flowing through a resistor generates heat. The electrical resistance to an alternating current with a high frequency is called impedance. The heat produced is proportional to the power deposition $P$, which is expressed in watts $(W)$. 
At a frequency of $500 \mathrm{KHz} \quad P=\frac{0.5|j|^{2}}{\sigma}=0.5 \sigma E^{2}$

where $j$ is the current density vector field, $\sigma$ is the specific electrical canductivity of the tissue, and $E$ is the oscillating amplitude of the voltage ${ }^{6}$. The amount of heat that is generated in the vicinity of the active tip is therefore a function of tissue conductivity, which varies according to the tissue compasition and to the amount of contained water.

The tip temperature does not depend on the power deposition only. Heat is also removed from the lesion area by conductive heat lass and by the blood circulation. This is referred to as heat "washout". Heat washout can conveniently be expressed as $W / C^{\circ}$. Considerable variations of tissue factors contribute to heat washout. For example, bone is an effective heat insulator with little water content. For this reason, RF lesions close to bone will not suffer the same degree of heat washout as they milght in more conductive tissue. Similarly, the segmental blood vessels, in relation to the dorsal root ganglion (DRG), may cause considerable heat washout, thereby reducing the size of the lesion. Other factors influencing the size of the lesion are the diameter and the shape of the electrode, the tip temperature and the time of exposure to the RF current ${ }^{\text {s }}$.

The alternating RF signal produces two types of basic fields in the tissue: electrical fields and magnetic fields. At $500 \mathrm{KHz}$, magnetic fields are negligible. The calculated strength of the magnetic field around the electrode is comparable to the strength of the earth's magnetic field and 10,000 times weaker than the magnetic field in most of the Magnetic Resonance Imaging (MRI) scanners ${ }^{3}$. The electric field (E) has two types of effect. First, it gives rise to electrical forces on mobile ions in the tissue electrolytes, which in turn produce the current density vector field. The current density vector field (j) produces ionic friction and heat ${ }^{7}$. Secondly the electric field has an effect that is not temperature dependent. It has the potential of producing modification of neural structures and neuronal behavior when the E-field becomes high enough and this might be relevant in understanding how RF current can be used. 


\section{Pulsed radiofrequency}

In PRF, short pulses of RF current are applied to the neural tissue ${ }^{3}$ (See figure 1). The RF lesion generators with a PRF mode are equipped to deliver PRF signals with pulse durations ranging from 10 to 30 milliseconds $(\mathrm{ms})$ and pulse repetition rates ranging from 1 to 8 pulses per second. The oscillating frequency of the alternating current is $300-500 \mathrm{KHz}$, which is the same as for $\mathrm{RF}^{6}$. In clinical practice, in $1 \mathrm{~s}$ two bursts of $20 \mathrm{~ms}$ each of an alternating current are usually delivered. During one cycle the "active" phase of $20 \mathrm{~ms}$ is followed by a silent period of $480 \mathrm{~ms}$ to allow for washout of the generated heat. The output is usually set at $45 \mathrm{~V}$, but if the electrode tip temperature exceeds $42^{\circ} \mathrm{C}$, it is decreased to prevent cell damage. This temperature is selected based on the findings that necrosis in various soft tissue cell lines could only be induced by heating to temperatures greater than $43^{\circ} \mathrm{C}^{4,5}$. Because the RF pulse duration is only a small percentage of the duty cycle, the average tissue temperature rise for the same RF voltage on the same electrode is less for PRF than for RF. For the same reason, higher RF voltages can be applied to the electrode in PRF than are commonly used in RF. The effects of PRF follow the same physical laws as RF, but they differ in space, time and strength of the resultant fields $s^{6}$.

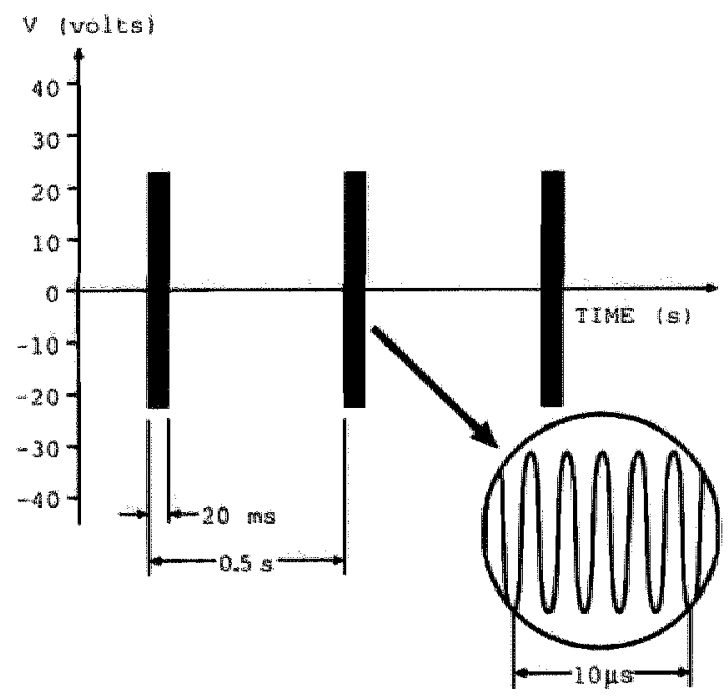

Flgure 1: The configuration of pulsed radiofrequency

Based on: Sluijter ME. Radiofrequency Part l; Flivopress, Meggen, Switzerland 2001 With permission of the author 
The physical effects of PRF can be classified as follows:

- Thermal effects

Mean tip temperature

Temperature spikes

- Non-thermal effects

Electric field

Magnetic field

Current density effects

\section{Thermal effects of pulsed radiofrequency}

\section{Mean tip temperature}

This is the temperature parameter that is displayed on lesion generators. During the PRF pulses heat is produced, and this may or may not increase the mean tip temperature.

The mean tip temperature depends on:

- The quantity of heat that is produced during the active pulses. This in turn depends on:

Pulse duration and pulse frequency

Voltage

Impedance

- The quantity of heat that is eliminated from the tissue during the sillent phase. This depends an:

Tissue conductivity

Circulation

The actual temperature gradient from the vicinity of the electrode to the tissue, $\Delta T$.

Since the voltage is kept constant during PRF, irrespective of the impedance, the current density j will depend on the specific electrical conductivity of the tissue. Since power deposition at a constant voltage is proportional to $j^{2}$ heat production will be $\|$ ow in a high-impedance environment and vice versa ${ }^{B}$. High impedance is thought to reflect a condition of low vascularization, and the vascular supply of a tissue is one of the factors that determine the rate of heat washout. In the case of PRF, a smaller quantity of heat is produced in a high-impedance environment, but it is eliminated at a lower rate. This results in little if any effect on the mean tip temperature. 


\section{Temperature spikes}

During PRF pulses the voltage is set at a level (usually $45 \mathrm{~V}$ ) that is considerably higher than during the maintenance phase of a RF lesion, where voltages are in the order of magnitude of $15-20 \mathrm{~V}$. The heat production during a pulse can be important, but of very short duration. This must lead to a very brief rise in temperature around the needle tip, and these brief elevations have been named "temperature spikes". These spikes have been predicted in a computer model, and they have indeed been measured with a very fast thermocouple ${ }^{\sigma}$ (See figure 2 ). They are predictably larger with a higher voltage and when the pulse duration is longer, although the relationship with the pulse duration is not linear. Computer models are very useful in predicting the spread of the rise in temperature into the tissue.

The heat mostly spreads ahead of the tip of the electrode, since this is where the strongest electric field is. But the penetration into the tissue is minimal; the rise in temperature beyond a distance of $0.1 \mathrm{~mm}$ from the electrode is irrelevant (See figure 3).
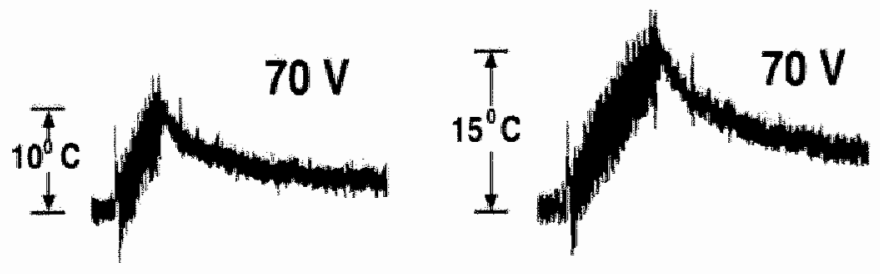

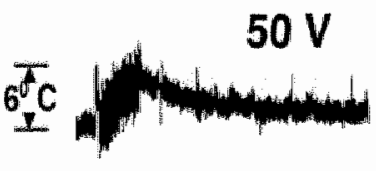

$10 \mathrm{msec}$

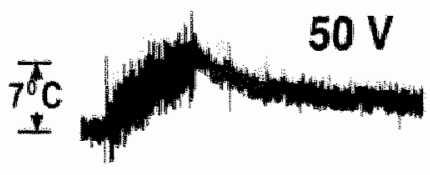

$20 \mathrm{msec}$

Figure 2: Measured temperature bursts during PRF pulses in liver at $70 \mathrm{~V}$ and $50 \mathrm{~V}$ (peak) settings: on the left for duration $=20 \mathrm{~ms}$, and on the right for duration $=10 \mathrm{~ms}$.

Based on Cosman ER and Cosman ER. Electric and thermal field effects in tissue around radiofrequency electrodes. Accepted Pain Medicine. With permission of the authors 


\section{Non-thermal effects of pulsed radiofrequency}

\section{Electric fields}

The effect on neurons of the high electric fields encountered in PRF can be estimated and is plausibly very significant. The distribution of the electric fields has been calculated in a computer model (figure 4$)^{6}$. The pattern is comparable to the distribution of temperature, but there is a significant difference. The electric field at a reasonable distance from the electrode is still of an order of magnitude that may plausibly cause a biological effect, whereas the rise in temperature during a temperature spike is insignificant at a distance of $>0.2 \mathrm{~mm}$. This calculation is made after the first $20 \mathrm{~ms}$ pulse. But, during clinical application PRF is applied for $120 \mathrm{~s}$. The effect of these temperature-spikes at that time point is not known.

It can be estimated that close to the electrode tip the electric fields, for typical PRF parameters, are capable of rupturing cell membranes ${ }^{6}$. But other modifications of an axonal membrane, less extreme than catastrophic rupture, may result at larger distance. Voltage-gated or transmitter-gated ion channels or ion pumps in the membrane that control the conduction of $\mathrm{Na}^{+}, \mathrm{K}^{+}, \mathrm{Ca}^{2+}$, and other ions are vital to cell function ${ }^{6}$. Since these ion channels are known to be delicate composites of charged proteins, it is plausible that violent agitation of these structures by large PRF electric fields could disrupt, modify, or destroy them. 


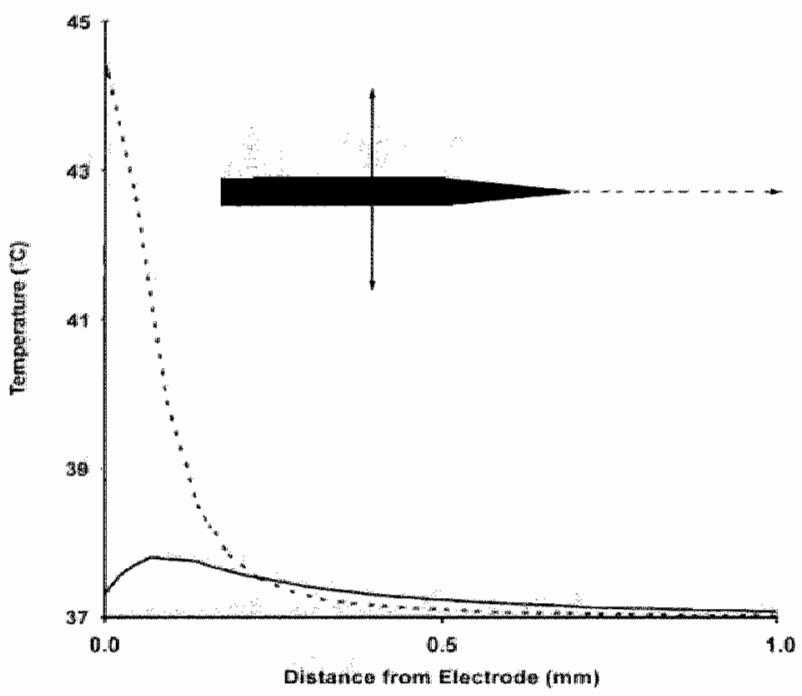

Figure 3: The temperature field magnitudes as a function of distance from the radiofrequency electrode (SMK) along two different directions for PRF with $V$ (peak) $=45 \mathrm{~V}$ and duration $=20 \mathrm{~ms}$. Based on Cosman ER and Cosman ER. Electric and thermal field effects in tissue around radiofrequency electrodes. Accepted Pain Medicine. With permission of the authors.

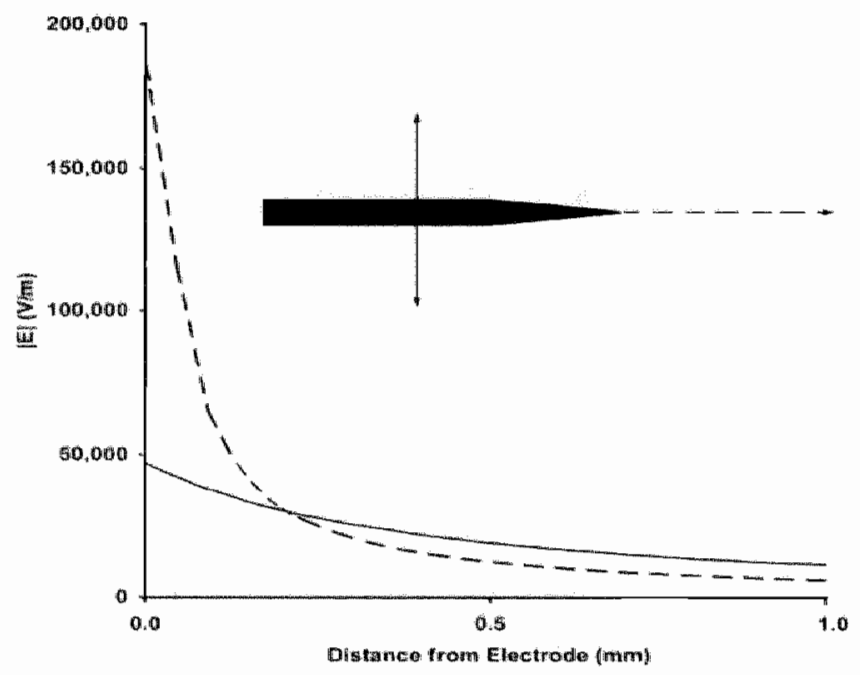

Figure 4: The electric field magnitudes as a function of distance from the radiofrequency electrode (SMK) along two different directions for PRF with $\vee($ peak $)=45 \mathrm{~V}$ and duration $=20 \mathrm{~ms}$.

Based on Cosman ER and Cosman ER. Electric and thermal field effects in tissue around radiofrequency electrodes. Accepted Pain Medicine. With permission of the authors. 
In addition to the role of the voltage gated ion channels in the axonal membrane, also the diameter of the nerve fibers may be important for the electric field effect on the target nerve. The model of figure 5 suggests that for the smallest $C$-tibers with radius $r \cong 0.5 \mu \mathrm{m}$, and for a PRF voltage of $\mathrm{V}$ (peak) $=45 \mathrm{~V}$ an alternating transmembrane potential of magnitude $\mathrm{Um} \cong 0.01$ to $0.1 \mathrm{~V}$ will be produced with resulting alternating intracellular and trans-membrane currents. For thinly myelinated nociceptive A- $\delta$-fibers, the values would be $r \cong 2 \mu \mathrm{m}$ and $\mathrm{Um} \cong 0.04$ to $0.4 \mathrm{~V}$. An alternating potential $\mathrm{Um}$ at $500 \mathrm{KHz}$ will hyperpolarize and depolarize the cell away from its normal resting potential of $-0.07 \mathrm{~V}$ at the same frequency. Although $500 \mathrm{KHz}$ is well above frequencies commonly associated with stimulating or excitatory signals for neurons, nonetheless the alternating transmembrane potential Um at $500 \mathrm{KHz}$ is capable of changing ionic balances and thus cellular processes.

Some evidence of changes in gene expression in the dorsal horn by c-Fas formation has been reported following (P) RF exposure to the DRG in rats ${ }^{8.9}$. Long-term memory of PRF exposure to desensitize nociception by gene changes in more central structures would indeed be a fascinating end-effect of electric field exposure. It is not yet clear if this transsynaptal effect is directly caused by the electric field effects as described above. Increased experience with PRF and better understanding of the underlying electric and temperature field effects on neurons should lead to guidelines for optimal parameters for a desired clinical objective. The average tip temperature in PRF is not a good indicator of $E$ strength or of temperature-spikes. However, in PRF the RF voltage $V$ is a direct indicator of $E$ strength and of temperaturespikes. Thus, $V$ is a central parameter in understanding the effects, control and optimization of PRF. 


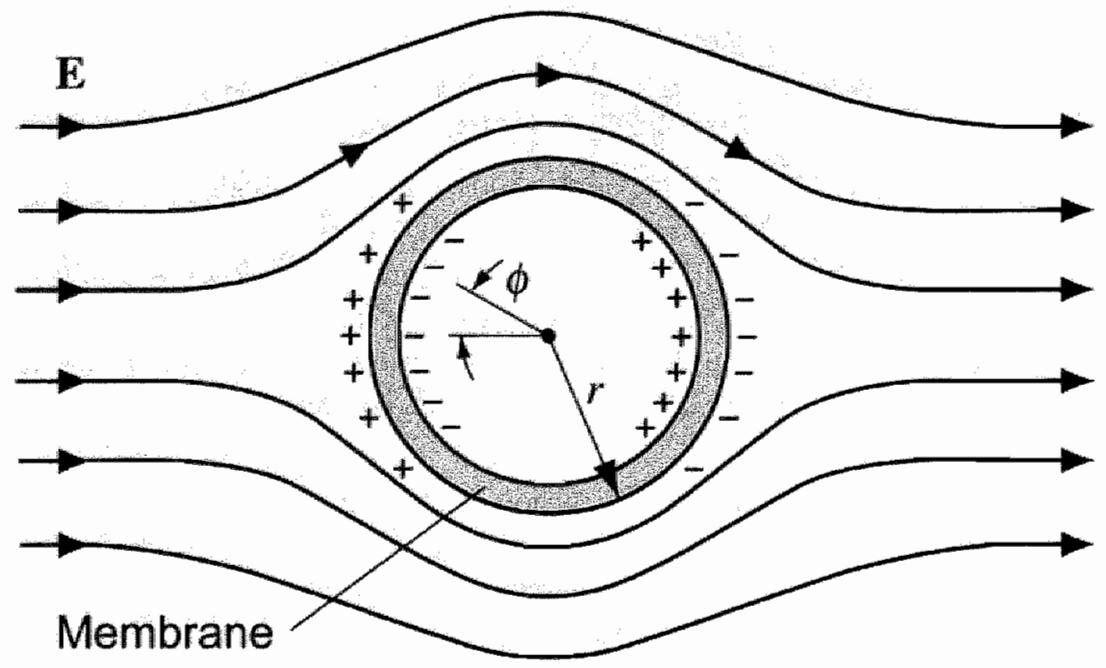

Figure 5: A simplified model of a spherical nerve cell in an applied electric field. The diagram is schematic and the elements such as membrane thickness to cell diameter are not drawn to scale.

Based on Cosman ER and Cosman ER. Electric and thermal field effects in tissue around radiofrequency electrodes. Accepted Pain Medicine. With permission of the authors

\section{Other possible field effects}

Other electric field related aspects of PRF are notable. Very large current densities in the range of $\mathrm{j}=10^{3}$ to $10^{5} \mathrm{Amp} / \mathrm{m}^{2}$ are predicted during PRF. These are enormous compared to biophysical levels such as $10 \mathrm{Amp} / \mathrm{m}^{2}$ for normal transmembrane current or $\sim 10 \mathrm{Amp} / \mathrm{m}^{2}$ for cardiac defibrillation. It is not known what the effect of such high currents will have on cell structures and molecules. Before the onset of observable heating, the sustained jostling of ions and bio-molecules, and their resultant collisions with other cell substructures may be of significance. 


\section{Generator settings in clinical use of pulsed radiofrequency}

In clinical practice, the impedance is checked before the start of the procedure. The value of manipulating the tissue impedance with the injection of a limited volume of saline is not yet known. The procedure is started with fixed voltage of $45 \mathrm{~V}$, during $120 \mathrm{~s}$ with bursts of $20 \mathrm{~ms}$ and $2 \mathrm{~Hz}$ frequencies. It is advocated to limit the mean tip temperature to $42^{\circ} \mathrm{C}$. The corresponding amperage is noted during the procedure and is usually $\pm 100 \mathrm{mAmp}_{\text {n }}$ depending on the impedance of the tissue wherein the needle is placed. In contrast to continuous RF the wattage cannot be shown on the display of the generator because of the interrupted current delivery. As with RF, the placement of the electrode is controlled fluoroscopically, and the sensory stimulation allows judging the distance to the nerve. When after applying PRF current a slight change in needle placement results in lower stimulation parameters, the treatment can be repeated.

\section{Conclusion}

Radiofrequency and PRF both rely on the application of high frequency electric current to the neural tissue. The main objective of the use of this current in RF is the generation of heat through ion friction. In the clinical application of PRF the electrode tip temperature is kept at a low level, but although the overall electrode tip temperature does not exceed $42^{\circ} \mathrm{C}$, more precision temperature measurements have indicated that during the electric burst, temperature-spikes are produced that may be above the $42^{\circ} \mathrm{C}$, the impact of these short temperature-spikes on the nervous cell has not been elucidated. The passage of high frequency electric current through a conducting medium in both RF and PRF induces a magnetic and electric field. It was described that the intensity of the magnetic field is negligible in comparison with the earth's magnetic field and the magnetic fields of MRI which justifies discarding the magnetic field as a potential mode of action of RF current on the pain conduction. The electric field however reaches high intensities capable of modifying or even destructing the cell membranes. In PRF higher current densities $(V)$ can be applied without reaching the neurodestructive temperatures, but yielding higher intensity electric fields. The intensity of the electric field is highest at the electrode tip and at the edges of the electrode insulation. The effect of PRF current on the neuronal cells will depend on the level and the distribution in the tissue of both the temperature spikes and the electric field, though other parameters may equally play a role. 


\section{References}

1. Cosman ER; Cosman B. Methods of making nervous system lesion, Neurosurgery, Edited by Wikens R \& Rengachary: SS. New York, McGraw-Hill, 1984 pp 2490-2499,

2. Melzack R, Wall PD. Pain mechanisms: a new theory. Science 1965, 150: 971-979

3. Sluifter $M E$, Cosman $E R$, Rittman II WB, van Kleef $M$. The effects of pulsed radiofrequency field applied to the dorsal root ganglion - a preliminary report. The Pain Clinic $1998 ; 11: 109$ 117

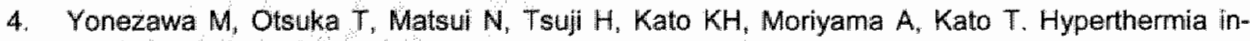
duces apoptosis in malignant fibrous histiocytoma cells in vitro. Int $J$ Cancer 1996; 66: 347-351

5. Hildebrandt $B$, Wust $\mathbb{P}_{\text {, Ahlers }} \mathrm{O}$, Dieing $A$, Sreenivasa $G_{n}$ Kerner $T$, Felix $R$, Riess $H$. The cellular and molecular basis of hyperthermia. Crit Rev Oncol Hematol 2002; 43: 33-56

6. Cosman ER, Cosman ER. Electric and thermal field effects in tissue around radiofrequency electrodes. Accepted Pain Medicine

7. Gowrishankar TR, Weaver JC. An approach to electrical modeling of single and multiple cells. Proc Natl Acad Sci U S A, 2003; 100: 3203-3208

8. Higuchi $Y$, Nashold BS, Sluijter ME Cosman E, Pearlstein RD. Exposure of the dorsal root ganglion in rats to pulsed radiofrequency currents activates dorsal horn lamina I and lif neurons. Neurosurgery 2002; $50: 850-856$

9. Van Zundert J, de Louw AJ, Joosten EA, Kessels AG, Honig W, Dederen PJ, Veening JG, Vles JS, van Kleef M. Pulsed and continuous radiofrequency current adjacent to the cervical dorsal root ganglion of the rat induces late cellular activity in the dorsal horn. Anesthesiology 2005; 102: $125-131$ 
CHAPTER V

\section{Pulsed and continuous radiofrequency} current adjacent to the cervical dorsal root ganglion of the rat induces late cellular activity in the dorsal horn

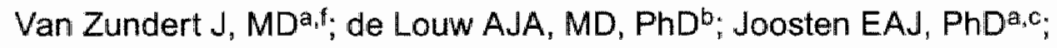
Kessels AGH, MSc; MDd, Honig Wc, Dederen PJWC ${ }^{e}$; Veening JG PhDe; Vles JSH, MD PhD', van Kleef M, MD, PhDa

a. Department of Anesthesiology and Pain Management, University Hospital Maastricht, Maastricht, The Netherlands b. Department of Neurology. University Hospital Maastricht, Maastricht, The Netherlands. c. Department of Neuroscience, Uniwersity Maastricht, Maastricht, The Netherlands d. Department of Chinical Epidembology and Medical Technology Assessment, University Hospital Maastricht, Maastricht, The Netherlands e. Department of Anatomy, University Medical Center Nijmegen, Nijmegen, The Netherlands f. Department of Anesthesiology. Critical Care and Multidisciplinary Pain Center. Ziekenhuis Oost-Limburg: Genk, Belghum 


\section{Abstract}

\section{Background}

Pulsed radiofrequency treatment has recently been described as a nonneurodestructive or minimally neurodestructive alternative to radiofrequency heat lesions. In clinical practice long-lasting results of pulsed radiofrequency treatment adjacent to the cervical dorsal root ganglion for the management of chronic radicular spinal pain have been reported without neurological complications. However, the mode of action is unclear. An early ( 3 hours) effect of pulsed radiofrequency as measured by an increase of c-Fos in the pain-processing neurons of the dorsal horn of rats has been described in the literature. This effect was not mediated by tissue heating. The authors investigated a possible late or long-term effect of three different radiofrequency modalities.

\section{Methods}

Cervical laminectomy was performed in 19 male Wistar rats. The cervical dorsal root ganglion was randomly exposed to one of the four interventions: sham, continuous radiofrequency current at 67 centigrade, or pulsed radiofrequency current for $120 \mathrm{~s}$ or $8 \mathrm{~min}$. The animals were sacrificed and the spinal cord was prepared for c-Fos labeling 7 days after the intervention.

\section{Results}

The number of $\mathrm{c}$-Fos immunoreactive cells in the dorsal horn was significantly increased in the three different radiofrequency modalities as compared to sham. No significant difference was demonstrated between the three active intervention groups.

\section{Conclusions}

The authors demonstrated a late neuronal activity in the dorsal horn after exposure of the cervical dorsal root ganglion to different radiofrequency modalities, which was not temperature dependent. 


\section{Introduction}

Cervicabrachialgia can be defined as a radicular pain originating from the cervical spine radiating from the neck beyond the elbow into the upper limb with referral to a particular spinal segment. It is most commonly caused by an irritation of the segmental nerve as a result of cervical disc protrusion or spondylosis resulting in narrowing of the intervertebral foramen ${ }^{1-3}$. Radiofrequency (RF) heat lesions have been described as treatment for chronic cervical radicular spinal pain that is refractory to conservative therapy (pharmacological treatment, physiotherapy, transcutaneous electrical nerve stimulation) $)^{4-6}$. The use of continuous RF treatment at $67^{\circ} \mathrm{C}$ adjacent to the dorsal root ganglion (DRG) for the management of cervicobrachial pain has been investigated in 2 randomized controlled trials ${ }^{5,6}$. Van Kleef et all. ${ }^{5}$ compared the efficacy of RF at $67^{\circ} \mathrm{C}$ with sham intervention and found a significant reduction in pain intensity 8 weeks after the intervention. Slappendel et al.$^{6}$ found no difference in outcome when RF treatment with an electrode tip temperature of $40^{\circ} \mathrm{C}$ was used compared with RF at $67^{\circ} \mathrm{C}$.

The mode of action of RF was initially attributed to the thermocoagulation of nerve fibers ${ }^{7}$, but contradictory findings, notably that only transient sensory loss in the relevant dermatome is observed while the pain relief may be of much longer duration, gave rise to the hypothesis that temperature is not the only mechanism responsible for changes in pain transmission ${ }^{4}$. Moreover, the use of RF heat lesions adjacent to the DRG for the management of non-malignant pain is becoming more controversial because of its potential neurodestructive nature. For that reason a non-neurodestructive or minimal destructive technique would be more attractive.

A modified technique, pulsed radiofrequency $(P R F)^{8}$ treatment is developed whereby in $1 \mathrm{~s}$ two bursts of $20 \mathrm{~ms}$ each of an alternating current are delivered. The oscillating frequency of the alternating current is $500 \mathrm{KHz}$. During one cycle the "active" phase of $20 \mathrm{~ms}$ is followed by a silent period of $480 \mathrm{~ms}$, to allow for washout of the generated heat. The output is usually set at $45 \mathrm{~V}$, but if the electrode tip temperature exceeds $42^{\circ} \mathrm{C}$, it is decreased to prevent cell damage. This temperature is selected based on the findings that necrosis in various soft tissues cell lines could only be induced by heating to greater than $43^{\circ} \mathrm{C}^{9,10}$. In clinical practice long-lasting effects after PRF treatment for both $120 \mathrm{~s}$ and $8 \mathrm{~min}$ has been reported in different indications ${ }^{8,11-19}$. In a recent clinical audit PRF treatment (120 s) adjacent to the cervical DRG in patients with chronic cervicobrachialgia or cervicogenic headache, showed a short-term clinical success in $72 \%$ of the patients and a mean duration of pain relief of 9.2 months. The median duration of action determined by the Kaplan Meier curve, however, is only 3 months, indicating a wide variability in clinical re- 
sponse ${ }^{14}$. Because of the variability in outcome and the use of different treatment protocols in clinical practice, further research on the mode of action is required ${ }^{20}$.

Sluijter ef al $^{8}$ suggested that the electric field rather than temperature induced changes in the nerve cells that were responsible for the pain relief observed in clinical practice. Exposure of cultured cells to an electric field is associated with upregulation of the non-specific intermediate-early gene marker, c-Fos, and also transcription of other, as yet unidentified, genes ${ }^{21}$. C-Fos based functional anatomic mapping has been validated as a powerful technique to detect activated neurons ${ }^{22}$. Evidence is accumulating to suggest that changes in early gene expression within the nervous system signal long-term adaptation within particular neural pathways ${ }^{23}$.

In rats, exposure of the cervical DRG to PRF current showed an early significant increase in C-Fos-immunoreactive neurons in the superficial lamina I and II of the dorsal horn, $3 \mathrm{~h}$ after the procedure ${ }^{24}$. The late effect on the dorsal horn of PRF has not previously been studied. Also, although used routinely in the clinical setting, the effects of continuous RF $\left(67^{\circ} \mathrm{C}\right)$ have not been investigated.

The aim of this study was to examine the late effect of different modes of RF current application (continuous RF $67^{\circ} \mathrm{C}$, PRF during $120 \mathrm{~s}$ and PRF during $8 \mathrm{~min}$ ) adjacent to the cervical DRG in rats on the neuronal activity of the dorsal horn, by identifying the inducible gene expression (c-Fos) 7 days after the intervention, a duration far beyond the normal window of c-Fos expression after an acute event ${ }^{22,23}$. This may enhance the understanding of the underlying mechanism of the reported clinical effect.

\section{Materials and methods}

\section{General conditions}

All studies were conducted following the ethical guidelines of the International Association for the Study of Pain ${ }^{25}$ and approved by the Local Animal Care Ethics Committee, Maastricht, The Netherlands. Three-month old male Wistar rats bred by Charles Rivers Laboratories (Sulzfeld, Germany) (weight, 275-335 gram) were used for the experiments. All animals were housed at the University of Maastricht facility for experimental animals in individual standard rodent cages with sawdust bedding and food and water ad libitum. The housing room was air conditioned with $12 \mathrm{~h}: 12 \mathrm{~h}$ light:dark cycle (lights on 7:00 AM.). Animals were checked daily for general condition and complications. 


\section{Surgical procedure}

Rats were anesthetized by an intraperitoneal injection of sodium pentobarbital (Sanofi, Maassluis, The Netherlands) solved at $60 \mathrm{mg} / \mathrm{m}$ land administered to the rats in a dose of $60 \mathrm{mg} / \mathrm{kg}$.

The abdomen and cervical regions were shaved and the rat placed on an induction pad connected to a RF generator (Radionics, Burlington, MA). After identifying the cervical vertebra prominence as a landmark, a cervical hemi laminectomy was performed at the C5 and C6 levels. The corresponding DRG on the right side was identified and a $100 \mathrm{~mm} 30 \mathrm{G}$ Levin cordotomy electrode (Radionics, Burlington, MA) with a $2 \mathrm{~mm}$ uninsulated tip was introduced adjacent to the DRG using a micromanipulator (Leitz, Wetzlar, Germany).

After verifying the impedance, an indicator of the type of tissue surrounding the electrode tip, electrical stimulation was started at a rate of $50 \mathrm{~Hz}$ and $2 \mathrm{~Hz}$. The rat was observed for withdrawal reaction of the right forelimb $(50 \mathrm{~Hz}$ threshold). If muscle contractions were observed in the corresponding levels the stimulation threshold ( $2 \mathrm{~Hz}$ threshold) was noted.

All animals were unilaterally treated at one DRG on the right side with one of the 4 treatment modalities listed below. The treatment options were selected at random.

\section{Treatment groups}

In group $1(n=4)$, the sham intervention group, the electrode was maintained in contact with the ganglion for $120 \mathrm{~s}$, but no current was passed through the electrode.

In group 2 ( $n=5$ ), the continuous RF group, the dorsal ganglion was heated by continuous RF current and maintained at a temperature of $67^{\circ} \mathrm{C}$ for $60 \mathrm{~s}$.

In group $3(n=5)$, the PRF 120 s group, the DRG was exposed to PRF for $120 \mathrm{~s}$ with a maximum temperature of $42^{\circ} \mathrm{C}$.

In group $4(n=5)$, the PRF 8 min group, the DRG was exposed to PRF for 8 min with a maximum temperature of $42^{\circ} \mathrm{C}$.

For all procedures impedance, temperature, ampere, voltage and wattage were recorded at the start and the end of the intervention, if available. At the end of the treatment, the skin incision was closed with 3-0 silk sutures, and the animal was allowed to recover from anesthesia. 


\section{Observation of the animals}

All animals were tested on the "grid walk" by an experienced observer who was unaware of the treatment (W.H.) within $48 \mathrm{hrs}$ post operatively and on the seventh day after intervention to observe potential treatment influences on gait. In the grid walk test, a general evaluation of the sensory motior function of the forelimbs and hindlimbs, animals have to cross a $100 \mathrm{~cm}$ wire grid containing $40 \times 40 \mathrm{~mm}$ holes. Footfalls (the inability to grasp a grid with one of the limbs results in a drop of the foot below the plane of the grid) were counted ${ }^{26}$.

\section{Tissue preparation}

At postoperative day 7 , the rats were deeply anesthetized by an intraperitoneal injection of sodium pentobarbital (Sanofi, Maassluis, The Netherlands $60 \mathrm{mg} / \mathrm{kg}$ ) and perfused transcardially with a flush of Tyrode solution $(\mathrm{pH} \mathrm{7.4)}$ followed by phosphate-buffered $4 \%$ paraformaldehyde $(\mathrm{pH} \mathrm{7.4)}$. The total cervical spinal cord was dissected and post fixed in phosphate-buffered $4 \%$ paraformaldehyde overnight at $4^{\circ} \mathrm{C}$. The spinal cord was then divided into parts comprising one segment each and embedded in $10 \%$ porcine gelatin. The gelatin cups were allowed to harden on ice for $1 \mathrm{~h}$ and postfixed in phosphate-buffered $4 \%$ paraformaldehyde for $2 \mathrm{~h}$. The tissue was cryoprotected in $15 \%$ sucrose in Tris-buffered salline overnight at $4^{\circ} \mathrm{C}$ and frozen in a liquid nitrogen cooled bath with 2-methylbutane $99 \%$. Subsequently, cryostat sections $(30 \mu \mathrm{m})$ were cut (Leica CM3050, Cryostat, Wetzlar, Germany) and collected in 0.1 M Phosphate Buffered Saline (PBS).

\section{Immunocytochemistry}

Sections were rinsed in $0.1 \mathrm{MPBS}$ for $10 \mathrm{~min}$, using the free-floating method. The following incubations have been carried aut at room temperature. The sections were incubated with $0.3 \%$ hydrogen peroxide (aglainst endogenous peroxidase) for 30 min in $0.1 \mathrm{M}$ PBS and subsequently washed 3 times in $0.1 \mathrm{M}$ PBS during $20 \mathrm{~min}$. A pre-incubation in $0.1 \mathrm{M}$ PBS with $0.1 \%$ Bovine Serum Albumin and $0.2 \%$ Triton-X100 (PBS-BT) was carried out for $30 \mathrm{~min}$ before the overnight incubation with rabbitantij-C Fos $(1: 20,000)$ (Santa Cruz Biotechnology Inc. SC-052, Santa Cruz, CA, USA) in 0.1 M PBS-BT. After rinsing 3 times with 0.1 M PBS for $20 \mathrm{~min}$, the sections were incubated with donkey-anti-rabbit immunoglobulin $G$ biotin conjugated $1: 1,500$ in 0.1 M PBS-BT (Jackson ImmunoResearch Laboratories Inc. Westgrove, PA) for 90 min. Then after three washes in $0.1 \mathrm{M}$ PBS, sections were incubated with Vector ABC-Elite (Vector Laboratories, Ltd, Burlingame, CA) (1:800 M in 0.1 M PBS-BT) for 90 min followed by a pre-incubation with Di-amino-benzidine-Ni solution without perhydrol for 10 min. Then sections were incubated with Di-amino-benzidine-Ni solution with perhydrol for exactly $10 \mathrm{~min}$. Finally, sections were rinsed three times for 
$20 \mathrm{~min}$ in $0.1 \mathrm{M}$ PBS and then mounted on gelatin-coated object glasses $10.5 \%$ gelatin $+0.05 \%$ potassium chrome (III) sulfate), dried overnight in the oven at $37^{\circ} \mathrm{C}$. Slices are dehydrated in alcohol series and cleared in Xylol before mounting them in Entellan. Omission of the primary antibody was used for negative controls. The slices received a code allowing blinded counting of c-Fos immunoreactive cells.

\section{Analysis}

Quantification of the number of c-Fos immunoreactive cells in the dorsal horn was performed for each animal in one section $(30 \mu \mathrm{m})$ of the $\mathrm{C} 5$ and $\mathrm{C} 6$ levels, both ipsiand contralateral. Counting was done by a blinded and experienced investigator (W.H.). A second investigator (E.J.), also blinded to the origin of the slices, performed control counting of randomly selected preparations. To describe the distribution of the c-Fos immunoreactive cells in the dorsal horn, the median was calculated for the sum of $\mathrm{C} 5$ and $\mathrm{C} 6$ at the ipsilateral and contralateral side for the four treatment groups. The sum of $\mathrm{C} 5$ and $\mathrm{C} 6$ were used for further analysis. Differences between the four study groups were compared using the Kruskal-Wallis test, and if this test was significant the sham group was pairwise compared with the active groups using the Mann-Withney $U$ test. Ipsilateral versus contralateral comparison of the number of c-Fos immunoreactive cells in the dorsal horn was analyzed by a Wilcoxon signed rank test. For all analyses significance was reached if $P<0.05$.

\section{Results}

A total of 19 rats were investigated, four in the sham and five in each active intervention group (RF at $67^{\circ} \mathrm{C}, \mathrm{PRF} 120 \mathrm{~s}$ and PRF $8 \mathrm{~min}$ ). The sections of two rats could not be analyzed because they were not anatomically intact, thus not allowing the determination of the level and a correct count of the c-Fos immunoreactive cells. The results presented below refer to the c-Fos immunoreactive counted cells in the sections of 17 animals. All data are shown in Table 1. The pre-intervention details are not significantly different between the groups: weight $(P=0.99)$, stimulation threshold at $50 \mathrm{~Hz}(P=0.09)$ at $2 \mathrm{~Hz}(P=0.2)$ and start impedance $(P=0.07)$.

The animals did not show postoperative complications during the 7-day observation period. All animals performed well on the grid walk, when tested within $48 \mathrm{hrs}$ and 7 days post-intervention, indicating that the surgical intervention did not result in major sensory motor impairment of the forelimbs or hindlimbs. No aberrations in gait (footfalls), even with special attention to the right forelimb, have been observed.

Quantification of c-Fos immunoreactive cells in the dorsal horn was performed for each animal at the level $\mathrm{C} 5$ and $\mathrm{C6}$. To avoid double counting of cells, only one sec- 
tion of $30 \mu \mathrm{m}$ was used per level. The number of cells were added and presented per side in table 2.

The number of $\mathrm{c}$-Fos immunoreactive cells among the four study groups were significantly different for the ipsilateral side $(P=0.03)$ and the contralateral side $(P=0.02)$ (Kruskal Wallis test). The animals that received a sham procedure showed a relatively low number of c-Fos immunoreactive cells. A significant increase in the number of c-Fos immunoreactive cells is observed in all sections of the animals that received active intervention as compared with sham operated animals $(P<0.05)$ (Mann-Whitney test) (See table 2). The typical nuclear stained c-Fos cells were mainly localized in the dorsal horn as shown in Figure 1. No c-Fos-immunoreactive cells were observed in the ventral or intermediate gray matter zones of the spinal cord. A few c-Fos immunoreactive cells were observed in lamina $X$, surrounding the central canal. Control incubations, (absence of the primary antibody and using $0.1 \mathrm{M}$ PBS-BT only), were negative (figure 1). Inspection of c-Fos expression at other spinal segments than $\mathrm{C5}-\mathrm{C} 6$ did not show a particular increase at those levels. No statistical significant difference in the number of c-Fos immunoreactive cells was noted between the active intervention groups. No significant difference was reached for the comparison between the number of c-Fos immunoreactive cells between the ipsilateral and the contralateral side for the combined data of all animals $(P=0.20)$. Even for the c-Fos-immunoreactive cell counts of only the animals that underwent active intervention, no significant difference was noted $(P=0.12)$. There was, however, a trend towards a higher number of c-Fos -IR cells on the ipsilateral side. 


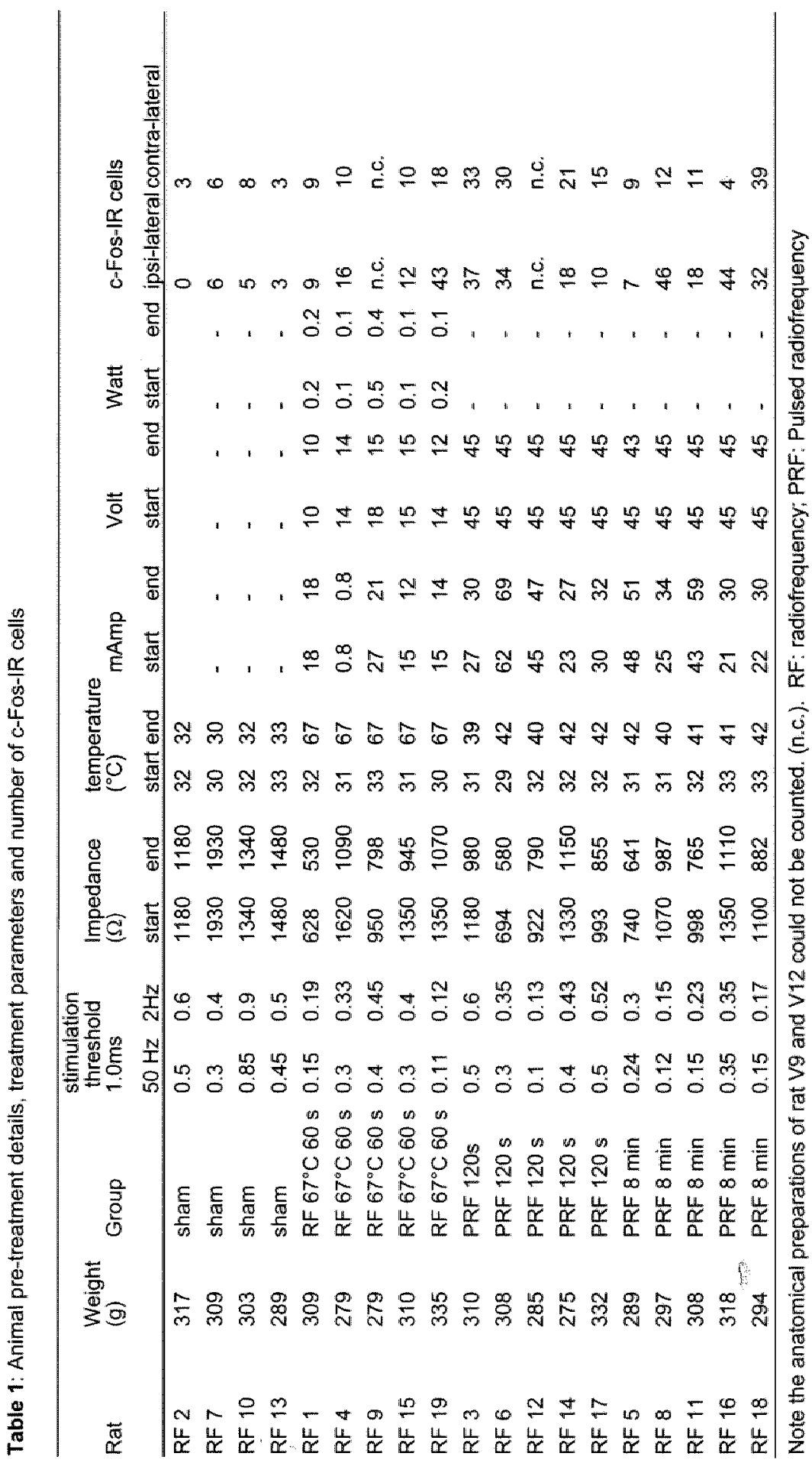




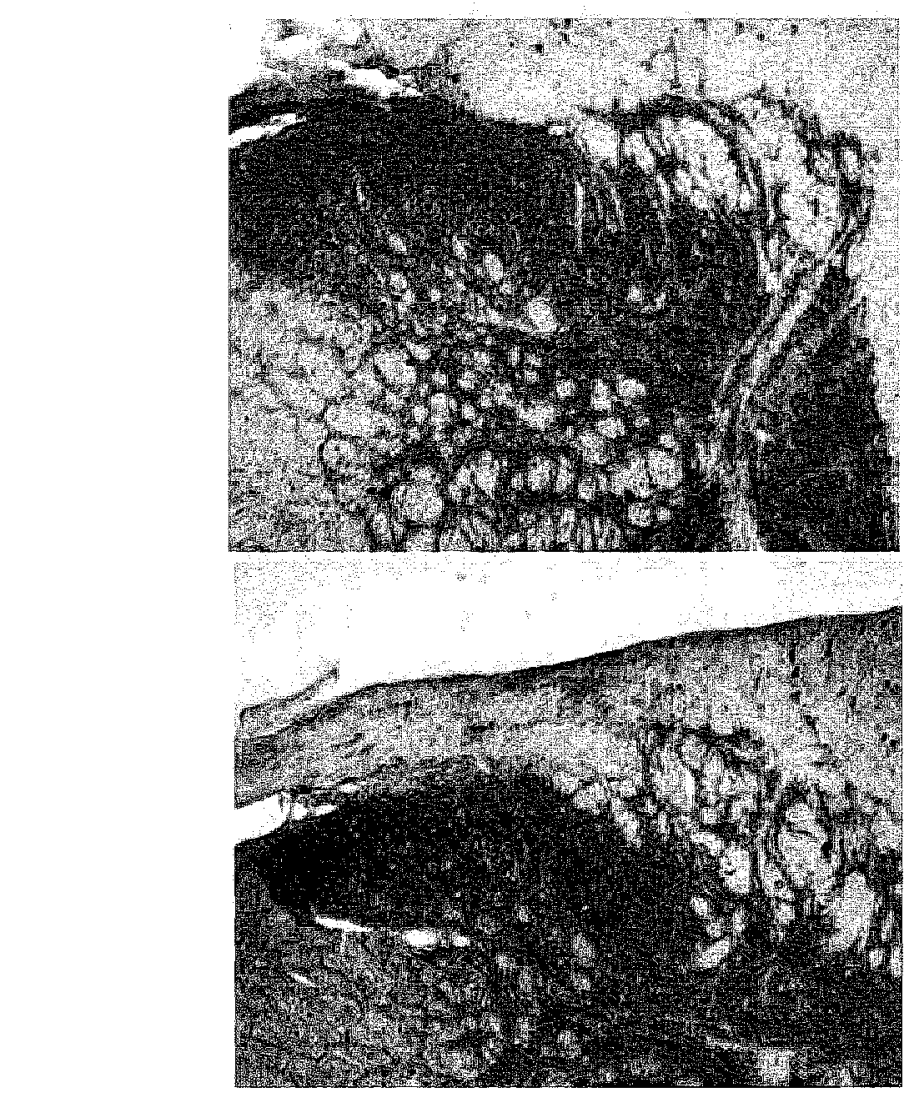

A

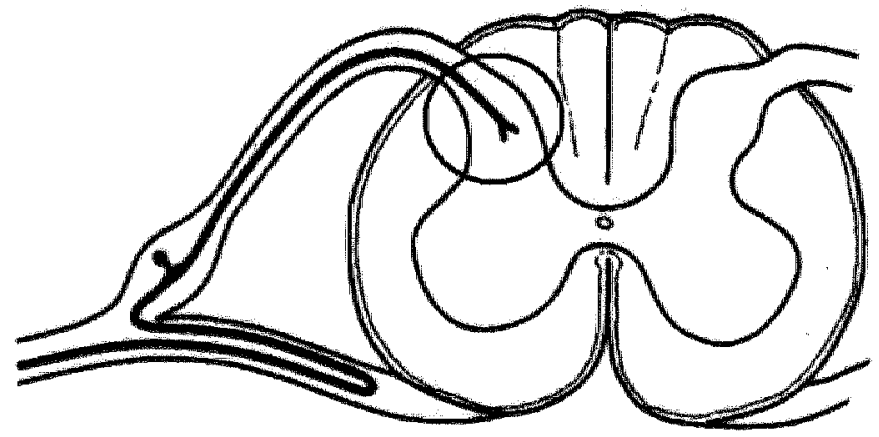

B

C

Figure 1: Transwerse sections of the cervical spinall cord at C5: nuclear G-Fos immunoreactive cells. located in the dorsal hoin of an animal treated with pulsed radiofrequency adjacent to the dorsal rowt ganglion $(A)$ as compared to a sham operated animal $(B)-(C)$ Schematic drawing of a transverse section of rat spinal cord at $C 5$. The position of the area shown in Fig $A$ and $B$ is indicated. 
Table 2: Median number (range) of c-Fos immunoreactive cells and $\mathrm{P}$ values

\begin{tabular}{lllll}
\hline Treatment & \multicolumn{4}{c}{ Median ne (range) of c-Fos immunoreactive cells in C5/C6 } \\
& ipsilateral side & P ws. Sham & contralateral side & P VS. Sham \\
\hline Sham & 5 & & 4.5 & \\
$(n=4)$ & $(0-6)$ & 0.02 & $(3-8)$ & 0.02 \\
RF 67 ${ }^{\circ} \mathrm{C}$ & 16 & & 10 & \\
$(n=4)$ & $(9-43)$ & 0.02 & $(9-18)$ & 0.02 \\
PRF 120s & 34 & & 25.5 & \\
$(n=4)$ & $(10-37)$ & 0.01 & $(15-33)$ & $<0.049$ \\
PRF 8min & 38 & & 11 & \\
$(n=5)$ & $(7-46)$ & & $(4-39)$ & \\
\hline
\end{tabular}

\section{Discussion}

Pulsed radiofrequency has recently been introduced as a non-neurodestructive or minimally neurodestructive alternative to RF for the management of chronic pain ${ }^{8}$. The mode of action of RF is not yet clear. The selective effect of RF lesions on small $A-\delta$ and $C$ fibers, followed by a delayed effect on fibers in the A- $\alpha$ and $\beta$ group has been described in the cat ${ }^{27}$. Although a fiber-selective effect is suggested, other authors have described an "indiscriminate" effect on all types of peripheral fibers in the beagle $\operatorname{dog}^{7}$. Furthermore, RF at $67^{\circ} \mathrm{C}$ adjacent to the DRG of the goat produced proliferation of satelite cells and regeneration of damaged nerve fibers two weeks after the intervention, without microscopically observable signs of tissue damage (e.g. necrosis) ${ }^{28}$. Considering the contradictory findings regarding the selectivity in nerve fiber destruction it is assumed that also other mechanisms than thermocoagulation are involved in its mode of action.

Because pain transmission is modulated in the dorsal gray matter, we investigated the late effect in the rat dorsal horn of continuous and pulsed RF ( $120 \mathrm{~s}$ and $8 \mathrm{~min}$ ) current adjacent to the cervical DRG versus sham intervention. Our study results demonstrate a late or sustained effect of the three different RF current delivery modalities, 7 days after the intervention. We observed a significant increase of c-Fos expression in the dorsal horn of animals that underwent active intervention compared to the sham-operated controls. An early increase in c-Fos immunoreactive cells in lamina I and II of the dorsal horn has been described after $\mathrm{PRF}^{24}$. Here we demonstrated an additional late c-Fos activity with a bilateral response. Under basal conditions the detectable c-Fos concentrations are very low ${ }^{29}$, a finding that was confirmed in the sections of the sham-operated animals and also in sections from higher and lower segments of the spinal cord of animals from the active groups. After an acute challenge, c-Fos proteins, non specific markers for cellular activity, are induced within a few minutes and the maximum concentrations occur between 1 and $3 \mathrm{hrs}^{22,30-35}$. In addition another peak of C-Fos expression was seen within the 
deep layers, commencing at $8 \mathrm{~h}$ and peaking at $16 \mathrm{~h}$. This second wave of labeling started ipsilaterally and spread to become bilateral ${ }^{23}$. For this reason we selected the time point of 7 days after the intervention to evaluate the late effect, because it is far beyond the described window of c-Fos expression after an acute event. Our findings indicate no significant difference in neuronal activity in the dorsal horn of animals after RF and the modified technique PRF. These results further support our hypothesis that temperature is not an important factor for the obtained effect on cFos expression. In addition, Cahana et al. ${ }^{36}$ demonstrated in a cell culture model, that the acute effects of PRF are more reversible and less destructive than continuous RF even under non-thermal conditions.

It is well known that stimulation of central nervous system neurons with rectangular electrical pulses can induce immediate early genes expression, e.g. the inducible transcription factor c-Fos. These immediate early gene products are involved in triggering the long-term changes in gene expression that underlie neuronal plasticity ${ }^{24}$. Alterations in the genetic program of neurons underlie the central nervous system changes responsible for long-term potentiation and other phenomena ${ }^{37}$. Randic et al. ${ }^{38}$ reported that brief high-frequency electrical stimulation of primary afferent $A-\delta$ fibers produced a long-term potentiation or long-term depression of fast monosynaptic and polysynaptic excitatory postsynaptic potentials in a high proportion of dorsal horn neurons. A distinct long-lasting modulation of synaptic efficiency can be induced at primary afferent synapses with neurons in the superficial lamina of the spinal dorsal horn by high-frequency stimulation of dorsal root afferents. These changes may be physiologically relevant for transmission and integration of sensory information. Furthermore, Sandkühler et al. ${ }^{39}$ identified a robust long-term depression of synaptic transmission in substantia gelatinosa neurons that can be induced by low-frequency stimulation of primary afferent A- $\delta$ fibers, which may be relevant for long-lasting segmental antinociception after afferent stimulation. This is in accordance with our results, which indicate that PRF, delivered at $2 \mathrm{~Hz}$, during $120 \mathrm{~s}$ and $8 \mathrm{~min}$, produced late changes in the dorsal horn.

These changes may also contribute to the mode of action of the different RF techniques. Based on our experiments, we were not able to explain the difference in neuronal effects between RF and PRF. Further controlled experimental studies on the efficacy and safety of (P)RF should be performed to establish the differential characteristics observed in the clinical practice. Our observations on late bilateral cFos expression in the rat suggest that bilateral effects might be obtained in clinical practice. To our knowledge this has not been investigated. Further clinical research is needed to evaluate this potential bilateral response. 


\section{Conclusions}

Exposure of the cervical DRG to continuous RF $\left(67^{\circ} \mathrm{C}\right)$ and PRF current induces increased cellular activity in the dorsal horn ipsi- and contralateral 7 days after the intervention. The hereby demonstrated late and temperature-independent cellular activity in the rat spinal cord after application of different RF modalities is suggested to be part of the underlying mechanism during clinical use of PRF.

\section{Aknowlegdements:}

The authors thank Marcel Durieux, MD, PhD, Professor, Department of Anesthesiology, University of Virginia, Charlottesville, Virginia, USA; Robert Pearistein, PhD, Associate Professor, Department of Neurosurgery/Anesthesiology, Duke University Medical Center, Durham, North Carolina, USA, for their constructive remarks on the manuscript and Nicole Van den Hecke, administrative research coordinator Multidisciplinary Pain Centre, Ziekenhuis Oost-Limburg, Genk, Belgium. 


\section{References}

1. Slujiter ME, Koetsweld-Baart CC. Interruption of pain pathways in the treatment of the cervical syndrome. Anaesthesia 1980; 35: 302-307

2. Bland J. Cervical spine syndromes. J Muscoloskel Med 1986; 3: 23-41

3. Merskey $H$, Bogduk $\mathbb{N}$. Classification of Chronic Pain: Descriptions of Chronic Pain Syndromes and Defintitions of Pain Terms. 2. Seattle, Wash: IASP Press, 1994

4. van Kleof $M_{1}$ Spaans $F$, Dingemans $W$, Barendse GAM, Floor $E$, Sluijter ME. Effects and side effects of a percutaneous thermal lesion of the dorsal root ganglion in patients with cervical pain syndrome. Pain 1993; 52: 49-53

5. van Kleef $M$, Lousberg $R$, Liem L, Barendse $G$, Kessels $F$. Sluijter $M$. Radiofrequency lesion adjacent to the Dorsal Root Ganglion for Cerwicobrachial pain: a prospective double blind randomized study. Neurosurgery 1996; 38: 1127-1132

6. Slappendel R, Crul BJ, Braak GJJ, Geurts JW, Booil LHDJ, Voerman VF, de Boo T. The efficacy of radiofrequency lesioning of the cervical spinal dorsal root ganglion in a double blinded randomized study: no difference between $40^{\circ} \mathrm{C}$ and $67^{\circ} \mathrm{C}$ treatments. Pain $1997 ; 73: 159-163$

7. Smith HAP, McWhorter JM, Challa VR. Radiofrequency neurolysis in a clinical model. Neuropathological correlation. $J$ Neurosurg $1981 ; 55: 246-253$

8. Siluijter ME, Cosman ER, Rittman IIWB, van Kleef M. The effects of pulsed radiofrequency field applied to the dorsal root ganglion - a preliminary report. The Pain Clinic 1998; 11: 109-117

9. Yonezawa $M$, Otsuka $T$, Matsui $N$, Tsuji $H$, Kato KH, Moriyama A, Kato T. Hyperthermia induces apoptosis in malignant fibrous histiocytoma cells in vitro. Int J Cancer 1996; 66:347-351

10. Hildebrandt $B$, Wust $P$, Ahlers $O$, Dieing $A$, Sreenivasa $G$, Kerner $T$, Felix $R$, Riess $H_{\text {. The }}$ cellular and molecular basis of hyperthermia. Crit Rev Oncol Hernatol 2002; 43: 33-56

11. Munglani $R$. The longer term effect of pulsed radiofrequency for neuropathic pain. Pain 1999; 80: $437-4.39$

12. Van Zundert J, Brabant $S$, Van de Kelft E, Vercruyssen $A$, Van Buyten JP. Pulsed radiofrequency treatment of the Gasserian ganglion in patients with idiopathic trigeminal neuralgia. Pain 2003; 104: 449-452

13. Mikeladze G, Espinal R, Finnegan R, Routon J, Martin D. Pulsed radiofrequency application in treatment of chronic zygapophyseal joint pain. Spine $J$ 2003; 3: 360-362

14. Van Zundert $J$ "Lamé IE, de Louw $A_{0}$ Jansen J, Kessels $F$, Patijn J, van Kleef M. Percutanecus Pulsed Radiofrequency Treatment of the Cervical Dorsal Root Ganglion in the Treatment of Chronic Cervical Pain Syndromes: A Clinical Audit. Neuromodulation 2003; 6: 6-14

15. Padfield $N$ : Pulsed radiofrequency treatment; a novel form of "on-off neuromodulation. In: 6 th INS World Congress. (INS, Ed). International Neuromodulation Society, Madrid.(2003). 68 abstr. 47

16. Padfield $\mathrm{N}$ : Pulsed radiofrequency treatment to the $\mathrm{C} 2$ and $\mathrm{C} 3$ dorsal root ganglia in refractory occipital neuralgia, a reliable alternative to peripheral nerve stimulation? $\| n$ : 6th INS Worid Congress. (INS, Ed). International Neuromodulation Society, Madrid (2003). 68 abst. 46

117. Gofeld M: Pulsed radiofrequency treatment of intractable meralgia paresthetica: case study. In: 6th INS World Congress. (INS, Ed). International Neuromodulation Society, Madrid.(2003). 58 abstr. 22

18. Ahadian FM. Pulsed radiofrequency neurotomy: advances in pain medicine. Curr Pain Headache Rep 2004; 8: 34-40

19. Cohen SP. Foster A. Pulsed radiofrequency as a treatment for groin pain and orchialgia. Urolagy 2003; 61: 645xxi-645xxiii

20. Abejon D, Reig E. Is Pulsed Radiofrequency a Neuromodulation Technique? Neuromodulation 2003; $6: 1-3$

21. Archer $\mathrm{S}, \mathrm{Li}$ TT, Evans AT, Britland $\mathrm{ST}$, Morgan $\mathrm{H}$. Cell reactions to dielectrophoretic manipulation. Biochem Biophys Res Comm 1999; 257:687-698

22. Kovacs KJ. c-Fos as a transcription factor: a stressful (re)wiew from a functional map. Neurochem Int 1998; $33: 287-297$ 
23. Munglani $R$, Hunt SP. Proto-oncogenes: basic concepts and stimulation induced changes in the spinal cord. Prog Brain Res 1995; 104: 283-298

24. Higuchi $Y$, Nashold BS, Sluijter ME, Cosman $E$, Pearlstein RD. Exposure of the dorsal root ganglion in rats to pulsed radiofrequency currents activates dorsal horn lamina Il and II neurons. Neurosurgery 2002; $50: 850-856$

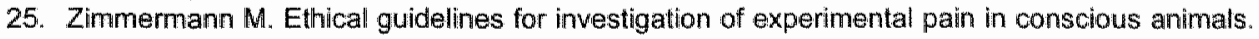
Pain 1983; 16: 109-110

26. Houweling DA, Lankhorst AJ, Gispen WH, Bar PR, Joosten EA. Collagen containing neurotrophin-3 (NT-3) attracts regrowing injured corticospinal axons in the adult rat spinal cord and promotes partial functional recovery. Exp Neurol 1998; 153: $49-59$

27. Letcher FS, Goldring $S$. The effect of radiofrequency current and heat on peripheral nerve action potential in the cat. J Neurosurg 1968; 29: 42-47

28. de Louw AJA, Vles $\mathrm{HSH}_{v}$ Freling $\mathrm{G}$, Herpers MJHM, Arends JW, van Kleef $M$. The morphological effects of radiofrequency lesion adjacent to the dorsal root ganglion (RF-DRG) - An Experimental study in the goat. Eur. J. of Pain 2001; 5: 169 - 174

29. Hughes $P$, Lawlor $P$, Dragunow M. Basall expression of Fos, Fos-related, Jun, and Krox 24 proteins in rat hippocampus. Brain Res Mol Brain Res 1992; 13: 355-357

30. Kovacs KJ, Sawchenko PE. Sequence of stress-induced alterations in indices of synaptic and transcriptional activation in parvocellular meurosecretory meurons. J Neurasci 1996; 16: 262273

31. Sonnenberg JL, Macgregor-Leon PF, Curran T, Morgan JI. Dynamic alterations occur in the levels and composition of transcription facior AP-1 complexes after seizure. Neuron 1989; 3 : 359-365

32. Imaki $T$, Shibasaki $T$, Hotta $M$. Demura $H$. Intracerebroventricular administration of corticotropin-releasing factor induces c-fos mRNA expression in brain regions related to stress responses: comparison with pattern of c-fos mRNA induction after stress. Brain Res 1993;616: 114-125

33. Chan RK, Brown ER, Ericsson A, Kovacs KJ, Sawchenko PE. A comparison of two immediateearly genes, ${ }_{1}$-fos and NGFI-B, as markers for functional activation in stress-felated neuroendocrine circuitry. J Neurosci 1993; 13: 5126-5138

34. Ding $\mathrm{JM}_{t}$ Carver $\mathrm{WC}$, Terracio $\mathrm{L}$, Buggy J. Proto-oncogene $\mathrm{c}$-fos and the regulation of vasopressin gene expression during dehydration. Brain Res Mol Brain Res 1994; 21: 247-255

35. Cullinan WE, Herman JP, Battaglia DF, Akil H, Watson SJ. Pattern and time course of immediate early gene expression in rat brain following acute stress. Neuroscience $1995 ; 64: 477-505$

36. Cahana $A_{n}$ Vutskits L, Muller D. Acute Differential Modulation of Synaptic Transmission and Cell Survival During Exposure to Pulsed and Continuous Radiofrequency Energy. The Journal of Pain 2003; 4: 197-202

37. Hughes $P E$, Alexi $T$, Walton $M$, Williams $C E$, Dragunow $M_{n}$ Clark $R G_{1}$ Gluckman $P D$. Activity and injury-dependent expression of inducible transcription factors, growth factors and apoptosis-related genes within the central nervous systerm. Prog Neurabiol 1999; 57: 421-450

38. Randic $M_{1}$ Jiang $M C_{1}$ Cerne $R$. Long-term potentiation and long-term depression of primary afferent neurotransmission in the rat spinal cord. J Neurosci 1993; 13:5228-5241

39. Sandkühler J, Chen JG, Cheng $G$, Randic $M$. Low-Frequency Stimulation of Afferent A -fibers induces Long-Term Depression at Primary afferent Synapses with Substantia gelatinosa neurons in the rat. J Neurosci $1997 ; 17: 6483-6491$ 


\section{CHAPTER VI}

\section{Pulsed radiofrequency treatment of}

the Gasserian ganglion in patients with idiopathic trigeminal neuralgia

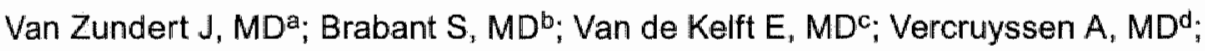
Van Buyten JP, MDe

a. Department of Anesthesiology, Intensive Care, Emergency Medicine and Multidisciplinary Pain Therapy. Ziekenhuis Oost-Limburg, Genk, Belgium b. Department of Anesthesia and Pain Management, H. Hart Ziekenhuis, Roeselare, Belgium c. Department of Neurosurgery, A. Z. Maria Middelares, St.-Nikllaas, Belgitum d. Department of Neurology, A.Z. María Middelares, St. Niklaas, Belgium e. Department of Anesthesia and Pain Management, A.Z. Maria Middelares, St.-Niklaas, Belgium 


\section{Abstract}

Pulsed radiofrequency treatment has been described as a minimal invasive alternative to radiofrequency thermocoagulation for the management of chronic pain syndromes. We present here our first 5 high-risk patients with idiopathic trigeminal neurallgia who were treated with pulsed radiofrequency after multidisciplinary assessment; with a mean follow-up of 19.2 months (range 10-26). These patients were at high risk due to age, co-morbidities or previous interventional and surgical treatments. An excellent long-term effect was achieved in three of the five patients, a partial effect in one patient and a short-term effect in one patient. No neurological side effects or complications were reported. 


\section{Introduction}

Patients suffering from idiopathic trigeminal neuralgia (ITN) that is refractory to pharmacological treatment are candidates for interventional therapy. The three percutaneous procedures are balloon compression, retrogasserian glyceral injection and radiofrequency (RF) thermocoagulation. These procedures are neurodestructive and may be associated with side effects such as sensory loss, dysesthesia, anesthesia dolorosa and corneal anesthesia ${ }^{1-3}$.

Conventional RF treatment, using a constant output of high-frequency electric current applied at the Gasserian ganglion, is documented as one of the most effective interventional techniques when conservative treatment fails ${ }^{3-5}$. Radiofrequency current applied to the nerve creates a friction of molecules, which in turn warms the tissue. This technique uses increasing temperatures starting at $60^{\circ} \mathrm{C}$, thus producing lesions in the ganglion. The size of the lesion will depend on the temperature obtained in the tissue, the duration of the procedure, the size of the noninsulated electrode tip and the electrode diameter. The use of pulsed radiofrequency (PRF) current, whereby the high-frequency current is applied in bursts of $20 \mathrm{~ms}$ with a silent time of $480 \mathrm{~ms}$, allowing elimination of heat, has been documented to be safe

and efficacious in the management of spinal pain ${ }^{6,7}$. Our study reports results from the first five high-risk patients with ITN who were treated in our hospital with PRF of the Gasserian ganglion. To our knowledge no other literature exists on the long-term effects of this new treatment option.

\section{Patients and methods}

Patients presenting to our hospital with refractory trigeminal neuralgia receive a multidisciplinary assessment, with complete neurological evaluation and magnetic resonance imaging. Within this population several patients have multiple co-morbidities: some have already received interventional treatment for ITN. In order to be a candidate for RF or PRF treatment, the conservative, pharmacological treatment options must have been tested for a sufficiently long period to allow the patient to be classified as refractory. All patients had previously been treated with carbamazepine. gabapentin and/or valproic acid without pain relief or with intolerable side effects. PRF was performed in patients who had either undergone other interventional treatments or whose co-morbidity did not justify invasive surgical procedures because of assumed efficacy and safety issues. After providing the patients with complete information regarding the technique and its expected effects and side effects, we obtained their verball informed consent. 
The patient was lightly sedated with propofol and a Sluijter-Mehta thermocouple 10$\mathrm{cm}$ electrode with a 4-mm noninsulated tip was positioned under fluoroscopic guidance as described by Sweet and Wepsic ${ }^{5}$. After verifying the correct position of the needle, the patient was woken up to test the sensory threshold by means of electrostimulation at $50 \mathrm{~Hz}$. The PRF current was then applied for $120 \mathrm{~s}$ with a generator (Radionics, Burlington, MA.) output of $45 \mathrm{~V}$, not exceeding a temperature of $42^{\circ} \mathrm{C}$ at the tip of the electrode. Thereafter the sensitivity of the face and cornea were tested. If required, a second PRF treatment was carried out for a further $120 \mathrm{~ms}$. Patients were followed for efficacy, side effects and complications on a regular basis for up to 2 months. Careful neurological evaluations were performed with special attention for sensory loss and dysesthesia. Long-term follow-up, by an evaluator not involved in patient selection and/or treatment, took place in the middle of 2001; mean follow-up time being 19.2 months (range 10-26 months).

\section{Results}

\section{Patient 1}

A 69-year-old man had suffered from trigeminal neuralgia in the first branch of the trigeminal nerve for 10 years. Previous interventional treatments consisted of retrogasserian glycerol injection and thermocoagulation of the first branch of the trigeminal nerve 2 years prior to PRF treatment. His medical history included aortic valve repair for aortic stenosis. His current episode of ITN had started several months earlier with a sudden flash of pain above the right eye, which was resistant to pharmacological treatment. Triggers for the attacks of pain were cold, wind and eating. Sensory stimulation $(50 \mathrm{~Hz})$ resulted in tingling above the right eye at $0.4 \mathrm{~V}$ and PRF treatment was carried out as described above. Two $120 \mathrm{~ms}$ interventions took place during the same session. The onset of pain relief was reported 1 day after the intervention. At long-term follow-up 20 months after the procedure he was completely pain free. No additional pharmacological or other treatments were required during this period, and no side effects or complications were reported.

\section{Patient 2}

A 68-year-old woman had suffered from painful attacks in the region of the second branch of the trigeminal nerve for 9 months. Her medical history included arterial hypertension, atrial fibrillation and implantation of a pacemaker. She experienced very painful attacks in her jaw, which were triggered by touch and speaking. The electrode was positioned at the level of the second branch of the left trigeminal nerve. Sensory stimulation $(50 \mathrm{~Hz})$ evoked sensations on the painful site at $0.04 \mathrm{~V}$. A PRF current was applied and resulted in pain relief after 12 days. At long-term 
follow-up 10 months after PRF treatment, she was completely pain free. No additional pharmacological or other treatments were required during this period, and no side effects or complications were reported.

\section{Patient 3}

A 67-year-old woman had experienced trigeminal neuralgia for the past 12 years, which was triggered by touch, eating and colld, and was located in the second and third branch on the right side. She had previously undergone three craniotomies with microvascular decompression (Janetta procedure) in another hospital, and refused to undergo another severe surgical intervention. An extensive pharmacological approach provided insufficient results and, because of sensory changes in the painful area, PRF treatment was proposed. The first attempt had to be interrupted because the position of the electrode in the foramen ovale could not be visualized, and a hematoma developed. Two weeks later a new attempt was made and the electrode could now be positioned at the level of the Gasserian ganglion. Sensations at the painful site were obtained by sensory stimulation at $0.1 \mathrm{~V}$ with $50 \mathrm{~Hz}$. Pulsed radiofrequency treatment resulted in complete analgesia after 20 days, which lasted for up to 4 months; thereafter, low-intensity attacks recurred. Additional carbamazepine ( $800 \mathrm{mg}$ daily) and gabapentin ( $900 \mathrm{mg}$ daily) treatment resulted in good pain relief for many months. Fifteen months after the first PRF treatment a second intervention was performed, this resulted in complete pain relief after 27 days. At long-term follow-up 18 months after the first PRF treatment and 3 months after the second intervention, complete pain relief had been achieved without additional pharmacological treatment. No additional sensory changes or dysesthesia were noted.

\section{Patient 4}

An 81-year-old woman had trigeminal neuralgia for 10 months in the right third branch of the trigeminal nerve. The triggers were cold and eating. Pharmacological treatment was stopped because of intolerance. An electrode was placed at the $V 3$ portion of the Gasserian ganglion. Electrical stimulation at $0.37 \mathrm{~V}$ with $50 \mathrm{~Hz}$ resulted in sensations at the painful site and was followed by PRF treatment, which was performed without any technical difficulties. At the follow-up visit 19 days after the PRF treatment, $90 \%$ pain reduction was noted. At long-term follow-up 22 months after the procedure, she still reported $90 \%$ pain reduction. No additional pharmacological or other treatments were required during this period, and no side effects or complications were reported. 


\section{Patient 5}

A 70-year-old man had suffered from trigeminal neuralgia in the left second branch of the trigeminal nerve for 20 years. In addition to pharmacological treatment he underwent surgical extraction of all his teeth and an RF procedure had been carried out twice in another hospital. In this patient, placement of the electrode at the left V2 portion of the Gasserian ganglion was difficult because of foramen sclerosis. Sensations in the painful region were obtained with sensory stimulation at $0.1 \mathrm{~V}$. Initial pain relief was noted 10 days after the intervention. One month after PRF treatment he experienced a reduction in the number of painful attacks and a $75 \%$ decrease in pain intensity. However, 5 months after the treatment he consulted another pain centre where RF thermocoagulation of the Gasserian ganglion was performed with only minimal additional pain relieving effect. At long-term follow-up, 26 months after the PRF intervention, the patient was referred to the neurosurgeon for microvascular decompression.

\section{Overall results}

Our small series indicates that PRF of the Gasserian ganglion can be effective in terms of pain reduction. Three patients had an excellent (90-100\%) reduction in pain and required no additional pharmacological or interventional treatment. One patient had partial pain relief and needed a second treatment after 15 months to become asymptomatic. The reduction in pain intensity and/or frequency of the attacks was experienced as a major improvement in quality of life. One patient had only short-term pain relief, which was not improved after an additional conventional thermocoagulation treatment. No neurological or other complications were observed. Pulsed radiofrequency of the Gasserian ganglion is a percutaneous minimal invasive procedure, which was safe and well tolerated in our high-risk patients. 


\section{Discussion}

The treatment of patients with intractable ITN is often a challenge in clinical practice. Within a multidisciplinary pain center, different treatment options exist. The pharmacological approach remains the first step therapy. When this treatment fails, or intolerable side effects occur, a choice can be made between the interventional and sur. gical approach. The microvascular decompression technique, which was first described by Janetta, is the most common performed (open) surgical treatment ${ }^{*}$. It consists of opening a keyhole in the mastoid area and freeing the trigeminal nerve from the compression/pulsating artery by a piece of Teflon. The value lies in its potential treatment of the etiology rather than the symptoms of the disorder. The published results mention a high success rate, although recurrence can also occur. It is a major surgical intervention at the central nervous system with a small but definitely existing risk for serious peri operative complications including, mortallity $(0.5 \%)$, permanent disability (1\%) and cranial nerve palsies (5\%) according to a recent review $w^{9}$. For those reasons physicians can start with a less invasive percutaneous intervention in their treatment algorithm.

Glycerol injection, balloon compression and conventional RF treatment are described as effective interventional treatment options for ITN. Their mode of action is based on (partial) nerve destruction. Undesired effects depend on the extent of the lesion. These side effects are well documented for conventional RF treatment. Kanpolat et al. ${ }^{3}$ ist $1 \%$ dysesthesia, $0.8 \%$ anaesthesia dolorosa and $5.7 \%$ diminished corneal reflex. Relapse of pain depends on the chosen techniques, with the highest recurrence rate after glycerol injection, but large inter-individual differences are mentioned. Sluijter et al. ${ }^{6}$ pointed out that heat destruction of the nerve could not be the only mode of action of RF treatment because the temperature is only measured at the electrode tip and is known to diminish rapidly at a distance of $1-2 \mathrm{~mm}$. This is consistent with the observation that in patients treated with RF lesions adjacent to the dorsal root ganglion, the sensory loss in the relevant dermatome is only transient whereas the pain relief lasts much longer. During application of RF treatment the generation of heat is not the only event that occurs; the tissue is also exposed to the RF electric field. Such electric fields are known to have a biological effect ${ }^{10}$ which may explain the mode of action of RF although the mechanism is still ill understood.

Radiofrequency may therefore be used in a non-or minimal destructive fashion. Pulsed radiofrequency uses a high generator output for a short period of $20 \mathrm{~ms}$ folllowed by a "silent" period of $480 \mathrm{~ms}$. The heat generated during the active burst can be eliminated during the silent period and temperature at the electrode tip does not exceed $42^{\circ} \mathrm{C}$. The use of conventional RF treatment in the management of trigemi- 
nal neuralgia is more extensively documented. However, possible side effects and complications, justify the use of the less invasive PRF treatment option. Our case reports indicate that PRF treatment for ITN can be an alternative to other percutaneous techniques. It is minimally invasive and we did not observe neurological side effects or complications. In current clinical practice we discuss both treatment options with the patients, who make an informed choice. Further trials are required to define criteria for the correct patient selection. 


\section{References}

1. Apfelbaum RI. Advantages and disadvantages of various techniques to treat trigeminal neuralgia., Trigeminal neuralgia, Edited by Rovit RL, Murali, R \& Jannetta, PJ.Baltimore, Williams \& Wilkins, 1990 , pp 239-250,

2. Fraioli $B$, Esposito $V$, Guidetti $B$, Crucci $C$, Mangredi $M$. Treatment of trigeminal neuralgia by thermocoagulation, glycerolization and percutaneous compression of gasserian ganglion and or retrogasserial rootlets: Long term results and therapeutic protocol. Neurosurgery 1989; 24 : 239-245

3. Kanpolat $Y$, Savas A, Bekar $A$, Berk $C$. Percutaneous Controlled Radiofrequency Trigeminal Rhizotomy for the Treatment of Idiopathic Trigeminal Neuralgia: 25- years. Experience with 1600 Patients. Neurosurgery 2001; 48: 524-534

4. Jho HD, Lunsford LD. Percutaneous retrogasserian glycerol rhizotomy. Current technique and results. Neurosurg Clin N Am 1997; 8: 63-74

5. Sweet WH, Wepsic JG. Controlled thermocoagulation of trigeminal ganglion and root for differential destruction of pain fibers. Part l: Trigeminal neuralgia. J Neurosurg 1974; 39: 143-156

6. Slujiter $M E_{1}$ Cosman $E_{n}$ Rittman II WB, van Kleef $M$. The effects of pulsed radiofrequency field applied to the diorsal root ganglion - a preliminary report. The Pain Clinic 1998; 11: 109. 117

7. Munglani R. The longer term effect of pulsed radiofrequency for neuropathic pain. Pain 1999; 80: $437-439$

8. Jannetta P. Arterial compression of the trigeminal nerve at the pons in patients with trigeminal neuralgia. J Neurosurg 1967; 26: 159-162

9. Louw DF, Burchiel K. Surgical Treatment of Trigeminal Neuralgia, Bonica's Management of Pain, 3rd. Edited by Loeser JD. Philadelphia, Lippencott "Williams \& Wilkins, 2001, pp 20352047.

10. Archer $S, L i T T$, Evans AT, Britland ST, Morgan H. Cell reactions to dielectrophoretic manipulation. Biochem Biophys Res Comm 1999; 257: 687-698 
CHAPTER VII

Percutaneous pulsed radiofrequency treatment of the cervical dorsal root ganglion in the treatment of chronic cervical pain syndromes: A clinical audit

Van Zundert J, MDa,d; Lamé IE, MSca " de Louw A, MD" Jansen J, MDa: Kessels F, MD, MSc c; Patijn J, MD, PhD; ${ }^{a}$, van Kleef M, MD, PhDa

a. Department of Anesthes iology and Pain Management, University Hospital Maastricht, Maastricht, The Netherlands b. Department of Neurology, Uniwersity Hospital Maastricht, Maastricht, The Nethertands c. Chinical Epidemiology and Medical Technology Assessment, University Hospital Maastricht, Maastricht, The Netherlands d. Department of Anesthesiology" Critical Care and Multidisciplinary Pain Center, ZOL; Genk. Bielghum 


\section{Abstract}

\section{Background}

Cervicogenic headache and cervicobrachialgia are frequent diagnoses of chronic cervical pain. After failure of conservative treatment, an interventional approach may be indicated in the absence of any indication for causal surgical treatment. The pulsed radiofrequency technique exposes the nerve to a high-frequency electric field while the temperature of the electrode tip does not exceed $42^{\circ} \mathrm{C}$. This method is thought to be nondestructive, and almost free of neurological side effects and complications. Our extended pilot study was performed to confirm the perceived efficacy of pulsed radiofrequency for short- and long-term relief of chronic cervical pain.

\section{Methods}

We carried out a clinical audit of the first 18 patients treated with pulsed radiofrequency at the cervical dorsal root ganglion. An independent evaluator reviewed the medical records. Patients with good clinical results at 8 weeks were evaluated for long-term effect ( $>6$ months), based on a 7-point Likert scale.

\section{Results}

Thirteen patients (72\%) showed short-term clinical success ( $\geq 50 \%$ pain relief). Mean follow-up was 19.4 months (SD 8.9 months), maximum 2.5 years. The duration of satisfactory pain relief ( 6 or 7 on the Likert scale) varied between 2 and over 30 months, with a mean duration of 9.2 months (SD 11.2 months). Kaplan-Meier analysis illustrated that $50 \%$ of patients experienced success 3 months after treatment. We could not identify predictive variables for clinical outcome. None of the patients reported post-treatment neuritis or other adverse events.

\section{Conclusions}

To our knowledge, this is the first documented series of chronic cervical pain syndromes treated with PRF. Satisfactory pain relief of at least $50 \%$ was achieved in $13 / 18(72 \%)$ patients at 8 weeks. More than 1 year after treatment, six patients (33 $\%)$ continue to rate treatment outcome as good or very good. No side effects were reported. 


\section{Introduction}

Cervical pain is a common complaint in medical practice ${ }^{4,2}$. The prevalence of this type of pain in the general population is estimated as $34.4 \%$ and $13.8 \%$ reported neck pain that lasted for more than 6 months ${ }^{3}$. The pain is well localized in the majority of patients, and can be defined as mechanical neck pain that originates in the facet joints or the intervertebral disk ${ }^{4}$. Sometimes the cervical pain syndrome is more complex and is accompanied by involvement of a segmental nerve. This may change the clinical picture into cervicobrachialgia or cervicogenic headache. When conservative treatment fails to provide satisfactory pain relief, invasive, nonsurgical treatment may be indicated. Radiofrequency (RF) thermolesions $\left(67^{\circ} \mathrm{C}\right.$ ) adjacent to the dorsal root ganglion (DRG) have been described as a treatment option for cervicobrachialgia $^{5,6}$. This treatment is well documented, but remains controversial due to the potential hazard of neurological complications. Moreover, the positive results described by several authors ${ }^{5-9}$ may be subject to debate because of the small number of controlled trials and their clinical and technical heterogeneity, as described by Geurts et al. ${ }^{10}$, who reviewed the available literature and concluded that there is limited evidence that RF heating of the DRG is more effective than placebo in chronic cervicobrachialgia.

In 1998, Sluijter and coworkers ${ }^{8}$ described the use of an isothermal RF treatment. This technique, known as pulsed radiofrequency (PRF) treatment, is not thought to destroy the nerve tissue. This therapeutic option could prove more attractive for the management of chronic spinal pain, including neuropathic pain syndromes, compared with conventional RF thermolesions ${ }^{8.41}$. In this paper, we present the results of a clinical audit of PRF treatment applied to the cervical DRG for the management of patients suffering from chronic cervicobrachialgia or cervicogenic headache refractory to conventional treatment. 


\section{Materials and methods}

Between January 1998 and June 2000, patients with chronic cervicogenic headlache or cervicobrachialgia were included in this clinical audit provided they met the following criteria:

A history of chronic pain in the cervical region for over 6 months, radiating to the head or shoulder and/or arm

- Unsatisfactory pain control with oral pharmacotherapy

- Documentation of sufficient conservative treatment such as physical or manual therapy, transcutaneous nerve stimulation, and/or a rehabilitation program

- Age over 18 years

- Temporary pain relief after a diagnostic segmental nerve block

- Ability to understand the information provided

- Informed consent

At intake the neurologist screened the patients to detect exclusion criteria: systemic disease, a tumor or clinically demonstrable neurological deficit, andior signs of radicular compression. This audit is an evaluation of a modified technique, based on two endpoints, short and long-term, for the first 18 patients responding to the inclusion criteria. Patients were treated after having received full oral information about the procedure and possible side effects. Diagnostic segmental nerve blocks were performed at weekly intervals at all relevant levels to the localization of the pain. These blocks included segmental levels $\mathrm{C} 2-\mathrm{C} 3$ for cervicogenic headache and C4$\mathrm{C} 7$ for cervicobrachialgia. Patients who had at least $50 \%$ pain relief, measured by the 7-point Likert scale ${ }^{12,13}$ were selected for treatment according to a standardized protocol.

In the Maastricht University Hospital patients' data are collected on a standardized form and close supervision guarantees compliance for recording all the relevant information. For this clinical audit two evaluations were performed by an independent person, not involved with patient selection and treatment.

The first evaluation was done retrospectively 8 weeks after the intervention, when patients normally attend the pain clinic for evaluation. The response to treatment was abstracted from the record cards. This evaluation was considered the primary endpoint. Patients with at least $50 \%$ pain reduction at this point were included for the second evaluation. The second evaluation to investigate the long-term effect was done at a given point in time, minimum 6 months after the last patient was in- 
cluded. Patients were interviewed regarding treatment satisfaction, using the 7-point Likert scale, the duration of satisfactory pain relief and the requirement of other adjuvant treatments.

The main objective of this clinical audit was to evaluate the clinical results and the side effects of this technique applied in patients with cervical pain syndromes, prior to setting up a randomized controlled trial.

\section{Technique for diagnostic segmental nerve block and assessment}

A viewing technique was used to perform diagnostic segmental nerve block, with the C-arm of the fluoroscopy unit (Philips BV 25, Eindhoven, The Netherlands) positioned in such a way that the X-rays were parallel to the axis of the intervertebral foramen. The axis points $25-35^{\circ}$ anterior and $10^{\circ}$ caudal. With the $\mathrm{C}$-arm in this position, the entry point was located by projecting a metal ruler over the caudal part of the foramen. A $60 \mathrm{~mm} 24 \mathrm{G}$ neurography needle (Cotop International BV, Amsterdam, The Netherlands) was carefully introduced parallel to the beam of the X-rays. The direction of the $X$-rays was then changed to the antero-posterior position and the cannula introduced further until the tip projected just lateral to the facetal column. After the segmental nerve had been identified with $0.4 \mathrm{ml}$ iohexol contrast medium, $0.5-1 \mathrm{ml}$ of $2 \%$ lignocaine was slowly infiltrated around the nerve $\mathrm{e}^{5,6}$. Accidental overfiow into the epidural space was avoided by close observation of the radioopaque mixture (Fig. 1). Pain relief was assessed 30 minutes after the procedure. Three or more adjacent levels were blocked, with an interval of 1 week between each block. Patients who had a positive response to the prognostic block (at least $50 \%$ temporary pain relief measured by the 7-point Likert scale) were selected for PRF treatment of the cervical DRG. The level that provided the best analgesic response was selected for treatment.

\section{Technique for PRF of the cervical DRG}

The technique used was the same as that for the diagnostic blocks ${ }^{5.6}$. The entry point was found by projecting the metal ruler over the caudal and posterior part of the foramen. The cannula (22 G SMK Pole needle $54 \mathrm{~mm}$ with $4 \mathrm{~mm}$ active tip, Cotop International BV, Amsterdam. The Netherlands) was introduced parallel to the beam of the $X$-rays and, if necessary, the approach was corrected whille it was still in the superficial subcutaneous layers until the cannula projected on the screen as a single dot (Fig. 2). 


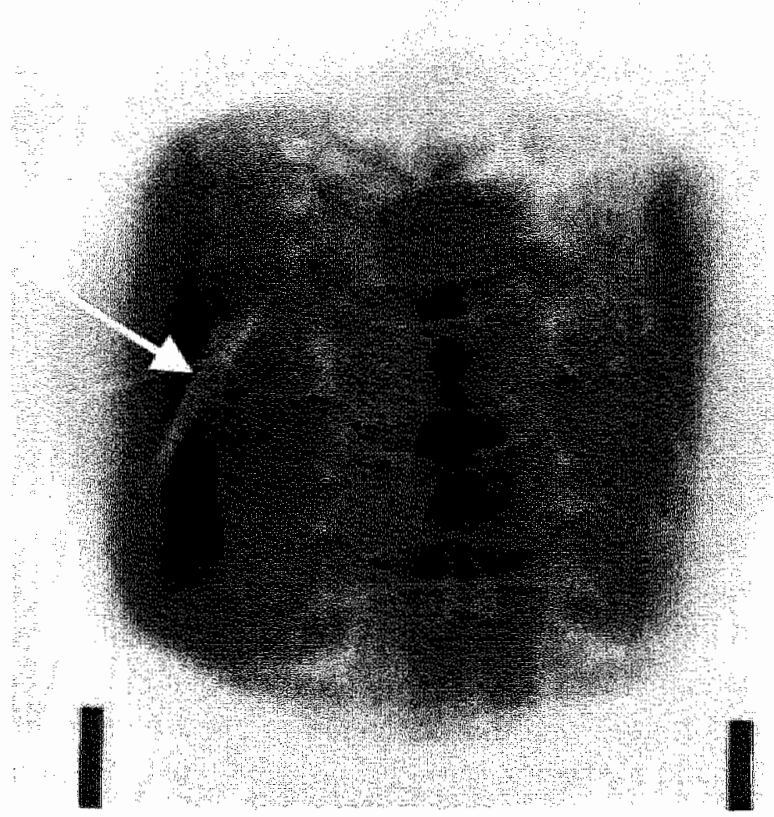

Figure 1: Antero-posterior view after injection of contrast medium. Arrow indicates needle position and spread of contrast medium

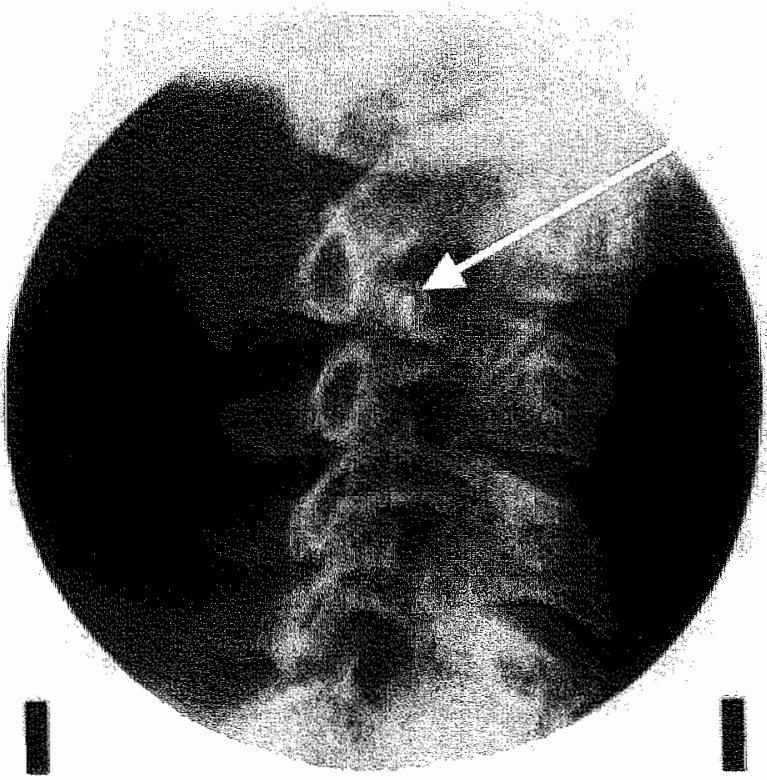

Figure 2: Fluoroscopic image with the $\mathrm{C}$-arm in the lateral-oblique position. Arrow indicates needle position in the posterior caudall quadrant of the neuroforamen. 
In practice, this dot should lie directly over the dorsal part of the intervertebral foramen, the transition between the middle and most caudal third part. This dorsal position was chosen to avoid possible damage to the vertebral artery, which runs anterior to the ventral part of the foramen. The direction of the $X$-rays was then changed to antero-posterior and the cannula was introduced further until the tip projected over the middle of the facetal column (Fig. 3).

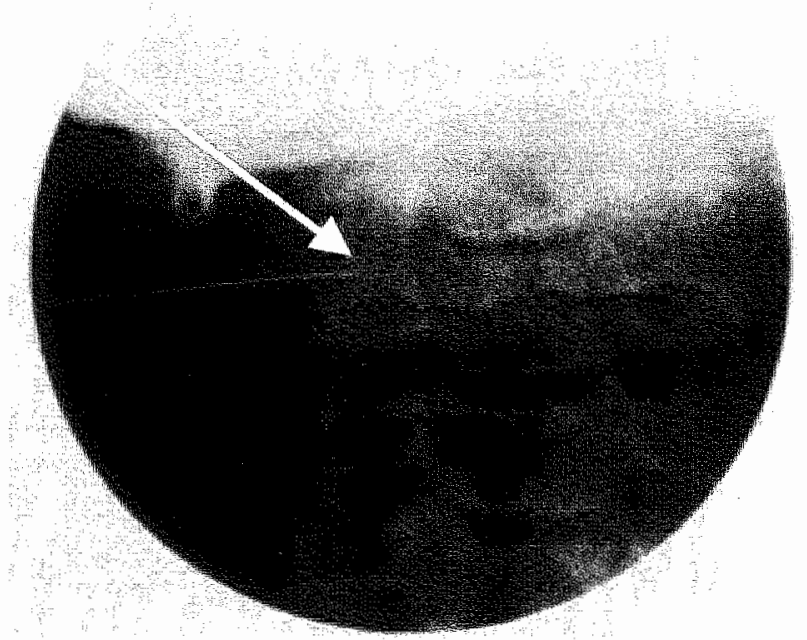

Figure 3: Pulsed radiofrequency of the cervical dorsal root ganglion. Arrow indicates final needle position in the antero-posterior view.

The stylet was then replaced by the RF probe (SMK-TC 5, Radionics, Burlington, MA). After checking the impedance, indicating a normal closed electrical circuit, stimulation was started at a rate of $50 \mathrm{~Hz}$ to obtain a sensory stimulation threshold. The patient should feel a tingling sensation at $<0.5 \mathrm{~V}$, indicating a limited variability of the distance to the DRG in all the patients ${ }^{14}$.

The PRF current produced by the lesion generator (Radionics RFG 3C Plus) was then passed through the electrode. In order to deliver a high-frequency current at 45 $V$ for $20 \mathrm{~ms}$, and to allow the heat to be washed out by the circulation within $480 \mathrm{~ms}$, the total duration of pulsed application of the electrical current was $120 \mathrm{~s}$. During each procedure of PRF treatment temperature, impedance, voltage, wattage and current density (amperage) are continuously monitored. The output will be adjusted in order not to exceed the $42^{\circ} \mathrm{C}$. This temperature is defined as a maximal temperature and not as a target temperature. 


\section{Evaluation criteria}

Evaluation was based on a standardized 7-point Likert scale (global perceived ef$\left.f_{e c t}\right)^{12.13}$. An independent evaluator who had not been involved in patient selection or treatment evaluated the patients at 8 weeks (primary endpoint) and at long term: $>6$ months (secondary endpoint).

The patient was asked to score the treatment outcome according to the questionnaire illustrated in Table 1. Successful treatment was defined as a score of 6 or 7 on the Likert scale ${ }^{12,93}$.

Table 1: Likert scale 7-point scoring system: Global perceived Effect

\begin{tabular}{lll}
\hline Score & $\%$ Change & Description \\
\hline 7 & $\geq 75 \%$ improvement & Very good \\
6 & $50-74 \%$ improvement & Good \\
5 & $25-49 \%$ improvement & Fairly good \\
4 & $0-24 \%$ improvement or worse & Same as before \\
3 & $25-49 \%$ worse & Fairly bad \\
2 & $50-74 \%$ worse & Bad \\
1 & $\geq 75 \%$ worse & Very bad \\
\hline
\end{tabular}

We recorded the medical history and diagnosis, the results of the diagnostic blocks, treatment details, side effects, and use of pain medication. The primary endpoint was defined as at least $50 \%$ improvement on the Likert scale after 8 weeks. Analysis of possible predictive variables for treatment outcome in the study population or treatment modalities was included. The secondary endpoint ( $>6$ months), which assessed long-term efficacy, was evaluated using the 7-point Likert scale. Patients were also questioned about the duration of the effect, other treatments, and use of pain medication.

\section{Statistics}

The primary endpoint was the percentage success at 8 weeks. The Chi-square and, if appropriate, the Fisher exact tests were used to compare this success rate between different prognostic groups. A value of $p<0.05$ was considered to be statistically significant. A Kaplan-Meier survival curve was constructed to determine the time-dependent success rate ${ }^{15}$. 


\section{Results}

Eighteen consecutive patients, admitted to the "third line referral" university pain management center, were included in this clinical audit. PRF treatment was performed at the $\mathrm{C} 2$ level in 4 patients, $\mathrm{C} 3$ in two, C4 in two, C5 in four, C6 in three, and $\mathrm{C} 7$ in three. Patients' demographics, the duration and diagnosis of pain, use of medication at intake and follow-up, level of treatment, score on the 7-point Likert scale, duration of effect, and consecutive invasive treatment are described in Table 2. The mean duration of long-term follow-up after treatment was 19.4 months (SD 8.9 ; range 6-30 months).

Five men and 13 women with a mean age of 50.3 (range 27-77) years were included in this study. Six patients had chronic cervicogenic headache and 12 had chronic cervicobrachialgia, the duration of which ranged from $<1-40$ years. The origin of the complaints was identified as post-traumatic in 6 patients, degenerative in 9 , and failed neck surgery syndrome and complex regional pain syndrome $\|$ in one patient each. Twelve patients were using analgesic medication: 7 were taking mild analgesics (WHO class I) and five were on weak opioids (WHO class II). None of the patients was on strong opioids (WHO class III). Six patients were no longer taking any pain medication at the time of PRF treatment, because of lack of effect or too many side effects. All patients had received previous conservative treatment defined as oral pharmacotherapy, manual or physical therapy, and transcutaneous electric nerve stimulation. Two patients had previously undergone surgery and 12 had earlier interventional pain management consisting of cervical epidural steroid injections ( $N=3$ ), RF neurotomy of the cervical facet joints $(N=6)$, or conventional RF lesions adjacent to the cervical DRG at a different level $(N=3)$. We concluded that the chronic cervical pain was intractable in all patients to other treatment options, including other interventional pain management techniques. 
Table 3: Analysis of the Study Population Subgroups

\begin{tabular}{|c|c|c|c|}
\hline$N=18$ & $\begin{array}{l}\text { Pain reduction successful } \\
N=13\end{array}$ & $\begin{array}{l}\text { Pain reduction not successful } \\
N=5\end{array}$ & $P$ value \\
\hline $\mathrm{Age}^{*}$ & $53,2($ sd 10,4$)$ & $43,0($ sd 9,3$)$ & 0,05 \\
\hline Sex & & & 0,58 \\
\hline Male & $3(60 \%)$ & $2(40 \%)$ & \\
\hline Fernale & $10(77 \%)$ & $3(23 \%)$ & \\
\hline Neuropathic pain & & & 0,28 \\
\hline No & $9(64 \%)$ & $5(36 \%)$ & \\
\hline Yes & $4(100 \%)$ & 0 & \\
\hline PRF level & & & 0,27 \\
\hline $\mathrm{C}_{2} \cdot \mathrm{C}_{3}$ & $3(50 \%)$ & $3(50 \%)$ & \\
\hline $\mathrm{C} 4-\mathrm{C7}$ & $10(83 \%)$ & $2(17 \%)$ & \\
\hline Duration of pain & & & 0,28 \\
\hline$\leq 1$ year & $4(100 \%)$ & 0 & \\
\hline$>1$ year & $9(64 \%)$ & $5(36 \%)$ & \\
\hline Treaiment before & & & 0,53 \\
\hline Conservative & $2(50 \%)$ & $2(50 \%)$ & \\
\hline Invasive & $11(79 \%)$ & $3(21 \%)$ & \\
\hline Medicines at intake & & & 1,0 \\
\hline No or light & $9(69 \%)$ & $4(31 \%)$ & \\
\hline Heavy & $4(80 \%)$ & $1(20 \%)$ & \\
\hline
\end{tabular}

* Two-talled test. SD, standard deviation; PRF, pulsed radiofrequency

Table 4: Results of primary and secondary evaluation: Number and percentage $(95 \% \mathrm{Cl})$ of patients with ongoing pain relief after pulsed radiofrequency treatment of the cervical dorsal root ganglion

\begin{tabular}{llll}
\hline$N=18$ & $6-8$ weeks & $3-11$ months & $\geq 1$ year \\
\hline Number of patients & 13 & 10 & 6 \\
Percentage $(95 \% \mathrm{Cl})$ & $72(50$ to 94$)$ & $56(33$ to 80$)$ & $33(11$ to 55$)$ \\
\hline
\end{tabular}


Survival probabilities, using the Kaplan-Meier method, are usually presented as a survival curve $^{15}$. The Kaplan-Meier curve of the probability of successful treatment as a function of time illustrates that $50 \%$ of patients experienced a successful result 3 months after treatment. The "curve" is a step function, with sudden changes in the estimated probability corresponding to times at which an event (return to $<50 \%$ pain reduction) was observed (Fig. 4).

Figure 4: Kaplan-Meier curve of the probability of success

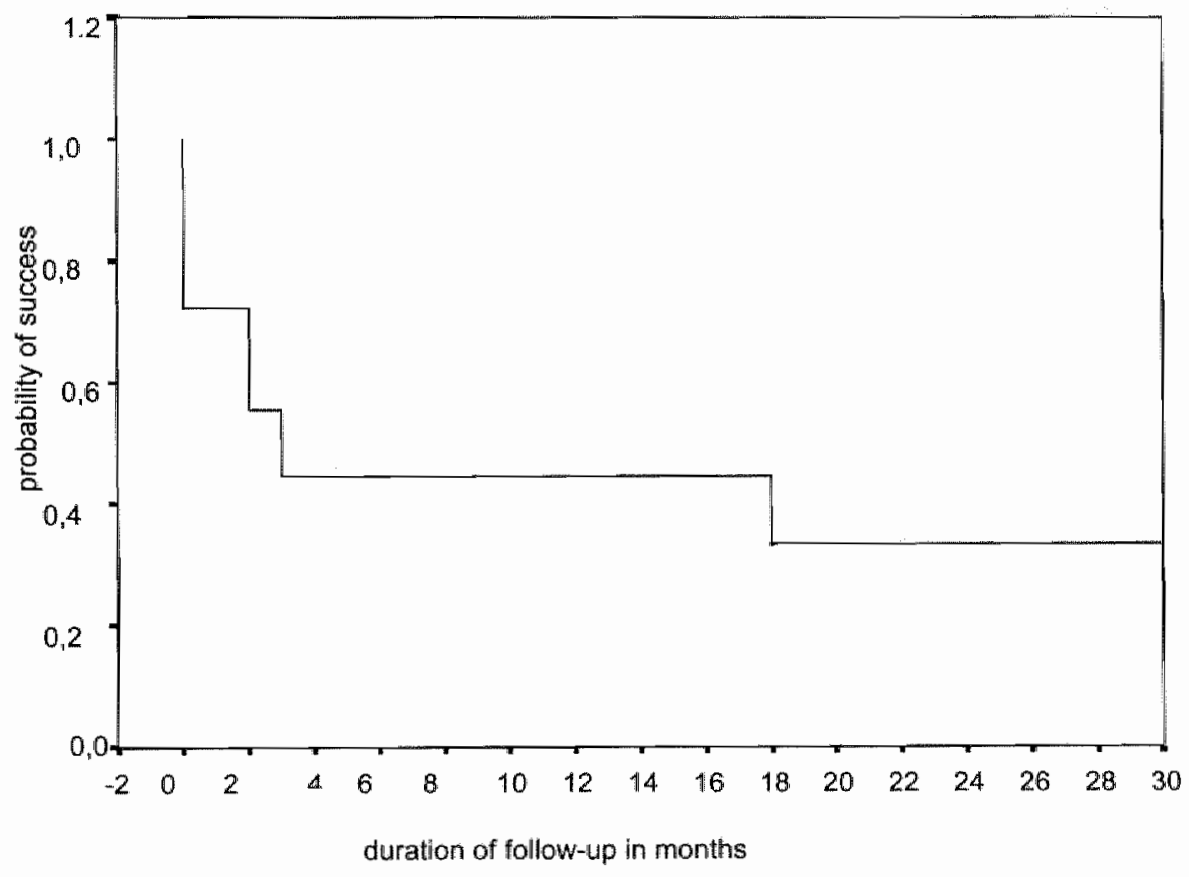




\section{Discussion}

Several authors have reported that patients with intractable cervicobrachialgic pain could be treated with a RF lesion adjacent to the cervical $\mathrm{DRG}^{5-7,9.16}$. Its application in chronic non-cancer pain remains controversial because of the presumed neurodestructive action of this technique and the potential side effects.

Pulsed radiofrequency has recently been described as a nondestructive alternative to RF thermocoagullation for the management of chronic spinal pain syndromes ${ }^{8.11}$. Sluijter et al. ${ }^{8}$ pointed out that heat destruction of the nerve did not fully explain the clinical findings seen after RF treatment, as generation of heat is not the only event that occurs during application of such treatment. The tissue is also exposed to the RF electric field, and such electric fields are known to have a biologic effect ${ }^{17}$. Radiofrequency treatment may therefore be used in a nondestructive, pulsed fashion whereby the temperature of the electrode tip does not exceed $42^{\circ} \mathrm{C}$. This is achieved by exposing the nerve to a high-frequency electric field of $45 \mathrm{~V}$ during only $20 \mathrm{~ms}$ per $500 \mathrm{~ms}$, allowing the $480 \mathrm{~ms}$ pause to eliminate the heat generated during the active cycle. This technique is thought to be nondestructive to nerve tissue.

This paper reports the results of a clinical audit of the first consecutive 18 patients who presented to our hospital with intractable cervicobrachialgia and who were treated with PRF of the cervical DRG. Patient population and selection were comparable to those of van Kleef and Slappende $\left.\right|^{5,6,9}$.

In an open, nonrandomized study, van Kleef et al. ${ }^{5}$ also defined clinical success as $>50 \%$ pain reduction, which was obtained in $50 \%, 30 \%$, and $22 \%$, respectively, of patients 3,6 , and 9 months after the intervention, ${ }^{6.9}$. The blinding code in the two randomized trials was broken at 3 months, thus limiting the follow-up of both control and active treatment groups to this period. Van Kleef et al. ${ }^{6}$ noted treatment success in eight of nine patients in the group treated at $67^{\circ} \mathrm{C}$ and one of 11 patients in the control group. In the active group the mean pain reduction measured on the visual analogue scale reached statistical significance $(p<0.01)^{6}$. Slappendel et all. ${ }^{9}$ noted a reduction of at least 2 points on the visual analogue scale at the 3-month follow-up in $47 \%$ and $51 \%$ of patients in the $67^{\circ} \mathrm{C}$ and $40^{\circ} \mathrm{C}$ groups, respectively ${ }^{9}$.

These results seem to be of the same order of magnitude as the results in our series of patients. Whether the application of heat will have an additional effect is a question that cannot be answered on the basis of the data presently available.

Conventional RF treatment caused burning pain in $60 \%$ of patients and hyposensitivity of the dermatome in $35 \%$ in the open study carried out by van Kleef et al. ${ }^{5}$. 
These side effects were still present at 3 weeks but resolved spontaneously at 6 weeks. In the controlled study ${ }_{n}^{6}, 77 \%$ of patients mentioned a vague burning sensation in the treated dermatome, which lasted for a mean of 17 days. Slappendel et all. ${ }^{9}$ noted neuritis in six of 32 and five of 29 patients, respectively, in both treatment groups. In our series no such side effects were noted, nor were there any neurological complications. Until now animal experiments could not show a neurodestructive character of $\mathrm{PRF}^{18,19}$. With $\mathrm{RF}$ lesions adjacent to the $\mathrm{DRG}$ the temperature at the electrode tip increases slowly to $67^{\circ} \mathrm{C}$, aiming at selective destruction of the nerves. It has been suggested that these lesions predominantly interrupt the small-fiber system, leaving the large-fiber system intact ${ }^{20}$. A recent morphologic study could not confirm these findings; moreover, when the lesion is adjacent to the DRG, no objective signs of coagulation are observed inside the ganglion ${ }^{21}$. The morphologic findings of de Louw et al. ${ }^{21}$ are in line with the clinical results observed by Slappendel et al. ${ }^{9}$, suggesting absence of any relationship between the temperature used for thermal lesioning and the desired clinical effect.

The alternative isothermal PRF treatment described by Sluijter et al. ${ }^{8}$ has recently been compared in animal experiments with continuous treatment at $38^{\circ} \mathrm{C}$. In PRF applied to the DRG of the rat, c-Fos, a marker of neuronal activation, was expressed in lamina I and II of the corresponding part of the dorsal horn, which was not observed after continuous treatment at $38^{\circ} \mathrm{C}^{18}$. This implies that in PRF treatment adlacent to the DRG the effects of exposure to electric fields are transmitted to more central neurons. Additionally, tissue impedance reportedly has an influence on the effect of PRF treatment ${ }^{22}$. 


\section{Conclusions}

This clinical audit, which reports the first results obtained with PRF treatment adjacent to the cervical DRG, does not allow us to draw definite conclusions. But the satisfactory pain relief obtained in the majority $(72 \%)$ of our patients justifies the start of a randomized controlled trial (RCT). In addition, further research is needed on the required exposure time and voltage and on the role of tissue impedance.

\section{Acknowledgements}

The authors thank Dr. W. Weber, MD, PhD, who was the neurologist in the Department of Pain Therapy during the study, for screening the patients. 


\section{References}

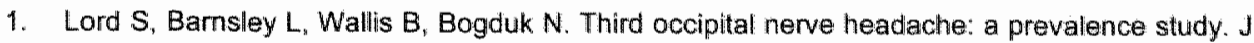
Neurol Neurosurg Psychiatry 1994; 57: 1187-1190

2. Bland J. Cervical spine syndromes. J Muscoloskel Med 1986; 3: 23-41

3. Bovim G, Schrader H, Sand T. Neck pain in the general population. Spine 1994; 19(12): 13071309

4. Bogduk N, Aprill C. On the nature of neck pain, discography and cervical zygapophyseal joint blocks. Pain 1993; $54: 213-217$

5. wan Kleef $M$, Spaans F, Dingemans W, Barendse GAM, Floor E, Sluiller ME. Effects and side effects of a percutaneous thermal lesion of the dorsal root ganglion in patients with cervical pain syndrome. Pain $1993 ; 52: 49-53$

6. wan Kleef $M$, Liem $L$, Barendse $G$, Kessels $F$, Sluijter ME. Radiofrequency lesion adjacent to the dorsal Root Ganglion for Cervicobrachial pain: a prospective double blind randomized study. Neurosurgery 1996; 38: 1127-1132

7. Sluijter ME, Koetsveld-Baart CC. Interruption of pain pathways in the treatment of the cervical syndrome. Anaesthesia 1980; 35: 302-307

8. Sluijter ME, Cosman ER, Rittman II WB, van Kleef $M$. The effects of pulsed radiofrequency field applied to the dorsal root ganglion - a preliminary report. The Pain Clinic 1998; $11: 109$ 117

9. Slappendel R, Crul BJ, Braak GJJ, Geurts JW, Booij LHDJ, Voerman VF, de Boo T. The efficacy of radiofrequency lesioning of the cervical spinal dorsal root ganglion in a double blinded randomized study: no difference between $40^{\circ} \mathrm{C}$ and $67^{\circ} \mathrm{C}$ treatments. Pain 1997; $73: 159-163$

10. Geurts J, van Wijk RM, Stolker R, Groen GJ. Efficacy of radiofrequency procedures for the treatment of spinal pain: a systematic review of randomized clinical trials. Reg Anesth Pain Med 2001; 26: 394-400

11. Munglani $R$. The longer term effect of pulsed radiofrequency for neuropathic pain. Pain 1999; 80: $437-439$

12. Farrar JT, Jr. JPY, LaMoreaux L, Werth JL, Poole RM. Clinical importance of changes in chronic pain intensity measured on an 11-point numerical scale. Pain 2001; 94: 149-158

13. Likert R. A technique for the measurement of attitudes. Archives of Psycalogy $1932 ; 22: 140$

14. Ford DJ, Pither $C$, Raj PP. Comparison of insulated and uninsulated needles for locating peripheral nerves with a peripheral nerve stimulator. Anesth Analg 1984; 63: 925-928

15. Bland J, Altman D. Survival probabilities (the Kaplan-Meier method). BMJJ 1998; 317 : 1572

16. Vervest $A_{*}$ Stolker $R$. The treatment of cervical pain syndromes with radiofrequency procedures. Pain Clinic 1991; 4: 103-112

17. Archer $\mathrm{S}, \mathrm{Li}$ TT, Evans AT, Britland ST, Morgan H. Cell reactions to dielectrophoretic manipulation. Biochem Biophys Res Comm 1999; 257: 687-698

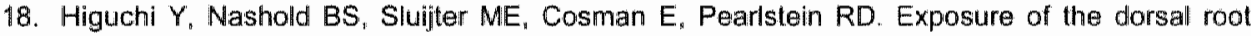
ganglion in rats to pulsed radiofrequency currents activates dorsal horn lamina I and II neurons. Neurosurgery 2002; 50: 850-856

19. Cahana A, Muller D. Pulsed radiofrequency (PRF) but not radiofrequency lesions, transiently modulates excitatory synaptic lesions, transiently modulates excitatory synaptic transmissian in organotypic nervous tissue cultures. The Journal of Pain 2002; Abstracts of the 21st Amnual Scientific Meeting, American Pain Society March 14.17:

20. Letcher FS, Goldring S. The effect of radiofrequency current and heat on peripheral nerve action potential in the cat. J Neurosurg 1968; 29: 42-47

21. de Louw AJA, Vles HSH, Freling G, Herpers MJHM, Arends JW, van Kleef M. The morphological effects of radiofrequency lesion adjacent to the dorsal root ganglion (RF-DRG) - An Experimental study in the goat. Eur. J. of Pain 2001; 5: $1691-174$

22. Sluijter ME. Radiofrequency part I, Flivopress, Meggen, Switzerland, 2001, 


\section{Pulsed radiofrequency adjacent to the} cervical dorsal root ganglion in chronic cervical radicular pain: a double blind sham controlled randomized clinical trial

Van Zundert J, MDa,d; Patijn J, MD, PhD; Kessels A, MSc, MD ${ }^{\text {; }}$; Lamé I, MSca; van Suijlekom J, MD, PhDc; van Kleef M, MD, PhDa

a. Department of Anesthesiology, Pain Management and Research Centre. University Hospital Maastricht. Maastricht, The Netherlands b. Clinical Epidemiology and Medical Technology Assessment, University Hospital Maastricht, Maastricht, The Netherland's c. Department of Anesthesiology and Pain

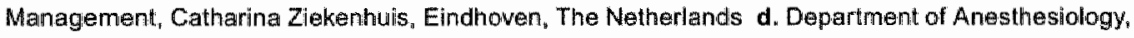
Critical Care and Multicisciplinary Pain Center, Zlekenhuis Oost-Limburg, Genk, Belgium 


\section{Abstract}

\section{Background}

Cervical radicular pain syndromes affect approximately 1 on 1,000 adults per year, and have a high impact on the patient's quality of life. Although many treatment modalities are described in the literature, the available evidence for efficacy is not sufficient to allow definitive conclusions on the optimal therapy to be made. The effect of pulsed radiofrequency treatment for this type of patients was evaluated in a prospective audit that showed pain relief for a mean period of 9.2 months, justifying a randomized sham controlled trial.

\section{Methods}

Two hundred fifty six patients with cervicobrachialgia referred to the multidisciplinary pain centers of the three participating hospitals were screened. Twenty-three patients who met the inclusion criteria were randomly assigned to receive pulsed radiofrequency treatment or a sham intervention adjacent to the relevant cervical dorsal root ganglion. Patients were evaluated by an independent observer before and at 4 weeks, at 3 months and 6 months after the intervention. Primary outcome measurement at 3 months was considered successful if there was a minimum of $50 \%$ improvement of the global perceived effect, a 20-points reduction of pain intensity measured on a 100-point visual analogue scale, and a reduction in intake of pain medication compared to the baseline consumption. Secondary outcome measurements included all the primary outcome parameters measured at 4 weeks and 6 months, and the quality of life after treatment based on the SF-36 questionnaire and the Euroqol at 4 weeks, 3 months and 6 months.

\section{Results}

Eleven patients were assigned to receive pulsed radiofrequency and 12 to receive sham interventions. One patient from the sham group dropped out after the first evaluation. At 3 months the pulsed radiofrequency group showed a significantly better outcome with regard to the global perceived effect and visual analogue scale. The quality of life scales also showed a positive trend in favor of the pulsed radiofrequency group, but significance was only reached in the SF-36 domain vitality at 3 months. The need for pain medication was significantly reduced in the pulsed radiofrequency group after six months. No complications were observed during the study period. 


\section{Discussion}

These study results are in agreement with the findings of our previous clinical audit concluding that pulsed radiofrequency treatment of the cervical dorsal root ganglion may provide a prolonged pain relief in selected patients with chronic cervical radicular pain. Considering the presumed less tissue-destructive nature of pulsed radiofrequency, this therapeutic approach may have a better risk/benefit ratio than direct radiofrequency lesioning in this area. 


\section{Introduction}

Pain in cervical radicular syndromes affects approximately 1 on 1,000 adults per year ${ }^{1}$, and has a high impact on the patient's quality of life ${ }^{2}$. Cervical radicular pain is characterized by radiation from the neck over the posterior shoulder into the upper limb according to a particular segmental pattern. The pain is most commonly caused by an irritation or injury of the cervical spinal roots due to a herniated intervertebral disc or narrowing of the intervertebral foramen ${ }^{3}$. Although many treatment modalities are described in the literature, the available evidence for efficacy is not sufficient to allow definitive conclusions on the optimal therapy to be made $e^{4,5}$. In clinical practice, conservative measures are often the treatment of first choice ${ }^{6}$. In cases of intractable pain, interventional or surgical treatment may be considered as part of a multidisciplinary approach. Radiofrequency (RF) adjacent to the cervical dorsal root ganglion (DRG) has been evaluated in two randomized controlled trials (RCT"s) as treatment for chronic cervical radicular pain that is refractory to conservative therapy ${ }^{7,8}$. According to two systematic reviews, there is limited evidence that RF of the cervical DRG is more effective than placebo in chronic cervical radicular pain $^{9,10}$. In both RCT's diagnosis was made based on clinical and neurological screening methods. However this was not always described in detail, which probably resulted in heterogeneous study populations.

Radiofrequency lesioning adjacent to the DRG remains controversial due to the potential risk of deafferentation syndrome ${ }^{11}$. For this reason a modification of the technique resulting in less neural damage would be more attractive for chronic pain management. In 1998, Sluijter et al. introduced the isothermal RF treatment known as pulsed radiofrequency (PRF) for the relief of chronic pain. The technique consists of application of brief pulses of high-voltage, high-frequency alternating current followed by a silent period to allow for washout of the generated heat in the tissue surrounding the electrode ${ }^{12}$.

The precise mode of action of PRF is not yet clear. Sluijter et al. suggested that the electric field rather than temperature may induce changes in the nerve cells, which may contribute in the observed clinical effect ${ }^{12}$. It has recently been reported that the electric fields generated by PRF may be capable of modifying neuronal membranes ${ }^{13}$. In neurobiollogy studies an early ${ }^{14}$ and $\mid a^{15} e^{15}$ temperature-independent cellular activity was demonstrated in the rat dorsal horn after exposure of the cervical DRG to PRF. Furthermore, the biological effect of PRF appeared to be selective to small diameter $\mathrm{C}$ - and $\mathrm{A}-\delta$-fibers and unlikely to be related to thermal damage ${ }^{16}$. The concept that PRF may produce inhibition of excitatory $\mathrm{C}$-fiber responses using a phenomenon such as long-term depression was proposed in an accompanying 
editorial to be an attractive hypothesis ${ }^{17}$. The author stressed the need for confirmation of the clinical value of PRF in RCT's, which up to now have been lacking.

In a previous clinical audit we reported long lasting pain relief after PRF adjacent to the cervical DRG for the management of chronic cervical radicular pain ${ }^{18}$. The positive therapeutic results of this audit was the reason to perform a sham controlled RCT with follow-up till 6 months in chronic cervical radicular pain to evaluate the efficacy and side effects of PRF treatment. The results of the first RCT on PRF are presented in this chapter.

\section{Methods}

\section{Participants}

Two hundred fifty six patients with cervicobrachialgia referred to the multidisciplinary pain centers of the University Hospital Maastricht, Maastricht. The Netherlands; Ziekenhuis Oost-Limburg, Genk, Belgium and Catharina Hospital, Eindhoven, The Netherlands, were screened for inclusion in the study by one of the two pain physician with at least 5 years experience (JVS and JVZ) under the supervision of a staff neurologist (JP). Because the participating institutions have a function as "third line" referral center for chronic pain patients, most of the patients were referred by medical specialists (neurologists, neurosurgeons, orthopedic surgeons, rheumatologists and rehabilitation physicians).

The institutional ethics review board of each of the participating centers approved the trial.

Patients were eligible for the study if they reported neck pain radiating over the posterior shoulder area to the arm that has been present for more than 6 months and conventional therapy such as; medication, physical therapy and transcutaneous electrical nerve stimulation, was not effective. Their signs and symptoms should suggest involvement of the cervical spinal nerve and be perceived along the affected nerve root. Pain from C5 extends into the upper arm, while that from $\mathrm{C} 6$ and $\mathrm{C} 7$ extends from the neck and shoulder into the forearm and hand. In both instances the pain occurs in the lateral border of the upper limb, but that of $\mathrm{C} 7$ extends more onto the dorsal aspect ${ }^{4,19}$. In order to select a homogeneous patient population "the neurological examination was supplemented with a protocol of physical examination to exclude shoulder-motion restriction. Only patients with a positive Spurling test as a sign of root involvement were included in the study ${ }^{20}$. The average pain intensity measured on a visual analogue scale (VAS) $(0=$ no pain, $100=$ "the worst pain imaginable") should be higher than 35 . 
Medical imaging techniques and electrophysiological studies were performed according to clinical indications, but the results were not used as inclusion criteria because of lack of data on their specificity and sensitivity in the diagnosis of cervical radicular pain. Moreover, prospective studies in asymptomatic subjects have shown abnormal magnetic resonance imaging (MRI) of the cervical spine in $19 \%$ to $28 \%$ of the patients depending on their age ${ }^{21,22}$.

Exclusion criteria were: patients younger then 20 years or older than 75 years, a history of cancer, fractures of the cervical vertebrae, myelopathy, previous cervical fusion or laminectomy, systemic diseases or connective-tissue diseases, diabetes mellitus, coagulation disorders and use of anticoagulants, multiple sclerosis, pregnancy, shoulder pathology, the presence of a cardiac pacemaker or spinal cord stimulator and previous RF or PRF treatment of the cervical DRG. Patients with a score of 45 or higher on the Pain Catastrophizing Scale were first referred to the psychologist for further investigation ${ }^{23}$.

After the clinical diagnosis of cervical radicular pain was made, the segmental level that appearded to be involved was confirmed by three separate diagnostic blocks at the cervical DRG of $\mathrm{C} 5, \mathrm{C} 6$ or $\mathrm{C} 7$ respectively. The technique used was previously described by van Kleef et al. ${ }^{7,24}$. Overflow into the epidural space and intravascular injection was avoided by careful observation of the spread of contrast medium by fluoroscopic real time imaging. After the location of the cervical DRG was confirmed by injecting a small volume (approx. 0.5-1 ml) of iohexol contrast medium (Amersham Health, Cork, Ireland), an equal volume of $2 \%$ lidocaine (AstraZeneca, Karlskoga, Sweden) was slowly injected.

Pain relief was assessed 10,20 and 30 min after the procedure. A diagnostic block was considered positive if it resulted in minimum $50 \%$ pain reduction measured on the VAS within 30 min. The level that responded with the largest pain reduction was selected for intervention (sham or PRF). After having given written informed consent, patients were randomly allocated to one of the two study groups according to a computer-generated randomization list stratified for the centre and in variable block size (2 or 4 patients).

An independent observer provided the treating physician with a sealed envelope numbered in advance according the computer-generated randomization list. The envelope was opened in the operating room as soon as the intervention cannula was positioned in the patient's cervical area. Immediately after the procedure, the randomization form together with the patient's identity and the technical details of the performed intervention were placed in an envelope, which was sealed and returned to the randomization centre. The independent observer, the data manager 
and the neurologist were never present in the operation facility during the treatment, and were thus unaware of the nature of the performed intervention. The sealed envelopes with the codes were opened after the last evaluation of the last included patient.

\section{Intervention technique}

A technique similar to the one for performing diagnostic nerve blocks was used for the interventions ${ }^{7,24}$. The $\mathrm{C}$-arm of the fluoroscopy unit (Philips BV 25, Eindhoven, The Netherlands) was positioned with the beam parallel to the axis of the intervertebral foramen (25-35 anteriorly and $10^{\circ}$ caudally). The entry point was located by projecting a metal ruler over the caudal and posterior part of the foramen. The $22 \mathrm{G}$ cannula (SMK Pole needle $54 \mathrm{~mm}$ with $4 \mathrm{~mm}$ active tip, Cotop International BV, Amsterdam, the Netherlands) was introduced parallel to the beam and, if necessary, the position was corrected in the superficial subcutaneous layers until the cannula was projected on the screen as a single dot. In practice, this dot should lie directly over the dorsal portion of the intervertebral foramen at the transition between the middle and most caudal third. This position was chosen to avoid possible injection into the vertebral artery, which runs anterior to the ventral part of the foramen. The fluoroscope was then adjusted to the anterior-posterior view and the cannula was inserted further until the tip projected over the middle of the facetal column.

The stylet of the cannula was then replaced by the RF probe (SMK-TC 5, Radionics, Burlington, MA). After checking the impedance indicating a normal, closed electrical circuit, stimulation was started at a frequency of $50 \mathrm{~Hz}$ to obtain a sensory stimulation threshold. A paresthesia was elicited along the tested cervical nerve root at less than $0.5 \mathrm{~V}$ in all patients, and was considered to indicate adequate proximity of the $\mathrm{DRG}^{25}$.

The PRF current was applied during $120 \mathrm{~s}$ from the lesion generator (Radionics RFG 3 C Plus, Burlington, MA) as described by Sluijter et al. ${ }^{12}$. During the procedure, the display of the generator was kept out of sight of the patient and auditory signals were turned off. For the sham intervention the identification of the target point and electrode placement proceeded in the same way as for the active treatment. Instead of passing current through the electrode, however the treating physician merely manipulated the generator without starting the procedure. During the intervention the same information regarding start, progress and end of the procedure was provided to both groups of patients. Two experienced pain physicians performed all procedure (21 patients JVZ, 2 patients JVS). Patients had no previous experience of PRF adjacent to the cervical DRG; and the applied current had a frequency outside the sensory range. 
Based on the experience with previous sham-controlled RCT's in our center, and the problems we had observed with patients' long-term adherence to the study protocol, we did not ask the subjects to guess, at the different evaluation points, which treatment they received ${ }^{25}$. Patients experiencing too much pain were offered oral (co)analgesics in an ascending step-wise protocol as rescue treatment.

\section{Outcome measurements}

Evaluations were performed by an independent observer blinded to the subjects' condition and the treatment given at four time points: immediately prior to the intervention (TO) and at 4 weeks (T1), and 3 months (T2) thereafter. Patients with a favorable outcome at $T 2$, were also evaluated 6 months (T3) after the intervention. Pain intensity was assessed by averaging three daily VAS measurements, ranging from 0 to 100 according to Jensen and McFarland ${ }^{27}$ for 4 consecutive days during the week prior to the evaluation visits ${ }^{26}$. The data manager phoned the patient to remind him/her to fill in the pain score diary. Global perceived effect (GPE) was scored by the patient on a 7-point Likert scale (from $\geq 75 \%$ worse = very bad to $\geq$ $75 \%$ improvement = very good) as illustrated in table $1^{28,29}$. The use of pain medication was scored as follows: WHO step I, peripheral anaigesics $=1 ;$ co-analgesics $=$ 1; WHO step II, weak opioids $=2$; WHO step III, strong opioids $=3$. The minimal score for pain medication was 0 , and the maximal score $4^{30}$.

Two validated instruments were used to assess the quality of life; SF-36 ${ }^{31}$ (Dutch version) ${ }^{32}$ and Euroqo $^{33,34}$. Side effects and complications were noted during the intervention, and a neurological examination was performed at each follow-up visit with special attention paid to changes in sensibility in the dermatomes $C 5, \mathrm{C} 6$ and C7 measured by pinprick. Changes from the baseline values were considered anomalous and rated; 0 (normal) to 2 (strong anomaly). 
Table 1: Likert scalle 7-point scoring system: Global perceived Effect

\begin{tabular}{lll}
\hline Score & $\%$ Change & Description \\
\hline 7 & $275 \%$ improvement & Very good \\
6 & $50-74 \%$ improvement & Good \\
5 & $25-49 \%$ improvement & Fairly good \\
4 & $0-24 \%$ improvement or worse & Same as before \\
3 & $25-49 \%$ worse & Fairly bad \\
2 & $50-74 \%$ worse & Bad \\
1 & $275 \%$ worse & Very bad \\
\hline
\end{tabular}

The primary outcome measurement of our trial was success or failure of the treatment 3 months (T2) after the intervention. Success was defined as at least $50 \%$ improvement of the GPE ( 6 or 7 on a 7 -point Likert scale) and 20 points reduction in pain intensity on the VAS score. Improvement was also judged by a reduction in the need for pain medication.

Secondary outcome measurements included all the primary-outcome parameters but measured at 4 weeks (T1) and at 6 months (T3). Patients with a lack of pain relief after 3 months were offered an alternative treatment and considered as a failure for further analysis. The influence of the treatment on the quality of life (QOL). measured by the SF-36 questionnaire and Euroqol at 4 weeks (T1), 3 months (T2) and 6 months (T3).

Six months after termination of the study, patients were contacted by phone to determine whether they had undergone cervical spine surgery since the end of the trial.

\section{Statistical analysis}

According to the experience in our centre with a previous sham controlled RCT on conventional RF in a similar patient population, a 20-point reduction on a 100-point VAS score 3 months after the intervention can be considered clinically relevant ${ }^{7}$. This study indicated that a standard deviation in VAS score of 27 points could be expected. For a power of $80 \%$ and $5 \%$ significance to reject the nil hypothesis (unilateral) 21 patients per treatment group or a total of 42 patients were required.

Analysis of the primary-outcome measurement was by intention to treat. The differences in the baseline values and outcome measurements, GPE, VAS, SF-36 and Euroqol between sham and PRF intervention were analyzed, dependent on the scale of the variable, using the Student's-t-test or the Chi-square test and if appropriate with Fisher's exact test (unadjusted values). To adjust for differences in the baseline values, the analyses are also performed using a multivariate logistic regression model (adjusted values). Consumption of medication was compared using the Man-Whitney-U test. Significance was reached if $P$ was less than 0.05 . 
All authors vouch for the veracity and completeness of the reported data, and all contributed to various aspects of the trial design, data gathering and analysis, and preparation of the manuscript.

\section{Results}

Between February 2002 and September 2004, 256 patients with neck pain radiating into the shoulder and/or arm were referred for the study to the pain clinic of one of the participating centers and were screened for participation. It was estimated that the calculated sample size of 42 patients would be reached after $11 / 2$ year. We stopped the patient recruitement after $21 / 2$ years because ongoing slow inclusion rate. Twenty-three patients were randomly allocated to PRF treatment $(n=11)$ or sham intervention $(n=12)$. The trial profile is illustrated in figure 1. One patient dropped out of the study after the first evaluation point ( 4 weeks). He was treated surgically and his data were considered a failure. The patient baseline characteristics are shown in table 2. There were significant differences in age and VAS scores: in the sham group the patients were older ( 52.9 versus 42 years) and started with a higher VAS score (76.2 vs. 55.7). 
Figure 1: Flow diagram illustrating the patient inclusion and exclusion

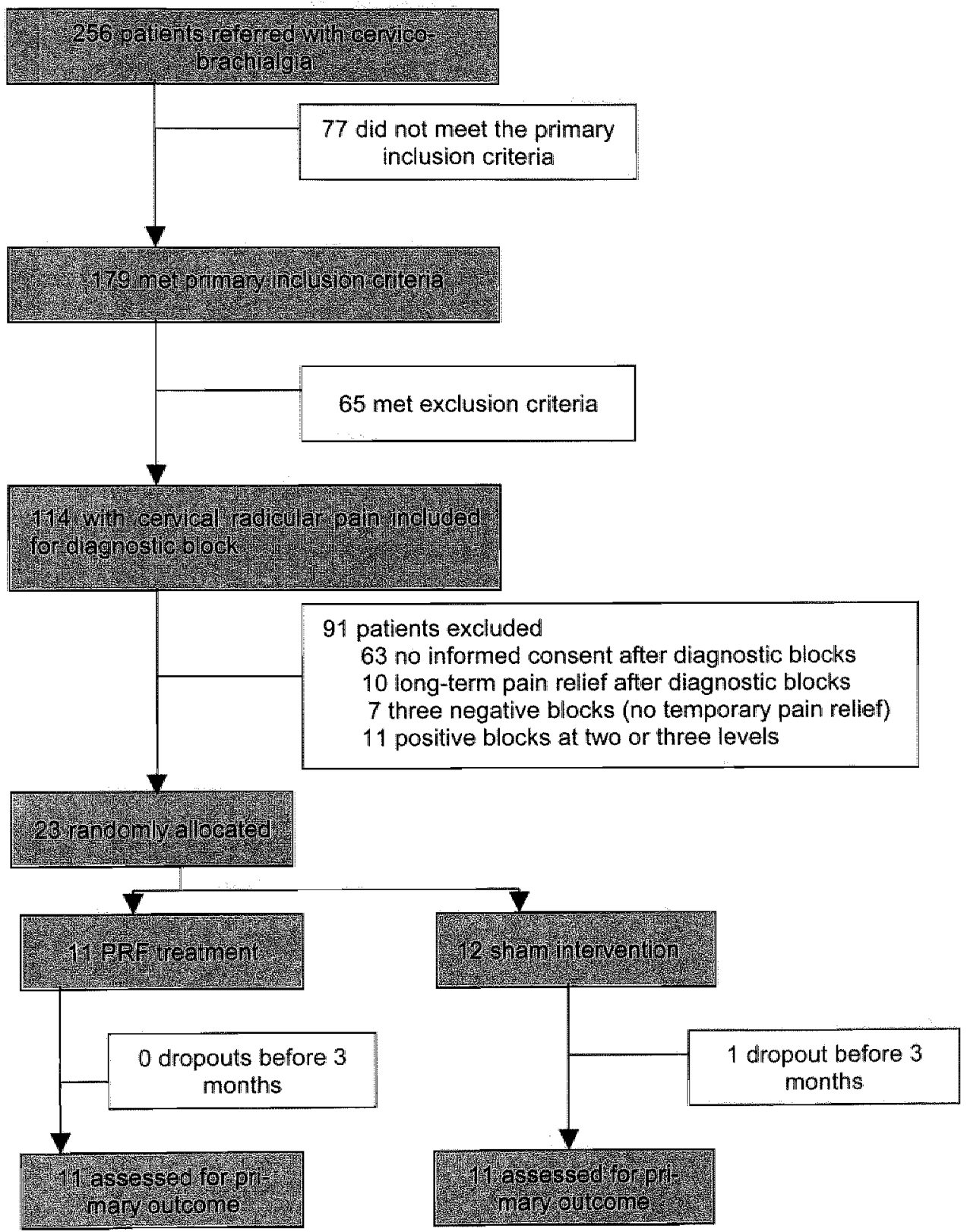


Table 2: Baseline patient characteristics

\begin{tabular}{|c|c|c|}
\hline & $\begin{array}{l}\text { PRF treatment group } \\
n=11\end{array}$ & $\begin{array}{l}\text { Sham treatment group } \\
n=12\end{array}$ \\
\hline Age (years, mean [SD]) & $42[12.2]$ & $52.9[11.9]$ \\
\hline Total duration of pain (months [SD]) & $53.6[40.0]$ & $60.3[65.0]$ \\
\hline PCS (mean [SD]) & $16.6[12.1]$ & $26.2[7.6]$ \\
\hline VAS (mean [SD]) & $55.7[17.3]$ & $76.2[14.2]$ \\
\hline \multicolumn{3}{|l|}{$\mathrm{SF}-36($ mean $[\mathrm{SD}])$} \\
\hline Physical functioning & $68.5[15.3]$ & $50.7[24.6]$ \\
\hline Social functioning & $65.9[25.1]$ & $59.4[28.3]$ \\
\hline Physical role limitations & $22.0[31.3]$ & $8.3[28.9]$ \\
\hline Emotional role limitations & $71.7[41.7]$ & $51.5[50.3]$ \\
\hline Mental health & $74.2[18.3]$ & $63.7[24.7]$ \\
\hline Vitality & $52.7[17.4]$ & $49.2[22.8]$ \\
\hline Pain & $47.1[11.4]$ & $29.1[19.3]$ \\
\hline General health & $71.8 \llbracket 15.2 \rrbracket$ & $48.6[23.1]$ \\
\hline Euroqol (mean [SD]) & $62.6[22.0]$ & $50.3[23.8]$ \\
\hline \multirow[t]{2}{*}{ Medication } & $1.6[1.0]$ & $1.3[1.1]$ \\
\hline & $\mathrm{n}(\%)$ & $n(\%)$ \\
\hline \multicolumn{3}{|l|}{ Gender } \\
\hline Male & $5(46)$ & $5(42)$ \\
\hline Female & $6(54)$ & $7(58)$ \\
\hline \multicolumn{3}{|l|}{ Marital status } \\
\hline Single & $4(36)$ & $1(8)$ \\
\hline Married/living together & $7(64)$ & $11(92)$ \\
\hline \multicolumn{3}{|l|}{ Educational level } \\
\hline Low & $B(73)$ & $7(58)$ \\
\hline Middle/high & $3(27)$ & $4(32)$ \\
\hline \multicolumn{3}{|l|}{ Employment status } \\
\hline Employed & $4(36)$ & $3(25)$ \\
\hline Unemployed & $5(46)$ & $8(67)$ \\
\hline \multicolumn{3}{|l|}{ Medication } \\
\hline No & $2(18)$ & $3(25)$ \\
\hline WHO step I & $2(18)$ & $4(33)$ \\
\hline WHO step II & $5(46)$ & $3(25)$ \\
\hline WHO step III & $2(18)$ & $2(17)$ \\
\hline \multicolumn{3}{|l|}{ Location nerve block } \\
\hline $\mathrm{C5}$ & $3(28)$ & $3(25)$ \\
\hline $\mathrm{c} 6$ & $4(36)$ & $4(33)$ \\
\hline $\mathrm{C7}$ & $4(36)$ & $5(42)$ \\
\hline \multicolumn{3}{|l|}{ Treatment location } \\
\hline Left & $7(64)$ & $8(67)$ \\
\hline Right & $4(36)$ & $4(33)$ \\
\hline
\end{tabular}




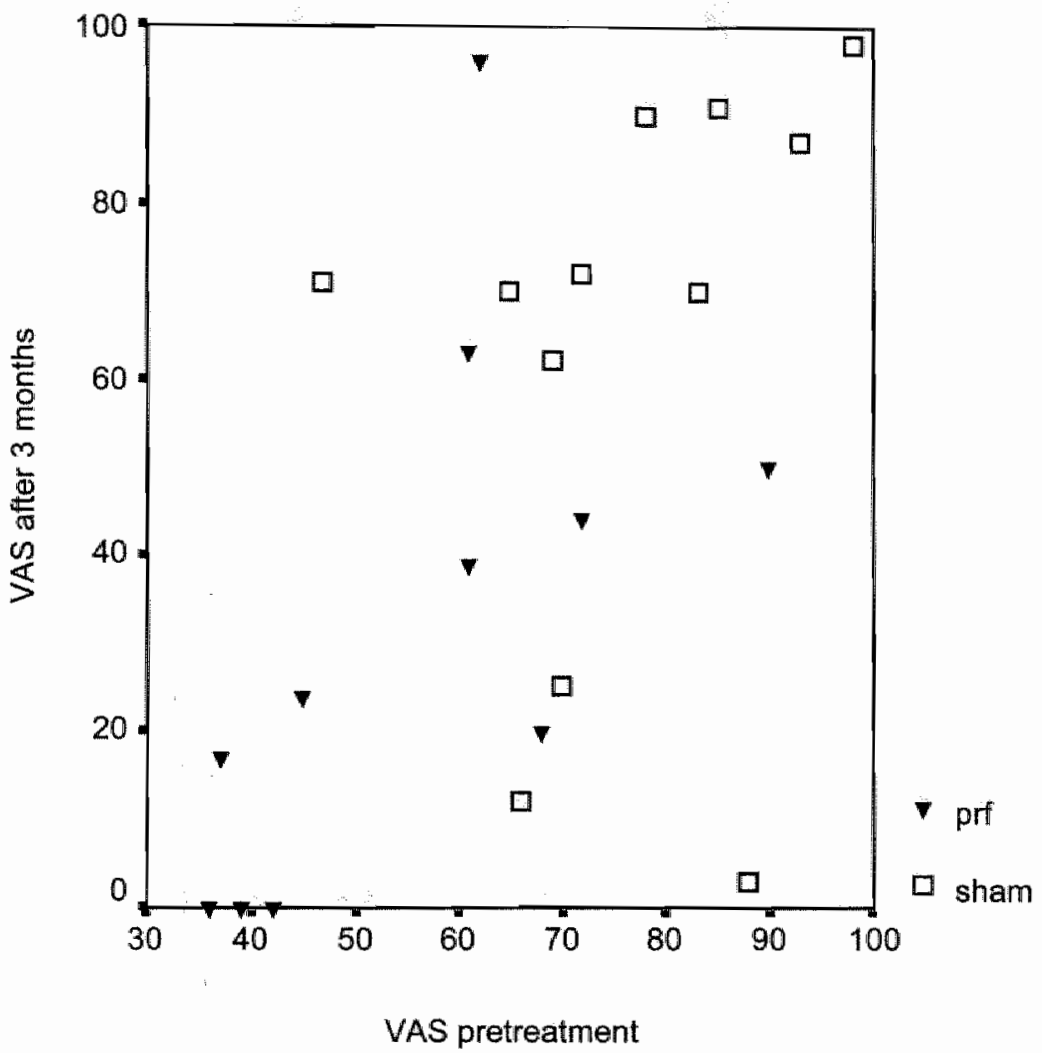

Figure 2: Scatterplot of the visual analogue scalle before treatment versus 3 months after the intervention

\section{Primary outcome measurement}

The primary outcome consisted of three measurements 3 months after the intervention. The first, success defined as at least $50 \%$ improvement of the GPE (6 or 7 on the Likert scale), was achieved in $9 / 11$ ( $82 \%$ ) patients in the PRF group and in $4 / 12$ $(33 \%)$ in the sham group. The difference between the two treatment groups is statistical significant $(P=0.03)$. 
The second primary-outcome measurement, a 20-points reduction in pain intensity measured by VAS score, was also statistically significant with more improvement achieved in $9 / 11(82 \%)$ patients in the PRF group compared with $3 / 12(25 \%)$ in the sham group $(P=0.02)$. The individual VAS scores are shown in figure 2 .

The third primary outcome was the reduction in intake of pain medication. A reduction was noted in the PRF group, but no significance was reached after 3 months. The evolution of the intake of pain medication is illustrated in figure 3 .

\section{Pain medication use}

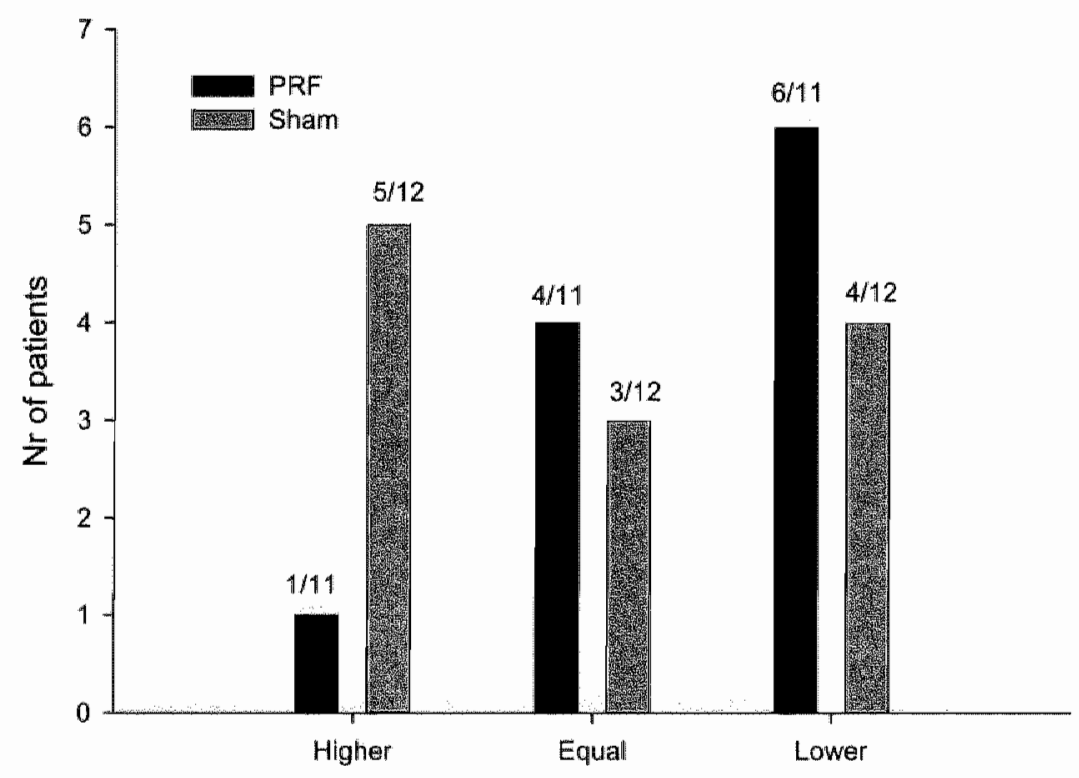

Figure 3: Evolution of intake of pain medication from baseline to T2 ( 3 months) 


\section{Secondary outcome measurements}

The secondary outcome with regard to the evolution of GPE between T1 and T3 is shown in figure 4. The differences in success (GPE and VAS) between the PRF and sham groups, with the odds ratios and $95 \%$ confidence interval over the three observation points are presented as unadjusted values and as values adjusted for variations in baseline characteristics in figure 5 . A value above 1 is a statistical significant improvement of PRF versus sham treated patients. At T1 the outcome of sham is better than PRF for the adjusted and for the unadjusted values; at T2 the outcome of PRF is better than sham for adjusted and unadjusted values and at T3 the unadjusted value for the outcome of PRF is better than for sham, while statistical significance is just not reached for the adjusted values. The use of pain medication was significantly decreased in the PRF group at T3 compared to baseline $(p=0.016)$. The QOL as evaluated by the Euroqol scale and SF-36 indicated a trend toward a better result after 4 weeks in the sham group and after 3 months and 6 months in the PRF group, but no statistical significance was reached. The differences in scores of the SF-36 items between T0 and T2 and Eurogol for both groups are shown in table 3; there was a statistically significant improvement of the domain vitality in the PRF group.

No side effects or complications were reported over the study period in neither group.

The telephone inquiry revealed that 4 out of the 23 patients were referred for neck surgery: 3 patients from the sham group and 1 from the PRF group.

Table 3: Results of the SF-36 and Euraqol outcome measurements at 3 months

\begin{tabular}{llcl}
\hline Iterm & PRF & Sham & $P$ \\
& Mean difference (SD) & Mean difference (SD) & \\
\hline Euroqol & $12.6(19.7)$ & $4.7(30.8)$ & 0.5 \\
Physical functioning & $9.0(16.6)$ & $6.9(15.0)$ & 0.8 \\
Social functioning & $12.5(28.0)$ & $-1.0(28.4)$ & 0.3 \\
Physical role restriction & $23.5(48.6)$ & $24.3(26.9)$ & 0.9 \\
Emotional role restriction & $24.2(36.8)$ & $0.0(53.7)$ & 0.2 \\
Mental health & $6.9(12.9)$ & $0.3(22.2)$ & 0.4 \\
Vitality & $17.3(17.1)$ & $2.1(16.0)$ & $0.04^{*}$ \\
Pain & $9.8(20.5)$ & $9.3(25.8)$ & 0.9 \\
General health & $4.1(10.0)$ & $2.3(19.0)$ & 0.7 \\
\hline
\end{tabular}

* Statistical significant 


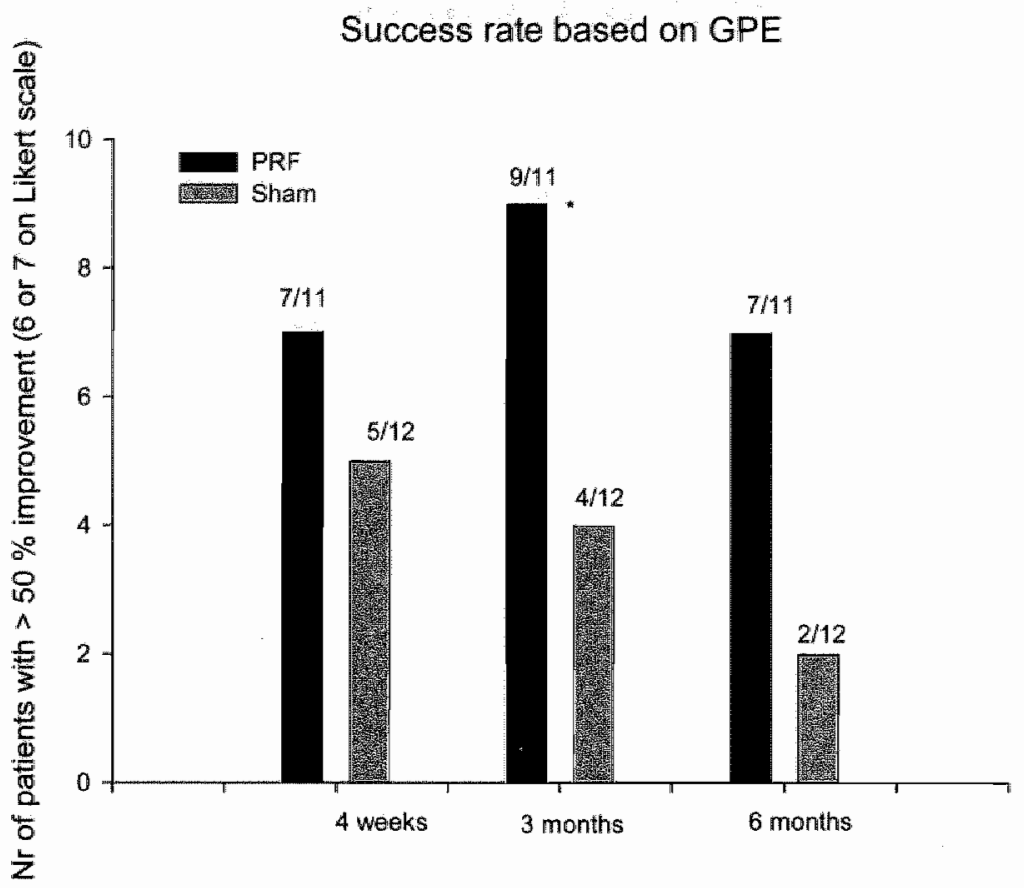

Figure 4: Success rate based on GPE at 4 weeks, 3 months and 6 months 


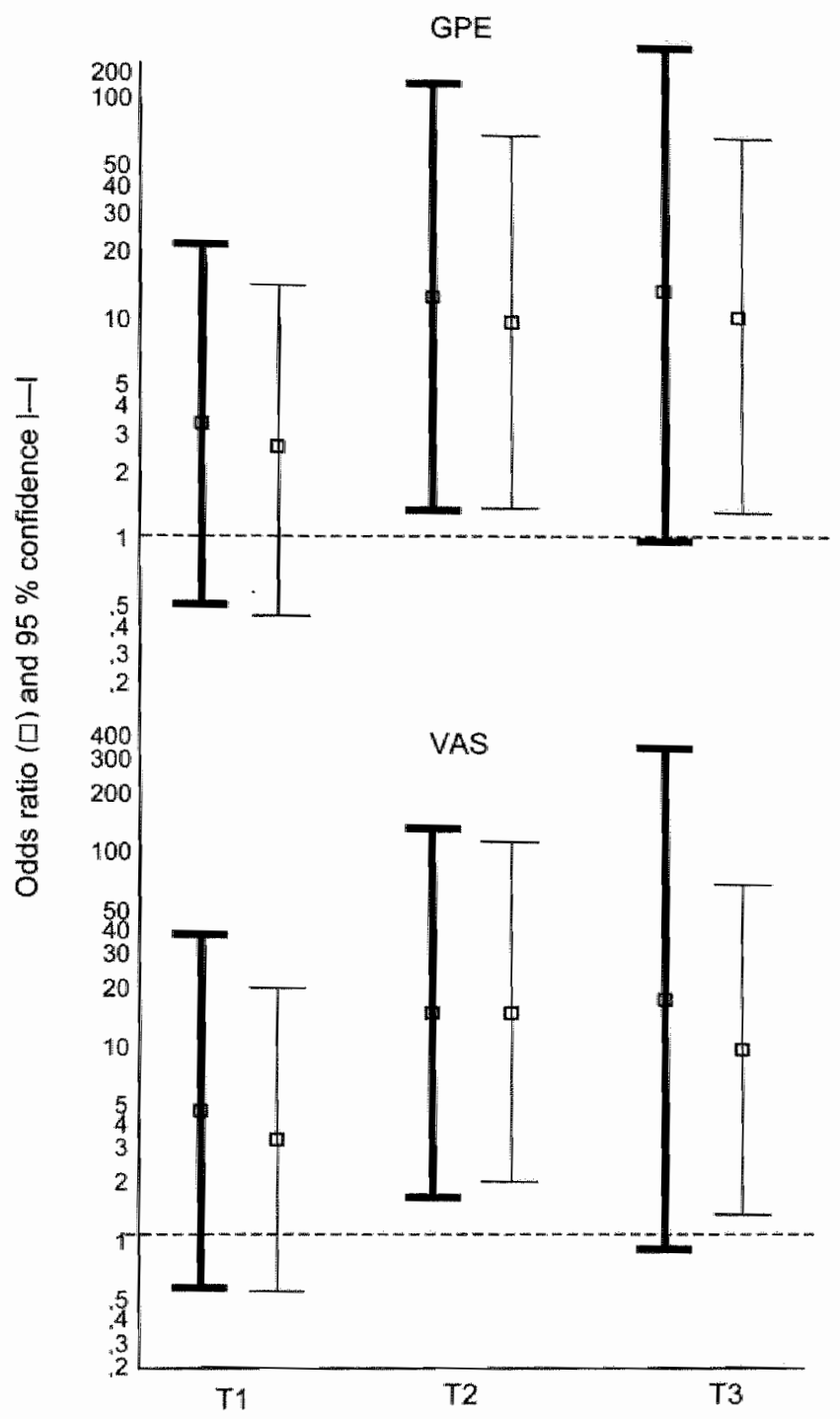

Figure 5: Evolution of the differences in success between PRF and sham group at $T 1$ (4 weeks), at T2 (3 months), and at T3 (6 months) with odds (D) ratios and $95 \%$ confidence interval (1- 1 ) of global perceived effect (GPE) and visual analogue scale (VAS): adjusted for variations in baseline values (bold lines) and unadjusted values. (light lines). Values above 1 represent a statistical significant improvement of PRF versus sham treated patients. 


\section{Discussion}

Treatment satisfaction score is increasingly being used as a measure of outcome in pain management. Although it is a subjective variable, it may nonetheless reflect the quality of care and may also predict other signficant patient behavior ${ }^{35}$. For this reason, we defined treatment success as minimum $50 \%$ improvement on the GPE and a 20-point pain reduction on VAS score. Our results indicated that PRF treatment of the cervical DRG for chronic cervical radicular pain provided better pain relief than sham intervention 3 and 6 months after the procedure, but significance was only reached after 3 months. The need for pain medication, which was defined as rescue treatment in the study protocol, was reduced in the PRF group and increased in the sham group. Statistical significance was reached after 6 months. Although it was considered a rescue treatment, pain medication may have an important influence on other outcome parameters. There was a tendency toward better outcome in QOL for sham patients after 4 weeks as measured by SF-36 and Eurogol, but, after 3 and 6 months, there was a trend towards a better improvement of QOL in the PRF group, although statistical significance was only reached for the domain vitality. No side effects or neurological complications were noted in either group during the study period.

To our knowledge, this is the first RCT of PRF treatment in patients with chronic pain. Because of the lack of a gold standard for the diagnosis of cervical radicular pain, special attention was paid to selection of the patients to form a homogeneous study population. The neurological and physical examination, supervised by a staff neurologist, consisted of a protocol to exclude shoulder motion restriction and to include patients with a positive Spurling test. Despite high selectivity but low sensitivity, this test is considered a valuable aid in the clinical diagnosis of patients with cervical radicular pain ${ }^{36}$. It has been validated in a controlled trial using electromyography as a reference, with comparable results (sensitivity of $30 \%$; specificity of $93 \%)^{37}$. In a recent publication, it was shown that a positive Spurling test has a high predictive value for soft cervical disc prolaps as detected on MRI. Moreover, these authors reported a significant correlation between the result of the Spurling test and the root-canal diameter ${ }^{38}$.

The difference in the baseline demographic characteristics is a flaw of this study. Therefore, both unadjusted and adjusted statistical analyses were performed for age, sex, duration of pain and variations in baseline characteristics. The trend in primary-outcome measurements was similar for both analyses. However, statistical significance was just not reached after 6 months on the adjusted analysis for GPE and VAS pain score. This was probably related to the most important weakness of our study, the low inclusion rate, which resulted in an underpowering for different parameters. It is often difficult to convince the patient to sign the informed consent 
when there is a $50 \%$ chance of receiving a placebo intervention. Not only is the patient reluctant to enter a sham-controlled trial, but the referring specialists may also have a strong influence in causing the patient not to participate in the study ${ }^{39}$.

We could only include 23 patients of the 42 needed ( 256 were screened) which makes it difficult to extrapolate our results into daily practice ${ }^{40}$. This is in accordance with the experience in a recent RCT on RF lesioning of the DRG for chronic lumbosacral radicular pain, where only 83 of the 1,001 patients examined could be included ${ }^{41}$. The problem of patient recruitment and low inclusion we encountered in this sham-controlled interventional trial has already been reported in other studies and systematic reviews of interventional pain management techniques ${ }^{9,42-44}$. A double blind sham/placebo controlled randomized clinical trial is considered to provide the highest level of evidence according to evidence-based medicine guidelines ${ }^{45,46}$ but the true value of placebo/sham interventions in pain management trials is under debate $^{47,48}$. A RCT has the objective to compare the effects of a treatment with the natural course of the disease. The question of whether a sham intervention really reflects the natural course of the disease, however, is becoming more and more controversial, one reason being that PET studies have documented that placebo and opioids activate the same brain regions ${ }^{49}$.

We performed this study in patients with chronic cervical radicular pain because the available evidence in the literature did not provide any indication for the best treatment option. In case of intractable pain, cervical spine-surgery is often performed ${ }^{5}$. However, there is a lack of evidence to support this treatment, which is associated with a small but definite risk of complication ${ }^{50.51}$. For this reason, during the last decade interest has been directed to less invasive percutaneous interventional pain management techniques. Other less invasive techniques such as cervical interlaminar epidural steroids ${ }^{52}$, have limited evidence of efficacy ${ }^{53}$. Recently, several case reports indicate the possibility of serious complications such as spinal-cord lesions after cervical transforaminal epidural steroids, which are hypothesized to be related to intra-arterial injection of particulate steroid with occlusion of critical vessels that supply the spinal cord ${ }^{54-57}$. Hence, some colleagues have questionned the suitability of this approach ${ }^{58}$, and even suggest temporarily abandoning the transforaminal approach above the L3 level until more scientific data are available ${ }^{59}$.

Two RCT's concerning RF techniques adjacent to the cervical DRG for the management of chronic cervical radicular pain have been published ${ }^{7.8}$, with limited evidence according to two systematic reviews ${ }^{9,44}$. Our study included a comparable number of patients compared with van Kleef et al. ${ }^{7}$, whereas Slappendel et al. ${ }^{8}$ included larger patient groups. Our study had a longer follow-up period than the other two, for up to 6 months. In both the other RCT's the diagnosis was made based on clinical and neurological screening methods. However, they were not always de- 
scribed in detail, which may have resulted in some degree of heterogeneity in the intervention groups. By specific testing of shoulder motion range and including the Spurling test we believed that a more homogeneous study population was achieved in our study.

An important issue in clinical practice for choosing between continuous RF and PRF is the risk for neurological side effects and complications. Drawing conclusions on safety of a treatment based on studies involving low numbers of patients is not justifiable, which is a weakness of most sham-controlled studies in interventional pain medicine. Therefore, data from large well-designed cohort studies may provide more valid information on safety. It has been demonstrated that these studies do not systematically overestimate the effect of the intervention in comparison with $\mathrm{RCT}^{\mathrm{s}}{ }^{60}$.

Future research should concentrate on elucidating the mode of action of PRF. At present five neurobiology trials are published. They indicate that PRF and sham treatments have different biological effects ${ }^{14-16,61,62}$, the mode of action is temperature-independent ${ }^{14 * 16,62}$, and that neural destruction with conventional RF and PRF is dependent on the distance between the electrode and the tissue, but is less pronounced and transient with $\mathrm{PRF}^{61.62}$. Furthermore, PRF appears to have selective effects on small-diameter $\mathrm{C}$ - and $\mathrm{A}$ - $\delta$-fibers according to one neurobiology trial $^{16}$. The frequency at which PRF should be applied in order to optimize the therapeutic outcome in clinical practice needs to be investigated. The pathology causing cervilcall radicular pain may be present at more than one level and the question whether simultaneous PRF treatment at different levels yield a better outcome remains unanswered.

In conclusion, the results of our study are in accordance with the findings of the clinical audit ${ }^{18}$ that PRF treatment of the cervical DRG may provide a long-term pain relief in selected patients with chronic cervical radicular pain. Considering the presumed less neurodestructive nature of PRF, this approach may have a better risk/benefit ratio than continuous. RF lesioning, but this hypothesis needs to be confirmed in larger observational studies. 


\section{Acknowledgements}

The authors want to thank the cooperating physicians: $O$. Rohof, MD, DrMed, $V$. Van Dongen, MD, Dept of Pain Management, Maasland Hospital, Sittard, The Netherlands; J. Pasmans, MD, Dept of Neurology, Atrium Medical Centre, Heerlen, The Netherlands; A. de Louw MD, PhD, and W. Weber, MD, PhD, Dept, of Neurology, University Hospital Maastricht, Maastricht, The Netherlands; S. Haspeslagh, MD, and C. Lawrence MD, Dept. of Anesthesiology and Pain Management, University Hospital Maastricht, Maastricht, The Netherlands; M. Puylaert, MD, and K. Vissers, MD, PhD, Dept of Anesthesiology and Multidisciplinary Pain Centre, Ziekenhuis Oost-Limburg, Genk, Belgium; RJ. Stolker, MD, PhD, and A. Van Zundert, $M D, P h D$. Dept. of Anesthesiology and Pain Management, Catharina Ziekenhuis, Eindhoven, The Netherlands. The authors are grateful to Nicole Van den Hecke for coordination and administrative support and Susan Balogh for English editing 


\section{References}

1. Radhakrishnan $K$, Litchy WJ, O'Fallon WM, Kurland LT Epidemiology of cervical radiculopathy. A population-based study from Rochester, Minnesota, 1976 through 1990. Brain 1994; 117 (Pt 2): $325-335$

2. Daffner $S D$, Hilibrand $A S$, Hanscom $B S$, Brislin $B T$, Vaccaro $A R$, Albert $T J$. Impact of neck and arm pain on overall health status. Spine 2003; 28: 2030-2035

3. Merskey $H$, Bogduk N. Classification of Chronic Pain Descriptions of Chronic Pain Syndromes and Definitions of Pain Terms., 2. Seattle, Wash: IASP Press, 1994,

4. Bogduk N. Medical Management of acute cervical radicular pain: and evidence-based approach, 1st. Newcastle, Australia, The Newcastle Bone and Joint Institute, 1999,

5. Rathmell JP. Aprill $C_{n}$ Bogduk N. Cervical transforaminal injection of steroids. Anesthesiology 2004; 100: 1595-1600

6. Saal JS, Saal JA, Yurth EF. Nonoperative management of hemiated cervical intervertebral disc with radiculopathy. Spine 1996; 21: 1877-1883

7. van Kleef $M$, Liem $L$, Lousberg $R$, Barendse $G$, Kessels $F$, Sluijter $M$. Radiofrequency lesion adjacent to the dorsal roof ganglion for cervicobrachial pain: a prospective double blind randomized study. Neurosurgery 1996; 38: 1127-1131; discussion 1131-1122

8. Silappendel R. Crul BJ "Braak GJ, Geurts JW, Booij LH, Voerman VF, de Boo T. The efficacy of radiofrequency lesioning of the cervical spinal dorsal root ganglion in a double blinded randomized study: no difference between 40 degrees $C$ and 67 degrees $C$ treatments. Pain 1997; 73: $159=163$

9. Geurts J, van Wijk RM, Stolker R, Groen GJ. Efficacy of radiofrequency procedures for the treatment of spinal pain: a systematic review of randomized clinical trials. Reg Anesth Pain Med 2001; 26: 394-400

10. Niemisto $L$, Kalso $E$, Malmivaara A, Seilsalo $S$, Hurri $H$. Radiofrequency denervation for neck and back pain: a systematic review within the framework of the cochrane collaboration back review group. Spine $2003 ; 28$ : $1877-1888$

11. Sluijter ME. Radiofrequency part I, Flivopress, Meggen, Switzerland, 2001.

12. Sluijter ME, Cosman ER, Rittman IIWB, van Kleef $M$. The effects of pulsed radiofrequency field applied to the dorsal root ganglion - a prelimimary report. The Pain Clinic 1998; 11: 109-117

13. Cosman EJ, Cosman ES. Electric and thermal field effects in tissue around radiofrequency electrodes. Pain Medicine 2005; In press:

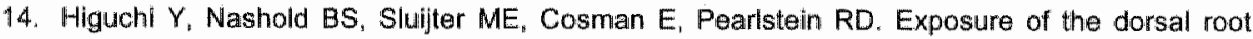
ganglion in rats to pulsed radiofrequency currents activates dorsal horn lamina I and II neurons. Neurosurgery 2002; 50: 850-856

15. Van Zundert J, de Louw AJ "Joosten EA, Kessels AG, Honig W, Dederen PJ, Veening JG, Vles JS, van Kleef $M$. Pulsed and continuous radiofrequency current adjacent to the cervical dorsal root ganglion of the rat induces late cellular activity in the dorsal horn. Anesthesiology 2005; 102: 125-131

16. Hamann W. Abou-Sherif $S$, Thompson $S$, Hall S. Pulsed radiofrequency applied to dorsal root ganglia causes a selactive increase in ATF3 in small neurons. Eur J Pain 2005; in press:

17. Richebe $P$, Rathmell JP. Brennan TJ. Immedialle early genes after pulsed radiofrequency treatment: neurobiology in need of clinicall trials. Anesthesiology 2005; 102: 1-3

18. Van Zundert J, Lamé IE, de Louw A, Jansen J, Kessels F, Patijn J, van Kieef M. Percutaneous Pulsed Radiofrequency Treatment of the Cervical Dorsal Root Ganglion in the Treatment of Chronic Cervical Pain Syndromes: A Clinical Audit. Neuromodulation 2003; 6: 6-14

19. Slipman CW, Plastaras CT, Palmitier RA, Huston CW, Sterenfeld EB. Symptom provocation of fluoroscopically guided cervical nerve root stimulation. Are dynatomal maps identical to dermatomal maps? Spine $1998 ; 23 ; 2235-2242$

20. Spurling $R$, Scoville $W$. Lateral rupture of the cervical intervertebral discs: a common cause of shoulder and arm pain. Surg Gynecol Obstet 1944; 78: 350-358 
21. Teresi LM, Lufkin RB, Reicher MA, Moffit BJ, Vinuela FV, Wilson GM, Bentson JR, Hanafee WN. Asymptomatic degenerative disk disease and spondylosis of the cervical spine: MR imaging. Radiology 1987; 164: 83-88

22. Boden SD, McCowin PR, Davis DO, Dina TS, Mark AS, Wiesel S. Abnormal magneticresonance scans of the cervical spine in asymptomatic subjects. A prospective investigation. $\downarrow$ Bone Joint Surg Am 1990; 72: 1178-1184

23. Van Damme $S$, Crombez $G$, Vlaeyen JW, Van den Broeck $A$, Van Houdenhove $B$. De Pain Catastrophising Scale: Psychometrische karakteristieken en normering. Gedragstherapie, 2000, 33: 209-220

24. van Kleef $M$, Spaans F, Dingemans W, Barendse GAM, Floor $E$, Sluijter ME. Effects and side effects of a percutaneous thermal lesion of the dorsal root ganglion in patients with cervical pain syndrome. Pain 1993; 52: 49-53

25. Ford DJ, Pither $C$, Raj PP. Comparison of insulated and uninsulated needles for locating peripheral nerves with a peripheral nerve stimulator. Anesth Analg 1984; 63: 925-928

26. Turner JA, Jensen MP, Warms CA . Cardenas DD. Blinding effectiveness and association of pretreatment expectations with pain improvement in a double-blind randomized controlled trial. Pain 2002; 99: 91-99

27. Jensen MP, McFarland CA. Increasing the reliability and validity of pain intensity measurement in chronic pain patients. Pain 1993; 55: 195-203

28. Likert R. A technique for the measurement of attitudes. Archives of Psycology 1932; 22: 140

29. Farrar JT, Jr. JPY, LaMoreaux $L_{*}$ Werth JL, Poole RM. Clinical importance of changes in chronic pain intensity measured on an 11-point numerical scale. Pain 2001; 94:149-158

30. Steedman SM, Middaugh S, Kee WG, Carson DS, Harden R, Miller C. Chronic-Pain Medica-. tions: Equivalence Levels and Method of Quantifying Usage. Clin J Pain 1992; 8: 204-214

31. Ware JE, Sherbourne CD. The MOS 36-ltem Short-Form Health Survey. Medical Care 1992; 30: $473-481$

32. Aaronson NK, Muller M, Cohen PD, Essink-Bot ML, Fekkes $M_{\circ}$ Sanderman $R$, Sprangers $M A_{\text {, }}$ te Velde A, Verrips $E$. Translation, validation, and norming of the Dutch language version of the SF-36 Health Survey in community and chronic disease populations. J Clin Epidemiol 1998; 51: $1055-1068$

33. EuroQol-a new facility for the measurement of health-related quality of life. The EuroQol Group. Health Pollicy 1990; 16: 199-208

34. Brooks R. EuroQol: the current state of play. Health Policy 1996; $37: 53-72$

35. McCracken LM, Evon D, Karapas ET. Satisfaction with treatment for chronic pain in a specialty service: preliminary prospective results. Eur J Pain 2002; 6:387-393

36. Viikarl-Juntura $E$. Porras M, Laasonen EM. Validity of clinical tests in the diagnosis of root compression in cervical disc disease. Spine 1989; 14: 253-257

37. Tong HC, Haig AJ, Yamakawa K. The Spurling test and cervical radiculopathy. Spine 2002; 27 : $156 \cdots 159$

38. Shah $\mathrm{KC}$, Rajshekhar $\mathrm{V}$. Reliability of diagnosis of soft cervical disc prolapse using Spurling's test. Br U Neurosurg 2004; 18: 480-483

39. Sackett DL. Why randomized controlled trials fail but needn't: 1. Failure to gain "coall-face" commitment and to use the uncertainty principle. Cmaj 2000; 162:1311-1314

40. Carr DB, Goudas LC. Burning questions, randomized controlled trials, and the pain doctor"s dilemma. Reg Anesth Pain Med 2003; 28: 360-361

41. Geurts JWM, van Wijk RM, Wynne HJ, Hammink E, Busikens E, Lousberg R, Knape JT, Groen GJ. Radiofrequency lesioning of dorsal root ganglia for chronic lumbosacral radicular pain. a randomised, double blind, controlled triall. Lancet $2003 ; 361: 21-26$

42. Nelemans PJ, deBie RA, deVet HC. Sturmans F. Injection therapy for subacute and chronic benign low back pain. Spine 2001; 26: 501-515

43. Koes BW, Sicholten R.JPM, Mens JMA, Bouter LM. Epidural Steroid Injections for Low Back Pain and Sciatica: An updated Systematic Review of Randomized Clinical Trials. Pain Digest 1999; $9: 241-247$ 
44. Niemisto $L$, Kalso $E$, Malmivaara $A$, Seltsalo $S$ "Hum $H$. Radiofrequency denervation for neck and back pain. A systematic review of randomized controlled trialls. Cochrane Database Syst Rev 2003; CD004058

45. Evidence-based medicine. A new approach to teaching the practice of medicine. EvidenceBased Medicine Working Group. Jama 1992; 268: 2420-2425

46. Guyatt GH, Sackett DL, Sinclair JC, Hayward R, Cook DJ, Cook RJ. Users' guides to the medical literature. $I X$. A method for grading health care recommendalions. Evidence-Based Medicine Working Group. Jama 1995; 274: 1800-1804

47. Hrobjartsson $A_{\text {a }}$ Gotzsche PC. Is the placebo powerless? An analysis of clinical trials comparing placebo with no treatment: N Engl J Med 2001; 344: 1594 1602

48. Hrobjartsson A. Gotzsche PC. Is the placebo powerless? Update of a systematic review with 52 new randomized trials comparing placebo with no treatment. J Intern Med 2004; 256: 91100

49. Petrovic $P$, Kalso E, Peterson KM, Ingvar M. Placebo and opioid analgesia - imaging a shared neuronall network. Science 2002; 295: 1737-1740

50. Fouyas IP, Statham PF, Sandercock PA. Cochrane review on the role of surgery in cervical sponidylotic radiculomyelopathy. Spine 2002; $27: 736-747$

51. Jacobs W. Anderson P, Limbeek J, Willems P. Pavlov P. Single or double-level anterior interbody fusion techniques for cervical degenerative disc disease. Cochrane Database Syst Rev 2004; CD004958

52. Stav $A$, Ovadia $L$, Sternberg $A_{0}$ Kaadan $M_{0}$ Weksler $N$. Cervical epidural steroid injection for cervicobrachialgia. Acta Anaesthesiol Scand 1993; 37: 562-566

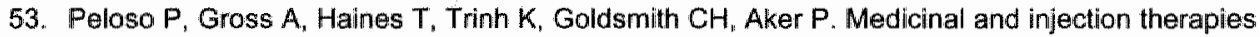
for mechanical neck disorders. Cochrane Database Syst Rev 2005; CD000319

54. Baker $R$, Dreyfuss $P$, Mercer $S$, Bogduk $N$. Cervical transforaminal injection of corticosteroids into a radicular artery: a possible mechanism for spinal cord injury. Pain 2003; 103: 211-215

55. Brouwers PJ, Kottink EJ, Simon MA, Prevo RL. A cervical anterior spinal artery syndrome after diagnostic blockade of the right C6-nerve root. Pain 2001; 91: 397-399

56. Rosenkranz M, Grzyska U, Niesen W. Fuchs K, Schummer W, Weiller C , Rother J. Anterior spinal artery syndrome following periradicular cervical nerve root therapy. $J$ Neurol 2004; 251: 229-231

57. Karasek M, Bogduk $N$. Temporary neurologic deficit after cervical transforaminal injection of local anesthetic. Pain Med 2004; 5: 202-205

58. Rathmell JP. Bienzon HT. Transforaminal injection of steroids: should we continue? Reg Anesth Pain Med 2004; $29: 397-399$

59. Huntoon MA, Martin DP. Reply to drs. Raghavendra and harney. Reg Anesth Pain Med 2005; $30: 208-209$

60. Concato J, Shah N, Horwitz RI. Randomized, controlled trials, observational studies, and the hierarchy of research designs. N Engl J Med 2000; 342: 1887-1892

61. Cahana A Vutskits L. Muller D. Acute Differential Modulation of Synaptic Transmissian and Cell Survival During Exposure to Pulsed and Continuous Radiofrequency Energy. The Journall of Pain 2003; 4: 197-202

62. Erdine $S$, Yucel $A$, Cimen A, Aydin S, Sav A. Bilir A. Effects of pulsed versus conventional radiofrequency current on rabbit dorsal root ganglion morphology. European Journal of Pain $2005 ; 9(3) ; 251-256$ 


\section{CHAPTER IX \\ Pulsed radiofrequency: Current clinical and biological literature available}

Cahana A, MD, DAAPM ${ }^{a}$; Van Zundert J, MD, FIPPb,c; Macrea L, MDa; van Kleef M, MD, PhD, FIPPc; Sluijter M, MD, PhD, FIPPc,d

a. Interventional Pain Program, Department of Anesthesiology, Pharmacology and intensive Care, Geneva University Hospital, Genewa, Switzerland b. Department of Anesthesiology Intensive Care, Emergency Medicine and Muttidisciplinary Pain Center; Zlekenhuis Oost-Limburg, Genk, Belghum

c. Department of Anesthesiology and Pain Management, University Hospital Maestricht "Maastricht, The Netherlands d. Department of Anesthesiology, Intensive Care and Pain treatment, The Swiss

Paraplegic Center, Nottwil Switzeriand 


\section{Abstract}

\section{Objective}

Pulsed radiafrequency, where short bursts of radiofrequency energy are applied to nervous tissue, has recently caught the attention of pain practitioners as a non or minimally neurodestructive technique, alternative to radiofrequency heat lesions. Clinical advantages and mechanisms of this treatment remain unclear. The objective of this study is to review current clinical and laboratory data.

\section{Design}

We systematically searched the MEDLINE database (PubMed) and tables of content of electronically available pain journals. Reference lists of relevant reports and international scientific pain congress abstract books were also hand searched. Only those reports on pulsed radiofrequency were withheld.

\section{Results}

The final analysis yielded 58 reports on the clinical use of pulsed radiofrequency in different applications: 32 full publications and 26 abstracts. We also retrieved six basic science reports, 5 full publications and one abstract.

\section{Conclusions}

The accumulation of these data shows that the use of pulsed radiofrequency generates on increasing interest of pain physicians for the management of a variety of pain syndromes. Although the mechanism of action has not been completely elucidated "laboratory reports suggest a genuine neurobiological phenomenon altering the pain signaling, which some have described as neuromodulatory. No side effects related to the pulsed radiofrequency technique were reported in the literature to date. Further research in the clinical and biological effects is justified. 


\section{Introduction}

Radiofrequency (RF) heat treatments have been used for over 30 years for a variety of pain syndromes: cervicogenic headaches ${ }^{3}$ occipital neuralgia ${ }^{2}$, whiplash injury ${ }^{3}$ cervical radicular pain ${ }^{4-6}$ intercostal neuralgia ${ }^{7}$, Iumbar radicular pain ${ }^{3,9}$, mechanical low back pain due to the zygapophyseal joint dysfunction ${ }^{10-13}$ "discogenic pain ${ }^{14,45}$ and pain associated with the sacroiliac joint ${ }^{16-13}$. Systematic reviews of RF heat treatments show limited to moderate evidence of its utility ${ }^{19-2 t}$. However, Hooten et al. ${ }^{22}$ discussed the methodological shortcomings in 3 randomized controlled trials (RCT's) in RF neurotomy for low back pain, resulting in an inaccurate estimate of clinical effectiveness obtained by systematic reviews.

The rationale for the application of RF denervation is the assumption that selectively heating nervous structures can impede nociceptive input. Practically this is achieved by percutaneous application of small electrodes at target neural tissues, to produce size controlled lesions. However others have questioned the utility of thermal lesioning, which is essentially neurodestructive, in the presence of neuropathic pain, and have shown that application of continuous low temperature RF is equally effective as RF heat lesion ${ }^{6}$.

In 1998 Sluijter et al. ${ }^{23}$ applied high voltage RF current in bursts of $20 \mathrm{~ms}$ per 500 $\mathrm{ms}$, permitting during $480 \mathrm{~ms}$ "silent phase" to allow the generated heat to be washed out. This idea of applying high voltage energy near a nerve without subsequent heat induced nerve injury with pulsed radiofrequency (PRF) was appealing. Initial clinical investigations had shown that PRF could be used safely as an alternative to heat lesions in patients suffering from refractory pain ${ }^{24-27}$. However today, it is still not clear what are the differences and/or advantages between PRF and RF, both in terms of clinical outcome and biological mechanisms involved. Pulsed radiofrequency treatment is a new technique for which evidence is gradually growing. New treatments evolve slowly in clinical (pain) medicine ${ }^{28}$, and it usually takes a 10year delay to accumulate sufficient clinical evidence in order to confirm or refute the value of the new treatment and present it in standard texts and reviews ${ }^{29}$. In RF's case it took even 26 years for lumbar RF facet denervation to establish its utility, between the first report in $1975^{30}$ and the first systematic review published in $2001^{19}$. This time lag has been similar in spinal cord stimulation were the first report for the treatment of complex regional pain syndrome was in $1986^{31}$, yet the first RCT was published only in $2000^{32}$.

Therefore constructing evidence for a new technique according to Evidence Based Medicine (EBM) guidelines is evolutionary. It usually starts with case reports and retrospective analysis and if these give encouraging results, prospective trials on 
larger number of patients are done. Finally RCT's and systematic reviews are performed ${ }^{33}$. On the other hand, basic research must accompany clinical trials in order to help and elucidate putative modes of action of this new technique. In this line of thought, the objective of this literature study was to make the inventory of the available clinical and laboratory data on PRF.

\section{Methods}

We systematically searched for studies reporting on PRF. We searched the MEDLINE database (PubMed), Science Citation Index, Cochrane database and Current Contents without language restriction using the free text terms: PRF, RF, radiation, isothermal RF and combination of these (figure 1). The electronically available tables of content of the recent issues of pain journals were also screened. Reference lists of relevant retrieved reports and international scientific congress abstract books were also hand searched. The information from abstracts, that were published as a full article later on, was not taken into account. We classified the information according to the type of study reported. We did not analyze reports dealing with RF (non PRF) techniques. Date of last electronic search was June 2005.

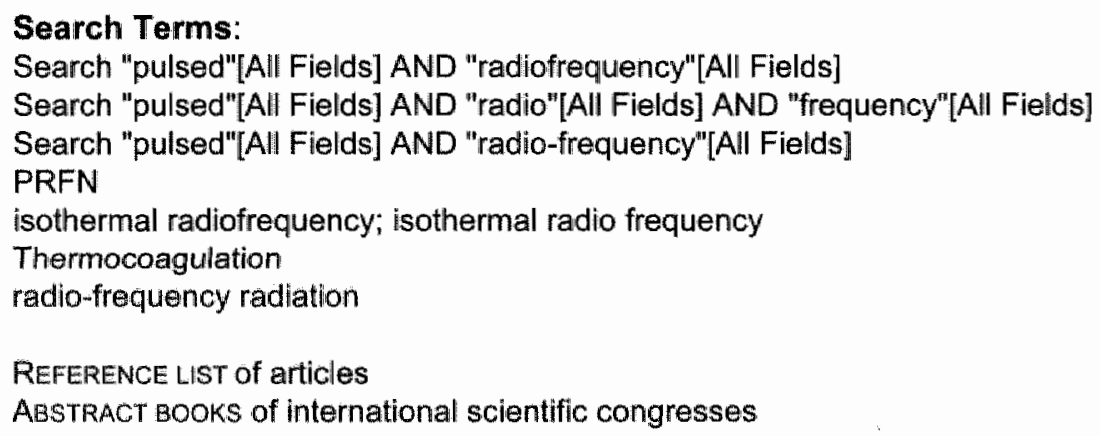

Figure 1: Search terms 


\section{Results}

The search yielded 301 potentially relevant reports, 243 were subsequently excluded (Figure 2). Forty trials reported on PRF not in medical applications, 14 reports were eventually not about PRF procedures, 32 reports were on human or animal effects of mobile phone radiation GSM (Global System for Mobile), 33 reports were of procedures using PRF in cardiac interventions, and 62 described the use of $\mathrm{PRF}$ in radiological interventions (magnetic resonance or Doppler echography).

Sixty-two reports were on the biological effects of PRF (Figure 3). Excluded were 26 reports on cellular and DNA effects of high frequency current from mobile phones and other sources, 7 reports on effects on tissue (muscle, cartilage), 3 were on the auditory effects of PRF, 2 on fertilization, 3 on osteogenesis, 3 on animal behavior, 3 on diathermal effects and 9 non classified. Thus for final analysis and critical reading 58 clinical reports ( 32 full publications and 26 abstracts) and 6 laboratory reports ( 5 full publications and 1 abstract) were describing the effects of PRF.

A flow chart of the complete literature search is summarized in figures 2 and 3 .

\section{Clinical reports on percutaneous pulsed radiofrequency}

The clinical reports on percutaneous PRF are summarized in table 1.

\section{Prospective trials}

We found 4 prospective trials in 122 patients. One full publication and three abstracts presented at international scientific congresses. The pilot study on PRF in cervical pain syndromes showed that 13 of 18 patients with cervicogenic headache and cervicobrachialgia treated with PRF adjacent to the cervical dorsal root ganglion (DRG) for 2 minutes, reported satisfactory pain relief of at least $50 \%, 8$ weeks post treatment. One year later six patients continued to rate their treatment outcome as good or very good ${ }^{27}$. In another report PRF was applied adjacent to the DRG for $B$ minutes in 30 consecutive patients who suffered pain that could be anatomically ascribed to discrete dermatomes. The authors suggest that PRF may be more effective in the management of neuropathic pain as opposed to nociceptive pain ${ }^{34}$. 
Figure 2. Flow chant of included and excluded trials and reports on pulsed radiofrequency

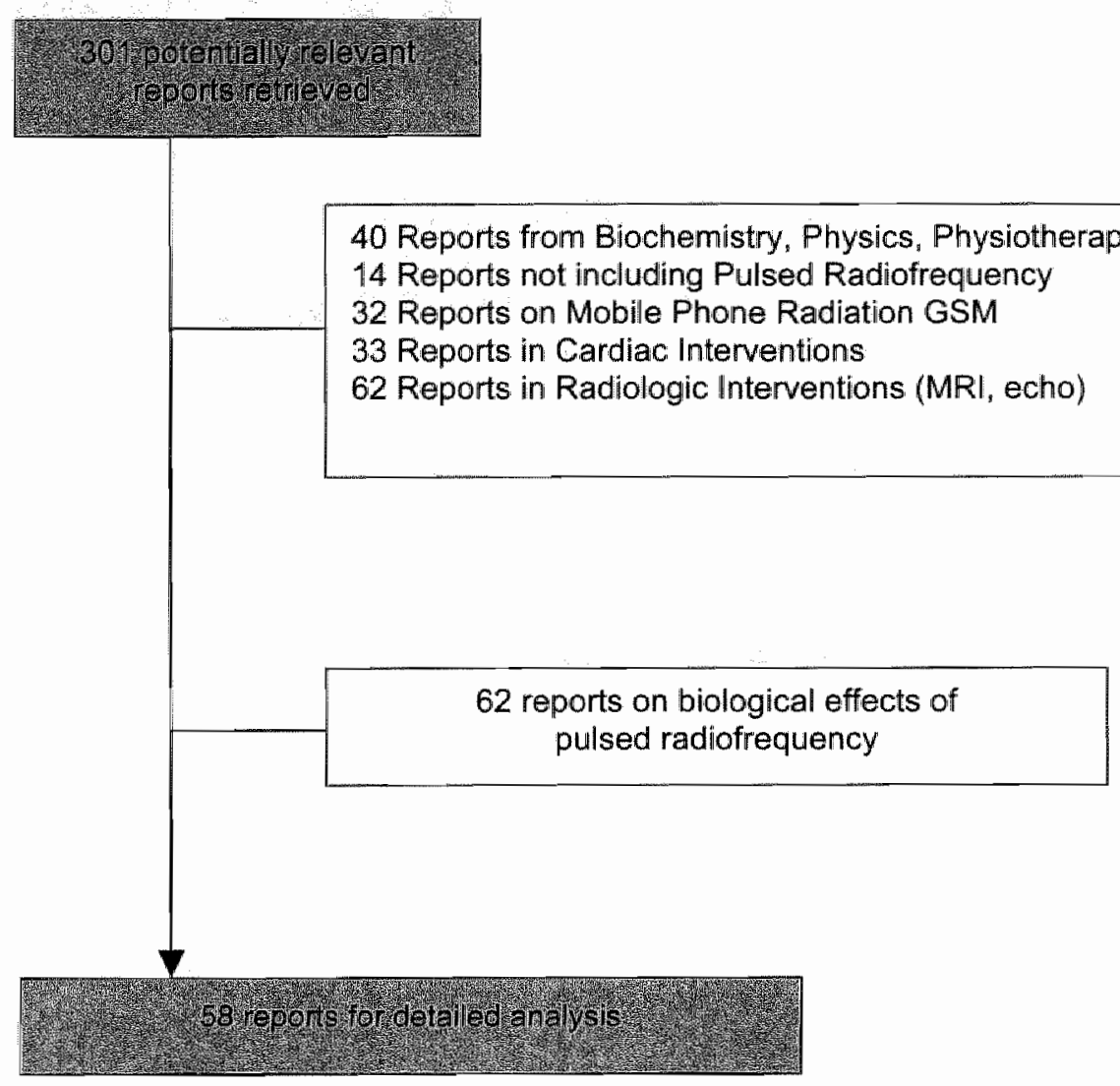


Figure 3. Flow chat of included and excluded trials in basic science

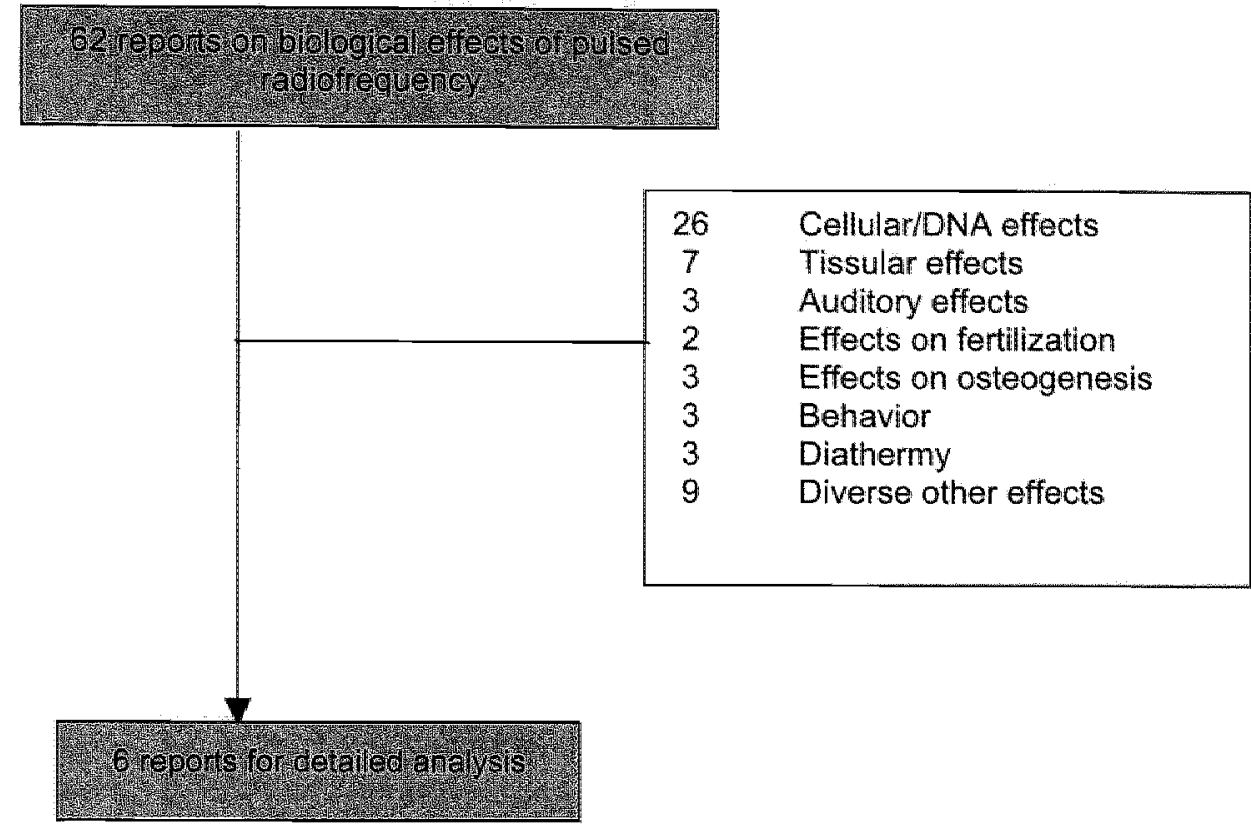

Pulsed radiofrequency treatment of the innervation of the sacroilliac joint (SIJ) (lateral branches L4-S3) was performed in 22 patients refractory to conventional treatment, including intra articular SIJ injections with corticosteroids/local anesthetics. Seventy three percent of the patients experienced good to excellent pain reduction with significantly improved quality of life scores for a duration of 6-32 weeks ${ }^{35}$. In 52 patients with chronic shoulder pain, PRF treatment of the suprascapular nerve resulted in a decrease in pain in $71 \%$ of them after 6 weeks ${ }^{36}$.

\section{Retrospective trials}

We found 15 retrospective trials in 809 patients.

The use of PRF for the management of patients with zygapophyseal joint pain was documented in 2 retrospective studies, one on lumbar and cervical level ${ }^{37}$ and one on cervical level ${ }^{38}$. A total of 166 patients were treated with a satisfactory clinical response of 3-6 months. The first published trial on PRF reported on 20 patients following failed back surgery treated with PRF adjacent to the lumbar DRG resulting in a decrease in VAS, less disability and an improved global effect up to one year after treatment, without any postoperative discomfort ${ }^{23}$. Additionally, 5 retrospective trials 
on PRF treatment adjacent to the DRG, including 222 patients were identified. Three of these studies evaluated clinical outcome with a good long-term response ${ }^{39-4 t}$, and two other studies evaluated technical parameters indicating the importance of impedance and the positive role of injecting contrast medium before PRF on clinical outcome ${ }^{42.43}$.

One retrospective study on the management of shoulder pain secondary to rotator cuff tear arthropathy on 12 patients reported a reduction in VAS pain score of 2 points in $75 \%$ of the patients up to 4 months post procedure ${ }^{44}$. One study on 46 patients with chronic head and facial pain who received PRF treatment of the sphenopalatine ganglion showed a mild to moderate relief in $65 \%$ of the patients for a duration of follow-up of 4-52 months ${ }^{45}$. Five retrospective trials report on patients with different pain syndromes including: lumbar and cervical zygapophyseal joint pain, lumbar and cervical radicular pain, shoulder pain, SIJ pain, complex regional pain syndrome, pelvic pain, post herpetic neuralgia, peripheral neuralgia, neuroma's and others. In total 343 patients were treated with satisfactory results ${ }^{46-50}$.

\section{Case series and reports}

Finally we found 18 case reports and case series including a total of 105 patients: two cases with glossopharyngeal neuralgia ${ }^{51}$ and 1 case of chronic post tonsillectomy pain ${ }^{52}$, one posttraumatic headache ${ }^{53}$, three patients with groin pain and orchialgia ${ }^{54}$, four patients with chronic back pain syndromes ${ }^{25}$ seven patients with occipital neuralgia ${ }^{55}$, eight patients with sacroiliac joint pain ${ }^{56}$ and thirty nine patients with discogenic pain responsive to L2 DRG block ${ }^{57}$. Other abstracts report on cases with, meralgia paresthesia ${ }^{58}$, neuropathic pain ${ }^{59}$, post herpetic neuralgia of head and face $^{60}$, complicated whiplash ${ }^{61}$, suprascapular nerve for shoulder pain ${ }^{62}$. In most of these case reports and retrospective trials there was a good pain relief with followup periods varying between thirty days and several years. Five case reports related to PRF treatment of the Gasserian ganglion were of patients refractory to any other treatment and often with a general condition precluding more invasive treatment. Three $e^{26,63,64}$ out of the five reports relate positive outcome and two reports ${ }^{65.66}$ no or little effect. 


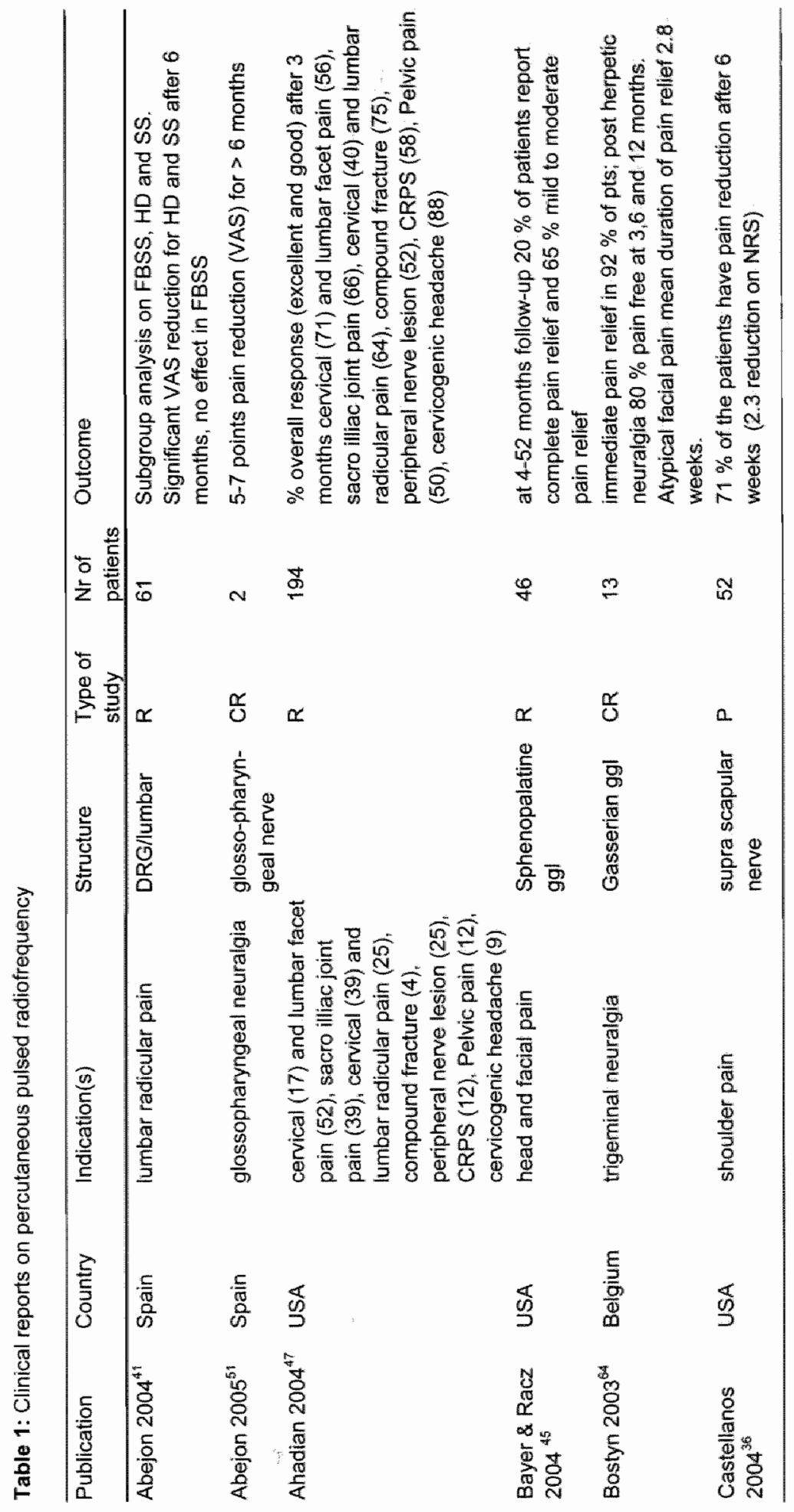




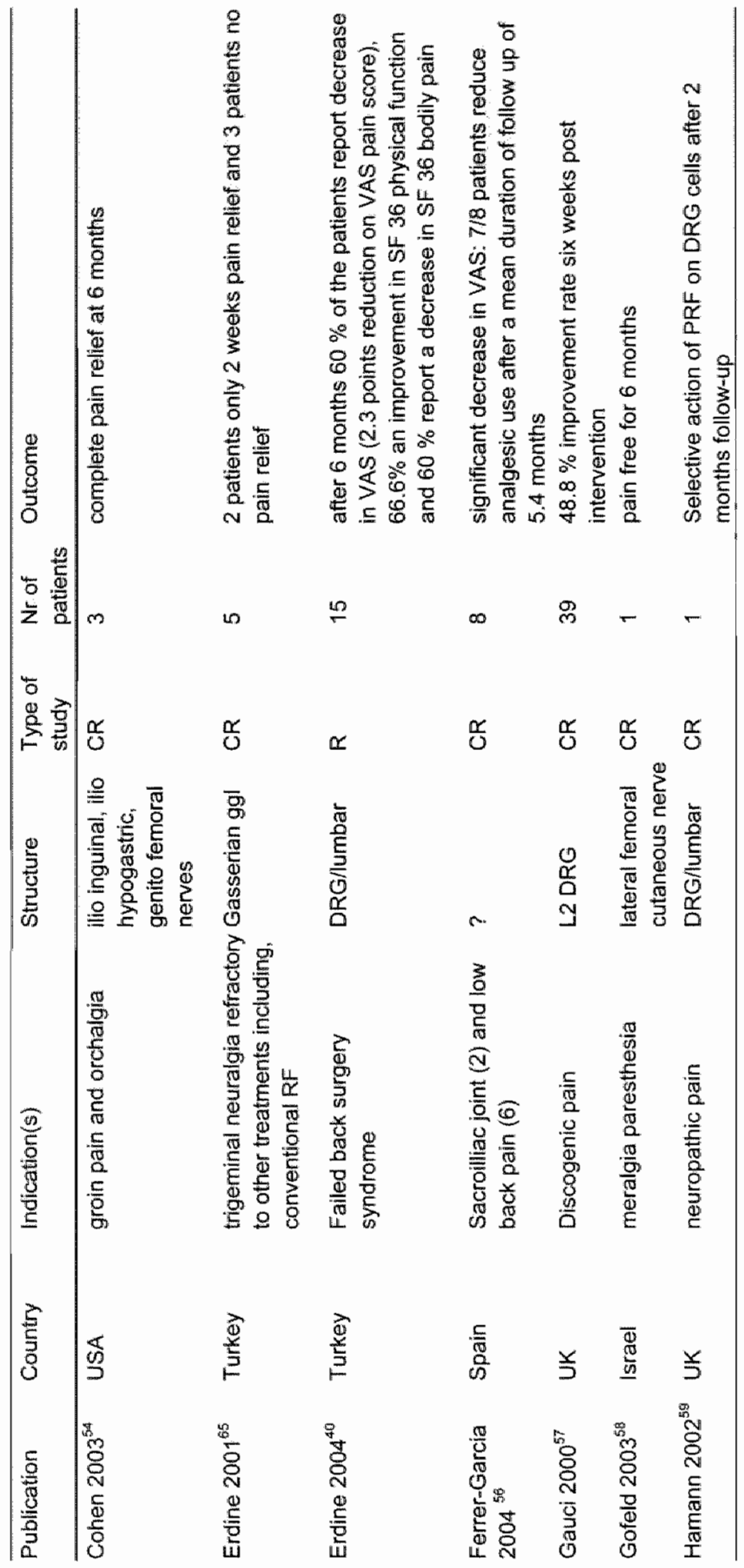




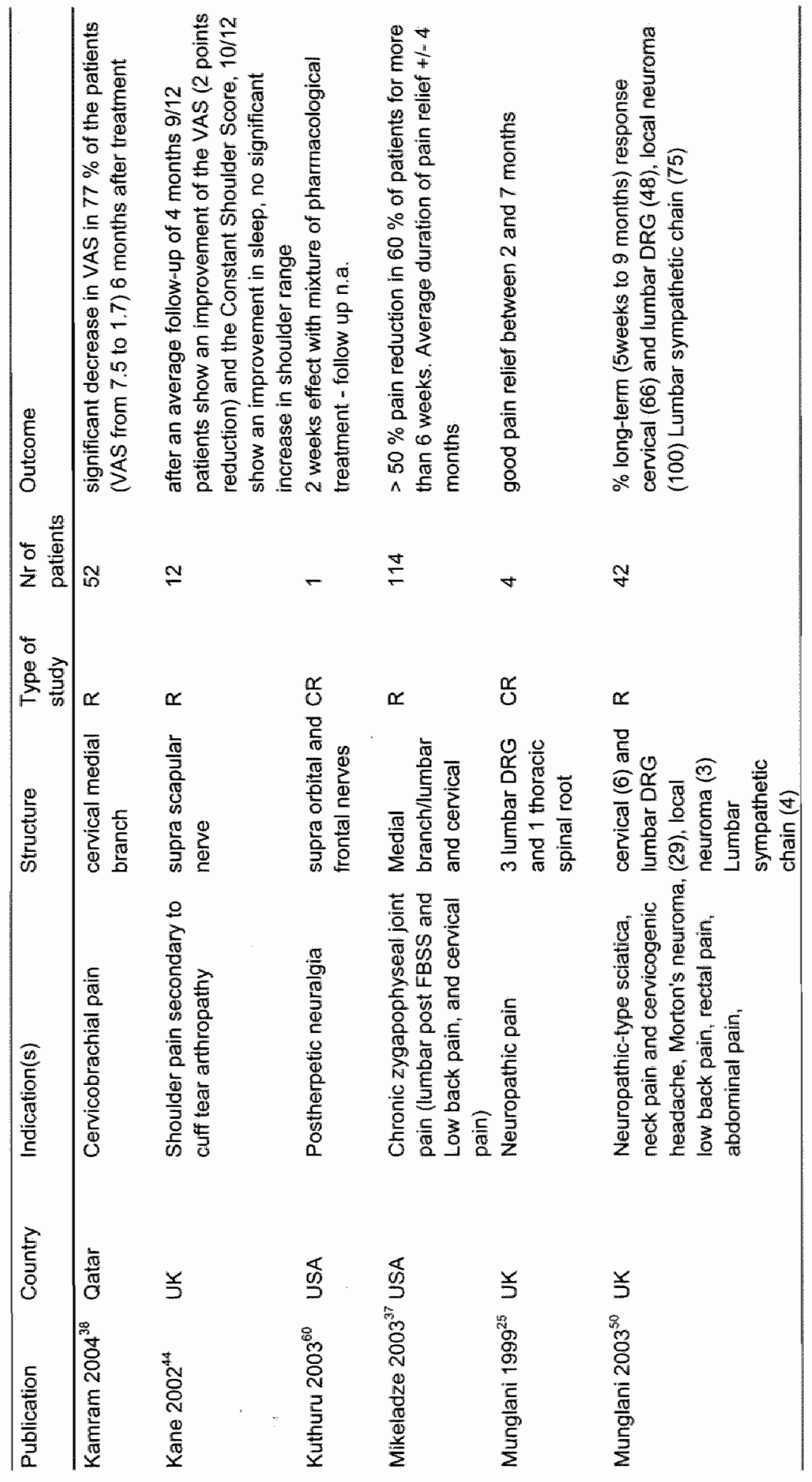




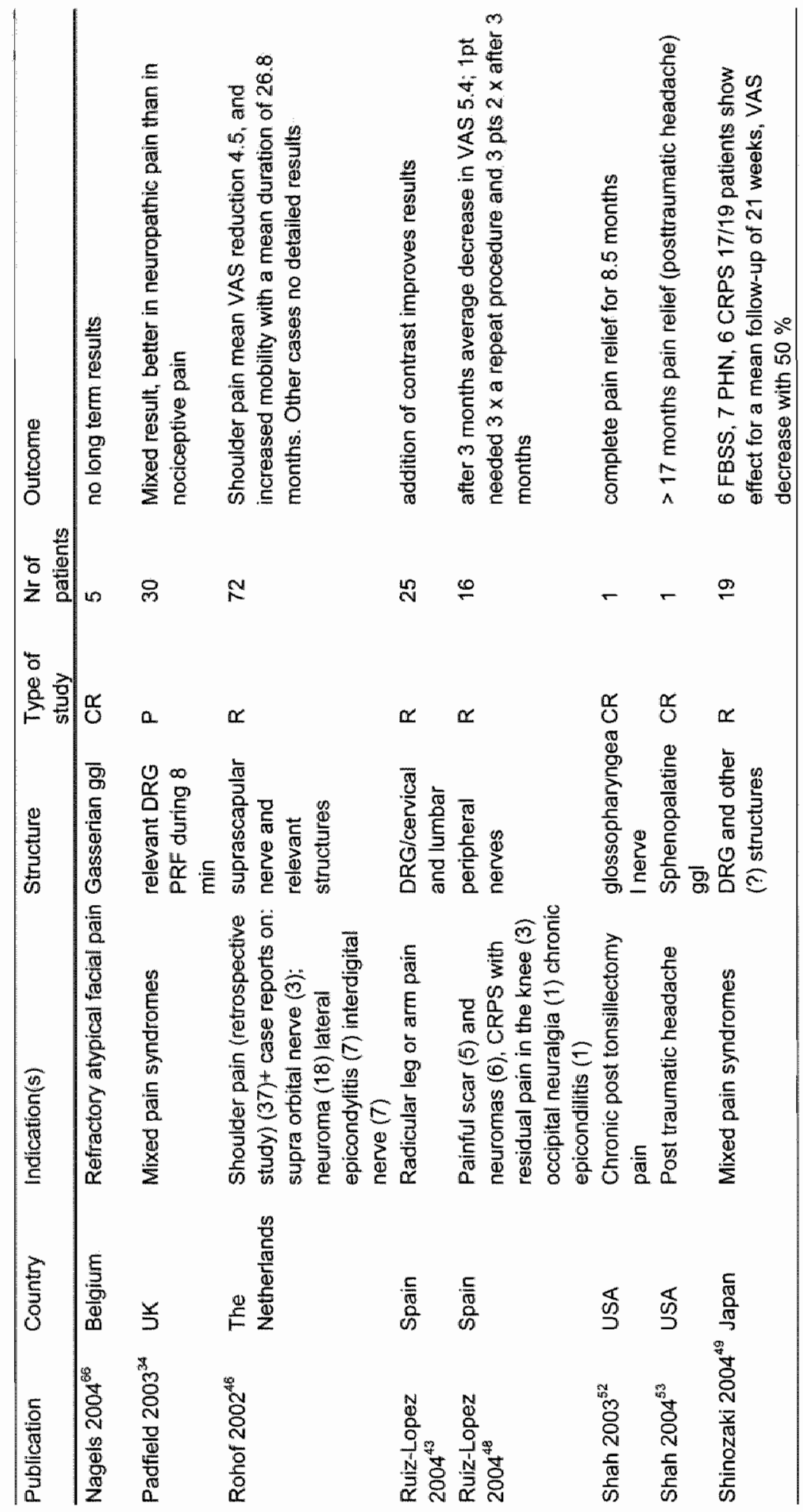




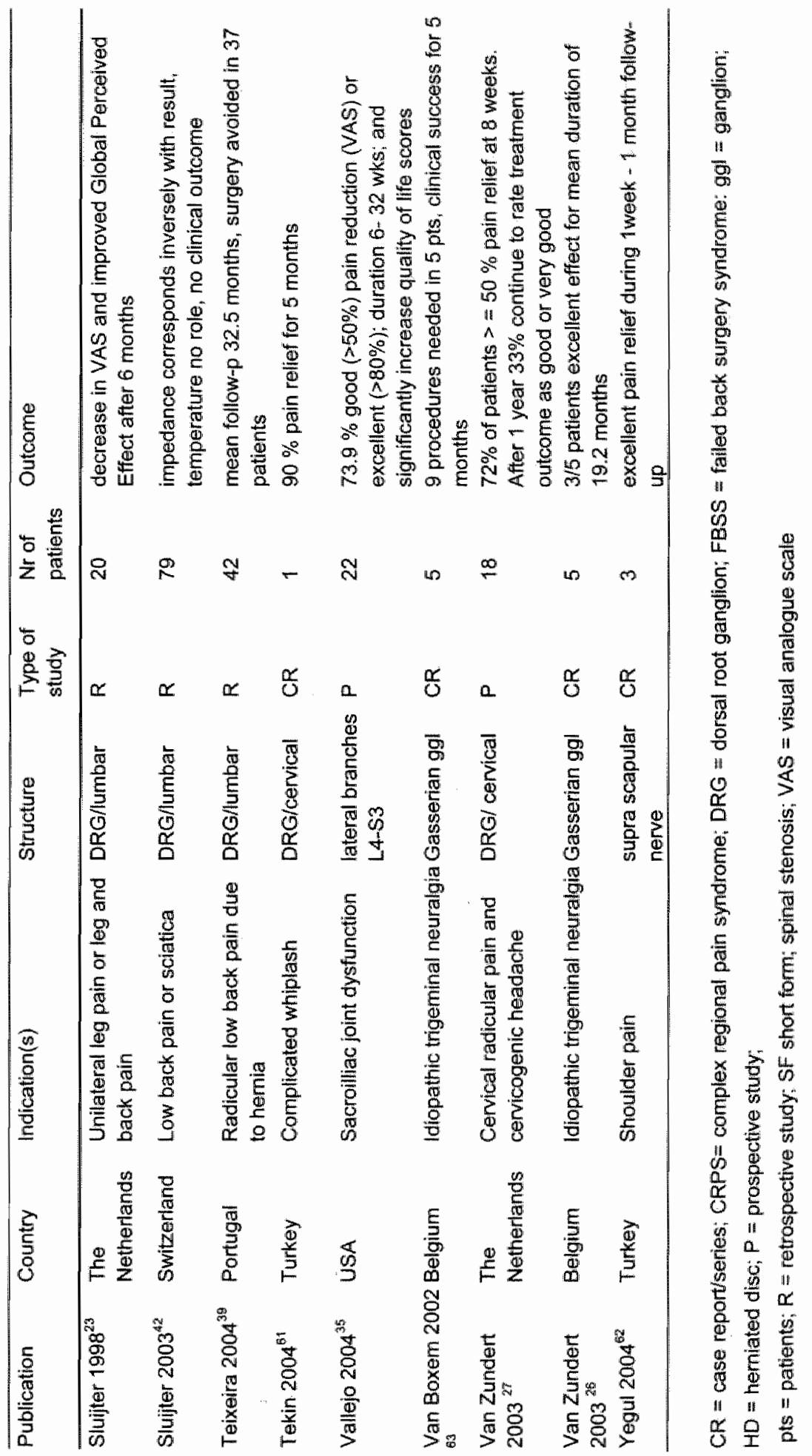




\section{General reviews}

Sixleen reviews, editorials, letters and comments discussing the use of PRF where found ${ }^{33: 67-89}$. In general most consider the use of PRF as a non or minimally neurodestructive alternative to RF heat lesions, because its potential better risk/benefit balance but there is also a call for higher quality clinical research. This call is even more justified by the fact that in none of the clinical reports on PRF treatment neurological side effects or complications were mentioned.

\section{Clinical reports on the transcutaneous application}

\section{Randomized clinical trial}

We found one double blind randomized controlled study including 40 patients with temporomandibular joint (TMJ) arthralgia treated with PRF energy therapy ${ }^{82}$. The reduction of pain (Numeral Rating Score) was significant for PRF and control groups $(p<0.001$ and $p=0.01$ respectively) however only the experimental group showed a significant increase in mouth opening and lateral jaw movements. No side effects were reported during the treatment and the two weeks follow-up period. The authors concluded that PRF is a safe and effective treatment for TMJ arthralgia.

\section{Prospective trials}

In addition we found three prospective trials on transcutaneous neuromodulation therapy using charge- balanced biphasic rectangular current, in phases of $200 \mathrm{~ms}$ with pulse repetition frequency varying from 4 to $10 \mathrm{~Hz}$. One report on radiating low back pain including 83 patients with 59 completing the 3 -month follow-up protocol ${ }^{83}$. There was a significant improvement in mean VAS scores, activity levels and sleep over the whole observation period. The Oswestry Low Back Pain Disability scores improved as well. Another case control cross over study reported twice, included 68 patients with non-radiating neck pain in which PRF stimulation was applied ${ }^{84,85}$. Reduced pain intensity, improved quality of sleep, increased physical activity was observed, and no side effects were reported.

\section{Case report}

One case report on 4 patients, one patient with pain in the radial part of the wrist and 3 with failed back surgery syndrome (or post laminectomy syndrome) benefited from short-term pain relief after transcutaneous PRF treatment ${ }^{86}$. 


\section{Laboratory reports}

Six reports of laboratory experiments on the neurobiological effects of PRF on neural substrates were available for critical analysis: five full publications and one abstract. Already in 1987 Wallace et al. showed that applying electrical current to the spinal cord in rats recovering from spinal cord injury carried no neurotoxic risk ${ }^{\text {Bi }}$, In 1999 it was shown that long-term, low-level RF expasure may influence c-Fos gene expression in the brain ${ }^{86}$. Two years later de Louw et al. showed that RF lesioning to the DRG in goat causes neural destruction even when the lesion is made outside the ganglion ${ }^{89}$. Similarly, PRF and RF current applied to the rat brain tissue both produced a neuronal destruction 21 days after treatment however the ratio of neurodestruction was considerably lower in the PRF group (5.5\%) compared to the RF group $(14.6 \%)^{90}$.

Exposure of cultured cells to an electric field is associated with up-regulation of cFos, as well as yet unidentified, genes ${ }^{91}$. C-Fos based functional anatomic mapping has been validated to detect neuronal activation ${ }^{92}$ and these changes represent long-term adaptation within particular neural pathways ${ }^{93}$. Specifically in rats, exposure of the cervical DRG to PRF current showed a significant early increase in cFos-immunoreactivity in the superficial laminae I and II of the dorsal horn, $3 \mathrm{~h}$ after the procedure ${ }^{94}$, as well as 1 week after PRF and RF treatment ${ }^{95}$. It was recently reported that the biological effect of PRF was unlikely to be related to an overt thermal damage and appears to be selective in that it targets the group of neurons whose axons are the small diameter $C$ and $A-\delta$ nociceptive fibers ${ }^{96}$. Finally PRF was shown to have a differential effect compared to RF on excitatory postsynaptic transmission, as well as cell morphology, even when RF heat lesions are performed in normothermic conditions ${ }^{97,98}$.

\section{Discussion}

After an extensive literature search, we could detect 42 reports from 11 different countries on the clinical use of percutaneous PRF in different applications on a variety of (chronic) pain syndromes in 1207 patients. Up till now in none of the listed reports, neurological side effects or complications with PRF were mentioned. Because this is a new technique, a substantial part of these results are reported in the abstract books of international scientific congresses. Their number is increasing yearly and they are progressively published in peer-reviewed journals. This is a similar evolution to other techniques in medicine in generall ${ }_{n}$ and pain medicine in particular. Although there is an increasing focus in the literature for PRF, the question still remains: "What is its place in the pain management algorithm?". 
In order to answer this question it is important to understand the concept behind RF and PRF treatment. It is presumed that the mode of action of RF heat lesions is that by selectively heating nervous structures, denervation can impede nociceptive input. However, the observation that after RF treatment pain relief lasts longer than the sensory loss in the relevant dermatome $e^{23}$, gave rise to the theory that heat is not the only mode of action and that other factors responsible for pain relief may be involved. Furthermore the role of heat was questioned after the results of Slappendel et al. ${ }^{8}$ who found no difference in patient outcome with RF treatment when an electrode tip temperature of $40^{\circ} \mathrm{C}$ was used compared to RF at $67^{\circ} \mathrm{C}$. Thus it was hypothesized that there must be another ${ }_{i}$ perhaps additional mechanism besides heat that alters pain signal transmission.

So PRF was conceived as a novel, potentially safer mode of administration of RF energy, whereby in $1 \mathrm{~s}$ two bursts of $20 \mathrm{~ms}$ each of an alternating current are delivered. The oscillating frequency of the alternating current is $500 \mathrm{KHz}$. During one cycle the "active phase" of $20 \mathrm{~ms}$ is followed by a "silent phase" of $480 \mathrm{~ms}$ to allow the generated heat to washout. The output is usually set at $45 \mathrm{~V}$, but if the electrode tip temperature exceeds $42^{\circ} \mathrm{C}$, the voltage is decreased.

In our review we have shown that since the initial publication on PRF treatment for spinal pain in $1998^{23}$, information from prospective and retrospective trials as well as several case reports on the percutaneous use of PRF is accumulating as illustrated in table 1. Interestingly, the transcutaneous use of PRF, which is a different application, has been documented to provide good pain relief in different modes. The available information on PRF treatment does not allow pooling the data because of the differences in the reporting, but also because of the fact that the technical parameters such as voltage, impedance, time of application of the PRF current and resulting electrode tip temperature are not always reported. There is an urgent need for a more standardized data collection and reporting.

In general RF stimulation within frequencies between $300 \mathrm{~Hz}$ and $300 \mathrm{GHz}$ create electrical fields, which generate both current and heat on exposed biological substrates. It is clear that heat lesions of neural substrates above $45^{\circ} \mathrm{C}$ result in nonselective destruction of both myelinated and non-myelinated nerve fibers ${ }^{99}$. However it has been shown that PRF and RF have differential neurobiological effects ${ }^{97}$ aside from the heat-induced morphological changes, c-Fos activation, a marker for neuronal activity in the rat dorsal horn, has been reported to be expressed immediately $(3 \mathrm{hrs})^{94}$ and up to 7 days ${ }^{95}$ after PRF treatment. The fact that c-Fos is present 7 days after stimulation suggests sustained activation of a pain-inhibiting process. The duration of Fos-like immunoreactivity exceeding the expected length of time for c-Fos expression caused by the acute effect of surgery and electrical stimulation of sensory nerves may be due to the inhibition of excitatory $\mathrm{C}$-fiber responses as seen in 
long-term depression, according to an accompanying editorial ${ }^{76}$. Moreover, it was recently reported that the biological effect of PRF was unlikelly to be related to an overt thermal damage and appears to be selective in that it targets the group of neurons whose axons are the small diameter $\mathrm{C}$ and $\mathrm{A}-\delta$ nociceptive fibers ${ }^{96}$.

We also found that PRF alters synaptic transmission. In vitro PRF stimuli of organotypic slices of the hippocampus induce transient decrease in excitatory postsynaptic potential with rapid and complete recovery, while in contrast, continuous RF create long lasting blockade of synaptic transmission even in temperatures $\angle 45^{\circ} \mathrm{C}$. Both continuous and pulsed RF treatments induce distance dependent tissue destruction under the stimulating needle, but the effect was more pronounced in the continuous group ${ }^{97}$. Similarly a morphological evaluation of the rabbit DRG two weeks after sham, continuous and pulsed RF, illustrated no pathological findings in control and sham operated group, minimal morphological changes in the PRF group and neurodestruction in the continuous RF group ${ }^{98}$. All these findings together indicate that the effects of PRF are more reversible and less destructive than those of continuous $R F$, even when lesions are performed $<45^{\circ} \mathrm{C}$.

Despite the fact that PRF might operate by modulating pain perception rather than directly destroying neural tissue, at present it is difficult to relate the results of these experiences to clinical data. Little is known about how PRF procedures at frequencies and temperatures used in current clinical practice would modify central and peripheral components of pain pathways and further well-designed in vitro and in vivo experiments are needed to clarify this issue. In addition, lesion parameters (sensory and motor stimulation thresholds), electrode position, lesion duration and local tissue properties can all be important variables, which may influence clinical outcome.

In face of this laboratory evidence a recent editorial urged practitioners to conduct randomized clinical trials to demonstrate the effectiveness (or lack thereof) of PRF treatment and only then use these data as a tool to understand and advance the technique $^{76}$. We find this statement troubling. Conducting sham controlled RCT's in interventional pain management has been shown to have important methodological and ethical limitations ${ }^{70,100-104}$. Randomized clinical trials have indeed become the gold standard for assessing the effectiveness of therapeutic agents but often produce inconsistent results ${ }^{105}$ and can have limited external validity ${ }^{106}$. Furthermore, Concato reported recently in the New England Journal of Medicine ${ }^{107}$ and The Lan$\mathrm{cet}^{108}$ that the results of well-designed observational studies do not systematically overestimate the magnitude of the effects when compared with randomized clinical trials. 


\section{Conclusions}

Animal data suggest that $P R F_{\text {I }}$ as an alternative mode to administer RF energy, has genuine differential biological effects in cell morphology, synaptic transmission and pain signaling. which are minimally destructive and non-temperature dependent. The clinical data on the use of PRF are progressively accumulating and up to now no report on neurological complications are documented. In order to further elucidate the mode of action of PRF and to define its true value in the management of chronic pain, more research on this promising technique is justified.

\section{Acknowledgements}

The authors would like to thank the other members of the European Collaborative Group for the Research of Pulsed Radiofrequency (ECG-PRF), Jacob Patijn, MD, $\mathrm{PhD}$, Neurology and Elbert Joosten, PhD, Medical Biology from the University Hospital Maastricht, Maastricht, The Netherlands; Wolfgang Hamann, MD, PhD, Anesthesiology; Teo Goroszeniuk, MD, Anesthesiology; Susan Hall, PhD, DSc, Anatomy and Human Sciences; Andy Adam, MD, PhD, Radiology; Natalie Gardiner, PhD; Derek Light, MD and Stephen Thompson, MD, Biological Science from Guy's, Kings and St. Thomas School of Medicine and School of Biomedical Sciences, London, United Kingdom and Laszlo Vutskits, MD, PhD, Anesthesiology; Dominique Muller, $\mathrm{PhD}$, Neuropharmacology, and Joszef Kiss, PhD, Morphology from the Geneva University Hospital and the University Medical School, Geneva, Switzerland for their endless efforts in exploring the effects of PRF, and to my dear colleague Philippe Mavrocordatos, MD, Anesthesiology for the endless hours of arguing whether PRF is real or not. Finally, the authors want to thank Nicole Van den Hecke for administrative coordination and patiently counting and aligning data and papers into a table. 


\section{References}

1. van Sujlekom JA, van Kleef M, Barendse G, Slujter ME, Sjaastad O, Weber WEJ. Radiofrequency cervical zygapophyseal joint neurotomy for cervicogenic headache. A prospective study in 15 patients. Functional neurology $1998 ; 13: 297-303$

2. Dubuisson D. Treatment of occipital neuralgia by partial posterior rhizotomy at $\mathrm{C} 1-3 . \mathrm{J}$ Neurosurg 1995; 82: $584-586$

3. Lord SM, Barnsley L. Bogduk $N$. Perculaneous radiofrequency neurotomy in the treatment of cervical zygapophyseal joint pain: a caution. Neurosurgery 1995; 36: 732-739

4. van Kleef $M$, Liem L, Lousberg R, Barendse $G$, Kessels $F$, Sluifter M. Radiofrequency lesion adjacent to the dorsal root ganglion for cervicobrachial pain: a prospective doubie blind randomized study. Neurosurgery 1996; 38: 1127-1131; discussion 1131-1122

5. van Kleef M, Spaans F, Dingemans W, Barendse GAM, Floor E, Slujter ME Effects and side effects of a percutaneous thermal lesion of the dorsal root ganglion in patients with cervical pain syndrome. Pain 1993; $52: 49-53$

6. Slappendel R, Crul BJ, Braak GJ, Geurts JW, Booil LH, Voerman VF, de Boo T. The efficacy of radiofrequency lesioning of the cervical spinal dorsal root ganglion in a couble blinded randomized study: no difference between 40 degrees $C$ and 67 degrees $C$ trealments. Pain $1997 ; 73$ : $159-163$

7. van Kleef $M$, Spaans $F$. The effects of producing a radiofrequency lesion adjacent to the dorsal root ganglion in patients with thoracic segmental pain by radiofrequency percutaneous partial rhizotomy. Clin J Pain 1995; 11: 325-332

8. Geurts JWM, van Wijk RM, Wynne Hd, Hammink $E_{x}$ Buskens E, Lousberg $R$, Knape JT, Groen GJ. Radiofrequency lesioning of dorsal root ganglia for chronic lumbosacral radicular pain. A randomised, double blind, controlled trial. Lancet $2003 ; 361: 21-26$

9. van Wijk RM, Geurts. JW, Wynne HJ. Long-lasting analgesic effect of radiofrequency treatment of the lumbosacral dorsal root ganglion. J Neurosurg 2001; 94: 227-231

10. van Kleef $M$, Barendse GA, Kessels F, H.M.Voets, Weber WE, de Lange $S$. Randomized trial of radiofrequency lumbar facet denervation for chronic low back pain. Spine 1999; 24: 1937 1942

11. Dreyfuss $P$. Halbrook $B$, Pauza $K$, Joshi $A$, McLarty $J$, Bogduk $N$. Efficacy and validity of radiofrequency neurotomy for chronic lumbar zygapophyseal joint pain. Spine 2000; 25: 1270-1277

12. Gallagher J, Vadi PLP, Wesley JR. Radiofrequency facet joint denervation in the treatment of low back pain-a prospective controlled double-blind study in assess to efficacy. Pain Clinic 1994: 7: 193-198:

13. Leclaire $R$, Fortin $L$, Lambert $R$, Bergeron $Y M$, Rossignol $M$. Radiofrequency facet denervation in the treatment of low back pain: a placebo-controlled clinical trial to assess efficacy. Spine 2001: $26: 1411-1416$.

14. Barendse $G$, van Den Berg SG, Kessels $F$, Weber WE, van Kleef $M$. Randomized controlled trial of percutaneous intradiscal radiofrequency thermocoagulation for chronic discogenic back pain: lack of effect form a 90-second $70^{\circ} \mathrm{C}$ lesion. Spine 2001:26: $287-292$

15. Ercelen O, Bulutcu $E$, Oktenoglu T, Sasani M. Bozkus H, Cetin Saryoglu A, Ozer F. Radiofrequency lesioning using two different time modalities for the treatment of lumbar discogenic pain: a randomized trial. Spine 2003; 28: 1922-1927

16. Ferrante $F M$, King LF, Roche SA, Kim PS, Aranda M, Dellaney LR, Mardini IA, Mamnes AJ. Radiofrequency sacroiliac joint denervation for sacroiliac syndrome. Reg Anesth Pain Med 2001; 26: 137-142

17. Cohen SP. Abdi S. Lateral branch blocks as a treatment for sacroiliac joint pain: A pilot study. Reg Anesth Pain Med 2003; 28: 113-119

18. Way Yin. Willard F. Carreiro J, Dreyfuss P. Sensory stimulation-guided sacroiliac joint radiofrequency neurotomy technique based on neuroanatomy of the dorsal sacral plexus. Spine 2003: 28: 2419-24:25 
19. Geurts J, van Wijk RM, Stolker $R$, Groen GJ. Efficacy of radiofrequency procedures for the treatment of spinal pain: a systematic review of randomized clinical trials. Reg Anesth Pain Med 2001; 26: 394-400

20. Niemisto $L$, Kalso $E$, Malmivaara $A$, Seitsalo $S$, Hurri $H$. Radiofrequency denervation for neck and back pain. A systematic review of randomized controlled trials. Cochrane Database Syst Rev $2003 ;$ CD004058

21. Slipman CW, Bhat AL, Gilchrist RV, issac $\mathbb{Z}$, Chou L, Lenrow DA. A critical review of the evidence for the use of zygapophyseal injections and radiofrequency denervation in the treatment of low back pain. Spine J 2003; 3:310-316

22. Hooten WM, Martin DP, Huntoon MA. Radiofrequency neurotomy for low back pain: evidencebased procedural guidelines. Pain Med 2005; 6: 129-138

23. Sluijter ME, Cosman ER, Rittman IIWB, van Kleef M. The effects of pulsed radiofrequency field applied to the dorsal root ganglion - a preliminary report. The Pain Clinic 1998; 11: 109-117

24. Sluijter M, van Kleef M. Characteristics and mode of action of RF lesions. Curr Rev Pain 1998; 2:

25. Munglani $R$. The longer term effect of pulsed radiofrequency for neuropathic pain. Pain 1999 80: $437-439$

26. Van Zundert J Brabant S, Van de Kelft E, Vercruyssen A, Van Buyten JP. Pulsed radiofrequency treatment of the Gasserian ganglion in patients with idiopathic trigeminal neuralgia. Pain 2003; 104: 449-452

27. Van Zundert $\downarrow d$, Lamé $I E$, de Louw $A$, Jansen $J$ "Kessels $F$, Patijn J, van Kleef M. Percutaneous Pulsed Radiofrequency Treatment of the Cervical Dorsal Roat Ganglion in the Treatment of Chronic Cervical Pain Syndromes: A Clinical Audit. Neuromodulation 2003; 6: 6-14

28. Rathmell JP, Carr DB. The scientific method evidence-based medicine, and rational use of interventional pain treatments. Reg Anesth Pain Med 2003; 28: 498-501

29. Lau J, Antman EM, Jimenez-Silva J, Kupelnick B, Masteller F, Chalmers. TC. Cumulative metaanalysis of therapeutic trials for myocardial infarction. N Engl J Medi 1992; 327: 248-254

30. Sheally CN. Percutaneous radiofrequency denervation of spinal facets. J Neurosurg $1975 ; 43$ : 448-451

31. Barolat $G$, Schwartzman $R$, Woo R. Epidural spinal cord stimulation in the management of reflex sympathetic dystrophy. Stereotact Funct Neurosurg 1989; 53: 29-39

32. Kemler MA, Barendse: $G A_{\text {, van Kleef }} M_{x}$ de Vet HC, Rijks CP. Furnee $C A$, wan den Wildenberg FA. Spinal cord stimulation in patients with chronic reflex sympathetic dystrophy. N Engl J Med 2000; 343: 618-62.4

33. Van Zundert J, Brabant S, Van de Kelft E, Vercruyssen A, Van Buyten JP. Response to Zakrzewska"s Letter to the Editor. Pain 2004; 109: 520-522

34. Padfield N: Pulsed radiofrequency treatment; a novel form of 'on-off' neuromodulation. In: 6th INS World Congress. (INS, Ed). International Neuromodulation Society, Madrid. (2003). 68 abstr. 47

35. Vallejo $R$, Benyamin RM, Stanton G: Pulse radiofrequency denervation: an effective treatment for untreatable sacro-lliac joint syndrome. In: 3rd World Congress of WIP. (Devor M, Erdine, $S$ \& Ruiz-Lopez, R, Eds). Blackwell publishing, Barcelona. (2004). 91-92

36. Castellanos R. Suprascapular Pulsed Radiofrequency Neurotomy: A new approach in the treatment of chronic shoulder pain. Arch Phys Med Rehabil 2004; 85: E42

37. Mikeladze $G$, Espinal $R$, Finnegan $R$, Routon J, Martin D. Pulsed radiofrequency application in treatment of chronic zygapophyseal joint pain. Spine $\mathrm{J}$ 2003; 3: 360-362

38. Kamran S: Role of pulse radiofrequency rhizotomy in the management of cervicobrachial pain. In: American Pain Society). Journal of Pain. (2004).

39. Teixeira A: Results of pulsed RF treatment of the DRG for hemiated disc in the lumbar region. In: 3rd World Congress of WIP. (Devor M, Erdine, S \& Ruiz-Lopez, R, Eds). Blackwell publishing, Barcelona. (2004). 220

40. Erdine S: Techniques and results of pulsed RF treatment of the DRG in failed back surgery patients. In. 3rd World Congress of WIP. (Devor M, Erdine, S \& Ruiz-Lopez, R, Eds). Blackwell publishing, Barcelona. (2004). 219 
41. Abejon D, Delgado C, Garcia del Valle S, Nieto C, Gomez-Amau J; Effects of applied pulsed radiofrequency to the lumbar spinal dorsal root ganglion. Comparative study among three groups. In: 3rd World Congress of WIP. (Devor M, Erdine, S \& RuizwLopez, R, Eds). Blackwell publishing, Barcelona. (2004): 92

42. Sluijter ME, Van Zundert $J$, van Kleef M, Kessels $F$, Schleinzer W: Factors influencing the outcome of Pulsed Radiofrequency procedures. In: Pain in Europe 4th Congress of EFIC. $((E F I C)$ EFolC, Ed). EFlC, Prague. (2003). 322 abstract nr. $486 \mathrm{~F}$

43. Ruiz-Lopez $R$, Pichot $C$, Acosta A: The influence of contrast medium in the clinical outcome of pulsed radiofrequency (PRF) treatment of the dorsall root ganglion. In: 3rd World Congress, World Institute of Pain. (Devor M, Erdine, S \& Ruiz-Lopez, R, Eds). Blackwell publishing, Barcelona, Spain. (2004). 98

44. Kane T, Hazelgrove J, Harper G, Rogers P: Pulsed radiofrequency ablation to the suprascapular nerve for chronic shoulder pain secondary to rotator cuff tear arthropathy. $\ln$ : 40 th World Congress on Pain), San Diego. (2002). 421 - 1272-P1188

45. Bayer $E$, Racz $G B$, Mites $R$, Heavner JE: Sphenopalatine ganglion pulsed-radiofrequency in 46 patients suffering from chronic face and neck pain. In: 3rd World Congress of WIP. (Devor $M$, Erdine, S \& Ruiz-Lopez, $\mathbf{R}_{n}$ Eds). Blackwell publishing, Barcelona. (2004). 126-134

46. Rohof OJJM. Radiofrequency treatment of Peripheral Nerves. Pain Practice 2002; 2: 257-260

47. Ahadian FM. Pulsed radiofrequency neurotomy: advances in pain medicine. Curr Pain Headache Rep 2004; 8: 34-40

48. Ruiz-Lopez R, Acosta A, Pichot C: Treatment of painful scar and neuromas with pulsed radiofrequency (PRF): Preliminary results in 16 patients. In: 3rd World Congress of WIP. (Devor $M$, Erdine, S \& Ruiz-Lopez, R, Eds). Blackwell publishing, Barcelona. (2004). 98

49. Shinozaki $M$, Toyokawa $H_{*}$ Tachikawa $S$, Naganuma $Y$, Oseto $K$ : Root block using pulsed radiofrequency for patients with neuropathic pain. In: 3rd World Congress of WIP. (Devor M, Erdine, S \& Ruiz-Lopez, R, Eds). Blackwell Publishing, Barcelona. (2004). 91

50. Munglani $R$, Stauffer KA. Pulsed Radiofrequency Treatment of Chronic Neck, Back, Sympathetic, and Peripheral Neuroma-Derived Pain, Pain: current understanding, emerging therapies and novel approaches to drug discovery, Edited by Bountra C, Munglani, R \& Schmidt, W. New York, Marcel Dekker, 2003, pp 213-222.

51. Abejon $D_{n}$ Garcia del Valle $S$, Nieto $C$, Delgado $C$, Gomez-Arnaut II. IPulsed radiofrequency treatment in idiopathic and secondary glossopharyngeal neuralgia: preliminary results in 2 cases]. Rev Esp Anestesiol Reanim 2005; 52: 109-114

52. Shah $R_{t}$ Racz GB. Pulsed Mode Radiofrequency Lesioning to Treat Chronic. Post-tonsillectomy Pain (Seciondary Glossopharyngeal Neurallgia). Pain Practice 2003; 3: 232-237

53. Shah RV, Racz GB. Long-term relief of posttraumatic headache by sphenopallatine ganglion pulsed radiofrequency lesioning: a case report. Arch Phys Med Rehabil 2004; 85: 1013-1016

54. Cohen SP, Foster A. Pulsed radiofrequency as a treatment for groin pain and orchialgia. Urology $2003 ; 61: 645 \times x i-645 \times x$ iii

55. Padfield $\mathbb{N}$ : Pulsed radiofrequency treatment to the $\mathrm{C} 2$ and $\mathrm{C} 3$ dorsal root ganglia in refractory occipital neuralgia, a reliable alternative to peripheral nerve stimulation? In: 6th INS World Congress. (INS, Ed). International Neuromodulation Society, Madrid. (2003). 68 abstr. 46

56. Ferrer-Garcia D, Nitu A: Pulsed radiofrequency treatment for refractory sacroiliac and low back pain. In: 3rd World Congress of WIP. (Devor M, Erdine, $S$ \& Ruiz-Lopez, R, Eds). Blackwell publishing. Barcelona. (2004). 92

57. Gauchi C: Pulsed Radiofrequency for the Management of Discogenic Low Back Pain. In: 9th World Congress. (Clinic TP, Ed), San Francisco - USA. (2000)

58. Gofeld M: Pulsed radiofrequency treatment of intractable meralgia paresthetica: case study. In: 6th INS World Congress. (INS, Ed). Intemational Neuromodulation Society, Madrid. (2003). 58 abstr. 22

59. Hamann W, Hall $S$, Sherif $S$, di Valdi $P$, Adam A: Relief from severe neuropathic pain without loss of touch sensation following needle injury of L5 root by CT-guided pulsed radiofrequency (PRF) of dorsal root ganglion (DRG). In: 10 th World Congress on Pain), San Diego. (2002). 420 abstract 1269-P1185 
60. Kuthuru M, Kabbara A. Boswell M. Pulsed Radiofrequency. Reg Anesth Pain Med 2003; 28: A56

61. Tekin I. Erhan $E_{i}$ Yegul I: Pulsed RF of cervical DRG for the treatment of complicated whiplash injury: a case report. In: 3ro World Congress of WIP. (Devor $M$, Erdine, $S$ \& Ruiz-Lopez, $R$, Eds). Blackwell publishing, Barcelona. (2004). 92-93

62. Yegul I, Eman E, Tekin I: Pulsed RF of suprascapular nerve as a treatment for chronic shoulder pain. In: 3rd World Congress of WIP. (Devor M, Erdine, S \& Ruiz-Lopez, R, Eds). Blackwell publishing. Barcelona (2004). 92

63. Van Boxem $K$, Van Zundert J, Puylaert $M$, Heylen $R$, Vissers K: Pulsed radiofrequency trealment of the Gasserian ganglion in trigeminal neuralgia. In: 1st World Congress on Regional Ariaesthesia and Pain Therapy - joint meeting of ESRA, ASRA, LASRA, and OASRA. (Medicom, Ed). IMRAPT, Barcelona. (2002), abstr; No. 189

64. Bostyn $A_{i}$ Vercruysse $P$, Ver Donck $A$ : Pulsed radiofrequency treatment for less-common atypicall, neuropathic or refractory trigeminal neuralgia. In: PRF. (Hamann W, Ed), London. (2003).

65. Erdine S: Pulsed RF does not relieve trigeminal neuralgia. in: 2nd World Congress of WIP. (Raj PP, Ed). Blackwell Science, Istanbul. (2001). 384

66. Nagels $W$. Brabant $S$, Van Zundert $J$ "Dobbels $P$. Treatment of refractory atypical facial pain with pulsed radiofrequency electrical current applied at the Gasserian ganglion. In: 3rd World Congress of WIP. (Devor M, Erdine, S \& Ruiz-Lopez, R, Eds). Blackwell publishing, Barcelona. (2004). 95-96

67. Shah RV, Ericksen $\mathrm{J} J$, Lacerte $M$. Interventions in chronic pain management. 2. New frontiers: invasive nonsurgical interventions. Arch Phys Med Rehabil 2003; 84: S39-44

68. Sluifter M, Racz GB. Technical Aspects of Radiofrequency. Pain Practice 2002; 2: 195-200

69. Sluijter ME. The role of radiofrequency in failed back surgery patients. Curr Rev Pain 2000; 4 : $49-53$

70. Van Zundert J, Raj $P$, Erdine $S_{s}$ van Kleef $M$. Application of Radiofrequency Treatment in Practical Pain Management: State of the Art. Pain Practice 2002; 2: 269-278

71. Abejon D, Reig E. ls Pulsed Radiofrequency a Neuromodiulation Technique? Neuromodulation $2003 ; 6: 1-3$

72. Devulder $\mathrm{J}$, Crombez $\mathrm{G}$, Brusselmans $\mathrm{G}$. Comment on "Pulsed radiofrequency treatment of the Gasserian ganglion in patients with idiopathic trigeminal neuralgia". Pain 2004; 107: 195

73. Van Zundert J. Response to 'Comment on Pulsed radiofrequency treatment of the Gasserian Ganglion in patients with idiopathic trigeminal neuralgia'. Pain 2004; $107: 196$

74. Orlandini G. Pulsed percutaneous radiofrequency treatment of the Gasserian ganglion for therapy of trigeminal rieuralgia: technical notes, validity of the method and selection of the patients. Pain 2004; 108: 297-298

75. Van Zundert J, Brabant S, Van de Kelft E, Vercruyssen A. Response to Orlandini"s letter to the editor, regarding Pulsed radiofrequency treatment of the Gasserian ganglion. Pain 2004; 108 : 298-299

76. Richebe $P$, Rathmell JP, Brennan TJ. Immediate early genes after pulsed radiofrequency treatment: neturoblology in need of clinical trials. Anesthesiology 2005; 102: 1-3

77. Van Zundert J, Raj P. Editorial. Pain Practice 2002; 2: 174-175

78. Zakrezewska J, Lopez BC. New techniques for surgical management of trigeminal meuralgia. Pain 2004: 109: 520

79. Cahana A: PRF treatment for Cervical Pain: Fact of Fiction? In: 3rd World Congress of WIP. (Devor M, Erdine, S \& Ruiz-Lopez, R, Eds). Blackwell publishing, Barcelona. (2004). 125

80. Holsheimer J. Letters to the Editor. Neuromodulation 2003; 6:270-271

81. Helm II S, Eisler R. Letters to the Editor. Neuromodulation 2003; 6: 272-273

82. All-Badawi EA, Mehta N, Forgione AG, Lobo SL, Zawawi KH. Efficacy of pulsed radio frequency energy therapy in temporomandibular joint pain and dysfunction. Cranio 2004; 22: 10-20

83. Borg-Stein J, Seroussi R. Safety and Efficacy of Percutaneous Neuromodulation Therapy in the Management of Subacute Radiating Low Back Pain. Pain Practice 2003: 3: $125-134$ 
84. White PF, Craig WF, Vakharia AS, Ghoname E, Ahmed HE, Hamza MA. Percutaneous neuromodulation therapy: does the location of electrical stimulation effect the acute analgesic response? Anesth Analg 2000; 91: 949-954

85. White PF, Craig WF, Vakharia AS. Percutaneous neuromadulation therapy: does the location of electrical stimulation effect the acute analgesic response? Pain Practice 2001: 1: 200-2001

86. Balogh S. Transcutaneous Application of Pulsed Radiofrequency: Four Case Reports. Pain Practice $2004 ; 4: 310$

87. Wallace $\mathrm{MC}$, Tator $\mathrm{CH}$, Gentles WM. Effect of alternating current stimulation of the spinal cord on recovery from acute spinal cord injury in rats. Surg Neurol 1987; 28: 269-276

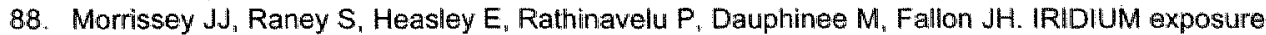
increases c-fas expression in the mouse brain only at levels which likely result in tissue heating. Neuroscience 1999; 92: 1539-1546

89. de Louw AJA, Vles HSH, Freling G, Herpers MJHM, Arends JW, van Kleef M. The morphological effects of radiofrequency lesion adjacent to the dorsal root ganglion (RF-DRG) - An Experimental study in the goat. Eur. J. of Pain 2001; 5: $169-174$

90. Tun, Kanpolat $Y$ : Histopathological and electron microsicopic examination of PRF and RF thermo coagulation lesions in rat brain. In: Neurosurgery), Turkey. (2002). 1093 abstr 1094.1017

91. Archer $S$, LI TT, Evans AT, Britland ST, Morgan H. Cell reactions to dielectrophoretic manipulation. Biochem Biophys Res Comm 1999; 257: 687-698

92. Kovacs KJ. c-Fos as a transcription factor: a stressful (re)view from a functional map. Neurochem Int 1998; 33: 287-297

93. Munglani R, Hunt SP. Proto-oncogenes: basic concepts and stimulation induced changes in the spinal cord. Prog Brain Res 1995; 104: 283-298

94. Higuchi $Y$, Nashold BS, Sluijter ME, Cosman E, Pearlstein RD. Exposure of the dorsal root ganglion in rats to pulsed radiofrequency currents activates dorsal horn lamina I and Ill neurons. Neurosurgery 2002; 50: 850-856

95. Van Zundert J, de Louw AJ Jloosten EA, Kessels AG, Honig W, Dederen $P \Downarrow$, Veening JG, Vles JS, van Kleef M. Pulsed and continuous radiofrequency current adjacent to the cervical dorsal root ganglion of the rat induces late cellular activity in the dorsal horn. Anesthesiology 2005; 102: $125-131$

96. Hamann W, Abou-Sherif $S$, Thompson S, Hall S. Pulsed radiofrequency applied to dorsal root ganglia causes a selective increase in ATF3 in small neurons. Eur J Pain 2005; in press:

97. Cahana $A$, Vutskits L, Muller D. Acute Differential Modulation of Synaptic Transmission and Cell Survival During Exposure to Pulsed and Continuous Radiofrequency Energy. The Journal of Pain 2003; $4: 197-202$

98. Erdine $S$, Yucel A, Cimen A. Aydin S, Sav A, Bilir A. Effects of pulsed versus conventional radiofrequency current on rabbit dorsal root ganglion morphology. European لJournal of Pain 2005; 9 (3): 251-256

99. Smith HP, McWhorter $J M_{\text {, }}$ Challa VR. Radiofrequency neurolysis in a clinical model. Neuropaw thological correlation. J Neurosurg 1981; 55: 246-253

100. Carr DB, Goudas LC. Evidence-based pain medicine: the good, the bad, and the ungly. Reg Anesth Pain Med 2001; 26: 389-393

101. Carr DB, Goudas LC. Reply to Dr. Bogduk. Regional Anesthesia and Pain Medicine 2002; 27 :

102. Carr DB, Goudas LC. Burning questions, randomized controlled trials, and the pain doctor's dilemma. Reg Anesth Pain Med 2003; 28: 360-361

103. Horton R. Second opinion Doctors; Diseases and Decisions in Modern Medicine, London, Granta Books, 2003,

104. Lenrow DA, Chou LH. Randomized controlled Trials in Interventional Spine: perils and pitfalls Pain Physician 2003; 6. 83-87

105. Horwitz RI. Complexity and contradiction in clinical trial research. Am J Med 1987; 82: $498-510$

106. Rabeneck L, Viscoli CM. Horwitz RI. Problems in the conduct and analysis of randomized clinical trials. Are we getting the right answers to the wrong questions? Arch Intern Med 1992; 152 : 507-512 
Pulsed radiofrequency : current literature available

107 Concato $J$, Shah $N$, Horwitz Rl. Randomized, controlled trials, abservational studies, and the hierarchy of research designs. N Engl $\mathrm{J}$ Med $2000 ; 342: 1887-1892$

108. Concato J. Honwitz RI. Beyond randomised versus obserwational studies. Lancel 2004; $363^{\text {* }}$ $1660-1661$ 


\section{CHAPTER X}

\section{General discussion}


Based on the research described in this thesis two major issues can be suggested for future investigation.

\title{
1. Basic research on the mode of action of pulsed radiofrequency (PRF)
}

\section{Clinical research on the use of PRF in chronic pain management}

\author{
2A Preferred indications for the use of PRF \\ 2B Optimal setting of the different electrophysical parameters in PRF \\ 2C Development of consensus guidelines on the appropriate use of PRF \\ amongst other interventional pain management techniques \\ 2D Development of a more appropriate methodology for clinical research in \\ interventional pain management techniques
}

\section{Basic research into the mode of action of pulsed radiofre- quency}

Two major mechanisms in the nerve are thought to induce radicular pain: (1) inflammatory processes and (2) changes in ion-channel functioning. The role of the dorsal root ganglion (DRG) in cervical radicular pain has not been completely elucidated and the impact of the electric field and/or current on the ion-channel modulation and the spontaneous firing DRG should be further investigated (Chapter III). The impact of PRF current on the inflammatory processes through potential inhibition of the release of trophic molecules and cytokines or the inactivation of receptors such as the vanilloid receptors and the heat-sensitive vanilloid-like receptors should be studied in appropriate animal models. We described the calculated effect of the high-density field on the trans-membrane potential of the nerve cell (Chapter IV).

Histological studies of the DRG and/or the nerve root may provide answers to the question relative to the effect on the target structure. Although electrophysiological measurements in cell cultures were performed ${ }^{4}$ it is obvious that attempts should focus on unraveling the in vivo effect of PRF on the nervous tissue. It is suggested that an electrophysiological study using Quantitative Sensorial Testing may shed a light on the influence of PRF on neuropathic pain. The basic research work reported in this thesis and in the literature review indicates that PRF initiates a transsynaptic neuronal activity in the spinal cord (Chapter $V$ and $I X$ ). Moreover, the repetitive stimulation of spinal networks has been suggested to result in the formation of new cells in the spinal cord ${ }^{2}$. Our preliminary protocol on the identification of cell proliferation and neogenesis using bromodeoxyuridine (BrdL) labeling techniques in the spinal cord did not allow any conclusion. Therefore an adapted protocol of BrdU labeling should be tested. A central effect of PRF treatment adjacent to the DRG 
was studied in the dorsal horn (Chapter V). Our observations on late bilateral c-Fos expression in the rat suggest that bilateral effects might be obtained in clinical practice. To our knowledge this has not been investigated. Further clinical research is needed to evaluate this potential bilateral response.

The findings of the transsynaptal induction of gene expression in the dorsal horn are potentially significant from a clinical point of view. If these findings were in fact an integral part of the mode of action, this would explain the fact that PRF procedures have a clinical effect, even if they are applied distal to the source of nociception. The increase of the early gene expression c-Fos in the dorsal horn after application of PRF current adjacent to the DRG only provides an indication in favor of central effects of PRF treatment of the DRG. The mode of action as suggested for PRF treatment of the DRG may be at least to some extent comparable to that described for nociception. Nociception causes a depolarization of the first neuron, with its cell body in the DRG. Ultimately nociception results in gene expression at the same location as (P)RF (chapter III and V). In PRF however, the mechanism of transsynaptal induction must be different. The frequency during the active phase of PRF is far beyond the physiological range. The way PRF acts on the DRG and/or the dorsal afferents is yet unknown. Nevertheless nociception is likely to result in spontaneous firing, due to which dramatic and physiological changes occur at the spinal cord level including the upregulation of neuropeptides, neurotransmitters and alterations in gene transcription. These changes are associated with increased excitability of neurons in the spinal cord, a phenomenon called central sensitization ${ }^{3}$.

The realization of the future basic research on the role and mode of action of $(P) R F$ will be done within the European Collaborative Group for the research of PRF in the University Hospital Maastricht, Maastricht, The Netherlands; Guy's, Kings and St. Thomas School of Medicine and School of Biomedical Sciences, London, United Kingdom and the University Medical School, Geneva, Switzerland. 


\section{Clinical research on the use of pulsed radiofrequency in chronic pain management}

When addressing this second issue several other items need to be addressed:

\section{A Preferred indications for the use of PRF}

As already outlined, PRF is a modified technique to use electrical current in pain management. Though its mode of action is not completely elucidated, there are accumulating reports on its clinical effects. Pulsed radiofrequency induces a high intensity electric field capable of changing the pain signal conduction without inducing clinically notable lesions to the nervous system. Up till now there are no mentions of deafferentation syndromes, which are particularly feared when targeting nerves with mixed sensory and motor functions. Therefore we suggest to concentrate the further clinical research with PRF on: the cervical and lumbosacral DRG, the Gasserian ganglion and peripheral nerves. Our research was focused on PRF at the cervical DRG in cervical radicular pain, in order to allow estimating the extend and the impact of this pain syndrome, a high quality population-based epidemiologic study on incidence and natural history of cervical radicular pain appears warranted.

\section{B Optimal setting of the different electrophysical parameters in PRF}

The use of short lasting bursts of high frequency electrical current followed by a silent period cannot be compared to any other use of electric current in pain management (chapter IV). The settings of the different parameters have been arbitrary chosen and some initial work has been done on their impact on clinical outcome 4 . The electric field has been advocated to play a major role in the effect of PRF. The total intensity of this field is however influenced by parameters such as voltage, amperage, puise duration and frequency of pulse application and the characteristics of the surrounding tissue; blood supply etc. The impedance measured in the target tissue may influence the treatment outcome and the relation of the injection a small volume of saline to reduce the impedance with treatment outcome must be investigated. Prospective studies designed to evaluate the influence of one parameter at the time may be helpful in optimizing the use of PRF.

Furthermore, there is a need for the use of a standardized terminology for RF techniques. The descriptions used in the literature: denervation, heating, lesioning, neurolysis " neurotomy, rhizolyis, rhizotomy, thermocoagulation, treatment, ... is too confusing. 


\section{C Development of consensus guidelines on the appropriate use of PRF amongst other interventional pain management techniques}

Patients suffering intractable chronic pain originating from the spinal column are the largest patient population referred to pain centers. Many therapeutic interventions for spinal pain are available, and decisions about optimal management are not easy to make. Too often patients are referred to pain clinics when they already had unsuccessful spinal surgical treatment without prior multidisciplinary evaluation. There is a high need for interdisciplinary guidelines on the role of interventional pain management techniques versus spine surgery in the treatment algorithm of spinal pain (Chapter II). Furthermore it is important in further clinical research to include proper patient selection criteria in order to obtain more homogeneous study populations.

The knowledge and training of physicians and liability for (P)RF procedures are variable between Belgium and The Netherlands and according to an executive summary on the current status of the practice of RF in the world, also throughout the world ${ }^{5}$. Accordingly the need for establishing consensus guidelines on teaching, adequate and appropriate theoretical knowledge and practical training of these procedures is high. In this view the development of the international practical interventional examination where candidates can become a Fellow in Interventional Pain Practice (FIPP), organized by the World Institute of Pain (WIP) deserves recommendation and acceptance.

\section{D Development of a more appropriate methodology for clinical research in interventional pain management techniques}

In the hierarchy of research designs, the results of randomized controlled trials are considered to be evidence of the highest grade, whereas observational studies are viewed as having less validity ${ }^{6}$. Randomized controlled trials have indeed become the gold standard for assessing the effectiveness of therapeutic agents ${ }^{7-9}$. In the literature we find different methods for ranking the evidence, the Cochrane Collaboration group gives rankings from $A 1$ (systematic reviews and meta-analysis) to $D$ (expert opinion), The Oxford-Centre for Evidence Based Medicine ranks the evidence according to the methodology as $1 \mathrm{a}, 1 \mathrm{~b}, 1 \mathrm{c}, 2 \mathrm{a}, 2 \mathrm{~b}, 2 \mathrm{c}, 3 \mathrm{a}, 3 \mathrm{~b}, 4$ and 5 . They provide a grade of recommendation from $A$ to $D$ depending on the level of the studies. Guyatt et al. published "Evidence-Based Guidelines" for the American College of Chest Physicians ${ }^{10}$. This proposed grading provides information on the clarity of the risk/benefit balance, and about the methodological quality of the evidence resulting in strength of recommendation from strong to very weak. Those differences in ratings make it for the reader of systematic reviews and recommendations not easy to unravel. 
The two systematic reviews published on radiofrequency treatment mention the low number of patients included in the RCT's as the most important weakness, leading to under powering of the studies and uncertainty about the homogeneity of the patient population. It is striking that in most of the randomized, sham controlled trials on interventional pain management techniques, a similar weakness is detected. During the patient recruitment phase in our RCT, we experienced difficulties in selecting a homogeneous patient population and in motivating the patient to participate in a study where the/she has $50 \%$ chance of receiving a sham intervention. The relatively small number of patients included in RCT's may also be attributed to the stringent inclusion criteria handled with the goal to evaluate a specific patient population. This may lead to results about a patient group that is not representative for the patients consulting in daily practice ${ }^{11}$.

Merill in his review states: "Guideline writers favor randomized controlled trials and, if few exist in the literature, the bias may be to eliminate therapy from the accepted category" ${ }^{\prime 2,13}$. In interventional pain management as with other new treatments it takes at least a 10-years delay to accumulate clinical evidence sufficient to confirm or refute the value of an intervention and present these conclusions in standard texts and reviews ${ }^{14}$. In RF's case it took even 26 years for lumbar RF facet denervation to establish its utility, between the first report in $1975^{15}$ and the first systematic review published in $2001^{16}$. This time lag has been similar in spinal cord stimulation were the first report for the treatment of complex regional pain syndrome dates from $1986^{17}$, yet the first RCT was published only in $2000^{18}$. Therefore constructing evidence for a new technique according to EBM guidelines is evolutionary. It usually starts with case reports and retrospective analysis and if these give encouraging results, prospective triais on larger number of patients are done. Finally RCT's and systematic reviews are performed ${ }^{19}$.

A comparison of the results of RCT's and contemporary performed observational studies on the same clinical topics revealed that the results of well-designed observational studies (with either a cohort or case-control design) do not systematically overestimate the magnitude of the effects of treatment as compared with those in RCT's $s^{6}$. Randomized controlled trials often produce inconsistent results ${ }^{20}$ that may lead to contradictory conclusions of systematic reviews ${ }^{21,22}$. Randomized controlled trials may also have limited external validity (generalizability) ${ }^{23}$. The evidence needed to support or refute interventional pain management techniques should provide answers on the efficacy and safety for patients consulting in daily practice, with attention for the variation in disease severity and co-morbidities ${ }^{b}$. The average randomized trial is too small and has not sufficient follow-up to detect rare adverse events $^{24}$. Large, contemporary performed, cohort trials and observational studies, prospectively conducted according to strict methods that mimic those of RCT's may be considered. The larger observational studies may overcome the major obstacle 
of patient recruitment and motivation to adhere to the study protocol and may be easier to perform in multi-center settings, thus yielding information large patient populations that may be suited for sub-analyses on specific groups, and evaluation of rare side effects and complications. This can give a better idea on the safety of the treatment under evaluation. Considering the increasing importance of the risk/benefit ratio in EBM recommendations ${ }^{10}$, the postulated improved safety of $\mathbb{P R F}$ needs to be investigated in larger observational studies. 


\section{References}

1. Calhana A, Vutskits L, Muller D. A.cute Differential Modulation of Synaptic Transmission and Cell Survival During Exposure to Pulsed and Continuous Radiofrequency Energy. The Journal of Pain 2003:4: 197-202

2. Horner PJ, Power AE, Kempermann G, Kuhn HG, Palmer TD, Winkler J, Thal LJ, Gage FH. Proliferation and differentiation of progenitor cells throughout the intact adult rat spinal cord. $J$ Neurosci 2000; 20: 2218-2228

3. Ji RR, Kohno T, Moore KA, Woolf C.J. Central sensitization and LTP: do pain and memory share similar mechanisms? Trends Neurosci 2003; 26: 696-705

4. Sluijter ME, Van Zundert $J$, van Kleef $M$, Kessels $F$, Schleinzer $W$ : Factors influencing the outcome of Pulsed Radiofrequency procedures. In: Pain in Europe 4th Congress of EFIC. ((EFIC) EFolC, Ed). EFIC. Prague. (2003). 322 abstract nr. $486 \mathrm{~F}$

5. Raj PP, Erdine S. The Current Status of the Practice of Radiofrequency in the World. Pain Practice 2002; 2: 176-179

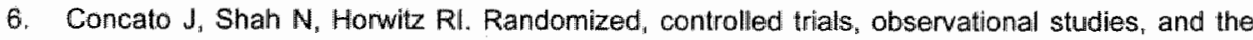
hierarchy of research designs. N Engl J Med 2000; 342 : 1887-1892

7. Byar DP. Simon RM, Friedewald WT, Schlesselman JJ "DeMets DL, Ellenberg JH, Gail MH, Ware $\mathrm{JH}$. Randomized clinical trials. Perspectives on some recent ideas. $\mathrm{N}$ Engl J Med 1976; 295: 74-80

8. Feinstein AR. Current problems and future challenges in randomized clinical trials. Circulation 1984: $70: 767-774$

9. Abel $U$, Koch $A$. The role of randomization in clinicall studies: myths and beliefs. J Clin Epidemiol 1999; $52: 487-497$

10. Guyatt $G$, Schunemann $H J$, Cook $D$, Jaeschke R, Pauker S. Applying the grades of recommendation for antithrombotic and thrombolytic therapy: the Seventh ACCP Conference on Antithrombotic and Thrombolytic Therapy. Chest 2004; 126:179S-187S

11. Carr DB, Goudas LC. Burning questions, randomized controlled trials, and the pain doctor's dilemma. Reg Anesth Pain Med 2003; 28: 360-361

12. Merrill DG. Hoffman"s glasses: evidence-based medicine and the search for quality in the literature of interventional pain medicine. Reg Anesth Pain Med 2003: 28: 547-560

13. Wilson EB. An Introduction to Scientific Research, New York, McGraw-Hill, 1952,

14. Lau J, Antman EM, Jimenez-Silva J, Kupelnick B, Mosteller F, Chalmers TC. Cumulative metaanalysis of therapeutic trials for myocardial infarction. N Engl J Med 1992; 327: 248-254

15. Sthealy $\mathrm{CN}$. Percutaneous radiofrequency denervation of spinal facets. J Neurosurg $1975 ; 43$ : $448-451$

16. Geurts $ل_{\text {, van Wijk }}$ RM Stolker R, Groen GJ. Efficacy of radiofrequency procedures for the treatment of spinal pain: a systematic review of randomized clinical trials. Reg Anesth Pain Med 2001; 26: 394-400

17. Barolat G, Schwartzman R, Woo R. Epidural spinal cord stimulation in the management of reflex sympathetic dystrophy. Stereotact Funct Neurosurg 1989; 53: 29-39

18. Kemler MA, Barendse GA, van Kleef $M$, de Vet HC, Rijks CP. Furnee CA, wan den Wildenberg FA. Spinal cord stimulation in patients with chronic reflex sympathetic dystrophy. N Engl $J$ Med 2000; 343: 618-624

19. Van Zundert J, Brabant S, Van de Kelft E, Vercruyssen A, Van Buyten JP. Response to Zakrzewska's Letter to the Editor. Pain 2004; 109: 520-522

20. Horwitz RI. Complexity and contradiction in clinical trial research. Am J Med 1987; 82: 498-510

21. McQuay HJ, Moore RA. Epidural corticosteroids for sciatica, In: An Evidence based resource for pain relief. Eds. McQuay H, Moore RA Oxford- New York- Tokyo, Oxford University Press, 1998, pp 216-219

22. Nelemans PJ, de Bie RA, de Vet HC, Sturmans F. Injection therapy for subacute and chronic benign low back pain. Spine 2001; 26: 501-515 
23. Rabeneck $L$, Viscoli $C M$, Horwitz RI. Problems in the conduct and analysis of randomized clinical trials. Are we getting the right answers to the wrong questions? Arch Intern Med 1992; 152: $507-512$

24. Vandenbroucke JP. When are observational studies as credible as randomised trials? Lancet 2004; 363: 1728-1731 
CHAPTER XI

\section{Summary}

set.

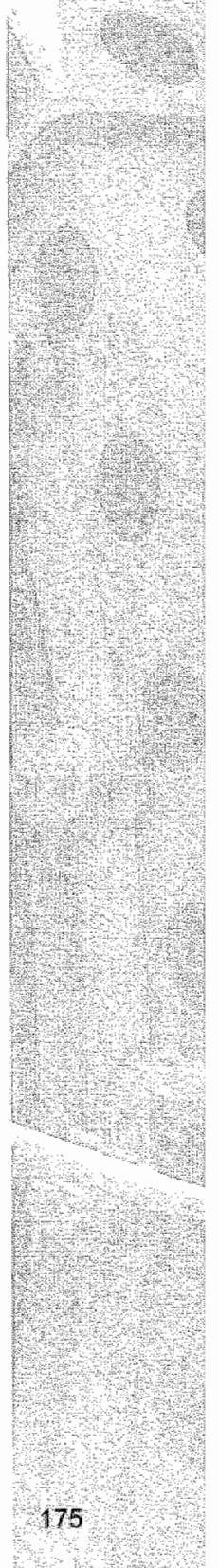


Even in the 21st century the management of chronic pain remains a difficult challenge, because of the variety in factors interfering with its clinical presentation, coping and consequently the pain behavior. The evolution in the understanding and appreciation of this complexity led to the integrated multidisciplinary approach, where cognitive behavioral treatment and physical rehabilitation programs are implemented alongside the algorithm for pharmacological and interventional pain management as proposed in chapter 11 . This is well described in the literature for low back pain ${ }^{1}$ but it is less well documented for pain originating from the cervical spine. Although many treatment modalities for cervical radicular pain are described in the literature, the available evidence for efficacy does not allow to formulate definitive conclusions on the optimal therapy.

The aim of this thesis was to evaluate the role of pulsed radiofrequency treatment for chronic pain management, with special attention to PRF application at the cervical dorsal root ganglion in chronic cervical radicular pain.

In chapter I an overview of the evolution of radiofrequency (RF) techniques in the management of chronic pain is given. The first use of RF for spinal pain was reported by Shealy ${ }^{2}$ for the treatment of lumbar zygapophyseal joint pain. Although Uematsu $^{3}$ first described RF lesions of the dorsal root ganglion (DRG), the technique only gained in popularity in some countries after the introduction of small diameter electrodes ( $22 \mathrm{G}$ disposable cannula with a thermocouple inside) known as Sluijter Mehta Kit (SMK) systems ${ }^{4}$. However, the RF lesioning of the DRG remains controversial due to the potential risk for deafferentation syndromes. For this reason a modification of the technique resulting in less damage would be more attractive for chronic radicular pain syndromes. In 1998 Sluijter, Cosman, Rittman, and van Kleef introduced a modified RF technique known as pulsed radiofrequency (PRF).

In order to evaluate the role of PRF it is imperative to make a review on the current status of continuous RF in pain management, which is presented in chapter II. Two systematic reviews on RF treatment of spinal pain issued similar conclusions: moderate evidence that radiofrequency lumbar facel denervation is more effective for chronic low back pain than placebo; limited evidence for efficacy of radiofrequency neurotomy in chronic cervical zygapophyseal joint pain after whiplash; limited evidence that radiofrequency heating of the dorsal root ganglion is more effective than placebo in chronic cervicobrachialgia ${ }^{\text {b-3 }}$. It is concluded from this literature review that all efforts should be made to narrow the gap between the Evidence Based Medicine (EBM) data and clinical practice using standardized protocols for patient selection and treatment. In line with the experience of conducting clinical trials with pharmacotherapy a multi-center approach using international accepted protocols should be considered. In this chapter we propose an algorithm for the management of chronic pain, whereby pharmacological and interventional pain treatments are 
presented as being complementary within a mulidisciplinary approach. Accurate use of RF treatment as part of a multimodal and multidisciplinary approach may avoid the use of more invasive and often more expensive treatment options. The current evolution of RF from the initial neuro-ablative thermocoagulation towards the less or minimally neurodestructive PRF may have additional advantages in the management of chronic pain, if its value can be demonstrated.

In particular, PRF adjacent to the (cervical) DRG may be an appealing application as compared to RF, basically due to the hypothesis that it is less neurodestructive. In order to understand the relation between DRG and cervical radicular pain, the first research question should be addressed. In chapter III we tried to clarify the role of the DRG in cervical radicular pain. The results of an extensive literature review are reported. The exact pathophysiological mechanisms underlying cervical radicular pain in humans are not yet fully understood. In line with the available literature on the pathophysiology of lumbar radicular pain, two major mechanisms are thought to induce cervical radicular pain: (1) nucleus pulposus material leaking onto the nerve root, and or (2) compression of the nerve root by anatomic abnormalities. Either of these pathogenic mechanisms will induce two processes in the nerve: (1) an inflammatory reaction and - related to this - (2) changes in ion channel functioning. Eventually, these effects cause a pattern of hyperexcitability and spontaneous ectoplc activity in the DRG, which is interpreted as pain. These discharges enter the spinal cord and induce central sensitization at the symapses located in the dorsal horn $^{9}$.

Many available treatment modalities for cervical radicular pain may interfere with the pathophysiological processes at the DRG. The pharmacological treatment modalities can be subdivided into those targeting the inflammatory changes ${ }^{10}$ and those targeting the ion channel modulation ${ }^{11-14}$, but their value has not been investigated in the management of cervical radicular pain. Several new molecules may result in alternative treatment options in the future ${ }^{15-21}$. The interventional pain management modalities targeting the cervical DRG and/or nerve root consist of epidural steroid administration ${ }^{22,23},(\mathbb{P}) \mathbb{R F}^{6,7.24}$, and neck surgery ${ }^{25,26}$. The available evidence for efficacy does not allow us to formulate definitive conclusions on the optimal therapy. However, based on the risk/benefit ratio there is weak recommendation against the use of neck surgery for chronic cervical radicular pain. For this reason less invasive percutaneous interventional pain management techniques have gained interest during the last decade, and amongst them the RF techniques are well described.

The made of action of RF was, for a long time, attributed to the effects of heat, but since the introduction of the modified PRF it was assumed that different mechanisms other than thermocoagulation might also be involved. Therefore it is necessary to discuss some electrophysiological principles underlying PRF, which are pre- 
sented in chapter $V$. During the administration of high frequency current adjacent to the meuronal tissue an electric field is generated that accounts for most of the effects, such as forces on and movement of ions in electrolytes, current densities and stresses on cellular substructures and membranes, which in turn produce ionic friction and heat. When delivering the current in a continuous way the temperature increases in the tissue surrounding the electrode tip and decreases gradually away from the electrode. In PRF during the "active" burst, higher voltages of RF current are delivered than with continuous RF. This results in a higher density electric field around the electrode for PRF, which is probably capable of altering the cell membrane $^{27}$. Exposure of cultured cells to an electric field is associated with upregulation of nonspecific intermediate-early gene marker, c-Fos, and also transcription of other, as yet unidentified, genes ${ }^{28}$. C-Fos based functional anatomic mapping has been vallidated as a powerful technique to detect activated neurons ${ }^{29}$. Evidence is accumulating to suggest that changes in early gene expression with in the nervous system signal long-term adlaptation within particular neural pathways ${ }^{30}$. This issue was further addressed in the second research question. "Does pulsed radiofrequency of the cervical dorsal root ganglion result in changes at the dorsal horn of the spinal cord in an experimental setting?"

An early (3h) effect of pulsed radiofrequency as measured by an increase of c-Fos in the pain processing neurons of the dorsal horn of rats has been reported in the literature $^{31}$. This effect was not mediated by tissue heating. In chapter $\mathbf{V}$, we published a late effect of three different radiofrequency modalities; continuous RF, PRF during $120 \mathrm{~s}$ and PRF during $8 \mathrm{~min}$ compared to sham, using the same experimental rat model as described by Higuchi et. al. ${ }^{31}$. The number of c-Fos immunoreactive cells, as a marker for neuronal activity, in the dorsal horn was significantly increased in the three different radiofrequency groups. No silgnificant difference was demonstrated between the three active intervention groups. The observation that c-Fos is still present 7 days after the intervention suggest sustained activity, because the duration of its activity exceeded the expected length of time for c-Fos expression caused by the effects of surgery and electrical stimulation. These findings may be physiologically relevant for transmission and integration of sensory information, in line with the reported long-term depression of synaptic transmission in substantia gelatinosa neurons that can be induced by low-frequency stimulation of primary afferent $A-6$ fibers ${ }^{32}$. The demonstrated late and temperature independent cellular activity in the rat spinal cord after application of different RF modalities is suggested to be part of the underlying mechanism.

As an extension to the c-Fos study we used Bromodeoxyuridine (BrdU) labeling to investigate if RF and PRF treatment adjacent to the cervical dorsal root ganglion would lead to an increased proliferation of cells in the spinal cord. The BrdU labeled cells were recognizable due to the intense staining of the nucleus. Immunopositive 
cells were randomly distributed throughout the spinal cord section. Our protocol did not result in any differences between the 4 treatment groups. Further experiments, using alternative BrdU labeling protocols are needed ${ }^{33}$.

In an accompanying editorial related to the c-Fos article, the authors find the concept that pulsed radiofrequency may produce inhibition of excitatory C-fibers using a phenomenon such as long-term depression in the spinal cord is an attractive hy. pothesis. However this hypothesis needs to be confirmed in clinical research and randomized controlled trials to evaluate the clinical value of $\mathrm{PRF}^{34}$.

After the initial publications on the clinical use of PRF from Sluijter ${ }^{5}$ and Munglanilis we reported in chapter $\mathrm{V} I$ the first 5 high-risk patients with idiopathic trigeminal neuralgia $^{36}$. They were treated with PRF after multidisciplinary assessment, with a mean follow-up of 19.2 months (range $10-26$ ). These patients were at high risk due to age, co-morbidities or previous interventional and/or surgical treatments. An excellent long-term effect was achieved in 3 of the 5 patients, a partial effect in 1 patient and a short-term effect in another patient. No neurological complications were reported. To come up with final conclusions regarding the efficacy of PRF of the Gasserian ganglion based on case series is impossible; there is need for well-controlled trials relying on standardized diagnostic criteria ${ }^{37}$. A clinical note is, however a good format to communicate on first findings with a new technique. To build up the evidence according to the rules of EBM, clinical research should be continued with retrospective analysis on larger numbers of patients, prospective trials and finally randomized climical trials and systematic reviews ${ }^{38}$. We all know it takes many years before all this work is done, especially taking into consideration a 3-year follow-up as recommended by Zakrzewska and Lopez ${ }^{39}$. As with other new treatments it takes generally 10 years from accumulation of clinical data to final confirmation ar rejection of an intervention ${ }^{40}$. The possibility of repeating the procedure during the same session, was questioned by some colleagues ${ }^{41,42}$. In fact, with continuous $R F$, thermocoagulation of the Gasserian ganglion is performed when the neadle position is considered to be optimal, based on the results of the stimulation. The needle cannot be repositioned in order to limit the extend of the lesion. Needle repositioning after a first treatment with PRF may result in a lower sensory stimulation threshold and in this case a second treatment should be performed in order to optimize the results ${ }^{43}$. Also the use of the terminology to describe side effects and complications after the continuous RF trigeminal rhizotomy was subject to some debate. Sensory loss was stated not to be a side effect but an expected and desired outcome and the conditio sine qua non to obtain the wanted long-lasting pain relief ${ }^{42}$. It can indeed be confusing, because, the goal of the intervention is to provide a long-lasting pain relief without disturbing neurological function. In clinical practice the border between the desired sensory loss and the undesired dysesthesia is narrow and for the long term difficult to predict ${ }^{44}$. 
Because our research focused on cervical radicular pain, we postulate the third research question: "What are the therapeutic effects and side effects of pulsed radiofrequency adjacent to the cervical dorsal root ganglion in cervical radicular pain?".

We studied prospectively the effect of PRF adjacent to the cervical DRG and reported the results in Chapter VII. This extended pilot study was performed to evaluate the outcome of PRF for short- and long-term relief of chronic cervical pain such as cervicogenic headache and cervicobrachialgia/cervical radicular pain. An independent evaluator reviewed the medical records of the first 18 patients treated with PRF at the cervical DRG. Patients with good clinical results at 8 weeks were evaluated for long-term effect ( $>6$ months), based on a 7-point Likert scale. Thirteen patients $(72 \%$ ) showed short-term clinical success (>50\% pain relief). More than 1 year after treatment, 6 patients $(33 \%)$ rated treatment outcome as good or very good. Kaplan-Meier analysis illustrated that $50 \%$ of patients experienced success 3 months after treatment. We could not identify predictive variables for clinical outcome. None of the patients reported post-treatment neuritis or complications. According to the EBM guidelines, the outcome of this clinical audit supported the setup of a randomized controlled trial.

The results of a double blind sham controlled RCT on the efficacy and side effects of PRF adjacent to the cervical DRG in patients with chronic cervical radicular pain are presented in chapter VIII. In order to have a homogeneous patient population, the patient selection was based on an extensive protocol of physical examination including a positive Spurling test to judge the radicular involvement. Twenty-three patients were randomly allocated to PRF treatment of the cervical DRG $(n=11)$ or sham intervention ( $n=12$ ). Assessment was done by an independent evaluator before treatment and at 4 weeks and 3 months. Patients who had a favorable outcome at 3 months were again evaluated 6 months after the intervention. In the primary outcome success was defined as minimal $50 \%$ improvement on the global perceived effect and 20 point reduction of the VAS pain score. Our results indicate that PRF treatment of the cervical DRG for chronic cervical radicular pain provides better pain relief than sham intervention 3 and 6 months after the procedure, but significance was only reached after 3 months. The need for pain medication, which was defined as rescue treatment in the study protocol, was reduced in the PRF group and increased in the sham group. Statistical significance was reached after 6 months. There is a tendency towards better outcome for sham after 4 weeks of quality of life measured by SF-36 and Euroqol. But, after 3 and 6 months, there was a trend towards a better improvement of quality of life in the PRF group, though statistical significance was only reached for the domain vitality. No side effects or neurological complications were noted in both groups during the study period. The ongoing slow inclusion rate forced us to stop the study before the calculated sample 
size of 42 patients was reached. This problem is frequently reported in sham controlled randomized clinical trials on interventional pain management techniques $^{6,7,45,46}$.

The results of an extensive literature search supplemented with the control of the reference lists of relevant papers and the abstracts presented during international congresses are reported in chapter IX. We could detect 58 reports on the clinical use of pulsed radiofrequency in different applications: 32 full publications and 26 abstracts. Because this is a new technique, a substantial part of these results are reported in the abstract books of international scientific congresses. Their number is increasing yearly and they are progressively published in peer reviewed indexed journals. We also retrieved six basic science reports, 5 full publications and one abstract. Although the mechanism of action has not been completely elucidated, laboratory reports suggest a genuine neurobiological phenomenon altering the pain signaling, which some have described as neuromodulatory ${ }^{47}$. No complications related to the PRF technique were reported to date. If indeed the latter is the case, the use of PRF in neuropathic and mixed pain states may be of interest. Further research in the clinical and biological effects is justified. 


\section{Samenvatting}

Zelfs in de 21 ste eeuw blijft de behandeling van chronische pijn een moeilijke uitdaging, met name door verschillende factoren die interfereren met het klinische beeld, de aanvaarding en het pijngedrag. De evolutie in het begrip en de aanvaarding van deze complexiteit was aanleiding tot een geïntegreerde multidisciplinaire aanpak, waarbij de cognitieve gedragsmatige therapie en fysische rehabilitatie programma's parallel met het algoritme voor farmacologische en interventionele pijnbestrijding worden toegepast, zoals voorgesteld in hoofdstuk II. Deze aanpak is in de literatuur goed beschreven voor de behandeling van lage rugpijn " maar is minder goed gedocumenteerd voor pijn uitgaande van de cervicale wervelzuil. Alhoewel verschillende behandelingsmogelijkheden voor cervicale radiculaire pijn beschreven zijn in de literatuur, laat de beschikbare evidentie voor doeltreffendheid niet toe om definitieve besluiten omtrent de optimale behandeling te formuleren.

De doelstelling van deze thesis is de waarde van gepulseerde radiofrequentie (PRF) behandeling voor chronische pijn te evalueren, met bijzondere aandacht voor de PRF toepassing op het cervicale dorsale ganglion (DRG) bij chronische cervicale radiculaire pijn.

In hoofdstuk I wordt een overzicht gegeven van de evolutie van de radiofrequentie (RF) technieken bij de behandeling van chronische pijn. De eerste toepassing van RF voor spinale pijn werd gerapporteerd door Shealy ${ }^{2}$ voor de behandeling van zygapofysaire gewrichtspijn. Alhoewel Uematsu ${ }^{3}$ als eerste de toepassing van RF laesies van het DRG beschreef, werd deze techniek pas populair in bepaalde landen na de introductie van elektroden met een kleine diameter (22 G wegwerp canule met binnenin een thermokoppel), bekend onder de naam Sluijter Mehta Kit (SMK) systemen ${ }^{4}$. De toepassing van RF laesies ter hoogte van het DRG blijft echter controversieel omwille van het mogelijke risico voor deafferentatie syndromen. Daarom zou een gewijzigde toepassingstechniek die minder schade zou veroorzaken aantrekkelijker zijn voor de behandeling van chronische radiculaire pijnsyndromen. In 1998 introduceerden Sluijter, Cosman, Rittman en Van Kleef een aangepaste techniek die gekend is als gepulseerde radiofrequentie ${ }^{5}$.

Om de rol van PRF te kunnen evalueren is het noodzakelijk om een overzicht te maken van de huidige stand van zaken van continue RF in de pijnbehandeling. Dit is weergegeven in hoofdstuk II. Twee systematische reviews betreffende de RF behandeling van spinale pijn resulteerden in gelijkaardige conclusies: matige evidentie dat radiofrequente lumbale facet denervatie doeltreffender is dan placebo voor de behandeling van chronische lage rugpijn; beperkte evidentie voor de doeltreffendheid van radiofrequente neurotomie bij chronische cervicale zygapofysaire 
gewrichtspijn na whiplash en beperkte evidentie dat radiofrequente verhitting van het DRG doeltreffender is dan placebo bij chronische cervicobrachialgie ${ }^{6-8}$. Van dit literatuuroverzicht kan geconcludeerd worden dat er bijkomende inspanningen moeten geleverd worden om de kloof tussen Evidence Based Medicine (EBM) data en klinische praktijk te overbruggen. Hiervoor moet gebruik worden gemaakt van gestandaardiseerde protocollen voor de patiëntenselectie en behandeling. In lijn met de ervaring voor het uitvoeren van klinische studies met farmacotherapie kan een multidisciplinaire aanpak op basis van internationaal aanvaarde protocollen overwogen worden. In dit hoofdstuk stellen wij een algoritme voor de behandeling van chronische pijn voor, waarbij de farmacologische en interventionele behandelingen voorgesteld worden als complementaire opties binnen een multidisciplinaire aanpak. Accuraat gebruik van RF behandelingen als onderdeel van een multimodale en multidisciplinaire aanpak kan het aanwenden van meer invasieve en meestal duurdere behandelingen vermijden. De huidige evolutie van radiofrequentie van neuroablatieve thermocoagulatie naar de minder of minimaal neurodestructieve PRF kan bijkomende voordelen hebben bij de behandeling van chronische pijn.

Gepulseerde radiofrequentie ter hoogte van het DRG kan een aantrekkelijke toepassing zijn in vergelijking met RF, vooral omwille van de hypothese dat het minder neurodestructief is. Om de relatie tussen het DRG en cervicale radiculaire pijn te begrijpen, moet de eerste onderzoeksvraag worden beantwoord. In hoofdstuk III willen wij de rol van het DRG in cervicale radiculaire pijn verduidelijken. De resultaten van een uitgebreid literatuuronderzoek worden weergegeven. De exacte pathofysiologische mechanismen die aan de grondslag liggen van cervicale radiculaire pijn bij mensen zijn nog niet volledig opgehelderd. In analogie met de beschikbare literatuur over de pathofysiologie van lumbale radiculaire pijn, worden twee mechanismen naar voor geschoven die mogelijk cervicale radiculaire pijn veroorzaken: (1) het lekken van materiaal van de nucleus puiposus op de zenuwwortel en/of (2) de compressie van de zenuwwortel door anatomische anomalieën. Beide pathogene mechanismen zullen twee processen in de zenuw induceren: (1) een inflammatoire reactie en - hiermee verbonden - (2) veranderingen in het functioneren van de ionenkanalen. Op lange termijn kunnen deze effecten een patroon van hyperexcitabiliteit en spontane ectopische activiteit in het DRG veroorzaken; dit wordt als piin geïnterpreteerd. Deze ontladingen dringen het ruggenmerg binnen en induceren centrale sensitizatie ter hoogte van de synapsen die gelokaliseerd zijn in de dorsale hoorn'.

Verschillende beschikbare behandelingsmogelijkheden voor cervicale radiculaire pijn kunnen interfereren met de pathofysiologische processen ter hoogte van het DRG. De farmacologische behandelingsmogelijkheden kunnen onderverdeeld worden in behandelingen, die de inflammatoire processen beïnvloeden ${ }^{10}$ en behandelingen, weike de ionen kanalen modulatie bewerkstelligen ${ }^{11-14}$, maar de waarde er- 
van werd niet onderzocht in de behandeling van cervicale radiculaire pijn. Verschillende nieuwe moleculen kunnen in de toekomst alternatieve behandelingen opleve$\operatorname{ren}^{15 \cdot 21}$. De interventionele pijnbehandelingsopties die gericht zijn op het DRG en/of de zenuwwortel bestaan uit epidurale toediening van steroïden ${ }^{22,23},\left(P^{2} F^{6.7 .24}\right.$ en nekchirurgie ${ }^{25,28}$. De beschikbare evidentie voor doeltreffendheid laat niet toe om definitieve besluiten omtrent de optimale behandeling te formuleren. Gebaseerd op de risico-voordelen balans kan een zwakke aanbeveling tegen het gebruik van nekchirurgie voor chronische radiculaire pain geformuleerd worden. Daarom hebben de minder invasieve percutane interventionele pijnbestrijdingtechnieken gedurende het laatste decennium meer aandacht gekregen; de RF technieken zijn goed beschreven.

Het werkingsmechanisme van RF werd gedurende lange tijd toegeschreven aan de hitte-werking, maar sinds de introductie van de gewijzigde PRF wordt verondersteld dat naast thermocoagulatie andere mechanismen een rol kunnen spelen. Het is daarom nodig enkele electrofysiologische principes die ten grondslag liggen aan PRF te bespreken. Dit wordt in hoofdstuk IV weergegeven. Gedurende de toepassing van hoog frequente stroom ter hoogte van neuronale weefsels wordt een elektrisch veld opgewekt dat verantwoordelijk is voor de meeste effecten, zoals de krachten op en het bewegen van ionen die op hun beurt frictie uitvoeren en warmte produceren. Wanneer de stroom op een continue manier wordt toegediend stijgt de temperatuur in het weefsel rond de electrodetip maar deze neemt geleidelijk af verder van de tip. In het geval van PRF worden tijdens de "actieve" stoot "hogere voltages van RF stroom afgeleverd dan bij continue RF. Dit resulteert, bij PRF, in een elektrisch veld met hogere densiteit rond de electrodetip. Dit elektrisch veld kan mogelijk de celmembraan veranderen ${ }^{27}$. Blootstelling van gecultiveerde cellen aan een elektrisch veld gaat gepaard met een op-regulatie van de niet-specifieke intermediaire vroege gen merker, c-Fos, en ook de transcriptie van andere nog niet geïdentificeerde gene ${ }^{28}$. Functionele anatomische mapping op basis van c-Fos werd gevalideerd als een krachtige techniek om geactiveerde neuronen te idlentificeren ${ }^{29}$. Er komen meer bewijzen die suggereren dat veranderingen in de vroege gen expressie in het zenuwstelsel een teken zijn voor lange termijn aanpassing binnen een specifieke neuronale baan $^{30}$. Dit onderwerp wordt verder bekeken in de tweede onderzoeksvraag; "Resulteert gepulseerde radiofrequentie ter hoogte van het DRG, bij een diermodel in veranderingen ter hoogte van de dorsale hoorn van het ruggenmerg?"

In de literatuur werd een vroeg ( $3 \mathrm{u}$ ) effect van gepulseerde radiofrequentie gemeld. Dit effect, dat niet door weefselverhitting gemedieerd werd, werd gemeten door een verhoogde c-Fos expressie in de pijnverwerkende neuronen van de dorsale hoorn van ratten ${ }^{31}$. In hoofdstuk $V_{\text {, }}$ publiceerden wij het laattijdige effect van drie verschillende manieren van toediening van radiofrequente stroom: continue RF, PRF gedu- 
rende 120 s en PRF gedurende $8 \mathrm{~min}$. Deze gegevens werden vergeleken met een sham interventie. Het experiment werd uitgevoerd op hetzelfde onderzoeksmodel dat door Higuchi et al beschreven werd ${ }^{31}$. Het aantal c-Fos immunoreactieve cellen, die een merker vormen voor neuronale activiteit in de dorsale hoorn, was significant verhoogd in de drie RF groepen. Tussen de actieve groepen onderling werd geen significant verschil gevonden. De observatie dat c-Fos nog steeds aanwezig is 7 dagen na de interventie suggereert een langdurige activiteit, aangezien het meetmoment aanzienlijk later is dan de verwachte duur van c-Fos expressie veroorzaakt door de heelkunde en de elektrische stimulatie. Deze bevin-dingen kunnen fysiologisch relevant zijn voor de transmissie en integratie van sensorische informatie, in lijn met de gerapporteerde lange termijn depressie van de synaptische transmissie in de substantia gelatinosa neuronen die kan geïnduceerd worden door lage frequentie stimulatie van de primaire afferente $A-\delta$ vezels ${ }^{32}$. Deze laattijdige en temperatuur onafhankelijke cellulaire activiteit in het ruggenmerg van de rat na toepassing van verschillende RF modaliteiten, kan een deel van de onderliggende werkingsmechanismen zijn.

We gebruikten de Bromodeoxyuridine (BrdU) kleuring als een extensie van de c-Fos studie om te onderzoeken of RF en PRF behandeling in de nabijheid van het cervicale DRG aanleiding zou geven tot een verhoogde proliferatie van de cellen in het ruggenmerg. De BrdU gekleurde cellen waren herkenbaar door de intense kleuring van de celkern. De immunopositieve cellen waren ad random verdeeld over de sectie van het ruggenmerg. Ons protocol gaf geen enkel verschil aan tussen de 4 behandelingsgroepen. Meer onderzoek met andere BrdU kleuringsprotocollen is no$\operatorname{dig}^{33}$.

In een begeleidend editoriaal op het c-Fos artikel, gaven de auteurs aan dat het concept, dat PRF een inhibitie van de excitatorische C-vezels kan bewerkstelligen door middel van een fenomeen zoals lange termijn depressie in het ruggenmerg. een aantrekkelijke hypothese is. Deze stelling moet echter bevestigd worden in klinisch onderzoek en gerandomiseerde gecontroleerde studies die de waarde van PRF evalueren ${ }^{34}$.

Na de initiële publicaties omtrent de klinische toepassing van PRF van Sluijter ${ }^{5}$ en Munglani ${ }^{35}$ rapporteren wij in hoofdstuk VI de eerste 5 hoog risico patiënten met iopatische trigeminus neuralgia ${ }^{36}$. Deze patiënten werden met PRF behandeld na een multidisciplinaire evaluatie, met een gemiddelde follow-up van 19.2 maanden (ratio 10-26). Deze patiënten hadden een verhoogd risico omwille van leeftijd, comorbiditeit of eerdere interventionele en/of heelkundige behandelingen. Er werd een uitstekend lange termijn effect bereikt bij 3 van de 5 patiëntem, bij een patiënt een gedeeltelijk effect en een korte termijn effect bij een andere. Er werden geen neurologische complicaties gemeld. Het is onmogelijk om aan de hand van casuïstiek 
definitieve besluiten te trekken omtrent de doeltreffendheid van PRF van het ganglion van Gasser, hiervoor zijn goed gecontroleerde studies nodig die gebaseerd zijn op gestandaardiseerde diagnostische criteria ${ }^{37}$. Een klinische nota is nochtans het goede formaat om initiële bevindingen met een nieuwe techniek mede te delen. Om de evidentie op te bouwen volgens de richtlijnen van de EBM, moet het klinische onderzoek voortgezet worden met de retrospectieve analyse van grotere aantallen patiënten, prospectieve studies en ten slotte gerandomiseerde klinische studies en systematische reviews ${ }^{38}$. We weten allemaal dat verschillende jaren nodig zijn om dit werk te realiseren, vooral indien rekening gehouden wordt met de 3-jaar followup die Zakrzewska en Lopez aanbevelen ${ }^{39}$. Zoals met andere nleuwe behandelingen vergt het meestal 10 jaar tussen het verzamelen van de klinische data en de uiteindelijke bevestiging of verwerping van een interventie ${ }^{40}$. De mogelijkheid om de procedure gedurende dezelfde sessie te herhalen werd door bepaaide collega's ter discussie gesteld ${ }^{41,42}$. Zo wordt, met continue RF, de thermocoagulatie uitgevoerd wanneer de plaatsing van de naald optimaal wordt beschouwd, afhankelijk van de stimulatiedrempels. Om de omvang van de leasie te beperken kan de naald best niet verplaatst worden. Met PRF kan na een eerste behandeling de naald verplaatst worden en, indien dit resulteert in lagere sensorische stimulatiedrempels, kan de behandeling herhaald worden om de resultaten te optimalisere ${ }^{43}$. Ook het gebruik van de terminologie om de bijwerkingen en verwikkelingen van continu RF te beschrijven werd ter discussie gesteld. Sensorieel verlies werd niet als bijwerking maar als een verwacht en gezocht effect beschouwd, het is een conditio sine qua non om langdurende pijnverlichting te bekomen ${ }^{42}$. Het kan inderdaad tot verwarring leiden, want de doelstelling van de interventie is een langdurige pijnverlichting te geven zonder de neurologische functie te verstoren. In de klinische praktijk is de grens tussen gewenst sensorieel verlies en ongewenste dysesthesia zeer nauw en moelijk te voorspellen op lange termijn ${ }^{44}$.

Aangezien ons onderzoek zich toespitste op cervicale radiculaire pijn, stelden wij de derde onderzoeksvraag: "Wat zijn de therapeutische effecten en neveneffecten van gepulseerde radiofrequentie ter hoogte van het cervicale DRG bij cervicale radiculaire pijn?"

Wij onderzochten prospectief de effecten van PRF nabij het cervicale DRG en rapporteerden de resultaten in hoofdstuk VII. Deze uitgebreide piloot studie werd uitgevoerd am de resultaten van PRF op korte en lange termijn te evalueren op de vermindering van chronische cervicale pijn zoals cervicogene hoofdpijn en cervicobrachialgia/cervicale radiculaire pijn. Een onafhankelijk evaluator nam de medische gegevens door van de eerste 18 patiënten die een PRF behandeling van het cervicale DRG kregen. Patiënten die goede klinische resultaten hadden op 8 weken werden gevolgd voor het lange-termijn effect ( $>6$ maanden), gebaseerd op een 7 punten Likert schaal. Dertien patiënten $(72 \%)$ hadden klinisch succes $>50 \%$ pijn 
verlichting) op korte-termijn. Meer dan een jaar na de behandeling scoorden 6 patienten $(33 \%)$ het resultaat van de behandeling als goed of zeer goed. Een KaplanMeier analyse toonde aan dat $50 \%$ van de patiënten succes hadden 3 maanden na de behandeling. We konden geen predictieve variabelen voor het klinische resultaat identificeren. Volgens de richtlijnen van EBM, rechtvaardigen de resultaten van deze klinische audit de opzet van een gerandomiseerde gecontroleerde studie.

De resultaten van een dubbel blind sham gecontroleerde RCT over de doeltreffendheid en de neveneffecten van PRF ter hoogte van het cervicale DRG bij patiènten met chronische cervicale radiculaire pijn worden voorgesteld in hoofdstuk VIII. Voor het verkrijgen van een homogene patiënten populatie, is de patiëntenselectie gebaseerd op een uitgebreid protocol van het klinische onderzoek met inbegrip van een positieve Spurling test die het radiculaire deel beoordeelt. Drieëntwintig patiènten werden ad random met PRF behandeld $(n=11)$ of kregen een sham interventie $(n=12)$. De evaluatie gebeurde door een onafhankelijk evaluator vóór de interventie en op 4 weken en 3 maanden. De patiënten die een gunstig resultaat hadden op 3 maanden werden opnieuw geëvalueerd 6 maanden na de interventie. Voor de primaire outcome werd succes gedefinieerd als ministens $50 \%$ verbetering van het globaal waargenomen effect en 20 punten reductie van de VAS pijn score. Onze resultaten tonen aan dat PRF behandeling van het cervicale DRG voor chronische radiculaire pijn betere pijnverlichting geeft dan sham interventie 3 en 6 maanden na de procedure, maar significantie werd enkel bereikt na 3 maanden. De behoefte voor pijnmedicatie, die in het studie protocol beschouwd werd als een noodoplossing, was verminderd in de PRF groep en verhoogd in de sham groep. Statistische significantie werd bereikt na 6 maanden. $E r$ is een trend voor een beter resultaat op de levenskwaliteit gemeten door de SF-36 en Euroqol voor de sham interventie na 4 weken. Maar na 3 en 6 maanden, was er een trend voor een betere levenskwaliteit in de PRF groep, alhoewel statistische significantie enkel bereikt werd voor het domein vitaliteit. Gedurende de studie periode werden geen neveneffecten of neurologische complicaties genoteerd in beide groepen. De aanhoudende trage inclusie ratio dwong ons ertoe de studie te stoppen vóór de berekende studie groep van 42 patiënten bereikt werd. Dit is een frequent voorkomend probleem in sham gecontroleerde gerandomiseerde klinische studies over interventionele pijnbehandelingstechnieken $n^{6,7,45,46}$.

De resultaten van een uitgebreid literatuuronderzoek naar PRF dat aangevuld werd met handmatige controle van de referentielijsten van relevante studies en de abstracts die voorgesteld werden tijdens internationale congressen worden in hoofdstuk IX gerapporteerd. Wij konden 58 rapporten identificeren over het klinische gebruik van gepulseerde radiofrequentie in verschillende toepassingen: 32 volledige publicaties en 26 abstracts. Omdat dit een nieuwe techniek betreft, is een groot deel van deze resultaten gepubliceerd in abstractboeken van internationale congressen. 
Jaarlijks neemt het aantal toe en worden progressief gepubliceerd in peer reviewed tijdschriften. Wij identificeerden eveneens 6 rapporten omtrent basaal onderzoek, 5 volledige publicaties en 1 abstract. Alhoewel het werkingsmechanisme niet volledig opgehelderd wordt, suggereren de laboratoriumverslagen een duidelijk neurobiologisch fenomeen dat het pilinsignaal verandert. Bepaalde auteurs beschreven dit als neuromodulatie ${ }^{47}$. Tot op heden werden geen complicaties, toe te schrijven aan PRF, gerapporteerd. Wanneer dit inderdaad het geval is, kan het gebruik van PRF in de behandeling van neuropathische en gemengde pijnsyndromen interessant zijn. Verder onderzoek naar de klinische en biologische effecten is dan ook wenselijk en gerechtvaardigd. 


\section{References}

1. Carragee EJ. Clinical practice. Persistent low back pain. N Engl J Med 2005; 352: 1891-1898

2. Shealy $\mathrm{CN}$. Percutaneous radiofrequency denervation of spinal facets. I Neurosurg 1975; 43 : 448-451

3. Uematsu S, Udwarhelyi GB, Benson DW, Siebens AA. Percuteneous radiofrequency rhiżotomy. Surg Neurol 1974; 2: 319-325

4. Slujiter $M$, Mehta $M$. Treatment of chronic back and neck pain by percutaneous thermal lesions. Persistent pain, modern methods of treatment, Edited by Lipton S. London, Academic Press, 1981, pp 141-179,

5. Sluijter ME, Cosman ER, Rittman IIWB, van Kleef $M$. The effects of pulsed radiofrequency field applied to the dorsal root ganglion - a preliminary report. The Pain Clinic 1998; 11: 109-117

6. Geurts J, van Wijk RM, Stolker $R_{r}$ Groen GJ. Efficacy of radiofrequency procedures for the treatment of spinal pain: a systematic review of randomized clinical trials. Reg Anesth Pain Med 2001; 26: 394-400

7. Niemisto $L$, Kalso E, Malmivaara A, Seitsalo S, Hurri $H$. Radiofrequency denervation for neck and back pain. A systematic review of randomized controlled trials. Cochrane Database Syst Rev 2003; CD004058

8. Niemisto $L$, Kalso $E$, Malmivaara $A$, Seitsalo $S$, Hurri $H$. Radiofrequency denervation for neck and back pain: a systematic review within the framework of the Cochrane collaboration back review group. Spine 2003; 28: 1877-1888

9. Guo W, Zou $S$, Guan $Y$, Ikeda $T$, Tal M. Dubner R, Ren K. Tyrosine phosphorylation of the NR2B subunit of the NMDA receptor in the spinal cord during the development and maintenance of inflammatory hyperalgesia. J Neurosci 200:2; 22; 6208-6217

10. van Tulder MW, Koes BW, Assendelft WJ, Bouter LM, Maljers, LD, Driessen AP. [Chronic low back pain: exercise therapy, multidisciplinary programs "NSAID's, back schools and behavioral therapy effective; traction nat effective; results of systematic reviews]. Ned Tijdschr Geneeskd 2000: 144: 1489-1494

11. MCQuay $H$, Carroll $D$, Jadad AR, Wiffen $P$, Moore A. Anticonvulsant drugs for management of pain: a systematic review. BMJ 1995; 311 : 1047-1052

12. Rowbotham M, Harden N, Stacey B, Bernstein P. Magnus-Miller L. Gabapentin for the treatment of postherpetic neuralgia: a randomized controlled trial. JAMA 1998; 280: 1837-1842

13. Backonja MM. Anticonvulsants (antineuropathics) for neuropathic pain syndromes. Clin J Pain 2000; 16: $567-72$

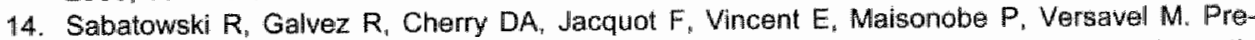
gabalin reduces pain and improves sleep and mood disturbances in patients with post-herpetic neuralgia: results of a randomised, placebo-controlled clinical trial. Pain 2004; 109: 26-35

15. Saklatvala J. The p38 MAP kinase pathway as a therapeutic target in inflammalory disease. Curr Opin Pharmacol 2004; $4: 372-377$

16. Lazzeri M, Spinelli M, Beneforti $P$, Malagulti $S$, Giardiello $G$, Turini $D$. Intravesical infusion of resiniferatoxin by a temporary in situ drug delivery system to treat interstitial cystitis: a pilot study. Eur Urol 2004; 45: 98; 102

17. Mitchell VA, White DM, Cousins MJ. The long-term effect of epidural administration of butamben suspension on nerve injury-induced allodynia in rats. Anesth Analg 1999; 89: 989-994

18. Gerner P. Nakamura T, Quan CF, Anthony DC, Wang GK. Spinal tonicaine: potency and differential blockade of sensory and motor functions. Anesthesiology 2000; $92: 1350-1360$

19. Carter GT, Sullivan MD. Antidepressants in pain management. Curr Opin Investig Drugs 2002; 3: $454-458$

20. Feighner JP. Mechanism of action of antidepressant medications. J Clin Psychiatry 1999;60 Suppl 4: 4-11; discussion 12-13

21. Strumper D. Durieux ME. Antidepressants as long-acting local anesthetics. Reg Anesth Pain Med 2004; 29: 277-285 
22. Peloso P, Gross A, Haines T, Trinh K, Goldsmith $\mathrm{CH}$, Aker P. Medicinal and injection therapies. for mechanical neck disorders. Cochrane Database Syst Rev 2005; CD000319

23. Stav $A$, Ovadia $L$, Sternberg $A$, Kaadan $M$, Weksler $N$. Cervical epidural steroid injection for cervicobrachialgia. Acta Anaesthesiol Scand 1993; 37: 562-566

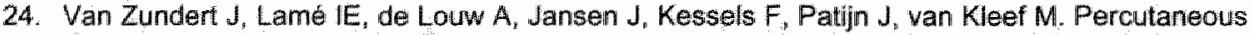
Pulsed Radiofrequency Treatment of the Cervical Dorsal Root Ganglion in the Treatment of Chronic Cervicall Pain Syndromes: A Clinical Audit. Neuromodulation 2003; 6: 6-14

25. Fouyas $I P$, Statham PF, Sandercack $P A$, Lynch $C$. Surgery for cervicall radiculomyelopathy. Cochrane Database Syst Rew 2001: CD001466

26. Persson LC, Carisson CA Carlsson JY. Long-lasting cervical radicular pain managed with surgery, physiotherapy, or a cervical collar. A prospective, randomized study. Spine 1997; 22 " $751-758$

27. Cosman ER, Cosman ER. Electric and thermal field effects in tissue around radiofrequency electrodes. Submitted

28. Archer $S, L T T$, Evans AT, Britland ST, Morgan H. Cell reactions to dielectrophoretic manipulation. Biochem Biophys Res Comm 1999; 257: 687-698

29. Kovacs KJ. c-Fos as a transicription factor: a stressful (re)view from a functional map. Neurochem Int 1998; $33: 287-297$

30. Munglani R. Hunt SP. Proto-oncogenes: basic concepts and stimulation induced changes in the spinal cord. Prog Brain Res 1995; 104: 283-298

31. Higuchi $Y$, Nashold BS, Sluijter ME, Cosman $E_{x}$ Pearlstein RD. Exposure of the dorsal root ganglion in rats to pulsed radiofrequency currents activates dorsal horn lamina I and II neurons. Neurosurgery 2002; $50: 850-856$

32. Sandkühler J, Chen JG, Cheng G, Randic M. Low-Frequency Stimulation of Afferent AD-fibers induces Long-Term Depression at Primary afferent Synapses with Substantia gelatinosa neurons in the rat. $₫$ Neurosci 1997; 17: 6483-6491

33. Van Zundert J, Joosten EA, Dederen PJ, Honig W, Veening JG, van Kleef M. Does (Pulsed) Radiofrequency treatment adjacent to the cervical dorsal root ganglion of the rat affect the number of newly formed cells in the spinal cord? Reg Anesth Pain Med 2005; Supplement: in press

34. Richebe $P$, Rathmell JP. Brennan TJ. Immediate early genes after pulsed radiofrequency treatment: neurobiology in need of clinical trials. Anesthesiology 2005; 102: 1-3

35. Munglani $R$. The longer term effect of pulsed radiofrequency for neuropathic pain. Pain 1999; 80: $437-439$

36. Van Zundert J, Brabant $S$, Van de Kelft $E$, Vercruyssen $A$, Van Buyten JP. Puised radiofrequency treatment of the Gasserian ganglion in patients with idlopathic trigeminal neuralgia. Pain 2003; 104: 449-452

37. Zakrezewska J, Lopez BC. New techniques for surgical management of trigeminal neuralgia. Pain 2004; 109: 520

38. Van Zundert J Brabant $S$, Van de Kelft $E$, Vercruyssen A, Van Buyten JP. Response to Zakrzewska"s Letter to the Editor. Pain 2004: 109: 520-522

39. Zakrzewska JM, Lopez BC. Quality of reporting in evaluations of surgical treatment of trigeminal neuralgia: recommendations for future reports. Neurosurgery 2003; 53 : 110-120; discussion $120-112$

40. Lau J, Antman EM, Jimenez Silva J, Kupelnick B, Mosteller $F$. Chalmers TC Cumulative metaanalysis of therapeutic trials for myocardial infarction. N Engl J Med 1992; 327: 248-254

41. Devulder J, Crombez $\mathrm{G}$, Brusselmans $\mathrm{G}$. Comment on "Pulsed radiofrequency treatment of the gasserian ganglion in patients with idiopathic trigeminal neuralgia". Pain 2004; 107: 195

42. Orlandini $G$. Pulsed percutaneous radiofrequency treatment of the Gasserian ganglion for therapy of trigeminal neuralgia: technical notes, validity of the method and selection of the patients. Pain 2004; 108: 297-298

43. Van Zundert J. Response to "Comment on Pulsed radiofrequency treatment of the Gasserian Ganglion in patients with idiopathic trigeminal neuralgia". Pain 2004; 107: 196 
44. Van Zundert J, Brabant $S$, Van de Kelf E, Vercruyssen A. Response to Orlandinit's letter to the editor, regarding Pulsed radiofrequency treatment of the Gasserian ganglion. Pain 2004: 108: 298-299

45. Nelemans PJ, deBie RA, deVet $H C$, Sturmans $F$. Injection therapy for subacute and chronic benign low back pain. Spine 2001: 26: 501-515

46. Koes BW, Scholten RJPM, Mens JMA, Bouter LM. Epidural Steroid Injections for Low Back Pain and Sciatica: An updated Systematic Review of Randomized Clinical Trials. Pain Digest 1999; 9: 241-247

47. Abejon D, Reig E. Is Pulsed Radiofrequency a Neuromodulation Technique? Neuromodulation $2003 ; 6: 1-3$ 
CHAPTER XII

$\mathrm{CV}$ and publications 


\section{Curriculum vitae}

Jan Van Zundert was born on August 12, 1965 in Antwerp, Belgium. He obtained his basic degree in medicine at the "University Center of Limburg, Diepenbeek", and obtained his doctoral degree cum laude in 1990 at the "Katholieke Universiteit Leuven". After his post-doctoral training in anesthesiology (Prof. dr. H. Adriaensen and Dr. L. Baute) he was recognized by the Belgian Board of Anesthesiology in 1995. In 1995-1996 he followed a postgraduate training in pain therapy at the Academic Hospital Sint-Radboud of Nijmegen, The Netherlands (Prof. dr. L. Booij and Prof. dr. B. Crul). He took the international examination of interventional pain management of the World Institute of Pain (WIP) and became Fellow Interventional Pain Practice (FIPP) in 2001.

In 2001 he obtained an additional degree in Hospital Management at the "Katholieke Universiteit Leuven" with a dissertation on: "The management of (chronic) low-back pain in a Multidisciplinary Pain Centre: effects and costs." (Promotor: Prof. dr. K. Kesteloot).

He started his professional career in AZ Maria Middelares, Sint-Niklaas, Belgium (Dr. L. Vanduffel and Dr. JP. Van Buyten) and is since September 2000 working in the department of Anesthesiology, Intensive Care, Emergency Medicine and Pain Management of the Ziekenhuis Oost-Limburg, Genk, Belgium, (Dr. R. Heylen and Dr. K. Vissers) where he became head of the Multidisciplinary Pain Centre in 2005. Since 2001 he has a scientific affiliation with the department of Pain Management of the University Hospital Maastricht, Maastricht, The Netherlands, where he prepared this PhD thesis (Promotor: Prof. dr. M. van Kleef).

He is an active member of different national and international anesthesiology and pain societies. He is frequently asked to give lectures at scientific meetings. Since 2002 he is a board member of the World Institute of Pain (WIP) and since 2005 he became chairman of the Vlaamse Anesthesiologische Vereniging voor Pijnbestrijding (VAVP). He organized several workshops on interventional pain management techniques and is involved in governmental working parties on chronic pain. He is executive editorial board member of Pain Practice and review editor of the International Monitor of Regional Anesthesia and Pain Therapy (IMRAPT).

Jan Van Zundert is maried to Katrien Hebbinckuys, general practitioner and has 2 children: Wouter ${ }^{\circ} 18-07-94$ and Pieter ${ }^{\circ}$ 19-01-96. 


\section{Publications}

1. Vercauteren $M$, Bettens $K$, Van Springel $G$, Schols $G$, Van Zundert J. A comparison of different mixtures of analgesic drugs for intrathecal administration in labor. International Journal of obstetric Anesthesia, 1997, 6: 242-246.

2. Van Zundert $J$. Current controversies in the use of epidural steroid injections (editorial). Pain Digest. 1999, 9 (4): 224-225.

3. Van Zundert J, Van Buyten JP. Current use of epidural steroid injections in Belgium. Pain Digest. 1999, 9 (4): 228-229.

4. Van Zundert J, Plaghki L, Adriaensen $H$. Value of epidural steroid injections in low back pain and sciatica (conclusions). Pain Digest. 1999, 9 (4): 248-251.

5. Van Buyten JP, Van Zundert J, Milbouw G. Treatment of failed back surgery syndrome patients with low back and leg pain: a pilot study of a new dual lead spinal cord stimulation system. Neuromodulation, 1999, 2 (4): 258-265.

6. Van Buyten JP, Van Zundert J, Vueghs $P$, Vanduffel L. Efficacy of spinal cord stimulation: 10 years of experience in a pain centre in Belgium. Eur $\mathrm{J}$ Pain, 2001, 5: 299-307.

7. Van Zundert J. Cost effectiveness of interventional treatment of chronic pain. In: Highlights in Regional Anaesthesia and Pain Therapy. Eds. Van Zundert A, Rawall N, 2002, 23-28.

8. Van Zundert J. Nerve blocks in the cervical area. In: Highlights in Regional Anaesthesia and Pain Therapy. Eds. Van Zundert A, Rawal N, 2002, 251257.

9. Van Zundert J. Transforaminale epidurale corticosteroïdinfiltraties voor de behandeling van het lumbosacraal radiculair syndroom: doeltreffend en kosten efficiënt? Nederlands Tijdschrift voor Pijn en Pijnbestrijding, 2002 , 22(11), 21-22.

10. Van Zundert J, Prithvi Raj P. Erdine S, van Kleef M. Application of radiofrequency treatment in practical pain management: State of the art. Pain Practice, 2002, 2(3): 269-278.

11. Van Zundert J; Prithvi Raj P. Editorial Pain Practice, 2002, 2 (3): 174-175

12. Van Zundert $J$, Lamé IE, de Louw $A$, Jansen J, KesselsF, Patijn J, van Kleef M.Percutaneus pulsed radiofrequency treatment of the cervical dorsal root ganglion in the treatment of chronic cervical pain syndromes: A clinical audit. Neuromadulation, 2003, 6(1): 6-14. 
13. Van Zundert J, Brabant $S$, Van de Kelft $E_{*}$ Vercruyssen $A$, Van Buyten $P$. Pulsed radiofrequency treatment of the Gasserian ganglion in patients with idiopathic trigeminal neuralgia. Pain, 2003, 104: 449-452.

14. Van Zundert J, van Kleef $M$, Vissers K. CRPS update: Spinal and peripheral nerve stimulation techniques. Highlights of Regional Anesthesia ands Pain Therapy, 2003, XII: 128-135.

15. Haspeslagh S, Van Zundent J, Puylaert M, Heylen $R$, van Kleef $M_{n}$ Vissers $K$. Unilateral diagnostic infiltration of lumbal $L 3$ nerve root resulting in an inadvertent discogram. The importance of fluoroscopic guidance in the interventional pain therapy! Anesthesiology, 2004, 100: 1019-1021.

16. Van Zundert J, Vissers K, Puylaert $M$, Van Zundert $A$, Heylen $R$, van Kleef M. Radiofrequency treatment for chronic pain syndromes. CPD Anaesthesia, 2004, 6(1): 13-17.

17. Van Zundert J. Transforaminal lumbar epidural (sleeve) steroid injections. Internationall Monitor Regional Anesthesia and Pain (IMRAPT), 2004.

18. Van Zundert J, van Kleef M, Sluijter M. Radiofrequency and pulsed radiofrequency - looking for the best use of electrical current in pain management. American Society of Regional Anesthesia \& pain Medicine (ASRA), 2004: 6 .

19. Harney DF, Shaikhani J, van Kleef M, Haspeslagh S, Van Zundert J. Gepulseerde radiofrequente lesies van het dorsale ganglion: Een zinvolle therapeutische aanvulling bij therapie resistente postherpetische neuralgie? Nederlands Tijdschrift voor Pijn en Pijnbestrijding, 2004, 23(20): 6-8.

20. Van Zundert J. Response to "Comment on Pulsed radiofrequency treatment of the Gasserian Ganglion in patients with idiopathic trigeminal neuralgia'.. Pain 2004; 107: 196

21. Van Zundert J, Brabant S, Van de Kelft E., Vercruyssen A, Van Buyten JP. Response to Orlandini's Letter to the Editor. Letters to the Editor, Pain, 2004, 108: 297-299

22. Van Zundert J, Brabant S, Van de Kelft E., Vercruyssen A, Van Buyten JP. Response to Zakrzewska's Letter to the Editor. Letters to the Editor, Pain, 2004, 109: 520-529.

23. Haspeslagh S, Van Zundert J, Vissers K. In reply to Huang "s Letter to the Editor, Anesthesiology, 2004, 101(6): 1482

24. Van Zundert $J$, de Louw AJA, Joosten EAJ, Kessels AGH, Honig W. Dederen PJWC, Veening JG, Vles JSH, van Kleef M. Pulsed and continuous radiofrequency current adjacent to the cervical activity in the dorsal horn. Anesthesiology , 2005, 102: 125-131.

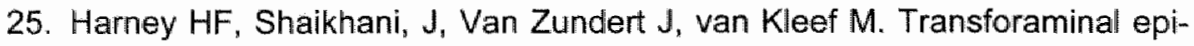
dural corticosteroid injection: Rational evidence-based practice. Letters to the Editor, Regional Anesthesia and Pain Medicine, 2005, 30(2): 2006 
26. Van Zundert J, Cahana A, Pulsed radiofrequency in chronic pain management: Looking for the best use of electrical current. Pain Practice 2005,5 (2): $74-76$

27. Van Zundert J, van Kleef M. Low Back Pain: From Algorithm to CostEffectiveness. Pain Practice 2005, 5 (3): 179-189

\section{Guest ediitor}

1. Pain Digest, 1999, 9(4), Prithvi P Raj (ed), Van Zundert J (Guest ed.): State of the Art: Epidural steroids in pain management

2. Pain Practie, 2002, 2(3), Prithvi P Raj (ed), Van Zundert J (Guest ed.): State of the Art: Radiofrequency techniques in pain management

\section{Books}

1. van Kleef M, Stolker RJ; Van Zundert J. Invasieve behandeling van pijn uitgaande van de wervelkolom; In Handboek Pijnbestrijding Eds. Van Kleef $M_{n}$ Weber WEJ, Winter F, Zuurmond WWA. De Tijdstroom, Leusden, 2000:265-277

2. Van Zundert J. Cost effectiveness of interventional pain treatment. In. The failed spine. Controversies in ethiopathogenesis, management and costs. Eds. Szpalski M, Gunsburg R., Lippincott, William \& Wilkins, Philadelphia, 2005: 229-239 ISBN: 0 - 7817-9613-X 
CHAPTER XIII

\section{Dankwoord}

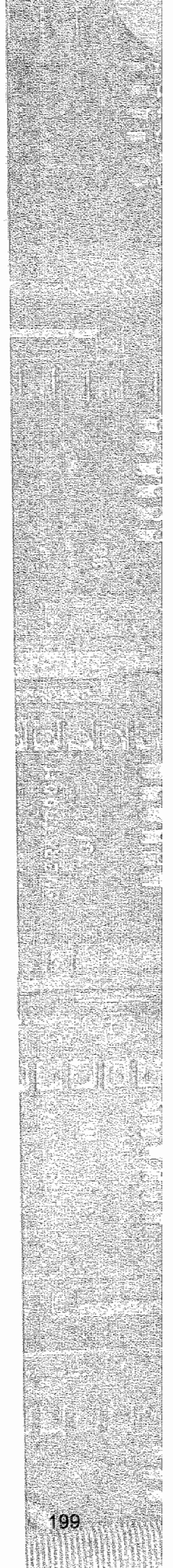


"Een proefschrift af maken is een besluit", deze wijze woorden van mijn promotor Prof. dr. van Kleef, hebben vaak geholpen om te beslissen een stap vooruit te zetten, een manuscript te submitten en uiteindelijk dit werk ook af te maken. Beste Maarten, hartelijk dank voor de vele uren van discussie en begeleiding als promotor, voorbeeld en vriend. Je benadrukte steeds om prioriteiten te stellen en selectief te zijn. "Wat niet wetenschappelijk onderbouwd is, mag je niet verkondigen". Op dit principe bleef je steeds hameren...ik denk dat het er nu wel inzit.

Dr. Joosten en dr. Patijn, co-promotoren, dank voor de gewaardeerde multidisciplinaire begeleiding die steeds in een erg aangename sfeer verliep. Beste Bert, van jou leerde ik om eerst mijn gedachten op een A4tje te bundelen, een uiterst nuttige techniek. Je verhelderende uitleg over de neurobiologie en je analytische manier van werken maakten het basaal wetenschappelijke luik van dit proefschrift mogelijk. Beste Jaap, als neuroloog/manueel geneeskundige introduceerde je een extra klinische dimensie van cervicale radiculaire pijn die achteraf in de gecontroleerde studie erg belangrijk bleek. Ik wil jullie ook beiden danken voor het kritisch nalezen en corrigeren van de meeste hoofdstukken, waarbij jullie pertinente opmerkingen me regelmatig verplichtten om een stuk te herschrijven of anders te formuleren, maar toegegeven, jullie hadden gelijk.

Prof. dr. Sluijter, als mentor en "uitvinder" van gepulseerde radiofrequentie mag je je eigenlijk het geestelijk vaderschap van dit werk toeëigenen. Dank beste Menno om je enthousiasme over te dragen en om moeilijke materie eenvoudig onder woorden te brengen, meestal tijdens het proeven van een goed glas Chardonnay of Bordeaux.

Ik wens ook mijn bijjzondere waardering uit te drukken voor de leden van de beoordelingscommissie: Prof. dr. Hans Vles, voorzitter, Prof. dr. Jacques Devulder, Prof. dr. Ruud Geesink, Prof. dr. Martin Prins en Prof. dr. Wouter Zuurmond, die tijdens de vakantiemaanden toch de tijd vrij maakten om het manuscript voor de afgesproken datum door te nemen en...goed te keuren.

Hoe interessant het wetenschappelijke werk ook moge zijn, het kon enkel gerealiseerd worden met de steun van de collega's stafleden van de Kritische Diensten van het Ziekenhuis Oost-Limburg te Genk. Dank Dr. Lieven Buyse, dr. Micheline Caubergh "dr. Bernadette Claessens, dr. Cathy De Deyne, dr. Jacques Deghislage, dr. Raf De Jongh, dr. Kim Engelen, dr. Gertie Goossens, dr. Frank Jans, dr. Luc Merckx, dr. Johan Van Canneyt, dr. Margot Vander Laenen, dr. Luc Van Keer, dr. Sven Van Poucke en dr. Guy Vundelinkx: een grote, diverse, maar complementaire groep met veel zin voor wetenschappelijk werk. Dr. Heylen, beste Rene, Limburger met Antwerpse humor, het is jouw grote verdienste om in een goede sfeer deze groep te laten functioneren als één geheel. Je leidt de dienst als een goede huisva- 
der en waarschuwt tijdig voor de addertjes onder het gras. Ik vind het dam ook en eer dat je me als paranimf wilt bijstaan, samen met dr. Marcus. Beste Marco, het doet me veel plezier om ook jouw steun te hebben bij de thesilsverdediging als uiting van onze wetenschappelijke samenwerking over de Maas heen.

Een speciaal dankwoord wil ik richten tot mijn naaste collega's van het Multidisciplinair Pijncentrum, dr. Vissers, dr. Puylaert en dr. Vanelderen. Beste Kris, Martine en Pascal, jullie sprongen in wanneer ik weer eens mel een deadline aan het vechten was, maar ook ervaarde ik steeds veel begrip en steun. Kris, je keert na een decenium terug als hoogleraar naar onze gemeenschappelijke "pijnroots" te Nijmegen. Het was een waar genoegen om met jou samen te werken en ik denk dat we trots mogen zijn op hetgeen we als groep de afgelopen jaren hebben opgebouwd.

Onderzoek is teamwerk! Als clinicus was ik er nooit in geslaagd om in dit proefschrift de verschillende aspecten van het probleem te beschrijven zonder de medewerking van de co-auteurs van de verschillende hoofdstukken. Ook de artsen die patiënten doorverwezen voor inclusie in de gerandomiseerde studie waren een grote hulp. Mijn bijzondere dank voor ieders bijdragell

Dr. Kessels, methodoloog/statisticus en Mevr Lamé, datamanager. Beste Fons en Inge, jullie werk was essentieel, want zonder jullie geen data, geen correcte resultaten en gieen grafieken.

Dr. de Louw, beste Anton, met jou zette ik mijn eerste stappen in het dierexperimenteel labo te Maastricht. Het gaf me een "eerste leerjaar ervaring", die achteraf in Café Zuid moest "geëvalueerd" worden.

Dr. Cahana from the University of Geneva, Switzerland, dear Alex, we were concerned about the same question: "Does pulsed radiofrequency work and how?". The European Collaborative Group for research on Pulsed Radiofrequency, was initiated thanks to your motivation. I look forward to a future collaboration in this context.

Prof. dr. Cosman senior and son from the Massachusetts Institute of Technology (MIT), Cambridge, USA, dear Eric and Eric, thank you for clarifying the difficult matw ter of electrical fields and other electrophysical parameters.

Looking at the pathophysiology of cervical radicular pain and the role of the dorsal root ganglion, dr. Harney proved to be of great support. Dear Donal, thanks for always finding a new article on this subject and summarizing it in a clear figure.

Prof. dr. Durieux, van de universiteit van Virginia, USA, beste Marcel, je hulp bij het reviewen van twee belangrijke hoofdstukken waren bijzonder waardevol. De grote afstand bleek geen obstakel te vormen, want je reageerde prompt op alle e-mails.

Prof. dr. Raj and Prof. dr. Erdine, respectively from the Texas Tech University, USA, and the University of Istanbul, Turkey, dear Prithvi and Serdar, thank you for cooperation in the RF State of the Art and the opportunity to widen my horizon by joining the editorial board of Pain Practice and the World Institute of Pain Board. 
Alle collega's en medewerkers van de Dienst Anesthesiologie en Pijntherapie, de Pijnpoli, het Pijn Keniiss Centrum van het Academisch Ziekenhuis Maastricht wens ik ook te bedanken voor de constructieve sfeer waarin dit proefschrift tot stand kon komen en zonder Mevrouw Resy Van den Broeck, zou het administratieve luik van dit proefschrift niet in orde zijn gekomen.

De teamleden van het Multidisciplinair Pijncentrum te Genk dragen mijn bijzondere waardering weg, aan allen dank voor de steun en aanmoedigingen bij het realiseren van dit proefschrift maar vooral voor het samenwerken in een echte ploeggeest. Tevens wil ik graag Mevr. Marielle Vandermierde, secretaresse van de Dienst Anesthesiologie bedanken die altijd klaar stond om te helpen.

De opleiders en de stafleden van de Antwerpse ziekenhuizen, het AZ Stuyvenberg, het $A Z$ Jan-Palfijn, het Kinderziekenhuis en het Universitair Ziekenhuis, wil ik danken voor de genoten opleiding tot anesthesioloog. Dr. Albert Van Steenberge, dr. Jean-Luc Hody, dr. Stephan Joos en dr. Luc Fannard van Anderlecht en Béziers Frankrijk, introduceerden mij in de loco-regionale anesthesie en leerden mij 'naalden' te gebruiken. Hierdoor werd ook de interesse voor de anesthesiologische pijnbestrijding opgewekt.

Het was bij Prof. dr. Hugo Adriaensen en Prof. dr. Marcel Vercauteren in het Universitair Ziekenhuis te Antwerpen en nadien bij Prof. dr. Ben Crul, dr. Robert van Dongen en dr. Rob Slappendel van het Universitair Medisch Centrum St. Radboud te Nijmegen dat ik de eerste stappen kon zetten in de chronische pijnbehandeling. Ook de collega's van het AZ Maria Middelares in St. Niklaas, dr. Luc Vanduffel, dr. Jean-Pierre Van Buyten, dr. Peter Vueghs en dr. Iris Smet wil ik graag vermelden omdat de pijnbehandeling er een extra dimensie kreeg. Aan alle artsen en medewerkers van deze pijncentra hartelijk dank voor de geboden mogelijkheden en samenwerking.

Ik vond het ook een hele eer om te mogen bijdragen aan de vorming van de verschillende residenten: $d r$. Steven Brabant, dr. Koen Lauwers, dr. Koen Van Boxem, dr. Ivo Baeckelmans, dr. Sara Haspeslagh, dr. Hilde Callewaert, dr. Werner Nagels, dr. Kalin Claeysone, die als erkende anesthesiologen een bijkomende pijnopleiding bij ons volgden en allen nadien nog verder in dit vakgebied actief bleven. Ook voor de huidige residenten dr. Mirella Dingens en dr. Ria Van Eynde ben ik ervan overtuigd dat de goede traditie kan verder gezet worden.

Mevr Van den Hecke, beste Nicole, trouwe en plichtsbewuste rechterhand, zonder jouw flexibiliteit en doorzettingsvermogen had dit boekje er nooit gekomen. Jij zorgde voor de coördinatie van de vele versies bij de opbouw van elk hoofdstuk, waarbij je steeds bleef streven naar de hoogste kwaliteit. Zelfs als we tegen de deadline 
weer eens wat wilden veranderen aan tekst of grafieken, was het nooit te veel gevraagd. Hartelijk dank woor de efficiênte en langdurige samenwerking.

Mijn ouders, schoonouders, broers en hun families volgden, vaak met onrust, de evolutie van dit project en slaagden erin om me met de voeten op de grond te houden. Ik ben jullie veel dank verschuldigd voor de gegeven kansen en blijvende steun. Maar ilk hoop, vader, dat je geneeskunde nu toch een goede keuze vond.

Beste familieleden en vrienden, ik was de laatste jaren weinig beschikbaar en wanneer jullie er toch in slaagden om mij van mijn bureau weg te halen, was ik mentaal soms ver van jullie weg. 'Aarde zoekt contact" is mij meermaals toegefluisterd. Ik probeer dit recht te zetten en dank jullie voor het begrip.

Katrien, dankzij jouw sterke persoonlijkheid en relativeringsvermogen kon ik dit proefschrift maken. Je hebt voor ons een "thuis" gebouwd in Genk en er voor gezorgd dat alles vlot bleef verlopen. Ik dank je voor je vertrouwen en steun.

Wouter en Pieter, de thesis is afl Op de vraag of voke nu zoveel simmer is geworden, durf ik niet te antwoorden. Maar kennis geeft nieuwsgierigheid naar "meer weten' en ik hoop dat dit werk ook jullie zal motiveren om de zaken in vraag te stellen en antwoorden te zoeken.... 


$\begin{array}{ll}{ }^{\circ} \mathrm{C} & \text { centigrades } \\ \text { Amp } & \text { Ampere } \\ \text { BDNF } & \text { Brain-derived neurotrophic factor } \\ \text { BrdU } & \text { Bromodeoxyuridine } \\ \text { COX } & \text { Cylco-oxygenase } \\ \text { CT } & \text { Computed tomography } \\ \text { DRG } & \text { Dorsal root ganglion } \\ \text { EBM } & \text { Evidence based medicine } \\ \text { FNSS } & \text { Failed neck surgery syndrome } \\ \text { G } & \text { Gauge } \\ \text { GPE } & \text { Global perceived effect } \\ \text { GSM } & \text { Global System for mobile } \\ \text { HZ } & \text { Herz } \\ \text { ITN } & \text { Idiopathic trigeminal neuralgia } \\ \text { KHZ } & \text { Kilo Herz } \\ \text { MM } & \text { Male } \\ \text { MAmp } & \text { milli Ampere } \\ \text { MAPK } & \text { Mitogen activated protein kinase } \\ \text { mI } & \text { milliliter } \\ \text { MPC } & \text { Multidisciplinary pain center } \\ \text { MRI } & \text { Magnetic resonance imaging } \\ \text { MS } & \text { milli seconds } \\ \text { NaV } & \text { Voltage-gated Na channel } \\ \text { NGF } & \text { Nerve growth factor } \\ \text { NSAID } & \text { Non-steroidlal anti-inflammatory drug } \\ \text { PBS } & \text { Phosphate buffered saline } \\ \text { PCS } & \text { Pain catastrophizing scale } \\ \text { PET } & \text { Positron emission tomography } \\ \text { PFD } & \text { Percutaneous facet denervation } \\ \text { PG } & \text { Prostaglandin } \\ \text { PRF } & \text { Pulsed radiofrequency } \\ \text { RCT } & \text { Randomized controlled trial } \\ \text { RF } & \text { Radiofrequency } \\ \text { S } & \text { Seconds } \\ \text { SD } & \text { Standard deviation } \\ \text { SF-36 } & \text { Short Form 36 items } \\ \text { SIJ } & \text { Sacroilliac joint } \\ \text { SMK } & \text { Sluijter Mehta Kit } \\ \text { SMK-TC } & \text { Sluijter Mehta Kit thermo couple } \\ \text { TMJ } & \text { temporomandibular joint } \\ \text { TNF } & \text { Tumor necrosis factor } \\ \text { V } & \text { Volts } \\ \text { VAS } & \text { Visual analogue scale } \\ \text { VR1 } & \text { Vanilloid receptors } \\ \text { VR-L1 } & \text { Vanilloid like receptors } \\ \Omega & \text { Whatts } \\ \text { W } & \text { World Health Organization } \\ \text { WHO } & \end{array}$


